\title{
Improving access to HIV/AIDS treatment in Brazil : when are compulsory licenses effective in price negotiations?
}

Citation for published version (APA):

Urias, E. M. P. (2015). Improving access to HIV/AIDS treatment in Brazil : when are compulsory licenses effective in price negotiations? [Doctoral Thesis, Maastricht University]. Datawyse / Universitaire Pers Maastricht. https://doi.org/10.26481/dis.20151028eu

Document status and date:

Published: 01/01/2015

DOI:

10.26481/dis.20151028eu

Document Version:

Publisher's PDF, also known as Version of record

Please check the document version of this publication:

- A submitted manuscript is the version of the article upon submission and before peer-review. There can be important differences between the submitted version and the official published version of record.

People interested in the research are advised to contact the author for the final version of the publication, or visit the DOI to the publisher's website.

- The final author version and the galley proof are versions of the publication after peer review.

- The final published version features the final layout of the paper including the volume, issue and page numbers.

Link to publication

\footnotetext{
General rights rights.

- You may freely distribute the URL identifying the publication in the public portal. please follow below link for the End User Agreement:

www.umlib.nl/taverne-license

Take down policy

If you believe that this document breaches copyright please contact us at:

repository@maastrichtuniversity.nl

providing details and we will investigate your claim.
}

Copyright and moral rights for the publications made accessible in the public portal are retained by the authors and/or other copyright owners and it is a condition of accessing publications that users recognise and abide by the legal requirements associated with these

- Users may download and print one copy of any publication from the public portal for the purpose of private study or research.

- You may not further distribute the material or use it for any profit-making activity or commercial gain

If the publication is distributed under the terms of Article $25 \mathrm{fa}$ of the Dutch Copyright Act, indicated by the "Taverne" license above, 


\section{Improving access to HIV/AIDS treatment in Brazil}

When are compulsory licenses effective in price negotiations?
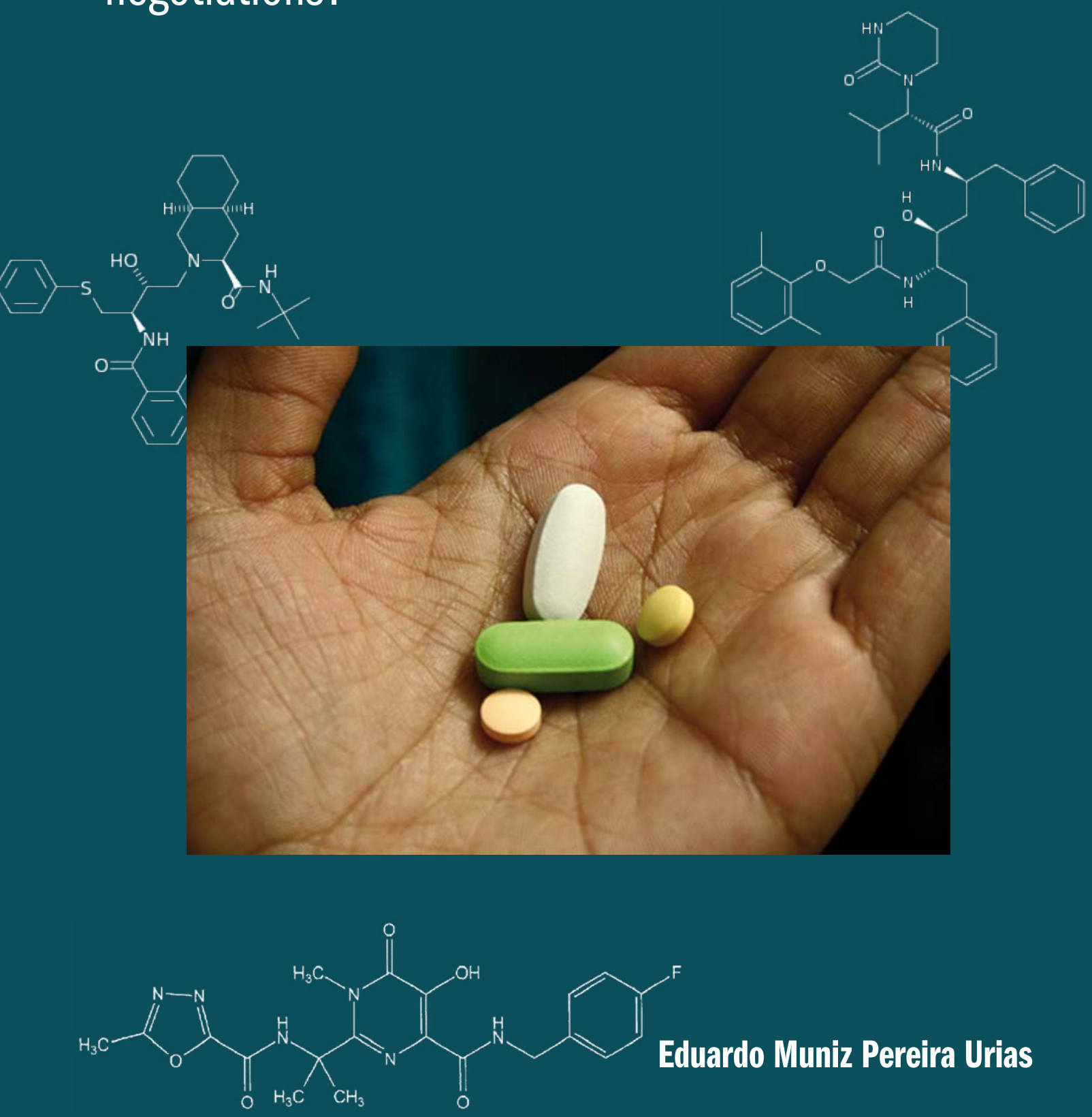
ISBN. 9789461594761

(C) copyright Eduardo Urias, Maastricht 2015

Printing: Datawyse / Universitaire Pers Maastricht 
Improving access to HIV/AIDS treatment in Brazil: When are compulsory licenses effective in price negotiations?

\section{DISSERTATION}

to obtain the degree of Doctor at the Maastricht University, on the authority of the Rector Magnificus Prof. dr. L. L. G. Soete, in accordance with the decision of the Board of Deans, to be defended in public on Wednesday 28 October 2015, at 10.00 hours by

Eduardo Muniz Pereira Urias

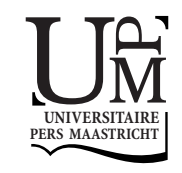




\section{Supervisor}

Prof. Dr. Shyama V. Ramani

\section{Assessment Committee}

Prof. Dr. Robin Cowan (Chairperson)

Prof. Dr. Angela Brand

Prof. Dr. Marie-Laure Cabon-Dhersin (Université de Rouen)

Dr. Samira Guennif (Université Paris XIII)

Dr. Mindel van de Laar 


\section{DEDICATION}

to Ariane for the courage to start my $\mathrm{PhD}$ to José for the strenght to conclude it 


\section{ACKNOWLEDGEMENTS}

Se há um responsável por eu ter saído do Brasil para fazer o doutorado, esse alguém é o Professor e grande amigo Joáo Furtado. Ele foi quem plantou essa semente, quem me incentivou e motivou a adentrar por essa jornada. Muito obrigado, João, por me tirar da zona de conformo e me levar a desafios que eu nem pensava em enfrentar. I want to start by thanking Joáo Furtado, who first said that I had no option but do my $\mathrm{PhD}$ abroad. Se há um responsável por eu ter saído do Brasil para fazer o doutorado, esse alguém é você, professor e grande amigo João. Foi você quem plantou essa semente, quem me incentivou e motivou a adentrar por essa jornada. Muito obrigado, Joáo, por me tirar da zona de conformo e me levar a desafios que eu nem pensava em enfrentar.

Of course, I could not complete this work without Prof. Shyama Ramani. Shyama, you are much more than my supervisor, you are family. I am truly grateful for your dedication (and patience) during the past five years we worked together.

Samira Guenniff also deserves a big thank you! First, you are the one who introduced me to Shyama when we met in the $7^{\text {th }}$ Globelics conference in Dakar, Senegal. Second, your insights and intriguing curiosity reoriented my research questions towards such a fascinating topic

My sincere thanks also goes to reading committee members for the valuable and insightful comments and critics that helped me to widen my research from various perspectives

I take this opportunity to express gratitude to all the staff at UNU-MERIT. Eric, Marc, Wilma, Sueli, Howard, Ad, Monique, Mourik, Herman your help and support contributed in different manners to my work and wellbeing in Maastricht.

No, I did not forget to write your name, dear Eveline. I reserved a special place for you not only on this page, but also (and most importanly) in my heart. I could not express in words my gratetude for all you did (and still do) for all of us.

I thank the professors and researchers for sharing their knowledge during the coursework, seminars, tutorials and other informal meetings. This was an essential part of my $\mathrm{PhD}$ and helped me grow as a researcher. 
A big thanks to all those who generously gave up their time for me to interview them, in especial to Dra. Eloan Pinheiro for the interesting follow up discussions we had by e-mail and Skype.

I am grateful for the financial support provided by the United Nations University and Capes Foundation for the accomplishment of this $\mathrm{PhD}$ dissertation.

During these five years at UNU-MERIT, I was fortunate enough to make many friends. I first want to thank Ajay, Francesca, Hibret, Jennifer and Michael for the stimulating discussions, for the endless days we worked together before deadlines, and for making the adaptation to a new country much easier. I thank all other $\mathrm{PhD}$ fellows at UNU-MERIT/MGSoG for the interesting talks about research, football, politics and many other random subjects. I also want to thank the Brazilians friends that I made in Maastricht for supporting us during though times and from giving a little bit of the Brazilian taste to our stay in Europe.

I also want to thank my parents, Joaquim and Ana for teaching me the true value of education since my early days. In addition, I want to thank them and my siblings, Carol and Guilherme, for all the support they gave me during this journey. Vocês, minha família de origem, são responsáveis pelos valores fundadores que carregarei pelo resto de minha vida. Agradeço pelo imensamente pelo amor, carinho, suporte e por ter sido táo afortunado e abençoado por ter vocês ao meu lado. Ter pais e irmãos como vocês é um grande privilégio e torna qualquer desafio muito mais fácil.

Agradeço também a família que 'ganhei' (ou que me adotou) nos últimos anos. Olívia, Ju, Paulinho, Nick, Gê e Lu, vocês são grandes tesouros em minha vida. Também agradeço o nosso querido Gilmar, que foi e ainda é um grande exemplo de dedicação, persistência e tantas outras coisas que não daria para escrever aqui. Tenho certeza que você está muito feliz e orgulhoso por mim de onde quer que esteja nos olhando agora.

Last, but definitively not least, I want to thank my family in Maastricht: Pin, Bê and José. Como agradecer alguém que pulou nessa aventura de atravessar o oceano ao meu lado? Que deixou família, carreira, amigos e tantas outras coisas para trás para poder estar aqui me apoiando e me motivando? E a Rebeca? Sempre nossa parceira, aprontando dia e noite e me fazendo sair na chuva tantas e tantas vezes! E 
o pequeno José... não seria correto dizer que ele chegou na reta final, pois foi o final que chegou depois que você tornou nossas vidas mais alegres (e nossos dias mais longos!). Amo vocês mais que tudo e isso não teria a menor graça sem vocês ao meu lado. 
Chapter 1 Introduction to the research …………............................................... 15

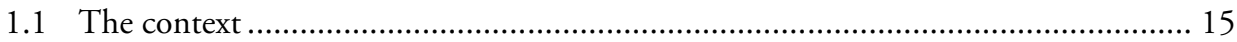

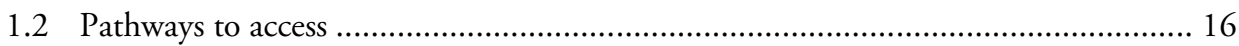

1.3 The role of the private sector in promoting access ................................................. 20

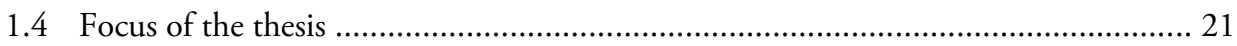

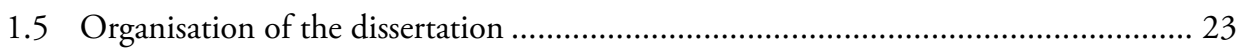

Chapter 2 Access to medicines - A review of the role of the pharmaceutical industry and the challenges of the current IPR system ...................... 27

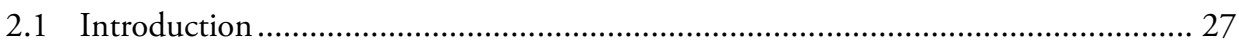

2.2 Pharmaceutical industry and health promotion ............................................... 33

2.3 Scoping study on the pharmaceutical industry contribution to health promotion.... 38

2.4 Intellectual property rights and access to medicines .......................................... 45

2.5 Scoping study on the negative impacts of IPR on access to medicines .................... 56

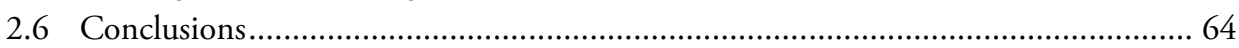

Chapter 3 Role of industry, state and MNEs in tackling the HIV/AIDS crisis in Brazil: A brief review..................................................................6 69

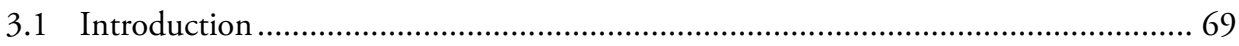

3.2 Emergence of the Brazilian pharmaceutical industry: the reign of public

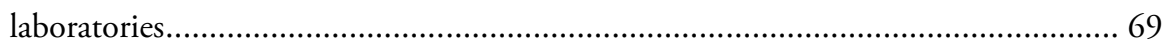

3.3 Private sector: paradigm shift and catch-up failure ............................................ 70

3.4 The Brazilian Universal Access Program .............................................................. 73

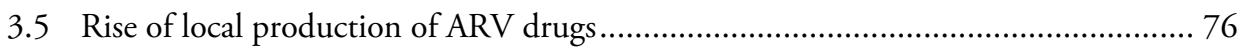

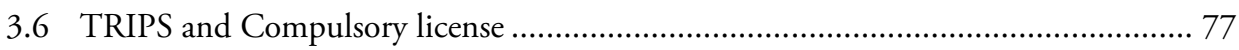

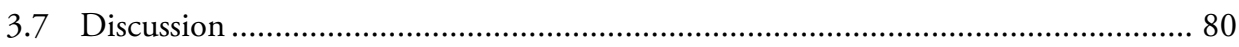

Chapter 4 The Brazilian price negotiation experience with ARV drugs ................81

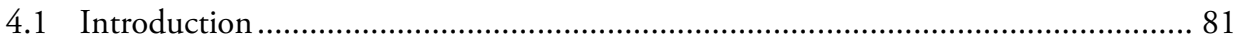

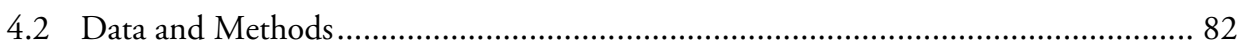

4.3 Historical reconstruction of price negotiations of ARV therapies in Brazil (2001 -

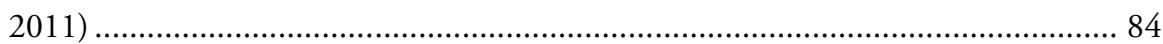

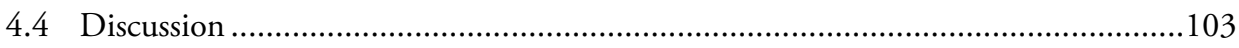


Chapter 5 When to push for a compulsory license? An Integrative Framework derived from the Brazilian experience with ARV drugs ....................... 105

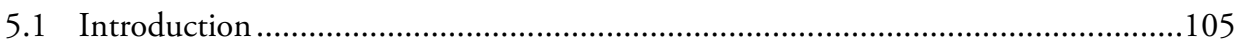

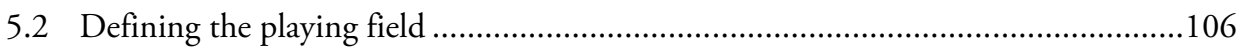

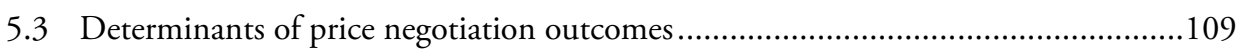

5.4 Illustrating the framework with selected episodes of price negotiation .....................117

Chapter 6 On the dynamics of compulsory license issuance: a game theoretical

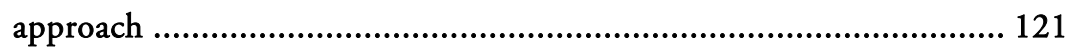

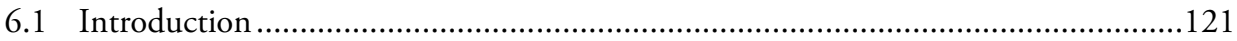

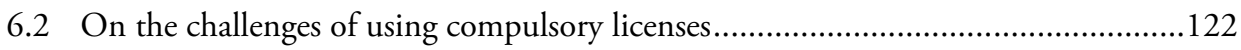

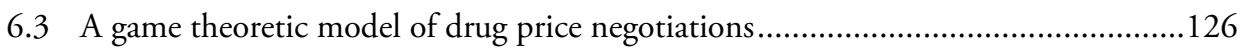

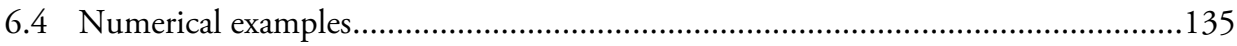

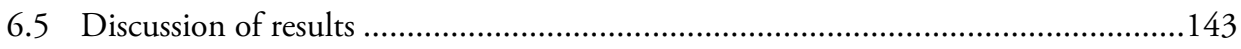

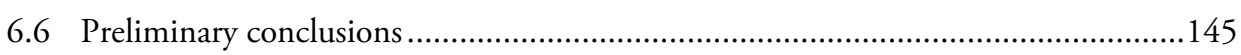

Chapter 7 Price negotiations of ARVs: Using game theory to explain the

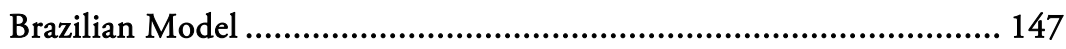

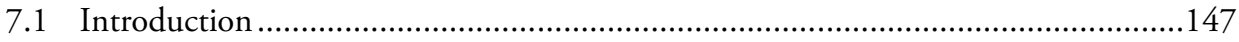

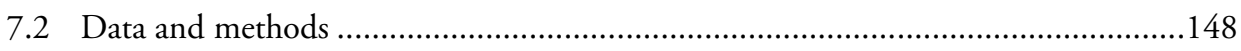

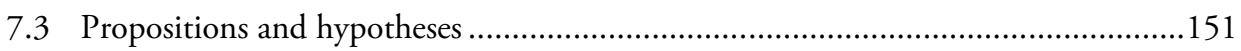

7.4 Validating the model against actual episodes of price negotiations............................153

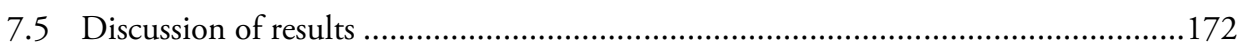

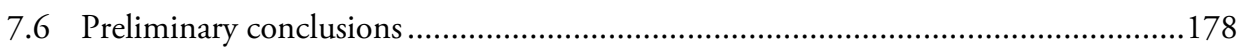

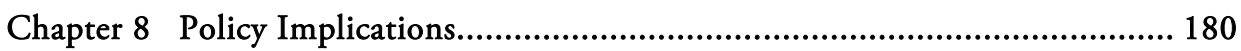

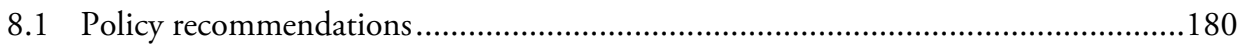

8.2 Emerging countries: a new pharmacy of the developing world? ...............................188

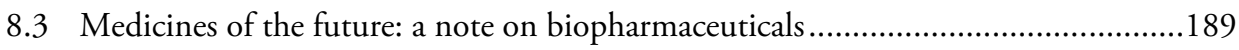

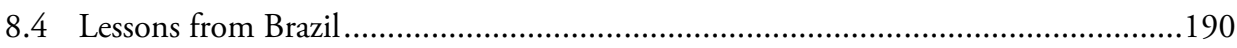

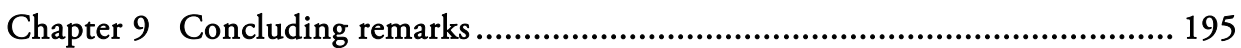

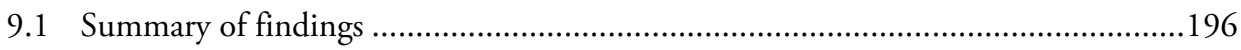

9.2 Limitations of the research and areas for further investigation .................................203

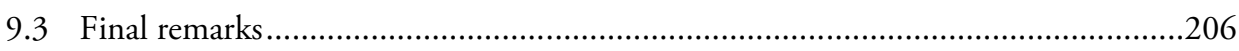

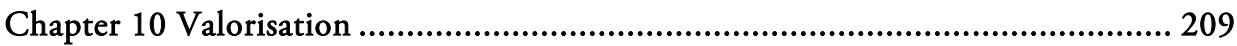

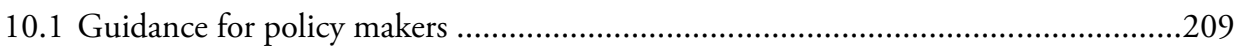

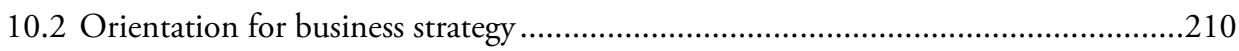

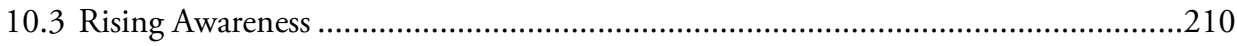


Annexes

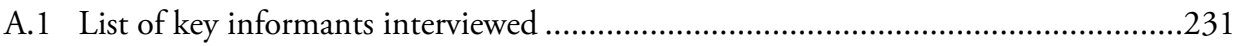

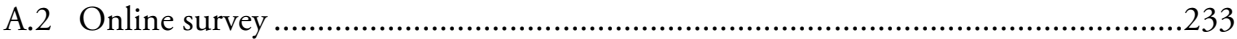

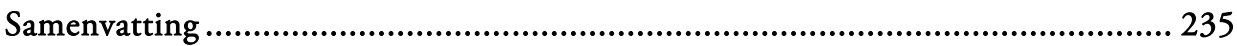

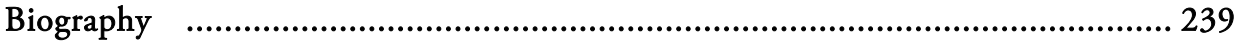




\section{LIST OF FIGURES}

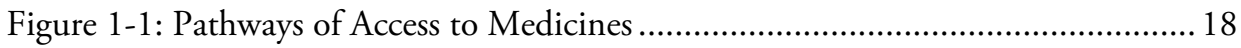

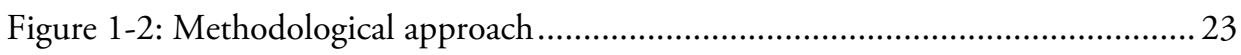

Figure 2-1: Interrelationships betweem health and economic growth.........................29

Figure 2-2: Health expenditure per capita and as share of GDP in 2012 by coutry

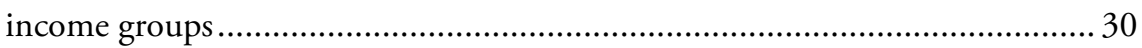

Figure 2-3: Pharmaceutical expenditure as share of total health expenditure, in 2006, by income level

Figure 2-4: Summary of the role of pharmaceutical expenditures in economic growth and development

Figure 2-5: Flow diagram of articles included in the systematic review on how pharmaceutical industry can support and promote health

Figure 2-6: Flow diagram of articles included in the systematic review on how access to medicines can be improved in the current IPR system ………...........57

Figure 2-7: Evolution of literature on access to medicines and IPR .............................58

Figure 3-1: MoH's total expenses with ARV Drugs in Brazil (1997 - 2013) ...............75

Figure 3-2 - Number of patients in the STD/AIDS Programme and Cost PPPY -

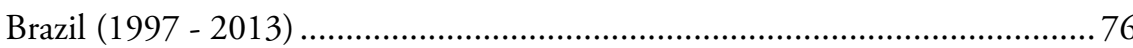

Figure 5-1. Cost per patient per year (PPPY) of selected ARV drugs as ratio of the

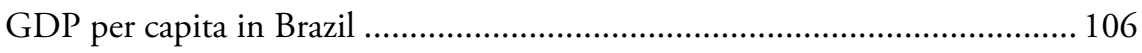

Figure 5-2: Brazilian ecosystem of price negotiation ................................................. 107

Figure 5-3. Framework of price negotiation within the Brazilian eco-system............. 117

Figure 6-1. Extensive form of the game under complete information....................... 129

Figure 6-2. Extended Game under incomplete information....................................... 133

Figure 6-3: Quantity obtained under compulsory license for different reprisal levels $\boldsymbol{m a x}(\boldsymbol{\alpha} \boldsymbol{L}, \boldsymbol{\alpha F})=1$

Figure 6-4: Quantity obtained under compulsory license for different levels of

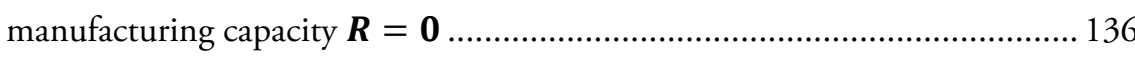

Figure 6-5: Patent holder's expected payoffs according to its belief and to the level

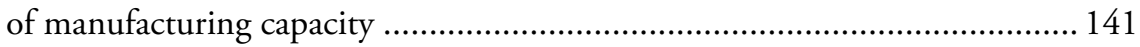

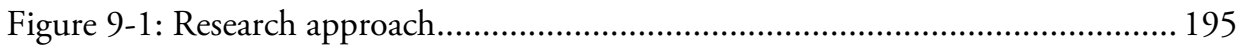

Figure 9-2: Levels of manufacturing capacity for drug production ............................. 200 


\section{LIST OF TABLES}

Table 2-1: Findings of the literature on economic growth, development and health 28

Table 2-2: Findings of the literature on the contribution of health to human capital accumulation and labour productivity

Table 2-3: Bibliometric analysis of pharmaceutical industry contributions towards health in low and middle-income countries

Table 2-4: Type of contributions of pharmaceutical industry to health and dimensions of access to medicines

Table 2-5: How pharmaceutical industry can improve health in developing countries ..... 41

Table 2-6: Type of initiative taken by pharmaceutical companies ................................. 42

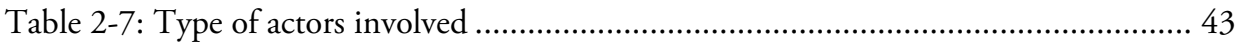

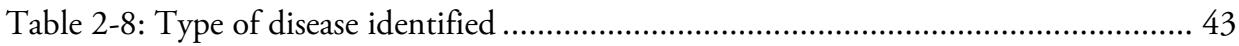

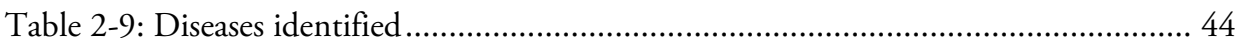

Table 2-10: Non-communicable Disease Burden in Low and Middle Income

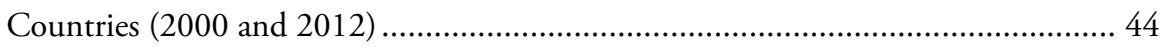

Table 2-11: Bibliometric analysis of pharmaceutical industry's contribution towards health in low and middle-income countries ...................................................... 57

Table 2-12: Distribution of the literature by country of affiliation of author(s) ............... 58

Table 2-13: Distribution of the literature by disease and disease type.............................. 59

Table 2-14: Strategies available to local governments to improve access to medicines in

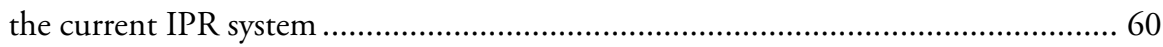

Table 2-15: TRIPS flexibilities and safeguards advocated by the literature on access to

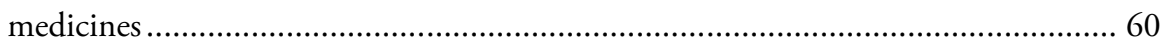

Table 2-16: Multi-actor strategies to improve access to medicines .................................. 61

Table 2-17: Supranational initiatives to improve access to medicines ................................ 62

Table 2-18: Strategies of pharmaceutical companies to improve access to medicines ........ 62

Table 2-19: TRIPS plus provisions in FTAs mentioned in the literature on access to

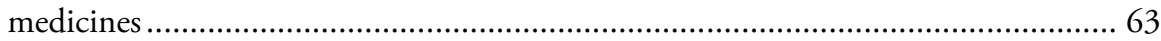

Table 4-1: Price negotiations of ARV drugs in Brazil ..................................................... 83

Table 4-2: Public-private partnership for local production of Lopinavir/Ritonavir (Episode 3A) ............................................................................................. 92

Table 4-3: Public-private partnership for local production of Efavirenz (Episode 3B) ...... 94

Table 4-4: Public-private partnership for local production of Tenofovir (Episode 3C) ..... 96

Table 5-1: Actors in the Brazilian Eco-system of price negotiation and their respective roles 
Table 5-2. Price negotiations and their respective outcomes

Table 5-3. Summary of actors' participation in each episode of price negotiation

Table 5-4: Coding criteria for categorisation of actor's relative strength in price negotiations

Table 5-5. Actor network strengths in price negotiations

Table 5-6: Coding criteria for categorisation of explanatory variables.

Table 5-7. Parameters of the bargaining game 116

Table 6-1: Factors influencing the issuance of compulsory licenses

Table 6-2: Fixed parameters for the numerical examples.....

Table 6-3: Different reprisal values used in this exercise

Table 6-4: Different manufacturing capacity values used in this exercise

Table 6-5: Quantity obtained under compulsory license for different levels of both reprisal and manufacturing capacity

Table 6-6: Patent holder's optimal counteroffer $\boldsymbol{p} 2$ to avoid compulsory license

Table 6-7: Patent holder's profit.

Table 6-8: Sub game-Perfect Nash Equilibrium for different reprisal and manufacturing capacity levels

Table 6-9: Values for manufacturing capacity level and beliefs $(\boldsymbol{\gamma} *)$ 141

Table 6-10: Outcome of the game under incomplete information 142

Table 7-1 Interview profiles. 150

Table 7-2: Summary of the negotiation episodes 168

Table 7-3: Testing H.1

Table 7-4: Testing H.2 170

Table 7-5: Testing H.3 .171

Table 7-6: Availability of generic ARVs during price negotiations between $\mathrm{MoH}$ and patent holders .172

Table 7-7: Results derived from validating the propositions with the cases......................173

Table 7-8: Results derived from pattern matching to test the hypotheses .......................174

Table 7-9. Typology of price negotiations after the validation exercise..... 177

Table 8-1: Price comparison of Efavirenz after compulsory licensing in Brazil (US\$ 2007 constant)

Table 8-2: Price comparison of Tenofovir after PPP for local production in Brazil 


\section{Chapter 1 Introduction to the research}

\subsection{The context}

Interest in the relationships between health, economic growth and economic development has increased over the last decades in both the academic and policymaking arenas. There is a strong positive correlation between health, measured by life expectancy, mortality rates or other indicators, and gross domestic product (GDP) per capita. This is indeed one of the best-known relations in international development (Bloom \& Canning, 2000).

The causal link running from income to health notice above has generally been well accepted since many decades. Higher income levels lead to higher living standards, better nutrition, access to safe water, sanitation, good quality health services and other conditions that promote health and enhance the prevention and treatment of diseases (Bloom \& Canning, 2000; Swift, 2011). However, from the 1990s, scholars started exploring the possibility that the health-income correlation could be partially explained by the reverse route, that is, through the influence of better health on economic growth (Bloom \& Canning, 2000; Swift, 2011). Ehrlich \& Lui (1991) were one of the first to explore the mutual causality between health and economic growth. They developed an overlapping-generations model of endogenous growth and concluded that an increase in longevity causes 'an unambiguous increase in the economy's steady-state growth rate' (p. 1056). In another early work in this field, Barro (1996) found that overall health status, which was measured by the log of life expectancy at birth, had a substantial positive effect on growth similar to that of education. In a panel estimation of approximately 100 countries from 1960 to 1990 , he found that, ceteris paribus, a rise in life expectancy from 50 to 70 years would raise the growth rate by 1.4 per cent per year. Therefore, the 'relation between health status and subsequent growth is clearly positive, roughly linear (in the log of life expectancy), and is not driven by outliers' (p. 317).

At least, two direct and two indirect mechanisms can account for this relationship between health status and subsequent growth. The direct channels are the effect on labour productivity and education. Healthier workers are physically more energetic and mentally more robust; a longer life expectancy provides stronger incentives to invest in developing their skills. The indirect channels are twofold. First, there is a positive effect on investment in physical capital, as longer life expectancy increases the incentives and needs for savings, which leads to more investment. Second, better health is also associ- 
ated with reducing fertility rates that allow a portion of the economy's investment to be used to raise capital per worker.

Hence, there are good reasons to expect improved health to result in economic development rather than being just an output of the development process. Therefore, the promotion of health deserves to join education as a key policy instrument for promoting the success of developing countries (Bloom \& Canning, 2003). Aligned to this view, several international organisations, such as the World Health Organization (WHO) and the European Commission (EC) have argued for greater spending on health as a means of promoting economic growth, for both developed and developing countries (Swift, 2011).

Therefore, medicines and health care services are essential goods, and their universal accessibility is important to promote a more equitable society. Along with skilled and dedicated healthcare providers, medicines - including drugs, vaccines and diagnostic chemicals - are the most significant means to improve the health status of a society by preventing, alleviating and curing diseases (Leach, Paluzzi, \& Munderi, 2005). However, many people in low and middle-income countries cannot access existing health interventions that can dramatically improve health and reduce the deaths associated with conditions that cause the vast majority of the excess disease burden in the developing world (Commission on Macroeconomics and Health, 2001).

\subsection{Pathways to access}

In 2000, the WHO collaborated with the Management Sciences for Health (MSH) in a framework to measure pharmaceutical access. The WHO-MSG framework, which defines four dimensions of access, is increasingly recognized as being of particular relevance to essential drugs, vaccines and other health commodities (Centre for Pharmaceutical Management, 2000). These four dimensions are presented below.

Physical availability is the relationship between the type and quantity of product or service needed, and the type and quantity of product or service provided (Centre for Pharmaceutical Management, 2000). Availability involves the logistics of making, ordering, shipping, storing, distributing and delivering a health technology to ensure it reaches the end-user (Frost \& Reich, 2009). 
Affordability is the relationship between prices of the products or services and the user's capacity (individuals, insurers or governments) to pay for them (Centre for Pharmaceutical Management, 2000). In short, affordability involves ensuring that health technologies and related services are not too costly for those who need them (Frost \& Reich, 2009).

Geographical accessibility is the relationship between the location of the product or service and the location of their users. For example, medicines must be accessible not only in urban centres but in all parts of a country, including remote rural areas (Centre for Pharmaceutical Management, 2000).

i. Acceptability is the relationship between the user's attitudes, perception and expectations about the products and services and their actual characteristics and appropriateness (Centre for Pharmaceutical Management, 2000). For example, pharmaceutical companies must ensure that their products are safe and appropriate for children and the elderly and ensure that clinical trials observe the highest ethical and human rights standards (Lee \& Hunt, 2012). Currently there are few child-friendly formulations for treating HIV/AIDS (i.e. smaller tablets easier to swallow), and those available tend to be more expensive than adult formulations; a best practice approach in terms of acceptability should involve the production of more child-friendly formulations at lower prices (Hartsough, Rosan, \& Sachs, 2006)

A substantial share of the population in the developing world still does not have adequate access to the essential medicines needed to treat diseases that cause loss of health status and well-being (Cameron, Ewen, Ross-Degnan, Ball, \& Laing, 2009). The problem of limited access to medicines seems to result from a number of inter-linked, yet crucial, pathways as represented in Figure 1-1 and outlined below. 


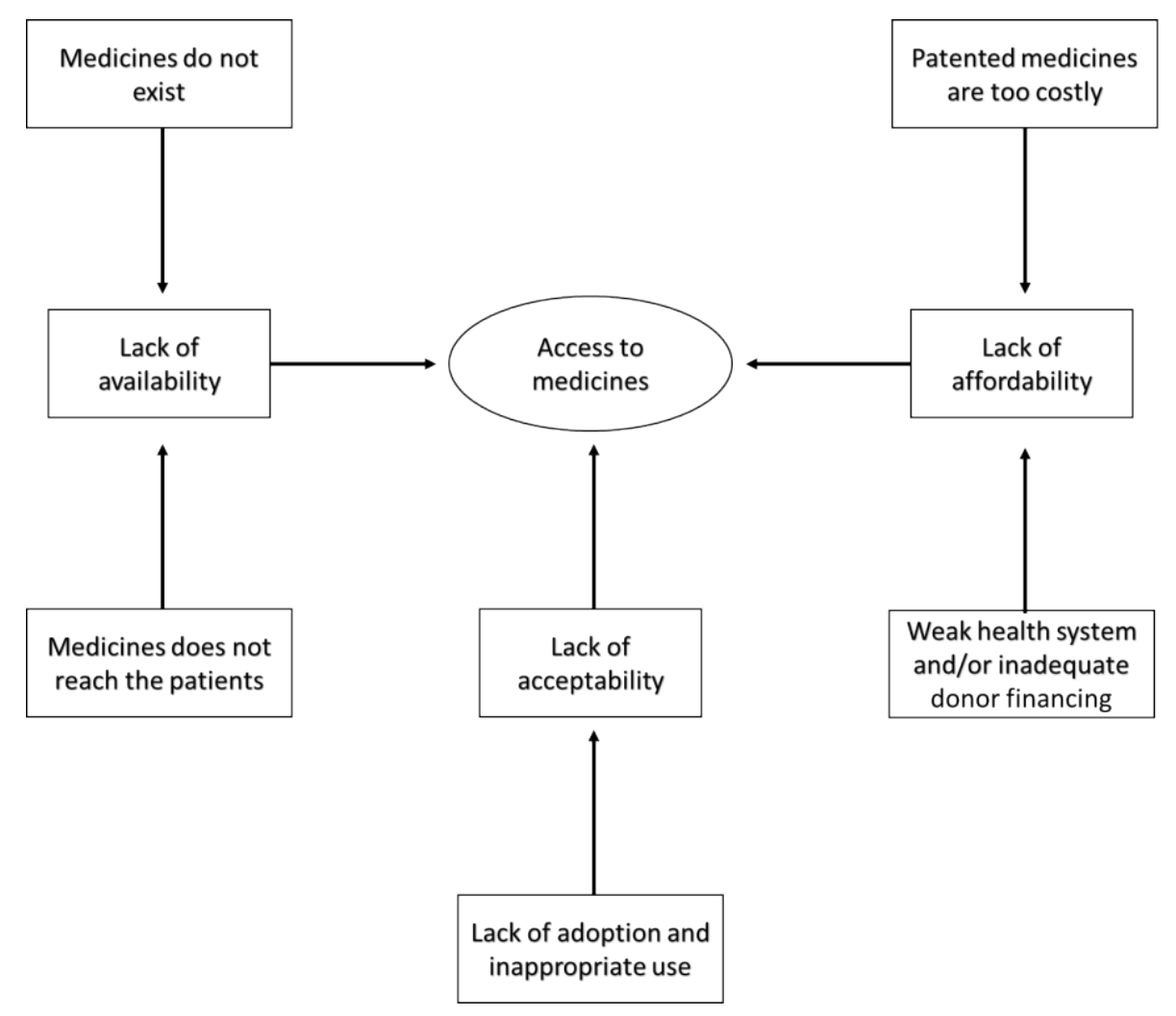

Source: Author' elaboration based on Centre for Pharmaceutical Management (2000), Commission on Macroeconomics and Health (2001), Frost \& Reich (2009), and Ramani, Dutta, \& Urias (2014)

Figure 1-1: Pathways of Access to Medicines

First, there is the problem of the lack of availability of drugs. In the extreme scenario there might be no effective drugs, diagnostics or vaccines available for a disease, in which case innovation would provide the only hope for containment (Ramani et al., 2014). These diseases are commonly referred to as neglected because they mostly affect the poorest, and therefore pharmaceutical companies do not have the financial incentives to invest in the research and development of health interventions for them. In other instances, effective medicines might be available globally, but not in the country concerned. The public health system of the country concerned may not have the resources or the capabilities to distribute the medicines to the needy or provide the required complementary healthcare services (Ramani et al., 2014). Some obstacles to availability can be self-imposed, as in cases of countries that impose import duties and domestic taxes on essential medicines, or implement burdensome procurement systems 
and regulatory procedures that unduly delay the market introduction of the needed medicines (Commission on Macroeconomics and Health, 2001). In addition, other factors such as corruption, poor logistics and lack of adequate infrastructure can impede patients in some regions receiving the existing drugs, even when these are offered free of charge.

Second, existing medicines may be out of the reach of the patients due to their (relative) high cost. The reasons for lack of access to medicines are several, but poverty is, by far, the most important. This means that neither the poor nor their governments can afford to purchase these essential goods, or ensure their proper use (Commission on Macroeconomics and Health, 2001). This comes under the problem of affordability in the access dimensions.

High prices are often linked to patent status of the drug. Patents are the most important appropriability instruments used by pharmaceutical companies to protect their inventions (Cohen, Nelson, \& Walsh, 2000; Teece, 1986). Since patents grant monopoly rights to the inventor, the price of patented products tends to be higher than in a competitive market. Therefore, patent protection tends to result in extremely high costs of the available medicines, keeping them out of the reach of the general population. As a result, the consumption of such essential goods is likely to be lower than the socially desirable level. It is worth nothing that even drugs and vaccines that are off patent are still unaffordable in low-income countries (or in regions of middle-income countries).

The price of medicines must be analysed according to the household, donor or public health budget. Thus in the context of poverty, neither the patient nor their governments can afford to purchase even off-patented essential medicines or ensure their proper use if prices are too high. Even when adequate donor financing is available, the drug pricing policies of pharmaceutical companies can lead to a significant expense, even though this problem is usually more frequent for patented medicines (Commission on Macroeconomics and Health, 2001).

Third, there is the problem of acceptability in the access dimension. Patients themselves may be unwilling or unable to take the medicines or to attend the health care facility. This dimension has an impact on the acceptance of the technology by the patient or consumer, which includes the appropriate use of the technology (Frost \& Reich, 2009). Acceptability is also affected by the provider's adoption and acceptance of the 
technology that will lead to appropriate prescribing (Frost \& Reich, 2009). Thus, the inadequate supply of doctors and other health workers trained to select, prescribe and use the available medicines in an appropriate manner can substantially hinder access to medicines (Commission on Macroeconomics and Health, 2001).

\subsection{The role of the private sector in promoting access}

The private sector is the main supplier of medicines and the breakthrough innovations in pharmaceuticals to date have been commercialized mostly by European and American firms. Thus, pharmaceutical companies play a critical role in enhancing health status worldwide, including in the developing world. This is acknowledged as such in the United Nations (UN)'s Millennium Development Goals (MDG) for which the industry can make significant contributions, particularly goal 4: reduce child mortality; goal 5: improve maternal health; goal 6: combat HIV/AIDS, malaria and other diseases; and goal 8: develop a global partnership for development (Sturchio, 2008). Furthermore, Goal 8: Target 8e explicitly evokes the need of cooperation with pharmaceutical companies to improve access to affordable essential drugs in developing countries. The pharmaceutical industry needs to ensure that the developing world has access to essential medicines at near-production cost through, for instance, tiered pricing mechanisms and licensing their products to generics producers (Commission on Macroeconomics and Health, 2001).

However, recognition of this issue has not been sufficient for major progress. According to the UN MDG task force, "[t] here has been little improvement in recent years in improving availability and affordability of essential medicines in developing countries." (UN, 2014). A possible solution for cases in which industry cooperation is not enough, as advocated by the Commission on Macroeconomics and Health of the WHO, is the application of the rules of international trade involving access to essential medicines in a manner that ensures the same results (Commission on Macroeconomics and Health, 2001).

By 'rules of international trade', the Commission on Macroeconomics and Health refers basically to the use, in the case of patented medicines, of the safeguards contained in the World Trade Organization (WTO) Agreement on Trade-Related Aspects of Intellectual Property Rights (TRIPS) to promote access to medicines. More precisely, the Commission on Macroeconomics and Health suggests the use of compulsory license; that is, the government authorization for a third party to produce the patented 
product or process without the permission of the patent holder, as a solution to promote access to medicines when pharmaceutical companies are inflexible, as in the excerpt below:

'Assuming that a patent holder chooses neither to offer an essential medicine on a no-profit basis nor to license the medicine to a generics producer, the low-income country will still need a way to ensure access at low cost. The current rules on intellectual property rights in the world trading system, known as TRIPS, envisage compulsory licensing as such a safeguard.' (Commission on Macroeconomics and Health, 2001, p. 90).

\subsection{Focus of the thesis}

From the above arguments, it is clear that drug price is a factor that crucially influences accessibility. This obstacle is even more pronounced in the case of patented medicines. Thus, governments of developing countries can be in a vulnerable position with respect to patent-protected drugs supplied by foreign firms, if the technology cannot be licensed or independently developed by local firms.

There is evidence that, in such instances, one possible solution is to negotiate for a price-drop with the patent holder, that is, research-based pharmaceutical multinationals. In addition, the literature on access to medicines stresses that the main strategy available to local governments in the current IPR system are the use of TRIPS flexibilities, notably compulsory licensing threats, as leverage in price negotiations between governments and pharmaceutical innovators. However, the conditions in which a developing country may have the confidence to threaten to use the compulsory license option or actually issue one, and in which such threats will successfully bring down the price of the vital drugs, are still unclear.

In the above context, the present thesis analyses how access to medicines can be improved via changes in drug prices. More precisely, the analysis focuses on a country's ability to obtain more affordable patented drugs by making compulsory license threat(s) in price negotiations with the seller. Therefore, the central research question of this dissertation is: What are the conditions under which a country can use compulsory licensing threats in price negotiations? This leads to additional questions: When will such threats be successful in obtaining more affordable lifesaving drugs? What are the drivers of bargaining outcomes of these negotiations between pharmaceutical multina- 
tionals and governments in developing countries? How do these drivers, individually and jointly, determine the outcomes?

To answer these queries, we follow an inductive research approach. We first develop a more complete understanding of the underlying context in order to identify the drivers of the bargaining outcomes. To do this, we initially carry out scoping reviews of the contribution of the pharmaceutical industry to health outcomes in the developing world and the challenges to access to medicines posed by the current IPR system. Thereafter, we carry out a systematic review of the literature on the use of compulsory licensing of patented medicines. Then, we complement the scoping studies and the systematic review with information gathered from both primary and secondary sources.

The primary data consists of 26 semi-structured and exploratory interviews with academics, politicians, lawyers, activists and businesspersons familiar with the Brazilian experience in price negotiation. The analysis of these expert interviews does not build on formalized coding protocols; rather it checks statements related to informational constraints, drivers of bargaining position, obstacles faced and alternatives for the future. Secondary sources of data include official documents, scientific articles, national and international reports, websites of the Ministry of Health $(\mathrm{MoH})$ of Brazil, and newspaper articles.

Furthermore, Brazil is taken as the country to be examined as it is widely acknowledged as a leading user of compulsory licensing threats in negotiation with pharmaceutical companies to reduce the price of HIV/AIDS treatments. However, in spite of the Brazilian success, to date there has been no detailed study of the drivers of price negotiation from the Brazilian experience. Brazil thus forms an interesting case study to gain insight on how the threat of issuing a compulsory license can be used to negotiate price reductions with innovator pharmaceutical companies.

Once the drivers of bargaining outcomes are identified, we, then, develop a descriptive case study based upon 14 episodes of price negotiation of antiretroviral (ARV) drugs between the $\mathrm{MoH}$ of Brazil and research-based pharmaceutical companies. This case study presents a detailed historical reconstruction of these negotiation episodes in order to examine the individual and interdependent influences of these drivers. After that, based on the context derived from the first step and on this historical reconstruction of the Brazilian experience, we formulate and solve a game theoretical model of price negotiation between a pharmaceutical company and a public agency in a developing 
country. This, in turn, forms the basis for an integrative analytical framework built from a set of assumption to explain the circumstances under which a country can use compulsory licenses in price negotiations, and the conditions under which such threats will result in more affordable drugs.

Finally, this integrative framework is validated against the 14 episodes of price negotiation of HIV/AIDS therapies in Brazil. We apply a 'pattern matching' data analysis technique to carry out this validation exercise. With this method, we compare whether the outcomes expected from the game-theoretical model match with the observed outcome in each price negotiation. In addition, we check whether the explanatory variables used in the model are indeed responsible for those observed outcomes.

This methodological approach is illustrated in Figure 1-2 below.

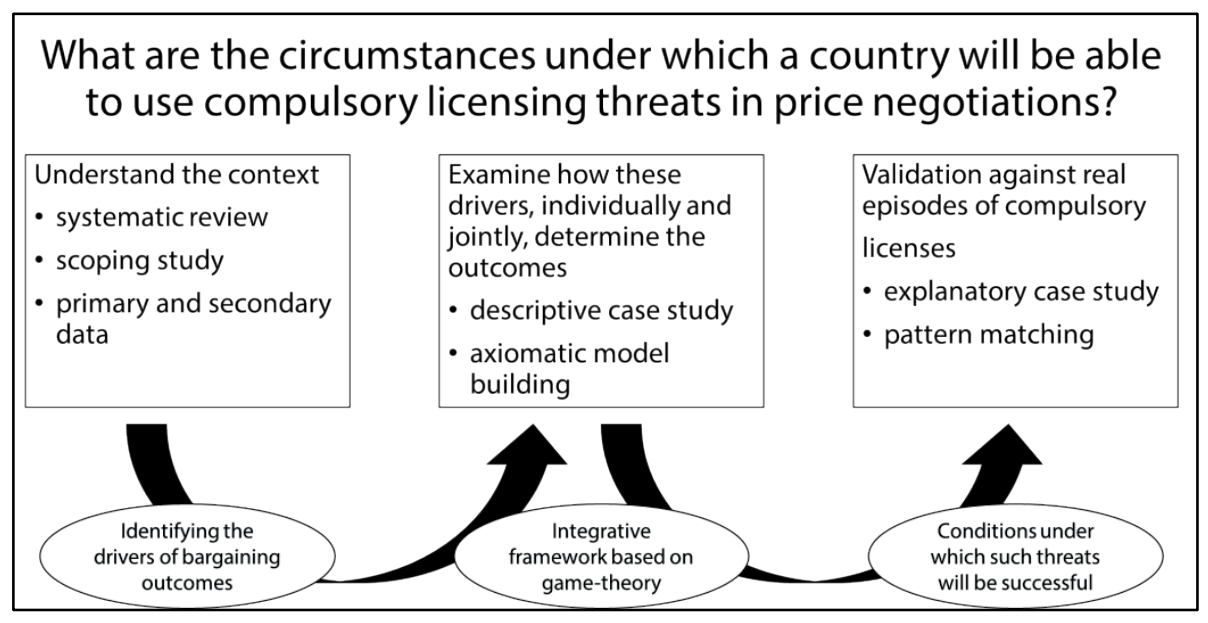

Figure 1-2: Methodological approach

\subsection{Organisation of the dissertation}

The monograph is organised as follows

Chapter 2 is dedicated to a review of the existing literature. Firstly, we examine the role of the pharmaceutical industry in enhancing the health status of the developing world. We start with a standard literature survey to gather examples of how pharmaceutical companies influence the realization of the right to health in developing countries via $\mathrm{R} \& \mathrm{D}$, pricing and other marketing and non-marketing strategies. Then, we carry out a 
meta-analysis based on 76 research articles that discuss the contribution of the industry to health promotion from an empirical, positive and normative perspective.

We conclude that pharmaceuticals companies can play a vital role by developing drugs appropriate for the developing world and by making their drugs more accessible to the poor. The literature stresses the importance of alternative funding and financing mechanisms as well as of alternative reward systems to provide higher incentives to pharmaceutical companies in the field of neglected diseases. In addition, large-scale donations programmes and tiered pricing systems are suggested as the main strategies to improve access to existing drugs in the developing world. Pharmaceutical companies often do not act in an isolated manner, as many of their actions involve a wide range of actors, from governments to international foundations and organised civil society. Furthermore, in many instances, their actions are a result of an initiative of, or even external pressure from, these actors.

Secondly, we review the literature on the obstacles created by the patent system vis-avis access to medicines and the possible solutions in the current Intellectual Property Rights (IPR) system. After a brief review of the present international IPR framework dictated by the TRIPS Agreement and the consequent impact on access to medicines, we present a scoping study based on 115 research articles to understand how access to medicines can be improved under this context.

In Chapter 3, we review the role of industry, state and multinational enterprises (MNE) in tackling the HIV/AIDS crisis in Brazil. An import part of the successful implementation of the anti-AIDS program, which covers more than 350000 people in 2013, is the capacity of the Brazilian government to reduce the price of treatments.

In Chapter 4, we present a descriptive case-study of the Brazilian experience in negotiating prices with pharmaceutical companies for ARV drugs that are part of the drug cocktail offered free of charge for people living with HIV/AIDS in the country. In spite of the Brazilian success, to date there has been no detailed study of the drivers of price negotiation from the Brazilian experience. In addition, there is no extensive research using episodes of price negotiation as the unit of analysis. In order to contribute to filling this gap, we collected data from all price negotiations for ARV drugs undertaken by the $\mathrm{MoH}$ of Brazil from 2001-2011 in which IPR matters were in discussion. Based on this data, we design a case study comprised of 14 episodes of price negotiations for acquisition of ARV drugs in Brazil. 
Based on this case study, in Chapter 5, we present the elements necessary for an integrative framework to analyse the price negotiations of ARV drugs in Brazil. We use the game theoretic reasoning to develop an integrative framework capturing the dynamics of price negotiations between $\mathrm{MoH}$ of Brazil and MNEs. When such a confrontation is taking place, both the $\mathrm{MoH}$ and MNEs have to interact with other strategic actors in order to seek the best outcome. We refer to this network of actors as the 'Brazilian ecosystem of price negotiation'. In this framework, the level of technological capacity, availability of import substitutes and internal and external pressure against compulsory licensing are identified as the ultimate sources of bargaining strength.

Chapter 6 develops a game theoretical model of such bargaining and identifies the conditions under which compulsory licenses can be issued. In this chapter, we identify in the literature the drivers of bargaining outcomes of price negotiations between multinationals and public agencies of developing countries. Then we model the individual and joint influence of these drivers in determining the type of outcomes. It shows that while compulsory licenses are impossible under complete information, they can be issued under incomplete information. We show that compulsory licenses are more likely the higher the initial drug price, and stronger the domestic manufacturing or access to imports of the drug. These results are published in the journal Social Science and Medicines (see Ramani \& Urias, 2015). We conclude this chapter with numerical exercises to illustrate how this dynamics takes place for different levels of local manufacturing capacity, availability of import substitutes and reprisal.

In Chapter 7, we test and validate our game-theoretical conceptual framework with the Brazilian experience on price negotiation of ARV drugs. Using 26 interviews and several sources of secondary data, we construct an explanatory case study based on 14 price negotiations of ARV drugs in Brazil. The propositions derived from the conceptual framework developed in Chapter 4 are further refined into three hypotheses, which, in turn, are tested using a pattern-matching method. This chapter provides further information on the industrial dimension of the successful Brazilian strategy and refines the conditions lying at its heart. It also re-specifies the issues concerning its potential replication in other developing countries, particularly those deprived of industrial capabilities. We find that the presence of informational constraints is indeed crucial to understand why Brazil issued its only compulsory license in 2007. In addition, our findings also provide evidence for further qualification on the importance of local manufacturing capacity. The existence of production capacity for a specific drug is not a necessary condition to obtain price reductions for the same. However, when such capacity exists, 
then it is likely that the negotiation will lead to a lower price relative to the lowest international one. Therefore, it is not only the current level of manufacturing capacity that defines the country's 'bargaining strength', but also its 'capacity to create manufacturing capacity' in the future.

Chapter 8 presents the policy recommendations. In order to increase their 'bargaining strengths' in price negotiations, both developing and least developed countries need to make the best use of industrial policy to build industrial and technology capabilities in pharmaceuticals. Countries that have lagged behind in terms of technological capabilities can first work towards building technological capacity in formulation and initiate institutional changes to facilitate the import of the cheap generic versions of patented drugs under compulsory license. In this context, promotion of South-South cooperation can be a valuable tool for both formal and informal knowledge exchange to facilitate this process of capacity building.

Finally, Chapter 9 summarizes the main findings and concludes this dissertation. To sum up, health is a critical component of both economic growth and economic development. Given the importance of health technologies in the health status of a population, access to these technologies, especially medicines, is a legitimate concern. The existing IPR system, on the one hand, is important to promote innovations. On the other hand, it creates obstacles to access to medicines. There are flexibilities and safeguards that countries can implement in order to circumvent these obstacles. However, while developing and least developed countries are subject to political and economic pressure from both companies and their home governments, it is very unlike that they will take full advantage of the existing TRIPS flexibilities to get more affordable drugs either by issuing compulsory licenses or by bargaining for price discounts with the patent holder. 


\section{Chapter 2 Access to medicines - A review of the role of the pharmaceutical industry and the chal- lenges of the current IPR system}

\subsection{Introduction}

Economic growth is typically understood as the quantitative expansion in a country's economy measured by the variation in the GDP. Development is a qualitative change in several intricate factors, such as per capita income, life expectancy, access to education and health care, employment opportunities, availability of clean air and safe drinking water, among other less tangible factors.

There are many reasons why the relationships between health, economic growth and development should be of special interest. On the one hand, a decline in the death rates is an indispensable component of long-term economic growth (Kuznets, 1975). On the other hand, it is undeniable that economic factors, such as disposable income, food supply, diffusion of medical and health technologies and better living standards, have contributed to the increase in life expectancy during the last century (Preston, 1975).

Economic growth and development can be intricately related in diverse ways as function of the evolutionary projection. By increasing a nation's total wealth, there is a higher potential for reducing poverty and solving other social problems. The process of demographic transition associated with economic development also contributes to the reduction in mortality rates, especially due to improved sanitation conditions. Higher income often triggers behavioural changes, such as increasing spending on health and nutrition. These changes, coupled with advances in health technology, notably medicines, have had a tremendous impact on life expectancy and health status as a whole. Table 2-1 summarizes some central findings from the literature on the contribution of economic growth to improved health. 
Table 2-1: Findings of the literature on economic growth, development and health

\begin{tabular}{|c|c|c|}
\hline Driver of health & Health measure & Source \\
\hline Income & Life expectancy & $\begin{array}{l}\text { López-Casasnovas \& Soley-Bori (2014); } \\
\text { Murthy \& Okunade (2014); Renton, Wall, \& } \\
\text { Lintott (2012) }\end{array}$ \\
\hline Education & Life expectancy & $\begin{array}{l}\text { López-Casasnovas \& Soley-Bori (2014); } \\
\text { Murthy \& Okunade (2014) }\end{array}$ \\
\hline Health expenditure & Life expectancy & Murthy \& Okunade (2014) \\
\hline Nutrition & $\begin{array}{l}\text { Cardiovascular disease } \\
\text { incidence }\end{array}$ & He et al. (2014); Venkitachalam et al. (2012) \\
\hline Nutrition & Child/infant mortality & Strulik \& Weisdorf (2014) \\
\hline Nutrition & $\begin{array}{l}\text { Stunting and underweight in } \\
\text { children }\end{array}$ & Vollmer et al. (2014) \\
\hline Health expenditure & Child/infant mortality & Lv \& Zhu (2014) \\
\hline Health expenditure & $\begin{array}{l}\text { Stunting and underweight in } \\
\text { children }\end{array}$ & $\begin{array}{l}\text { Moreno-Macías, Palma-Solís, \& Zapata- } \\
\text { Vázquez (2013) }\end{array}$ \\
\hline Medical Innovation & Life expectancy & (Renton et al., 2012) \\
\hline Health expenditure & $\begin{array}{l}\text { Cardiovascular disease } \\
\text { incidence }\end{array}$ & Venkitachalam et al. (2012) \\
\hline
\end{tabular}

On the other side of the relationship, the main mechanism by which health contributes to economic growth is human capital accumulation. Longer life span provides incentives to save and accumulate capital, due to an increase in the return to schooling, nutrition and health education. Thus, higher life expectancy acts as an important incentive to increase investment in education and health that will increase labour productivity. Table 2-2 summarizes important findings from the literature on the determinants of health that affects human capital accumulation and labour productivity. 
Table 2-2: Findings of the literature on the contribution of health to human capital accumulation and labour productivity

Determinant of Health

Health measure Source

\begin{tabular}{|c|c|c|}
\hline $\begin{array}{l}\text { Health expendi- } \\
\text { ture }\end{array}$ & Life expectancy & $\begin{array}{l}\text { Bloom, Canning, \& Sevilla (2004); } \\
\text { Fanti \& Gori (2013); Fanti, Gori, \& } \\
\text { Tramontana (2012); Hickson (2014); } \\
\text { Stenberg et al. (2014); Naidu \& } \\
\text { Chand (2013) }\end{array}$ \\
\hline $\begin{array}{l}\text { Medical innova- } \\
\text { tions }\end{array}$ & Life expectancy & $\begin{array}{l}\text { Acemoglu \& Johnson (2007); Hansen } \\
\text { (2013); Naidu \& Chand (2013) }\end{array}$ \\
\hline $\begin{array}{l}\text { Health expendi- } \\
\text { ture }\end{array}$ & Disease incidence & $\begin{array}{l}\text { Augier \& Yaly (2013); Goenka, Liu, \& } \\
\text { Nguyen (2014) }\end{array}$ \\
\hline $\begin{array}{l}\text { Health expendi- } \\
\text { ture }\end{array}$ & $\begin{array}{l}\text { Mortality reductions; mor- } \\
\text { bidity averted }\end{array}$ & (Hickson, 2014) \\
\hline $\begin{array}{l}\text { Disease preven- } \\
\text { tion }\end{array}$ & $\begin{array}{l}\text { Mortality reductions; mor- } \\
\text { bidity averted }\end{array}$ & Aksan \& Chakraborty (2014) \\
\hline $\begin{array}{l}\text { Medical innova- } \\
\text { tions }\end{array}$ & $\begin{array}{l}\text { Mortality reductions; mor- } \\
\text { bidity averted }\end{array}$ & Aksan \& Chakraborty (2014) \\
\hline $\begin{array}{l}\text { Drinkable water } \\
\text { and sanitation }\end{array}$ & Disease incidence & Clemens \& Douglas (2012) \\
\hline
\end{tabular}

Figure 2-1 presents illustrations of interdependences between health, economic growth and development that gave been highlighted in the literature.

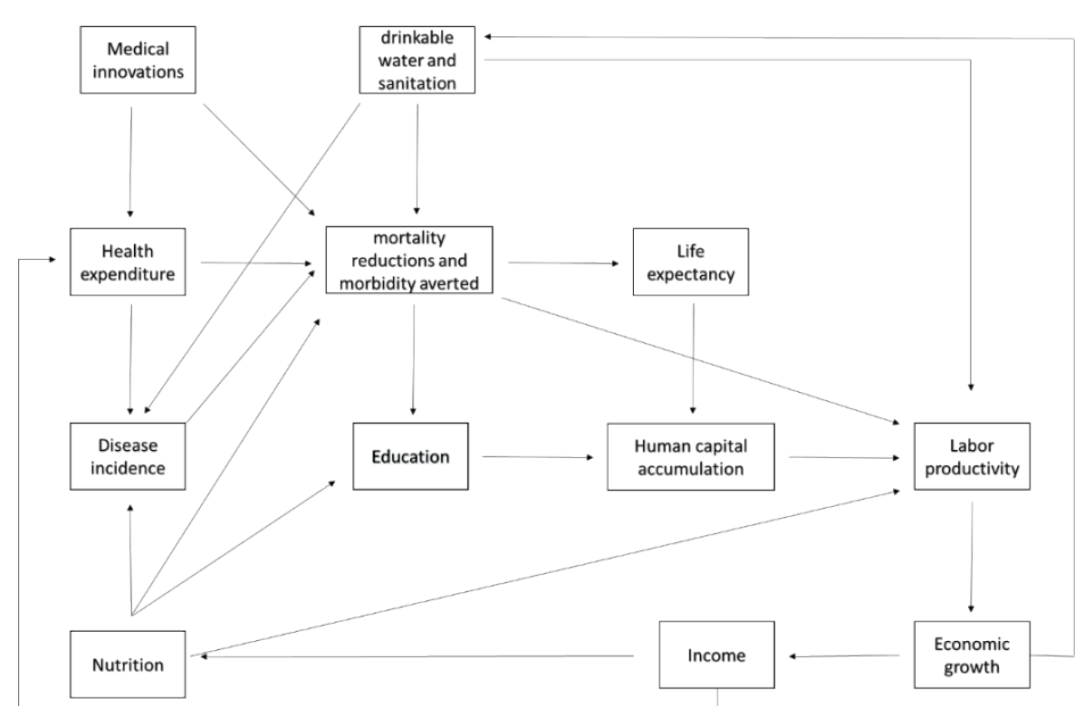

Figure 2-1: Interrelationships betweem health and economic growth 
Health outcomes are determined by several medical and non-medical factors such as education, technological change, income, nutrition, and total expenditure on health care. However, in the economics literature, the most used indicator of determinant of health status seems to be health expenditure, measured as the capital investment in health care infrastructure plus the public and private spending on medical goods and services, on public health and prevention programmes, and on administration.

The average per capita health care expenditures in 2012 ranged from US\$ 66 PPP (2005) in low-income countries to US\$ 4,513 in high-income countries (see Figure 2-2), with considerable variations both between countries of the same income group and between income groups in each country. In addition, the total health expenditure in low and middle-income countries is equivalent to only 5.4 per cent of the GDP, while the average expenditure on health in high-income countries is $12.2 \%$. Such expenditures are not only unaffordable but also inadequate, considering the enormous health care burden for developing countries (Novignon, Olakojo, \& Nonvignon, 2012).

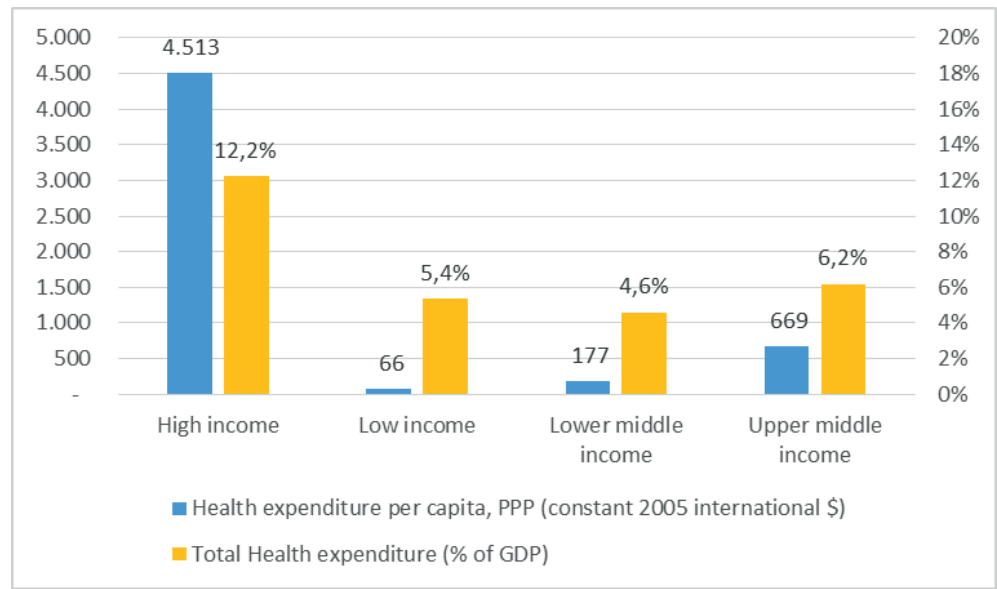

Source: The World Bank (2012a, 2012b)

Figure 2-2: Health expenditure per capita and as share of GDP in 2012 by coutry income groups

When health spending is disaggregated by the type of service or product, it is possible to see that medicines are not only responsible for a considerable share of the total health expenditure but are also the component that contributes most to its growth. The costs of medicines are the drivers of general health care spending and these also trigger increases in premiums of health insurance, and hospital spending (Rivers, Hall, 
\& Frimpong, 2006). Between 1995 and 2005, the consumption of pharmaceuticals grew in all income categories of all countries, but the relative growth was higher in lowincome countries than in high-income countries (Hoebert, Laing, \& Stephens, 2011).

The increased prescription of new medicines, which tends to be more expensive due to patent protection, is an important driver of the increase in spending on drugs. However, several other factors contribute to this scenario, such as increases in the total population and the aging population, increases in the incidence of chronic and noncommunicable diseases requiring drug therapy, the preference for drug therapy instead of other forms of treatment, increases in the use of prescription medicines and a shift towards higher and more frequent dosages, and the use of pharmaceutical innovations to treat conditions for which there was no effective treatment previously (Buske, 2002; Macdonald, 2003; Rivers et al., 2006).

On average, spending on pharmaceuticals represented 17 per cent of all health expenditure across countries of the Organisation for Economic Co-operation and Development (OECD) in 2011, making it the third largest component of expenditure (OECD, 2013). The annual drug expenditure per capita grew by 3.5 per cent in real terms on average in OECD countries and led several countries to introduce measures to reduce pharmaceutical spending, including price cuts, centralized public procurement of pharmaceuticals, promoting the use of generics, exclusion from reimbursement and increases in co-payments by households (OECD, 2013).

Figure 2-3 shows that the total expenditure, with medicines as a share of total health expenditures, is even greater in developing countries ( $\mathrm{Lu}$, Hernandez, Abegunde, \& Edejer, 2011; WHO, 2000). In 2006, pharmaceutical expenditures represented 43 per cent of total public and private health expenditures in Thailand, 33 per cent in Brazil, 36 per cent in China, 40 per cent in Mali, 63 per cent in Pakistan and 68 per cent in Tunisia (WHO, 2011). 


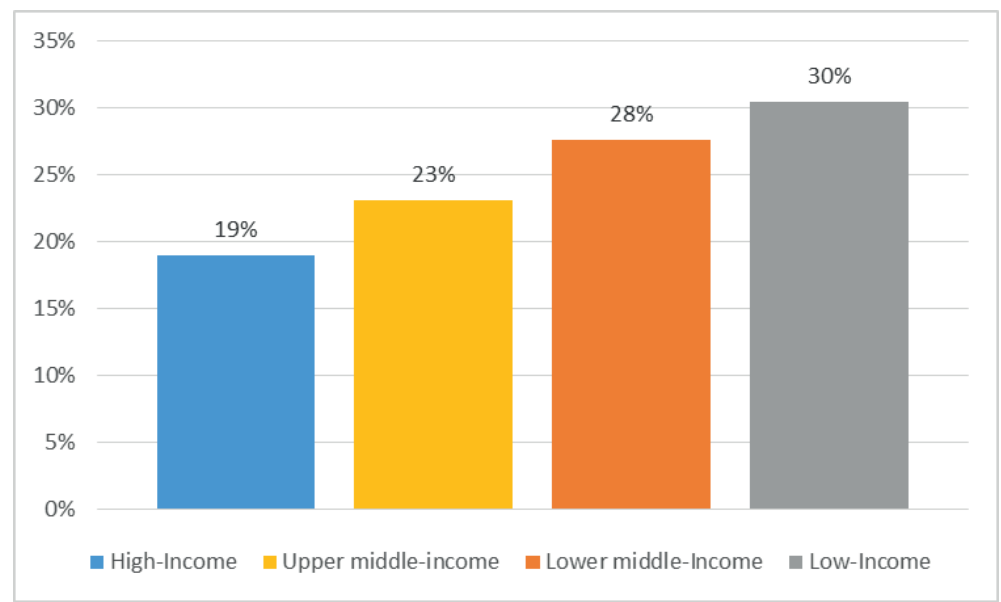

Source: WHO (2011)

Figure 2-3: Pharmaceutical expenditure as share of total health expenditure, in 2006 , by income level

The picture is even more dramatic when one takes into account that medicines are the largest family expenditure item after food in developing countries (Cameron et al., 2009). In 2012, more than 50 per cent of the population in low and lower middleincome countries purchased medicines through out-of-pocket payments (The World Bank, 2012c). In the upper middle-income countries, the out-of-pocket health expenditure is equivalent to 32.2 per cent of the total expenditure on health, while in high-income countries, the average is 13.8 per cent (The World Bank, 2012c). As a result, medicines are unaffordable for large sections of the global population and are a major burden on government budgets.

In sum, public and private spending on pharmaceutical goods are an important component of total health expenditure, which, in turn, is a central driver of health outcomes of a nation. These dynamics are illustrated in Figure 2-4. 


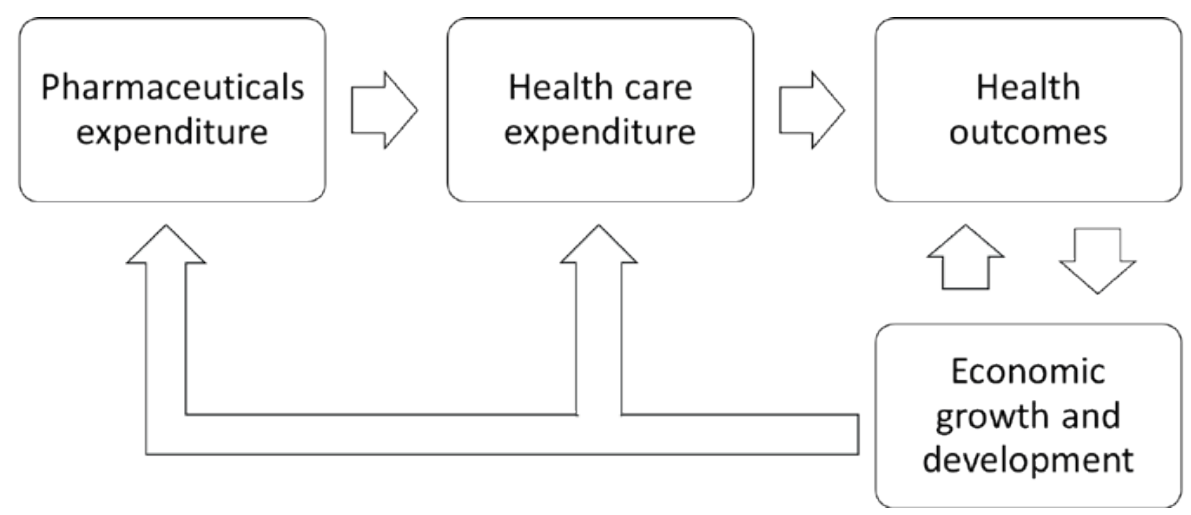

Figure 2-4: Summary of the role of pharmaceutical expenditures in economic growth and development

Given the role of pharmaceutical goods in the contribution of improved health and to economic development, it is important to understand the alternatives to increase access to medicines in low and middle-income countries. In the remainder of this chapter, we will approach this issue by doing scoping studies of two strains of literature. First, in Section 2.2 and Section 2.3, we analyse how pharmaceutical companies can support and promote access to health in the developing world. Second, in Section 2.4 and 2.5, we analyse the obstacles presented by the current international IPR system and the alternatives that exist to improve access to medicines in this context. Finally, Section 2.6 summarizes and concludes the chapter.

\subsection{Pharmaceutical industry and health promotion}

\subsubsection{General overview}

Although the State is responsible for ensuring the right to health to their citizens, pharmaceutical companies support and promote access to health, especially in low and middle-income countries. The pharmaceutical industry contributes to this goal through its core business operations and by working with States and other partners. It possesses unique resources and capabilities that are valuable for health promotion. For instance, the contribution of pharmaceutical companies is shaped by their research and development $(\mathrm{R} \& \mathrm{D})$, clinical training, drug delivery and distribution of new medicines and vaccines, and other healthcare technologies, including medical equipment and diagnostic kits (Sturchio, 2008). In sum, pharmaceutical companies via R\&D, pricing and other market and non-market strategies also influence the realization of the right to health in developing countries. 


\subsubsection{Generating health outcomes through R\&D}

Over the last century, many pharmaceutical companies have discovered, developed and provided innovative products and services that have saved and improved the lives of many people around the world. It must be acknowledged, however, that R\&D in the pharmaceutical sector has inadequately addressed the priority health needs of developing countries. In 2000, it was reported that less than 10 per cent of the global spending on health research by both the public and private sectors is devoted to 90 per cent of the world's health problems - a misallocation often referred to as 'the 10/90 gap' (Global Forum for Health Research, 2000). A more recent study found that the gap has narrowed, but it is still significant. Nearly 80 per cent of the new medicinal products are aimed at less than 50 per cent of the global health burden, accounting for 90 per cent of the disability-adjusted life-year (DALY) ${ }^{1}$ in high-income countries (Ferrán Catalá-López, Anna García-Altés, Álvarez-Martín, Gènova-Maleras, \& MorantGinestar, 2010). The main reason for this misallocation is the limited profit prospects for medicines to cure diseases that afflict the poorest people in low and middle-income countries. Therefore, the pharmaceutical industry is reluctant to sponsor trials for diseases of the developing world (also known as neglected diseases), even if effective treatments are developed (Isaakidis, Swingler, Pienaar, Volmink, \& Ioannidis, 2002) In addition, pharmaceutical companies standardize the production processes and design of drugs to reap the benefits of economies of scale in production and marketing (Still \& Hill, 1984; Viswanathan \& Dickson, 2007). There is normally little or no adaptation in terms of product characteristics (e.g. formulation, concentration, dosage forms) to the different markets in which they sell (Lane, 1998; Theodosiou \& Katsikeas, 2001). Usually, this is not a problem as drug impact on human patients are designed to have the same outcome. However, there are instances in which drugs are not appropriate for the developing world. For instance, there is a lack of heat-stable formulations and vaccines that are well suited for regions with limited or no electricity for cold chain refrigeration.

Furthermore, pharmaceutical companies are greatly criticized for selling drugs in low and middle-income markets that are not appropriate to their health needs. Although there is an increasing commitment to discovering and developing new medicines for neglected diseases prevalent in low and middle-income countries, the absolute figures are still extremely modest. According to the G-Finder Report, MNEs invested US\$

\footnotetext{
${ }^{1}$ DALYs for a disease are the sum of the years of life lost due to premature mortality and disability caused by a health condition or its consequences. They are equivalent to the difference between current health status and a scenario where the entire population lives free of disease and disability
} 
490.6 million in neglected disease R\&D in 2012. These figures reflect an increase of 2.6 times when compared to 2007 and now represent 16 per cent of the total invested (Moran, 2005; Moran et al., 2013). Many of these projects for product development are set up under public-private partnerships. For instance, companies, such as Merck \& Co., GlaxoSmithKline and Sanofi, are partners of the GAVI Alliance for vaccine development. Merck and Sanofi are also partners of the Programme for Appropriate Technology in Health (PATH), which is supported by the Bill \& Melinda Gates Foundation. Pharmaceutical majors are also partners in the Medicines for Malaria Venture, which focuses on product development for diseases prevalent in developing countries, and in TB Drug Development, to accelerate the discovery and development of costeffective new drugs for tuberculosis (Hotez et al., 2006; Osuji \& Umahi, 2012). The Swiss-based company Roche, for instance, set up two research institutes with a nonprofit mission to conduct research on new medicines and vaccines for neglected diseases. The institutes collaborate with multilateral organisations and other public and private partners. Their model is based on licenses to third parties to further develop and distribute medicines and vaccines (Greve, 2008).

\subsubsection{Pricing strategies to improve access to medicines}

Pharmaceutical companies can also contribute to health promotion by fostering access to existing and new drugs, vaccines and healthcare technologies in low and middleincome countries. In terms of the pathways to access to medicines presented in Chapter 1 , the effort made by pharmaceutical companies in the area of access to medicines is mainly targeted to make them more available and affordable.

Pharmaceutical companies have engaged in different strategies to make their drugs more affordable, including patent licensing, price discounts and adoption of tiered price structures. In fact, pricing strategy is the aspect of the pharmaceutical companies' marketing strategy that varies most across countries. The main reason why pharmaceutical companies discriminate prices for different markets across the globe is due to differences in demand elasticity and the willingness to pay for drugs across countries caused by income differentials (Mazumdar \& Banerjee, 2012). Indeed, studies by Danzon (1997), Danzon \& Chao (2000), Danzon \& Towse (2003), Ridley (2005), and Danzon, Mulcahy, \& Towse (2013) indicate that price differences of the drug are generally consistent with income differences of the countries concerned. Although, on average, the price of drugs is lower in low-income countries, there are large deviations from the average. Some studies have reported that several middle-income countries pay more for pharmaceuticals than high-income countries, while other middle-income 
countries pay less than low-income countries (Lichtenberg, 2011; Morel, McGuire, \& Mossialos, 2011). For instance, the mean price of drugs in Brazil is 16 per cent greater than in the United States. This pattern corroborates with research findings that suggest that other factors also affect the extent to which multinationals standardize their pricing strategies as, for instance, the level of similarity between home and host countries in terms of customer characteristics, legal environment, economic conditions, and stage of the product life cycle (Theodosiou \& Katsikeas, 2001).

However, there are many controversies surrounding pharmaceutical MNEs' pricing strategies in developing countries. Governments and Non-Governmental Organisations (NGO) are constantly putting pressure on MNEs for more affordable prices, especially when high prices are the consequence of patent monopolies. Pharmaceutical companies negotiate prices with governments of low and middle-income countries either on a case-by-case basis or via more organised mechanisms, such as the Accelerated Access Initiative (AAI), which was launched in 2000. In the AAI, a number of companies work with United Nations agencies and other international organisations to supply products at discounted prices to patients in low-income countries, notably in Africa (Osuji \& Umahi, 2012). Through this initiative, which is based on 'no profit, no loss' conditions, many pharmaceutical companies offer ARV drugs at cost price or at low prices in middle-income countries to contribute to access to these medicines (Greve, 2008).

\subsubsection{Licensing technology to improve access to medicines}

Another tool to improve access is voluntary licensing. Many companies have granted voluntary licenses to generic companies to improve access to medicines in resourcelimited countries (Ritter, 2010). More recently, pharmaceutical companies together with NGOs and international organisations are implementing more innovative licensing mechanisms, such as patent pools, for management of patents using public health objectives as the key driver.

Under a patent pool, patent holders voluntarily offer, under certain conditions, their intellectual property, and then any company that wants to use the intellectual property available in the pool for production and distribution of medicines in developing countries can obtain a license from the pool against the payment of royalties (Bermudez $\&$ 't Hoen, 2010; 't Hoen \& Passarelli, 2013). 
One promising experiment of this kind is the Medicines Patent Pool (MPP), implemented by UNITAID and sponsored by international NGOs such as Médecins Sans Frontières (MSF), Knowledge Ecology International and Act Up Paris (Gold \& Morin, 2012; 't Hoen \& Passarelli, 2013). However, as a voluntary mechanism, the success of this initiative will largely depend on the willingness of pharmaceutical companies to participate and commit their intellectual property to the pool. In addition, there is a concern that some arrangements under MPP do not lead to the efficiencies and benefits promised by a patent pool. For instance, companies may impose geographical or economic limitations and other restrictive licensing terms (Gold \& Morin, 2012). Other companies have also developed their own version of a patent pool, such as the Pool for Open Innovation against Neglected Tropical Diseases, created by GlaxoSmithKline through its joint venture with Pfizer, ViiV Healthcare, but the licensing term are also not ideal for some markets, especially middle-income countries. Because of the limitations and restrictions usually involved in voluntary licensing, some scholars advocate that a best practice would mean that companies do not have patents in countries that are major generic exporters and no patents in least developed countries (Hartsough et al., 2006)

\subsubsection{Non-market efforts to improve access to medicines}

Donation programmes by major pharmaceutical companies are also common in their strategies to improve access to medicines. Many drug donation programmes carried out by pharmaceutical companies seeks to overcome obstacles in the availability dimension, even though they also cross the border of the other dimensions and involve a wide range of non-market activities. This is especially true for some corporate social responsibility (CSR) efforts that go beyond pure drug donation and include helping states build health care capacity and strengthen health systems.

For instance, in the early 1980s, a group of pharmaceutical MNEs started a project to improve health care delivery in developing countries. ${ }^{2}$ They created the 'Gambia Project', so they could go beyond simply donating drugs and develop a stronger collaboration with host governments to ensure that more fundamental, long-term changes could be made (Levin, 1987). Companies like Merck, Glaxo, Bristol-Myers Squibb, Roche, Boehringer Ingelheim and Pfizer have partnered with international organisations to increase access to health care and AIDS treatment in developing countries, especially in Africa (Mackie, Taylor, Daar, \& Singer, 2006; Rozek \& Rainey, 2001). A recent study

\footnotetext{
${ }^{2}$ The companies involved in this project were Merck, Schering-Plough, Smith Kline \& French, and Sterling.
} 
found that the engagement by pharmaceutical manufacturers through drug donation programmes for neglected diseases substantially increased since the 'London Declara-

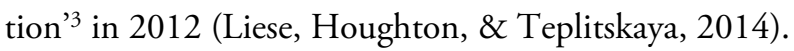

Many successful donation programmes are carried out as public-private partnerships (PPPs). These PPPs are designed to help expand access to medicines and build new markets by addressing public health issues, especially by helping to build infrastructure and achieve targeted goals in the prevention and treatment of major diseases (Liese et al., 2014; Sturchio, 2008). The reasoning for these PPPs is based on the understanding the donation of medicines alone will not be effective without support for strengthening the health care infrastructure to assure that medicines are used effectively (Ramiah \& Reich, 2006). A recent study by the International Federation of Pharmaceutical Manufacturers \& Associations (IFPMA) reported that there are more than 250 industry partnership programmes to help improve health in developing countries (IFPMA, 2013)

The African Comprehensive HIV/AIDS Partnerships (ACHAP) is one of these successful PPPs. In 2000, Merck \& Co. (and its company foundation) jointly with the Bill \& Melinda Gates Foundation and the Government of Botswana established the ACHAP to combat Botswana's HIV/AIDS epidemic (Ramiah \& Reich, 2006; Sturchio, 2008). In this partnership, Merck \& Co. provided its technical support and advice, while the Merck Company Foundation and the Bill \& Melinda Gates Foundation each provided $\$ 56.5$ million to the partnership. In addition, the company also donated its antiretroviral medicines to Botswana's national ARV treatment programme for the duration of the partnership (Sturchio, 2008).

\subsection{Scoping study on the pharmaceutical industry contribution to health promotion}

Based on the previous discussion, this section presents a scoping study to analyse how the pharmaceutical industry can support and promote health in developing countries. An approach similar to systematic reviews is adopted to capture how this phenomenon

\footnotetext{
${ }^{3}$ The London Declaration on Neglected Tropical Diseases is a collaborative disease eradication programme launched on 30 January 2012 in London by officials from WHO, the World Bank, the Bill $\&$ Melinda Gates Foundation, thirteen research-based pharmaceutical companies, and government representatives from United Sates, United Kingdom, United Arab Emirate, Bangladesh, Brazil, Mozambique and Tanzania. This coordinated effort aims to eliminate or control ten neglected diseases by 2020 by providing more than US $\$ 785$ million to support R\&D.
} 
is described in articles published in scientific journals. To do so, systematic searches and formal summaries of the literature are used to identify and classify results of all major studies in this particular topic.

We searched the Scopus database for articles in English following the query string presented in Table 2-3. Scopus is one of the largest abstract and citation databases of scientific journals, books and conference proceedings. We intentionally used broad search criteria in order to capture how the pharmaceutical industry can contribute to health, not only from an empirical but also positive and normative perspective. The search yielded 461 papers; we downloaded the respective titles, abstracts and other bibliometric information to a local database in December 2014. This search query string, however, retrieved papers that were outside the scope of this review. We therefore read through all abstracts to assess whether they dealt with our research questions. A total of 324 articles were excluded after this assessment. From the 137 articles eligible for full text assessment, 61 were further excluded from the analysis (six of them due to lack of access). This screening resulted in a short-list of 76 articles where we read the full paper. This procedure is summarized in Figure 2-5

\section{Table 2-3: Bibliometric analysis of pharmaceutical industry contributions towards health in low and middle-income countries}

\begin{tabular}{|c|c|c|c|}
\hline Question & Search query string & Search in & Corpus Size \\
\hline $\begin{array}{l}\text { How can } \\
\text { Pharmaceutical } \\
\text { industry con- } \\
\text { tribute to } \\
\text { health in low } \\
\text { and middle- } \\
\text { income coun- } \\
\text { tries? }\end{array}$ & $\begin{array}{l}\text { ( ( ( TITLE-ABS-KEY ( "pharmaceutical } \\
\text { compan*" ) OR TITLE-ABS-KEY ( "phar- } \\
\text { maceutical industr*" )) AND TITLE-ABS- } \\
\text { KEY ( investment* OR manufacturing } \\
\text { OR capacity OR capability OR discov- } \\
\text { er* OR R\&D OR research and develop- } \\
\text { ment) AND TITLE-ABS-KEY ( develop- } \\
\text { ing countr* OR low-income count* } \\
\text { OR middle-income countr* ) ) OR ( } \\
\text { TITLE-ABS-KEY ( "differential pric*" OR } \\
\text { "tiered pric*" OR "equity pric*" ) AND } \\
\text { TITLE-ABS-KEY ( pharmaceuticals OR } \\
\text { drugs OR medicines OR vaccin* ) ) OR } \\
\text { ( ( TITLE-ABS-KEY ( "pharmaceutical } \\
\text { compan*" ) OR TITLE-ABS-KEY ( "phar- } \\
\text { maceutical industr*" ) ) AND TITLE-ABS- } \\
\text { KEY ( donation OR cSr OR philanthro- } \\
\text { py OR "social responsibility" ) ) AND ( } \\
\text { LIMIT-TO ( LANGUAGE, "English" )) }\end{array}$ & $\begin{array}{l}\text { Title, Ab- } \\
\text { stract and } \\
\text { Keywords, } \\
\text { Journal } \\
\text { Articles, } \\
\text { Language - } \\
\text { English }\end{array}$ & 461 \\
\hline
\end{tabular}




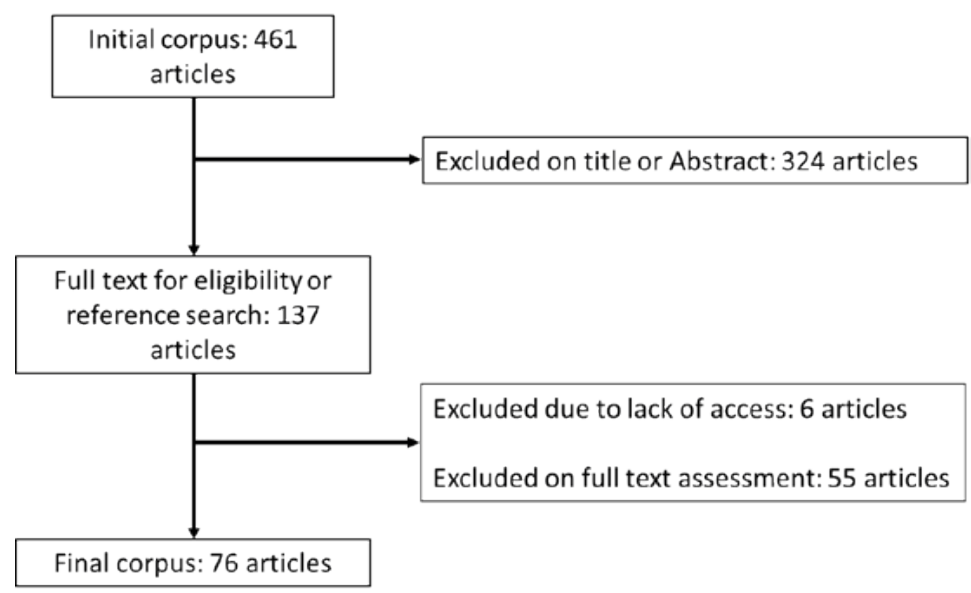

Figure 2-5: Flow diagram of articles included in the systematic review on how pharmaceutical industry can support and promote health

We classified the papers according to two broad categories of how pharmaceutical companies can contribute to health. We found that 36 articles focus on access to medicines and 22 focus on drug discovery. Another 18 articles discuss this subject considering both perspectives. This is particularly interesting, because the two categories are, to some extent, intertwined. The ability of pharmaceutical companies to improve health via drug development depends on the removal of access barriers so that they can reach the patient, especially those who cannot afford them. Then, we classified the papers that dealt with access to medicines (either independently or together with drug discovery) according to the four dimensions of the WHO-MSG framework (see Chapter 1, p. 16). The majority of the papers analyse the access to medicines problem according to an affordability and availability perspective, while geographical accessibility and acceptability are less discussed in the literature. Insight by these articles are summarized in Table 2-4.

Table 2-4: Type of contributions of pharmaceutical industry to health and dimensions of access to medicines

\begin{tabular}{|c|c|c|c|c|c|}
\hline \multirow{2}{*}{$\begin{array}{l}\text { Contribution of } \\
\text { pharmaceutical } \\
\text { industry to } \\
\text { health }\end{array}$} & \multirow[b]{2}{*}{ Articles } & \multicolumn{4}{|c|}{ Dimensions of access to medicines } \\
\hline & & Affordability & $\begin{array}{l}\text { Physical } \\
\text { Availability }\end{array}$ & $\begin{array}{l}\text { Geographical } \\
\text { Accessibility }\end{array}$ & Acceptability \\
\hline Drug discovery & 22 & & & & \\
\hline $\begin{array}{l}\text { Access to medi- } \\
\text { cines }\end{array}$ & 36 & 33 & 23 & 10 & 3 \\
\hline Both & 18 & 17 & 15 & 8 & 5 \\
\hline Total & 76 & 50 & 38 & 18 & 8 \\
\hline
\end{tabular}


We also classified the articles according to how the pharmaceutical industry can improve health, both conceptually and empirically. This classification provides a qualitative interpretation to the analysis and the results are presented in Table 2-5. In this framework, 'Developing drugs for the developing world' is the most frequent occurrence. This category refers to either drug development for neglected diseases (see for instance Chaudhuri (2010) and Sebbag (2007)) and development of drugs more suited to the developing world context (see, for instance Ridge \& Arachne (1997) and Winsbury (1999) for HIV/AIDS, and Anabwani (2002) for tuberculosis and malaria). This includes ensuring that clinical trials are representative of all ethnic groups that can potentially be the end users of a given pharmaceutical product (Lassen \& Thomsen, 2007).

Table 2-5: How pharmaceutical industry can improve health in developing countries Topic Articles

Developing drugs for the developing world 35

Price discrimination 32

Drug donation 22

Supporting alternative funding/financing mechanisms to promote drug/vaccine development and distribution

Corporate Social Responsibility (CSR)

Patent licensing 12

Price negotiation

Supporting alternative IPR/reward system

Compliance with regulation

Patent waiving

Implementation of price discrimination mechanisms and drug donation programmes in low and middle-income countries are the second and third most discussed topics in our review, respectively. Then, one can see that pharmaceutical companies can also improve health by supporting alternative funding/financing mechanisms to promote the development and distribution of drugs and vaccines for the developing world. This topic includes innovative financing mechanisms, such as advanced market commitments (see, for instance, Plahte (2012), Snyder, Begor, \& Berndt, 2011, and Stéphenne (2011)) and PPPs for product development, already discussed in the previous section. The scoping study identified other strategies of the pharmaceutical industry to improve health in developing countries, such as CSR projects of drug donation and support to strengthen healthcare infrastructure; patent licensing for generic production or drug development; 
negotiating price reductions with governments and international agencies; supporting alternative systems to the current IPR framework (such as a reward system); compliance with regulation, as in the case of price control, for instance; and waiving patents in countries that are major generic exporters and in least developed countries.

We could identify three types of initiatives in the pharmaceutical industry, as presented in Table 2-6. According to 28 articles, pharmaceutical companies proactively carry out activities that can lead to better health in low and middle-income countries. Many times these activities are not necessarily motivated by commercial returns, but rather by their long-term strategy for the establishment of their business and socio-political legitimacy. On the other hand, in 21 articles, the efforts towards drug development or access to medicines are a response to external shocks, public pressure over their failure to address developing country needs or the initiative of other actors (such as government, international organisations and the non-for-profit sector). For instance, in emerging countries, like India, patient groups and supporting NGOs have taken MNEs to court for patents that are just slight modifications of old drugs and block the market entry of generics (Guennif \& Ramani, 2012). Some companies have responded to this by offering voluntary licenses and technology transfer agreements to local generic manufacturers. Other examples include improved access to medicines in Africa after confrontation between the mainline pharmaceutical industry and AIDS activists, international organisations and other stakeholders (Dawkins, 2005), and price discounts and drug donation after compulsory license threats in developing countries (Beall \& Kuhn, 2012). Finally, 27 articles analyse this issue under both a proactive and reactive perspective.

Table 2-6: Type of initiative taken by pharmaceutical companies
\begin{tabular}{ll} 
Type of initiative & Articles \\
\hline \hline Proactive & 28 \\
Proactive and Reactive & 27 \\
Reactive & 21 \\
Total & 76 \\
\hline \hline
\end{tabular}

In many instances, pharmaceutical companies do not act alone; rather, they collaborate with other actors. As presented in Table 2-7, local governments and international organisations, such as UNAIDS and WHO, are the main actors that collaborate with the pharmaceutical industry in the context of this review. Actors from the private not-forprofit sector are also important. This includes private foundations, such as the Bill \& Melinda Gates Foundation, NGOs and humanitarian-aid organisations like MSF and 
UNITAID. Finally, universities and research institutes, and pharmaceutical companies from the developing world - especially generic manufacturers - also collaborate with the innovative pharmaceutical industry.

Table 2-7: Type of actors involved

\begin{tabular}{ll} 
Actors involved & Articles \\
\hline \hline International organisations & 45 \\
Governments & 45 \\
Private not-for-profit sector & 36 \\
Universities and Research Institutes & 10 \\
Indigenous companies / Generic manufacturers & 9 \\
\hline \hline
\end{tabular}

Lastly, 54 out of the 76 articles retrieved in our search query specify at least one disease in the discussion on access to medicines and/or drug discoveries for the developing world. The absolute majority, as shown in Table 2-8, refer to communicable diseases. HIV/AIDS and neglected diseases, which as a whole are the diseases discussed most in the literature retrieved in this review (see Table 2-9). The focus on communicable diseases can be justified by the fact that many low and middle-income countries are still in an early stage of the epidemiological transition, where infectious diseases are a high burden and an important cause of deaths.

Table 2-8: Type of disease identified

\begin{tabular}{ll} 
Type of disease & Articles \\
\hline \hline Communicable Diseases & 51 \\
Non-Communicable Diseases & 3 \\
Not specified & 22 \\
Total & 76 \\
\hline \hline
\end{tabular}

However, many countries are advancing quickly in this transition. According to the WHO, the burden of non-communicable diseases measured by the DALY increased markedly during the last decade in low and middle-income countries (see Table 2-10). By the year 2020, non-communicable diseases are expected to account for seven out of every ten deaths in the developing regions, compared with less than half today. As pointed out by Shankar, Kinsey, Thomas, Hooper, \& Tejani (2013), this rise coupled with the high emotional impact, high prices, and limited drug substitutes that characterize these diseases, create a worrying scenario in terms of access to medicines for this type of diseases. 
Table 2-9: Diseases identified

\begin{tabular}{ll} 
Diseases & Articles \\
\hline \hline HIV/AIDS & 22 \\
Neglected diseases (general) & 19 \\
Infectious diseases (general) & 5 \\
Malaria & 4 \\
Cryptococcal meningitis & 2 \\
Dengue & 2 \\
Pneumococcal disease & 2 \\
Tuberculosis & 2 \\
Alzheimer's & 1 \\
Cardiovascular disease & 1 \\
Chagas disease & 1 \\
Cysticercosis & 1 \\
Diabetes & 1 \\
Echinococcosis & 1 \\
Hepatitis C & 1 \\
Japanese encephalitis & 1 \\
Leishmaniasis & 1 \\
Lymphatic filariasis & 1 \\
Protozoan infections & 1 \\
River blindness & 1 \\
Rotavirus & 1 \\
Schistosomiasis & 1 \\
Tick-borne encephalitis & 1 \\
West nile & 1 \\
Yellow fever & 1 \\
\hline \hline
\end{tabular}

Table 2-10: Non-communicable Disease Burden in Low and Middle Income Countries (2000 and 2012)

\begin{tabular}{cllllll} 
& \multicolumn{2}{l}{ Low income } & \multicolumn{2}{l}{ Lower middle income } & \multicolumn{2}{l}{ Upper middle income } \\
\cline { 2 - 7 } Year & $\begin{array}{l}\text { DALYs } \\
\text { (000s) }\end{array}$ & \% total & $\begin{array}{l}\text { DALYs } \\
\text { (000s) }\end{array}$ & \% total & $\begin{array}{l}\text { DALYs } \\
\text { (000s) }\end{array}$ & \% total \\
\hline \hline 2012 & 155,429 & 30.6 & 530,318 & 46.6 & 504,353 & 71.2 \\
2000 & 124,714 & 21.4 & 441,623 & 36.8 & 437,433 & 62.1 \\
\hline \hline
\end{tabular}

Source: World Health Organization: Health statistics and information systems - Disease Burden 


\subsection{Intellectual property rights and access to medicines}

The debates on product patents and access to medicines have taken on a heightened stridency since the launching of TRIPS, in 1995. TRIPS is the most comprehensive multilateral agreement on intellectual property to date and is administered by the WTO. As the implementation of TRIPS is a necessary condition to become a WTO member, any country seeking to benefit from the market and trade opportunities opened by the WTO must strictly comply with the intellectual property provisions of TRIPS. One of the cornerstones of TRIPS is mandatory patent protection for product and process in all branches of manufacturing, including pharmaceuticals. This effectively eliminates the possibility for second innovators in developing countries to produce and sell drugs at cheaper prices through re-engineering. It also homogenizes the minimum period of protection to 20 years and bans discrimination between imported and domestic products.

\subsubsection{Setting the background: views on patents and access to medicines}

There is an extensive debate on the negative impact of IPR, especially patents, on the affordability of medicines and, thus, on the access to such essential goods. Since patents allow a monopoly right to the inventor, the price of patented products tends to be higher than it would be in a competitive market. As a result, some sick people may not be able to afford such patented medicines, putting not only their own lives, but also perhaps also those of others, at risk.

According to most advocates of the pharmaceutical industry, IPRs are a critical incentive for investments in R\&D of new drugs because they offer protection to companies' innovative products. Patents are widely employed in the pharmaceutical industry because it is very difficult to avoid imitation from competitors using other mechanisms, such as secrecy for example. Copying an innovative chemical-based molecule is relatively easy for an established pharmaceutical company with the imitation capabilities. Small molecules drugs are based on a mature knowledge base and there are a large number of companies that are capable of reverse engineering an innovative drug for a fraction of the costs incurred by the original innovator.

In addition, the R\&D associated with the drug discovery as well as the efforts necessary to provide substantial evidence of the drug's safety and effectiveness for regulatory 
requirements, involve very long and expensive processes ${ }^{4}$. Conversely, there is a solid institutional framework for the fast track and inexpensive regulatory approval of generic compounds. ${ }^{5}$

So, the conjunction of the specific characteristics of the technology (e.g. ease of copying) and of the innovative process (e.g. high costs and length of development) explains why patents are so important in the pharmaceutical industry. Without patent protection, pharmaceutical companies would have incentives for a free ride on the efforts of innovators. For instance, using data for 48 product innovations, Mansfield, Schwartz, \& Wagner (1981) found that about 90 per cent of pharmaceutical innovations would not have been introduced in the absence of patent protection. Mansfield (1986), in a research based on a random sample of firms, found that 65 per cent of the pharmaceutical innovations would not have been developed or commercially introduced if patent protection could not have been obtained.

Under these circumstances, an innovative pharmaceutical company would bear all the cost of developing a new drug and run the risk of sharing the resulting profits, since the competitors would have incentives to free ride on its inventive efforts. Therefore, without a patent system, incentives for invention would be weak, resulting in an underinvestment in the development of new drugs if compared to the public interest, especially for unmet medical needs. Thus, the social benefits of patent protection will be the additional inventions that would not have been developed without the safeguard of patents. On the other hand, patents generate social costs because the consequent monopoly power granted to the patent holder can result in higher prices and in lower quantities than in a competitive market.

While there is broad agreement on these outcomes, there are still heated debates on whether patents hinder access to pharmaceutical products. For instance, some researchers do not agree with the premise that the social cost of patented drugs is high. In this

\footnotetext{
${ }^{4}$ Based on the R\&D costs of 68 new drugs, DiMasi, Hansen, \& Grabowski (2003) estimated that the total R\&D cost per new drug is US\$ 802 million (in 2000 dollars). Regarding the length of the drug development process, DiMasi \& Paquette (2004) argue that it has taken, on average, 10 to 15 years from discovery to marketing approval.

${ }^{5}$ In many countries, including the United States and the European Union countries, generic medicines must only show that differences in excipients and/or the manufacturing process do not affect the absorption characteristics of the active substance (that is, they are bio-equivalent to the pioneering brand) to receive market registration (Versantvoort, Maliepaard, \& Lekkerkerker, 2008). This process only takes a few years, or even months, and costs \$1-2 million (Grabowski, 2002).
} 
vein, some studies, usually sponsored by the pharmaceutical industry, have highlighted that the impact of IPR on access to essential medicines is minimal and almost imperceptible. For instance, Attaran \& Gillespie-White (2001) undertook an influential research examining the relationship between patents and access to ARV drugs in 53 African countries. They used data for 15 ARV drugs patented by eight pharmaceutical companies and found that most of these drugs are not protected by patents in most of the African countries. According to them, South Africa is the unique exception, since 13 of the 15 drugs were patented in this country. The authors concluded that:

"II]t is doubtful that patents are to blame for the lack of access to antiretroviral drug treatment in most African countries. Conventional wisdom has spuriously assumed that drugs patented in Europe or North America must also be patented in Africa, or that a lack of generic competition and high retail prices (...) are prima facie evidence of patents, which they are not." (p.1890)

The Pharmaceutical Research and Manufacturers of America (PhRMA), in October $2001^{6}$, also tried to demonstrate the irrelevance of patents on the access to medicines in a public report. According to this publication, 'few patents exist in sub-Saharan Africa in any of the six categories of products accounting for nearly 50 per cent of mortalities due to communicable diseases.' The report goes further and highlights that there are no significant patents related to tuberculosis, malaria, opportunistic infections associated with HIV/AIDS and even to the newest and most innovative drugs used in ARV therapies designed to stop the progression of HIV infection. Furthermore, PhRMA affirms that the statistics presented in the report

'demonstrates the reality of the African patent situation, which
stands in stark contrast to the statements made by a number of or-
ganizations advocating drastic reinterpretations of the TRIPS
Agreement. They demonstrate what many have long believed; patents
are simply not an obstacle to access in almost every sub-Saharan Af-
rican nation.'

\footnotetext{
${ }^{6}$ This report was presented by Tom Bombelles at the American Society of Law, Medicine \& Ethics conference on Law and Human Right. Available at: <http://www.cptech.org/ip/health/africa/phrmasurveytext.html>.
} 
Finally, Attaran (2004) carried out an examination on this issue, covering 65 low and middle-income countries ${ }^{7}$ and the 319 products on the WHO's Model List of Essential Medicines. His findings show that only 17 essential drugs have patents postdating 1 April 1982, which means that they might be protected by patent in developing countries in 2002. The author argues that, for these 65 countries, the median and the mode of patented drugs are equal to 4 . According to him, it is because pharmaceutical companies usually did not seek patents in developing countries - even when they legally had the option - because their markets are too small. Then, he concludes that:

'Patents cannot cause essential medicines to be inaccessible in "many" developing countries because they do not exist 98.6 per cent of the time; similarly, patents cannot be a "global" necessity of pharmaceutical business because companies forgo them 69 percent of the time. '(p.159)

Summing up, this branch of literature claims that public health scholars should pay more attention to other barriers to access to medicines, rather than to patents. According to them, poverty, poor medical care and infrastructure, lack of political will, high trade tariffs and other economic policies are the main explanations for the existing lack of access to medicines.

On the other side of the fence, there are several research papers, books and reports that focus on the negative role played by IPRs in worsening the access to medicines for the poor (see, for instance, Bird, 2009; Ford, Wilson, Chaves, Lotrowska, \& Kijtiwatchakul, 2007; Thai White Paper I, 2007; 't Hoen, 2002; WTO, 2006). The claim that patents do not negatively affect the affordability of medicines is flawed, they say, because the existence of patents in potential exporter countries creates important obstacles to the supply of patented drugs to other countries. The pharmaceutical companies' IPR strategy does not focus on patenting in countries where the market is small (due to low income and/or low disease incidence, for instance) and the risk of copying is low (due to lack of technological capacity). Thus, the prevalence of patents is often higher in countries where a substantial market and technological capacity exist. This is why companies patent selectively in countries where competitors may copy their products and supply them to other countries at lower prices (WHO, 2005).

\footnotetext{
${ }^{7}$ Including all African countries, Brazil, China, India, Indonesia, Mexico, Russia, among other middle-income countries.
} 
Considering these factors, one could clearly argue that South Africa is not a mere exception, as Attaran \& Gillespie-White (2001) suggest. This country has one of the highest rate of HIV prevalence amongst the adult population (19.1 per cent in 2013), and a per capita income about 4 times greater than the average in sub-Saharan Africa actually, South Africa's GDP corresponds to more than 22 per cent of the GDP for this region in 2013. In addition, South Africa has a relatively good health care infrastructure and sufficient technological capacity for the production of generic drugs, making ARV treatment feasible (WHO, 2004). Therefore, the existence of patents in South Africa not only hinders the local population's access to medicines but also impedes any local generic company to supply those drugs to the rest of sub-Saharan Africa Furthermore, as reported by MSF, the newest HIV drugs that are used for third-line or salvage therapy are protected by patents and their prices remain extremely high (Médecins Sans Frontières, 2013). According to the same report, the best-possible price for a potential third-line regimen is about 15 times more expensive than the one-pill-a-day first-line treatment, and more than six times as expensive as the most affordable second-line regimen. This implies that the poorer countries cannot take full advantage of the benefits of technologically more advanced treatment options.

Summing up, there is a wide range of barriers to improved access to medicines. In addition, although IPRs cannot be blamed as the most critical hurdle to more affordable drugs, there are instances in which patents are harmful to access to medicines. Thus, to minimize the potential negative impact of patents on access to medicines, TRIPS does offer safeguards to remedy negative effects of patent protection, as discussed in the next section.

\subsubsection{TRIPS, Doha declaration and Article31bis}

\subsubsection{A historical reconstruction}

This debate on the potential negative implications of IPR on access to essential medicines has become more intense since 1995, as many developing countries began to adapt their respective IPR laws to be compatible with the TRIPS Agreement. The strategy of merging trade policy to intellectual property standards can be traced back to the early 1980s. Prior to TRIPS, several IPR-sensitive industries - such as chemicals, publishing, software, entertainment and pharmaceuticals - were demanding more rigid IPR worldwide, because their innovative efforts were being appropriated by free riders from developing countries (Sell, 2001). In 1984, eight trade associations representing around 1,500 copyright-intensive companies created the International Intellectual 
Property Alliance (IIPA) (Sell, 2001). This organisation started supporting the use of bilateral diplomacy to promote strong intellectual protection. Its political influence was so strong that IIPA undertook revisions of the US's trade policy in 1984 and 1988 in order to increase US trade leverage against countries that do not offer adequate protection to U.S.-held intellectual property (Sell, 2001).

This effort was critical for the inclusion of intellectual property provisions in trade programmes and regional trade agreements by the US government. Over time, lobbyist groups representing IPR-intensive industries had redefined IPR protection abroad as a barrier to legitimate trade and they were able to appeal to the General Agreement on Tariffs and Trade $\left(\right.$ GATT) ${ }^{8}$. These groups convinced the US Government to support and promote a multilateral agreement through the GATT and, transnationally, they convinced their European and Japanese counterparts to press for a TRIPS agreement in the GATT (Sell, 2001). Finally, this intense lobbying by the United States, and supported by the European Union and Japan, culminated with the establishment of the TRIPS agreement at the end of the Uruguay Round of the GATT, on April 14, 1994.

Pharmaceutical companies from the USA, Europe and Japan were agents in those lobbyist groups and pushed TRIPS onto the international agenda on the premise that product patents provide a critical incentive to pharmaceutical companies to invest in R\&D to generate new drugs. In the pre-TRIPS world, about 40 countries did not provide patent protection for pharmaceutical products (Boulet, Perriens, RenaudThéry, \& Velasquez, 2000). Therefore, copies of (new) medicines developed by research-based pharmaceutical companies were widely available, usually at a lower price than that of the original innovator. These copies could be manufactured by local companies or imported, without having to ask the patent holders' permission. This was highly resented by the global innovation pharma-leaders, which made product patents an inevitable demand for the profitability of their global business. In response, TRIPS decreed that pharmaceutical firms in member countries of the WTO could not reengineer patented drugs after the treaty came into effect in the countries concerned.

India is the most prominent example of this imitation strategy. According to the Indian Patents Act of 1970, patents would be granted only for pharmaceutical manufactur-

\footnotetext{
8 The General Agreement on Tariffs and Trade (GATT) was a multilateral agreement regulating international trade that came into force on 1 January 1948. In 1995, GATT was replaced by the creation of the WTO as an international organization, but the General Agreement remained under the WTO's treaty for trade in goods.
} 
ing processes but not for products. Thus, local pharmaceutical companies could manufacture copies of pharmaceutical drugs as long as they found new ways to make existing products. This institutional framework provided incentives for companies to build the technological capabilities needed to exploit the economic opportunities in the generic drugs market. Several Indian pharmaceutical firms took advantage of the lack of patent protection for pharmaceutical products and moved towards export markets of generics in both developing and developed countries. Therefore, by the 1990s, the country became a leading supplier of low-cost and more affordable generic drugs to the world. Because of that, India earned the title of 'pharmacy of the developing world'.

However, after the TRIPS Agreement harmonising patent protection for pharmaceutical products in all WTO member states, this practice is no longer possible. Copies of patented drugs will remain on the market of those countries that did not grant pharmaceutical patents before TRIPS. Nevertheless, they will not be allowed to manufacture and market copies of new-patented medicines. It is worth noting that drugs that were introduced to India between 1995 to 2005 may still be produced by generic manufacturers (Guennif \& Ramani, 2012; Kale \& Little, 2007). This is because the country made full use of the transitional period allowed by TRIPS to developing countries and a 'mailbox provision' was included in the Indian Patent Act. According to this provision, patent applications for medicines would be examined only after 2005, when the new patent law would be in effect. In cases where a patent is granted for drugs that were being produced and marketed in India prior to January 2005, the patent holder would only be entitled to receive 'reasonable royalty' from such enterprises, without being able to institute infringement proceedings. Therefore, drugs patented in India before 2005 are likely to be available worldwide at affordable costs because generic companies are able to continue to produce them, as long as they pay royalties to the patentee(s) (Babovic \& Wasan, 2011). However, generic production of drugs that were introduced after 2005 can start only once the patents pertaining to the drugs have expired or for those drugs for which the patents were rejected.

\subsubsection{Flexibilities and safeguards to protect access to medicines}

Due its potential negative impact on access to medicines, TRIPS contains flexibilities to facilitate increased access to pharmaceutical products by developing countries. First, besides the minimum standards of protection, TRIPS established a set of provisions dealing with domestic procedures and solutions for the enforcement of IPR in all countries. For instance, it distinguished transition periods, according to the country's state of development. Developing countries and transition economies had up to 1 January 
2005, and least developed countries (LDC) have up to 1 January 2006 to adjust their IPR systems. The transitional period for LDCs was extended in three different occasions. In 2002, the TRIPS Council followed the 2001 Doha Ministerial Declaration on TRIPS and Public Health (see next section) and extended the period for LDCs to comply with provisions on pharmaceuticals until 2016. In response to specifics request by the LDCs, the TRIPS Council extended the transitional period for LDCs twice. In November 2005, it was extended until 1 July 2013, and in June 2013, it was further extended until 1 July 2021.

This transitional period was to permit these countries to catch up in the pharmaceutical sector by allowing their local firms to learn to manufacture drugs through reengineering. Paradoxically, many countries have waived such rights and adjusted their respective laws much earlier than needed. For example, with the exception of Angola, Eritrea and Somalia, all African LDC that are WTO members have already granted product patents for pharmaceuticals, even though this is not necessary until the end of the transition period (Thorpe, 2002).

Second, Article 30 of TRIPS regulates exceptions, such as for 'experimental use' (also known as research exception) and the 'Bolar' provision (also known as regulatory exception). Experimental use allows researchers to exploit a patented invention for research, in order to better understand the invention, and thereby advance science and technology. The regulatory exception allows drug manufacturers to use the patented invention to obtain marketing approval for generic versions - for example from public health authorities - without the patent owner's permission and before the patent protection expires. By doing so, generic producers can market their versions as soon as the patent expires (WTO, 2006). This provision is commonly referred to as a Bolar exemption because it overruled the decision of the Court of Appeals for the Federal Circuit of U.S in Roche Products, Inc. vs. Bolar Pharmaceutical Co. (Bass, 2002).

Third, Article 31 of the TRIPS agreement regulates other uses without the authorization of the patent holder, including the compulsory license. The latter is the right to license a technology to a third party without the patentee's permission. Article 31 also limits the use of a compulsory license by requiring a period of negotiation between the member state and the patent holder unless it is for 'national emergencies', 'other circumstances of extreme urgency', 'public non-commercial use' or against 'anticompetitive' practices (WTO, 2006). 


\subsubsection{Controversies and refinements}

Although it is consensual that TRIPS should not prevent countries from taking measures to protect public health, still there are many controversies. For instance, originally, compulsory licensing could only be used for the purposes of supplying the domestic market of the country in which the license was issued. This, however, posed a problem for countries that do not have sufficient manufacturing capacity to produce their own generic pharmaceuticals and, therefore, rely on imports of medicines. Heated discussion on this problem led to the Declaration on the TRIPS Agreement and Public Health (also known as Doha Declaration) adopted by the WTO Ministerial Conference in Doha on November 14, 2001. The Doha Declaration legitimates the use of

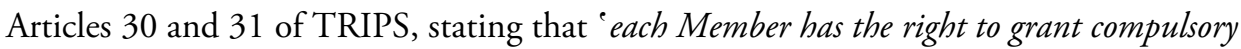
licenses and the freedom to determine the grounds upon which such licenses are granted. The Doha Declaration goes further and emphasizes that 'public health crises, including those relating to HIVIAIDS, tuberculosis, malaria and other epidemics, can represent a national emergency or other circumstances of extreme urgency'.

The Doha Declaration was an attempt to legitimize the right of developing countries to issue compulsory licenses for patented pharmaceutical products under the TRIPS Agreement. However, the Doha Declaration left the issue of the limitation of compulsory licenses 'predominantly for the supply of the domestic market' (TRIPS Agreement, Article 31, paragraph f) unresolved. In paragraph 6, the Doha Declarations acknowledges that 'WTO Members with insufficient or no manufacturing capacities in the pharmaceutical sector could face difficulties in making effective use of compulsory licensing under the TRIPS Agreement' and left it to the TRIPS Council to find 'an expeditious solution' to the problem. It was only in 2003 that the TRIPS Council announced a waiver allowing countries with insufficient technological capacity to import generics under compulsory licensing (the August 30 Decision). In short, the August 30 Decision removed the limit in the TRIPS Agreement's Article 31(f) on the amount nations can export under compulsory licenses to countries needing the medicines that they cannot produce locally. Finally, on 6 December 2005, this decision became permanent, when the TRIPS Agreement was amended by inserting Article 31bis after Article 31 and by inserting the Annex to the TRIPS Agreement after Article 73. This amendment ratified what is commonly known as the 'Paragraph 6 system', which allows generic medicines to be made under compulsory licenses exclusively for export to countries that cannot produce the medicines themselves. 
The Paragraph 6 system provides that a country willing to import a drug under compulsory license has to notify the TRIPS Council that it intends to do so as an importer - unless it is a LDC, in which case no such notification is needed. This country has also to do a second specific notification about the products, quantities and other specifications about the drug that it intends to import. However, no notifications have been made so far and Rwanda, a LDC, was the only country to use this system. It is worth noting that 33 countries have agreed not to use the system as importers ${ }^{9}$, and 11 others have announced voluntarily that if they use the system it would only be in national emergencies or other extremely urgent circumstances ${ }^{10}$. In addition, for all countries but the least developed ones, the lack of or insufficient manufacturing capacity has to be proved before issuing a compulsory license as an importer country.

\subsubsection{Facilitating conditions: better or worse?}

As reported by the WHO (2004), there are at least 84 developing countries with manufacturing capacity only in drug formulations and another 42, mainly in Africa, with limited or no competence in the production of medicines, relying on imports to satisfy their demand. Such developing countries can use a compulsory license to get the cheapest priced generic from the international market only if an imported alternative is available. However, when a drug is subject to one or more patents in the exporting country, the regulation provided by the Paragraph 6 system must be applied. In this case, the exporting country has to issue a compulsory license for export (also known as back-to-back compulsory license). Therefore, the use of a compulsory license - or of the threat of issuing a compulsory license - is not only limited by the existing local manufacturing capacity but also by importing possibilities.

The insufficient or no manufacturing capacity assessed in general is not the weighing factor. Even after the amendment of the TRIPS Agreement in 2005, several doubts about its full implementation have been raised. For instance, the burden of proof of insufficient manufacturing capacity on developing countries, and the possibility of review by the TRIPS Council, can reduce their willingness to use the system (Hannah, 2011). Moreover, it is not clear whether potential exporting countries must amend

\footnotetext{
${ }^{9}$ Australia, Austria, Belgium, Canada, Czech Republic, Cyprus, Denmark, Estonia, Finland, France, Germany, Greece, Hungary, Iceland, Ireland, Italy, Japan, Luxembourg, Latvia, Lithuania, Malta, Netherlands, New Zealand, Norway, Poland, Portugal, Slovak Republic ,Slovenia, Spain, Sweden, Switzerland, United Kingdom, and United States.

${ }^{10}$ Hong Kong China, Israel, Korea, Kuwait, Macao China, Mexico, Qatar, Singapore, Chinese Taipei, Turkey, and United Arab Emirates.
} 
their IPR laws if the same has no explicit provision for compulsory licensing to exports. Some countries such as Norway, Canada, India and the members of the members of the European Union have amended theirs laws to implement a compulsory licensing system for the production and export of generic medicinal products to developing countries. However, this framework does not provide any autonomy for countries willing to issue compulsory licenses as importer because the use of this system is dependent upon government decisions in exporting countries.

Obviously, for any country to import a drug under the Paragraph 6 system the existence of a generic company both willing and able to make the drug to supply to this particular market is necessary. Thus, the size of the market becomes an important variable, as it is critical for the realization of economies of scale. If the quantity required by the importer country is not big enough, it is likely that no generic company will find it profitable to manufacture and supply this drug (Dutfield, 2008). The system does not allow for pool procurement arrangements, and the requirement for back-to-back licensing adds unnecessary bureaucratic complications and uncertainty for companies willing to supply the drug. The uncertainty increases if one takes into account that, under this system, a company can only produce products for export on a license-bylicense basis, and this may deter generic companies from investing in additional manufacturing capacity and product development for export on 'speculation'. This means that companies may not have the incentive to invest in reverse engineering or organising API production and produce new products only for export under compulsory licenses, since this may not translate into a commercially feasible business (Gehl Sampath, 2005; Hannah, 2011).

These are major concerns of generic drugs manufacturers in India, which consider the system so constraining and legally risky that it will not make use of it, unless for products that they are already manufacturing as generic, that is drugs patented before 2005 or whose patents were rejected by the Indian Patent Office. A survey carried out by Gehl Sampath (2005) with 103 Indian firms indicates that more than three-quarters of the sample do not regard the use of compulsory license for exports as a useful option. The common reason is that such exports involve enormous procedural challenges, and this is not considered worthwhile, because the economic returns from such exports tend to be very low. Thus, India's position as the 'pharmacy for the developing world' is likely to change as the drugs for which patents claimed in the country after the adoption of the 2005 patent law are subject to longer periods of market monopoly by the inventor (Babovic \& Wasan, 2011; Gehl Sampath, 2005; Shadlen, 2007). 
The points raised so far have led several authors to conclude that the solution provided by Paragraph 6 system in the Article 31bis is a flawed deal that cannot contribute much for improved access to essential medicines in developing countries (Chami \& Wasswa-Kintu, 2011; Hannah, 2011). Ten years after the August 30 Decision there is a unique case of compulsory license for exports based on this framework. In addition, the single experience of practical use of this provision (by Rwanda, importing from Canada) raises several concerns on its practical value in fact. In short, the paragraph 6 system creates onerous administrative and operational costs for developing countries with limited resources as well as for generic manufacturers, and it is considered too complicated to work in practice.

\subsection{Scoping study on the negative impacts of IPR on access to medi- cines}

\subsubsection{Bibliometric analysis}

Based on the previous discussion, this section presents a scoping study to analyse how access to medicines can be improved in the current IPR system set by the TRIPS Agreement. We searched the Scopus database for articles in English following the query string presented in Table 2-11. In this case, we intentionally tried to narrow down the search criteria in order to capture only articles that discuss access to medicines from an IPR perspective. This search yielded 183 papers; we downloaded the respective titles, abstracts and other bibliometric information to a local database in February 2015. This search query string, however, retrieved papers that were outside the scope of this review. We therefore read all abstracts to assess whether they dealt with our research questions. A total of 41 articles were excluded after this assessment. From the 142 articles eligible for full text assessment, 27 were further excluded from the analysis (four of them due to lack of access). This screening resulted in a short list of 115 articles where we read the full paper. This procedure is summarized in Figure 2-6. 
Table 2-11: Bibliometric analysis of pharmaceutical industry's contribution towards health in low and middle-income countries

\begin{tabular}{|c|c|c|c|}
\hline Question & Search query string & Search in & Corpus Size \\
\hline $\begin{array}{l}\text { How can access } \\
\text { to medicines be } \\
\text { improved in the } \\
\text { current IPR } \\
\text { system? }\end{array}$ & $\begin{array}{l}\text { ( TITLE-ABS-KEY ( "access to drugs" ) } \\
\text { OR TITLE-ABS-KEY ( "access to } \\
\text { health*" ) OR TITLE-ABS-KEY ( "ac- } \\
\text { cess to medicines" ) ) AND ( TITLE- } \\
\text { ABS-KEY ( patent ) OR TITLE-ABS- } \\
\text { KEY ( ipr ) OR TITLE-ABS-KEY ( intel- } \\
\text { lectual property rights ) OR TITLE- } \\
\text { ABS-KEY ( "monopoly" ) OR TITLE- } \\
\text { ABS-KEY ( trips W/3 agreement ) ) } \\
\text { AND ( EXCLUDE ( PUBYEAR, 2015 ) ) } \\
\text { AND ( LIMIT-TO ( LANGUAGE, "Eng- } \\
\text { lish" )) AND ( LIMIT-TO ( DOCTYPE, } \\
\text { "ar" )) }\end{array}$ & $\begin{array}{l}\text { Title, } \\
\text { Abstract } \\
\text { and Key- } \\
\text { words, } \\
\text { Journal } \\
\text { Articles, } \\
\text { Language } \\
\text { - English }\end{array}$ & 183 \\
\hline
\end{tabular}

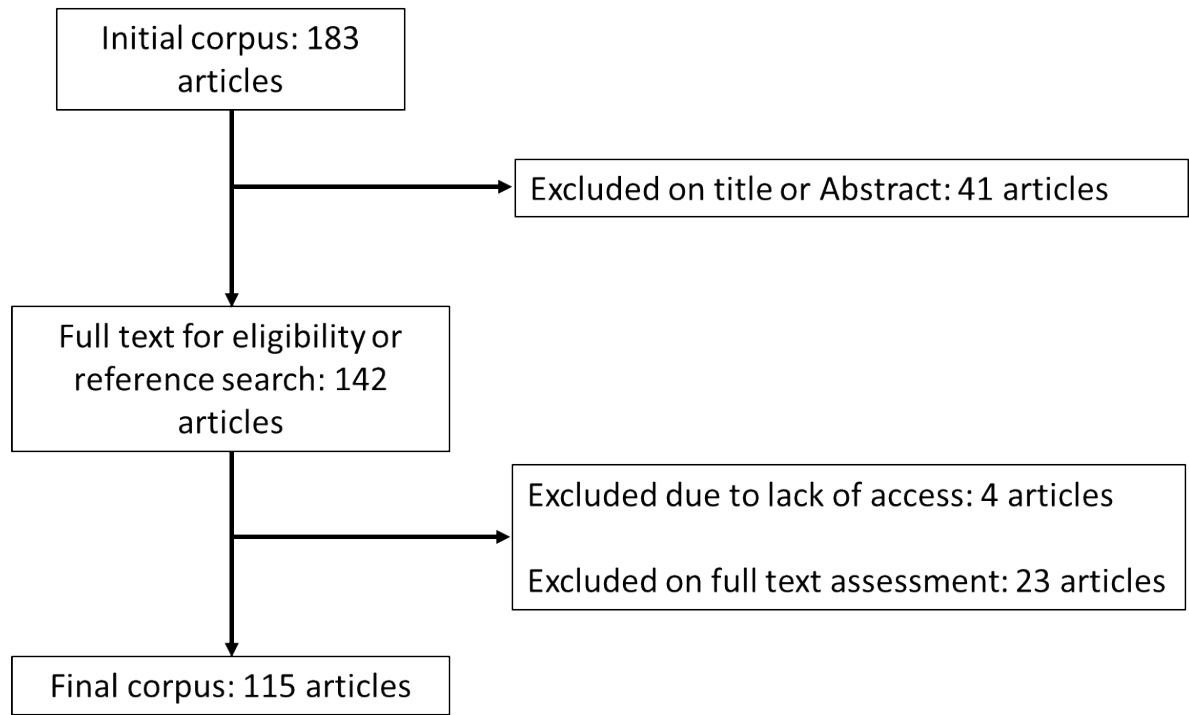

Figure 2-6: Flow diagram of articles included in the systematic review on how access to medicines can be improved in the current IPR system

Figure 2-7 presents the yearly evolution of literature on access to medicines and IPR. The first articles retrieved by our search query date back to 1999 . Thus, we may infer that the discussion about the negative impacts of IPRs on access to medicines became relevant only after the TRIPS Agreement came into force, in 1995. As discussed earlier in this chapter, before the implementation of minimum worldwide standards for intellectual property regulation, many countries could obtain generic versions of innovative 
drugs either by producing locally or by importing from countries where patents for pharmaceuticals were forbidden.

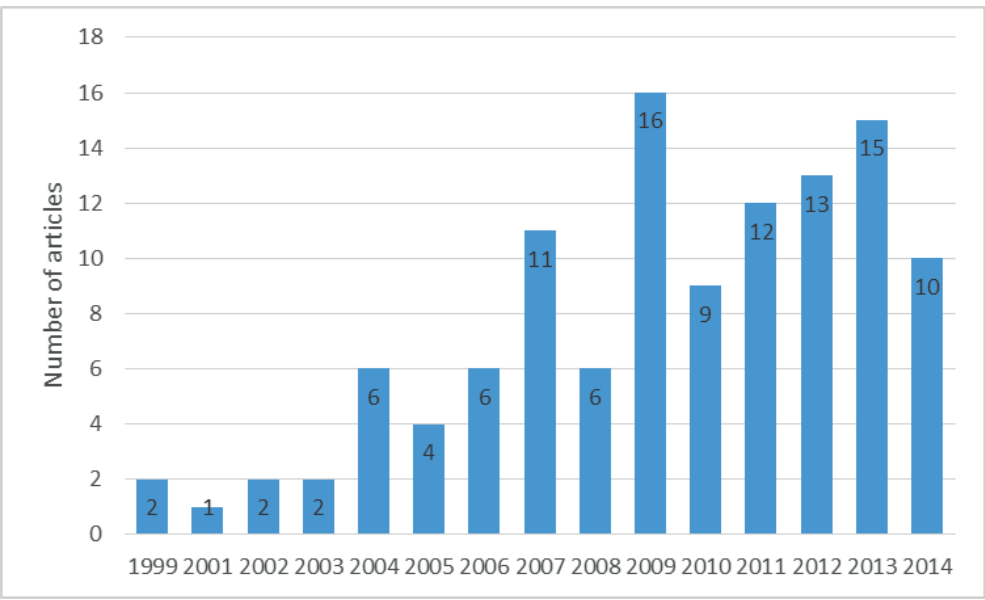

Figure 2-7: Evolution of literature on access to medicines and IPR

A total of 105 articles provide information on the country of affiliation of author(s). As presented in Table 2-12 there are 29 countries associated with these publications, and 13 countries with more than one article. United States, Canada and Australia are the countries with the highest number of articles on this subject, with 29, 25 and 13 publications, respectively. Fourteen low and middle-income countries contributed with the knowledge production in this field, with India (10), Brazil (4) and Thailand (3) being the countries with more articles. However, low and middle-income were responsible for less than 25 per cent of the articles in the final corpus.

Table 2-12: Distribution of the literature by country of affiliation of author(s)

\begin{tabular}{ll} 
Countries & Articles \\
\hline \hline United States & 28 \\
Canada & 25 \\
Australia & 13 \\
United Kingdom & 11 \\
India & 10 \\
Switzerland & 5 \\
Brazil, Netherlands & 4 \\
Thailand & 3 \\
Mexico; South Africa; New Zealand; Italy & 2 \\
Argentina; Belgium; China; Costa Rica; Denmark; Finland; Ireland; Jordan; & 1 \\
Kenya; Malaysia; Nepal; Nigeria; Spain; Sweden; Uganda & \\
\hline \hline
\end{tabular}


In the final corpus, a total of 29 articles discuss the implications of IPR for access to medicines for specific disease(s) or disease type(s). Table 2-13 shows that the vast majority of the articles focus on communicable diseases, especially HIV/AIDS. Six articles focus on non-communicable diseases while three focus on both types.

\begin{tabular}{|c|c|}
\hline Disease & Articles \\
\hline HIV/AIDS & 22 \\
\hline Cancer & 4 \\
\hline Tuberculosis & 1 \\
\hline HPV & 1 \\
\hline Malaria & 1 \\
\hline$C D$ & 1 \\
\hline Asian Flu & 1 \\
\hline Cardiovascular diseases & 1 \\
\hline Total communicable diseases (CD) & 20 \\
\hline Total non-communicable diseases (NCD) & 6 \\
\hline Total CD and NCD & 3 \\
\hline
\end{tabular}

\subsubsection{Strategies available to governments}

We, then, extracted from each of the 115 articles the strategies available to improve access to medicines in the current IPR system. Table 2-14 presents the strategies that can be initiated by local governments. The three main strategies suggested by the literature to local governments include the use of flexibilities and safeguards provided by the TRIPS Agreement (62 articles), the implementation of an appropriate local IPR framework (52 articles) and the avoidance of free trade agreements (FTAs) that impose more restrictive conditions in their patent laws than are required by the TRIPS Agreement (these are known as 'TRIPS plus' provisions) (18 articles).

As presented in Table 2-15, compulsory licensing it the most advised TRIPS safeguard to overcome the negative impact of IPR on access to medicines. In second place comes parallel importing - that is, imports of a patented product from a country where it is already marketed without the permission of the intellectual property owner. The other TRIPS flexibilities and safeguards advocated by the literature on access to medicines are exceptions to patent rights (e.g. research and 'Bolar' exceptions), full use of transitional periods by least developed and developing countries, and implementation of pre 
and post-grant opposition proceedings to allow third parties to formally dispute the validity of both pending patent applications and granted patents.

Table 2-14: Strategies available to local governments to improve access to medicines in the current IPR system

\begin{tabular}{ll} 
Strategies & Articles \\
\hline \hline Use of IP flexibilities & 66 \\
Provide adequate IPR framework & 52 \\
Avoid TRIPS Plus provisions in FTAs & 36 \\
Implementation of adequate framework for compulsory licensing for & 13 \\
exports by countries with pharmaceutical industry & 13 \\
Enforce human rights to health and medicines & 9 \\
Build technological capacity in developing countries & 9 \\
Strengthen public health systems & 5 \\
Promotion of generic medicines & 4 \\
Revise existing FTAs & 3 \\
Direct price regulation & 3 \\
Enforce competition policy & 3 \\
\hline
\end{tabular}

Table 2-15: TRIPS flexibilities and safeguards advocated by the literature on access to medicines

\begin{tabular}{ll} 
Flexibilities / Safeguards & Articles \\
\hline \hline Compulsory licensing & 64 \\
Parallel importing & 31 \\
Exceptions to patent rights & 16 \\
Use of transitional periods & 4 \\
Opposition proceedings & 3 \\
\hline \hline
\end{tabular}

In addition, 52 papers advocate that countries must implement an IPR framework adequate to protect innovations and minimize the potential negative impacts on access to medicines. This includes the implementation of stricter patentability criteria with high standards of novelty and inventive steps, provisions for easy implementation of flexibilities and safeguards when necessary, not going beyond what is demanded by TRIPS and implementation of 'health-friendly' provisions (for instance, Ministry of Health participation in patent analysis, prohibition of patents for second use and linking inventive steps to significant enhancement of efficacy and efficiency of the drug). 


\subsubsection{Strategies to improve access initiated by other actors}

In the literature, we identified strategies to improve access to medicines that involve a variety of actors, as presented in Table 2-16. The effective implementation of these strategies depends on actions and coordination of local governments, NGOs, international organisations, and the pharmaceutical industry, among other actors. Our search retrieved 29 articles that advocate for the necessity of alternative institutional frameworks to promote drug/vaccine development and distribution, since market forces and the current IPR system not only make possible innovative drugs not reaching the poor but also provide little incentive for innovation in the diseases of low-income countries. We found 25 articles pointing out the necessity of alternative funding and financing mechanisms, such as product-development partnerships, advance market commitments, patent buy-outs, and patent pools; and 16 articles acknowledging the need for alternative incentive structures to the current IPR-based reward system, such as prizes, health impact fund and other incentive systems based on disease burden in which returns depend on the actual impact on global health. In sum, these alternative institutional frameworks aim at implementing a needs-driven rather than merely marketdriven system (Dionisio, 2010).

There are also three articles that propose South-South cooperation as a strategy to improve access to medicines. This strategy could include joint research and development efforts (Shah, Warsh, \& Kesselheim, 2013), pooled procurement to facilitate compulsory license (Abbott \& Reichman, 2007), and technological capacity building in local pharmaceutical industry (Weilbaecher, 2009).

Table 2-16: Multi-actor strategies to improve access to medicines

\begin{tabular}{ll} 
Strategies & Articles \\
\hline \hline Alternative institutional frameworks to promote drug/vaccine develop- & 29 \\
ment and distribution & 25 \\
$\quad$ Alternative funding/financing mechanisms & 16 \\
$\quad$ Alternative incentive structure to the current IP-based reward system & 3 \\
South-South cooperation & 30 \\
Total & 30 \\
\hline \hline
\end{tabular}

Table 2-17 shows that 22 articles raise the importance of strategies that must be taken at the supranational level. According to this literature, two main routes could be taken to improve access to medicines. First, 18 articles suggest that the TRIPS Agreement must be revised. The majority of papers that address this issue point out that the in- 
tended outcome of the waiver decision has not materialised so far and, therefore, the paragraph 6 system to facilitate compulsory licensing for exports must be revised. Authors also claim that TRIPS must be revised to incorporate human rights to health in the interpretation of its norms (Amador, 2012; Owoeye, 2014), to explicitly include the principles evoked by the Doha Declaration (Kiddell-Monroe, 2014; Trotter, 2012), and to include more clear, workable and transparent guidelines for compulsory licensing (Nicol \& Owoeye, 2013). Finally, some researchers point out the need for a new international treaty for the funding of pharmaceutical R\&D (Moon, Bermudez, \& 't Hoen, 2012; 't Hoen, 2002; Velasquez, 2014), and a treaty on global health to enforce the obligations of pharmaceutical companies under the right to health and establish an effective accountability mechanism (Grover, Citro, Mankad, \& Lander, 2012; Lee \& Hunt, 2012).

Table 2-17: Supranational initiatives to improve access to medicines

\begin{tabular}{ll} 
Strategies & Articles \\
\hline \hline Revising TRIPS Agreement & 18 \\
Alternative international treaty & 5 \\
Total & 22 \\
\hline \hline
\end{tabular}

Finally, as presented in Table 2-18, eight articles acknowledge strategies that pharmaceutical companies can implement to improve access to medicines. The main strategy is the adoption of a tiered price mechanism, followed by CSR and voluntary licensing of IPR. All these strategies were already discussed in Section 2.2, when we analysed the contribution of pharmaceutical MNEs towards improved health in the developing world.

Table 2-18: Strategies of pharmaceutical companies to improve access to medicines

\begin{tabular}{ll} 
Strategies of pharmaceutical MNEs & Articles \\
\hline \hline Tiered pricing mechanisms & 7 \\
CSR & 3 \\
Voluntary licensing & 1 \\
Total & 8 \\
\hline \hline
\end{tabular}

\subsubsection{FTAs and TRIPS-plus provisions}

The negative impacts of TRIPS-Plus provisions in FTAs on access to medicines are discussed in 36 articles. The highlight the potential negative impact on access to medi- 
cines caused by data exclusivity provisions (26 articles), patent linkages ( 24 articles), patent term extensions (20 articles), the limiting scope for use of flexibilities and safeguards (13 articles), and the implementation of loose patentability criteria (11 articles).

\section{Table 2-19: TRIPS plus provisions in FTAs mentioned in the literature on access to medicines}

TRIPS Plus provisions in FTAs

\begin{tabular}{ll}
\hline \hline Data exclusivity & 26 \\
Patent linkage & 24 \\
Patent term extension & 20 \\
Limiting the grounds for the use of flexibilities & 13 \\
Easing patentability criteria / Evergreening & 11 \\
Total & 36 \\
\hline \hline
\end{tabular}

Data exclusivity is a provision to protect the safety and efficacy test data for a certain period of time, so that no other company can ask for market approval based on that data before the exclusivity period is over (Cullen, 2007). This provision can delay the entry of generic versions, as they prevent generic manufacturers relying on the confidential regulatory data for the approval of a generic drug without the innovator's permission (Chakrabarti, 2014). The TRIPS Agreement requires countries to protect undisclosed tests or other data against unfair commercial use, but not the adoption of exclusivity periods to protect such data (Article 39.3) (Cullen, 2007). Therefore, data exclusivity is a TRIPS-plus provision that adds an extra layer of protection for the drugs irrespective of the patent protection status, thus with potential adverse effects on access to medicines (Chakrabarti, 2014).

Patent linkage is a provision that 'links' the market approval of generic medicines to the patent status of the original drug. As a result, a country's national health authority cannot grant marketing approval to a generic version of a product if the originator is still patent protected, unless with the consent or acquiescence of the patent holder Correa (2006a). If a generic producer wants to register a generic equivalent, then it would have to certify that it is not infringing any IPR or the market approval would not be granted until patent expiration (Baker, 2008). Therefore, these provisions, which is not included in the TRIPS Agreement, create an extra burden on generic manufacturers due to higher uncertainty and costs and can delay the introduction of competing and affordable products (Sell, 2007). 
Provisions for patent term extension are a measure to compensate for delays either in the examination of patent applications or in the marketing approval of a medicine (Correa, 2006a). Therefore, these provisions can extend the patent term beyond the minimum of 20 years after the patent application stipulated in TRIPS Agreement. According to (Correa, 2006a), this creates uncertainty for generic producers and, when implemented, will delay the introduction of more affordable generic competitors and, therefore, hinder access to medicines.

Some FTAs impose provisions to limit the grounds for the use of flexibilities, especially parallel importing and compulsory licensing. There are instances where compulsory licensing is limited to cases of anticompetitive practices, public non-commercial use, national emergency or other circumstances of extreme urgency, and that patent owners were allowed to prevent parallel imports through the use of contract or other means (Correa, 2006a; El-Said \& El-Said, 2007).

Finally, there are TRIPS-plus provisions to implement ease patentability criteria to expand the scope of patentability (e.g., patents on plants, animals, and second uses of known formulations) (Sell, 2007). TRIPS does not specify clear definitions of what is novelty, inventive step and industrially applicable. Therefore, these criteria can be interpreted and applied by local governments in accordance with their national priorities. As opposed, some FTAs contain a definition of what constitutes 'industrial application', 'inventive step', and/or 'novelty' (Roffe, 2004). This prevents countries from adopting narrower definitions and may permit extended patent protection due to minor modifications in existing products (e.g. second use of known products, overassociated delivery systems, new pharmaceutical mixtures and new therapeutic methods), which is commonly known as evergreening (Roffe \& Spennemann, 2006).

\subsection{Conclusions}

There are good reasons to expect improved health status of a nation's citizens to result in economic growth and development, via improved functionality and productivity of labour. The same is true the other way around, since the health status and disease profile of human societies have historically been linked to the level of their economic development and social organisation. It is also commonly accepted that health care expenditure significantly influences health status through, for instance, improving life expectancy at birth and reducing morbidity, death and infant mortality rates. 
Within healthcare, medicines account for a considerable share of health related expenditure in both developed and developing countries. For instance, in the OECD countries, medicines correspond to approximately 16 per cent of the total spending on health care on an average. Whereas in developing countries medicines often account for more than one third of the total health expenditure. Therefore, it seems reasonable to conclude that improved access to medicines is likely to contribute to economic growth and development in all societies.

Present market forces and the current IP-based reward system directly affect two dimensions of access to medicines, namely affordability and availability. The patent monopoly, market exclusivity, and the oligopolistic nature of the supply of innovative drugs contribute to the high price of medicines. This issue became particularly important after the TRIPS Agreement came into force, as evidenced by the evolution of the scientific output in this field. In addition, for some diseases and conditions that mainly affect the poor, drugs are not available simply because they do not exist. Then, monopoly rights granted by patents do not provide enough incentives for pharmaceutical companies to innovate in the diseases of low-income countries, because the market is too small to recover the $\mathrm{R} \& \mathrm{D}$ costs.

As discussed in this chapter, pharmaceutical companies can play an important role to address this problem. First, they can undertake strategies to make their products more accessible in low and middle-income countries, such as price discrimination, drug donation and other CSR activities. Second, they can provide support to both alternative funding/financing mechanisms to promote the development and distribution of drugs more suited to the developing world and alternative reward systems, such as prizes and disease burden funds. The literature also acknowledges the need of alternative institutional frameworks to promote drug/vaccine development and distribution. These frameworks include, for instance partnerships for product development and patent pools, and require the involvement of several stakeholders, such as the pharmaceutical industry, local governments, NGOs and foundations, multilateral organisations, universities and other participants in the innovation system.

The findings of this chapter show that CSR, patent licensing and price negotiation strategies are considerably more frequently discussed in the literature on the contribution of pharmaceutical industry to health in low and middle-income countries than in the literature on the debate of IPR and access to medicines. This is probably because 
these strategies are generally punctual and do not target the core of the imbalances caused by intellectual property protection.

The literature on access to medicines from the perspective of both the contribution of the pharmaceutical industry and the constraints imposed by IPR majorly focuses on communicable diseases, with special attention given to HIV/AIDS. This reality reveals that the transition to higher incidence of non-communicable diseases in the developing world may bring additional challenges in terms of access to medicines.

This can be especially intriguing when one takes into account that, in the literature survey, we identified that the main strategy available to local governments to improve access to medicines in the current IPR system are use of TRIPS flexibilities, notably compulsory licensing. Compulsory licensing provisions in TRIPS implicitly suggest that this flexibility is more suitable to infectious epidemics, as they evoke terms like 'national emergency' or 'circumstances of extreme urgency' that are not trivially applicable to non-contagious public health crisis. On the other hand, the Doha Declaration explicitly focuses on infectious diseases as it specifies HIV/AIDS, tuberculosis, malaria, and other epidemics as particular diseases of concern. In addition, both Article 31 in TRIPS and the Doha Declaration were influenced by a context of crisis over access to HIV/AIDS treatment in low and middle-income countries. This fragility of the system increases the need for developing countries to implement an adequate local IPR framework that allows them to make use of such flexibilities possible and workable, and to implement health-friendly measures to avoid the granting of unnecessary patents. Nevertheless, the pressure over developing countries to refrain from taking measures to overcome IPR barriers to access medicines for non-communicable diseases can exceed that which has been exerted in the context of compulsory licensing for HIV/AIDS (Savoie, 2007).

There is substantial evidence that the threat to use TRIPS flexibilities can be used to advantage in price negotiations between developing countries and pharmaceutical companies. For instance, in 1997, the South African government announced its willingness to import patented drugs without the permission of the manufacturer, in order to increase the availability of affordable medicines in the country. However, no further actions were taken and the local government was not able to buy drugs at more affordable prices after this episode ('t Hoen, 2002). During the 2000s, the Brazilian government successfully negotiated discounts on a number of patented drugs. Their bargaining strategy had been backed up by threats to issue compulsory licenses, but no com- 
pulsory licenses were finally issued until 2007 (Ford et al., 2007). On the other hand, in 2006, the Thai Ministry of Public Health actually issued its first compulsory license for an antiretroviral drug after failing to achieve any significant price reduction with the patent holder (Thai White Paper I, 2007).

The compulsory license bandwagon is slowly gaining momentum with India issuing one in 2012 for a oncological drug, and China amending its intellectual property laws to allow for them (Francisco, 2012). Still many developing countries remain silent spectators, without even attempting to negotiate prices with the patent holders of branded drugs. This could be because as Kuhn \& Beall (2012) point out " patent holders-even though they carry no formal status at the WTO - wield tremendous force by threatening to withdraw their products from the local market or by encouraging their powerful host nations to retaliate against weaker nations' (p. 1168). In addition, there is a considerable body of research arguing that the paragraph 6 system must be revised so countries without manufacturing capacity can import drugs under compulsory licensing more easily.

However, some loaded questions remain unanswered. Under what conditions will a developing country have the confidence to threaten to use the compulsory licensing option or actually issue one? Under what conditions will such threats be successful in bringing down the price of the vital drug concerned? These queries, which the remainder of this dissertation seeks to answer, lie at the heart of policy choice among different possible mechanisms to improve access to critical medicines in developing countries. They are also of equal importance to innovation leaders in the pharmaceutical sector, which comprise firms from the developed countries. 



\section{Chapter 3 Role of industry, state and MNEs in tackling the HIV/AIDS crisis in Brazil: A brief re- view}

\subsection{Introduction}

Since 1996, Brazil has an official and well-structured policy of universal and free access to ARV drugs through the public-sector health system. This puts an enormous pressure on the Ministry of Health $(\mathrm{MoH})$ of Brazil to ensure an adequate supply of ARVs in the healthcare system. To ensure availability, there are two possibilities: local production and/or import of generic drugs. However, both possibilities are constrained by the existing IPR regime and especially the patent system. In addition, domestic production depends on the existence of technology capabilities, equipment, human resources and other factors that shape its techno-economic feasibility. In order to understand how each of these factors influences the success of the universal access program, this chapter reviews the Brazilian anti-HIV experience. We start with a brief historical review of the Brazilian pharmaceutical industry, stressing the role of state-owned laboratories (section 3.2) and private companies (section 3.3). In section 3.4, we review the foundations of the Brazilian public policies to tackle the HIV/AIDS epidemics and, in section 3.5, we highlight the role of local production of generic ARVs, especially in public laboratories. Given the increasing importance of patented drugs in the MoH's spending on ARV drugs, in section 3.6 e review the evolution of the local IPR framework after the TRIPS Agreement. Section 3.7 presents preliminary conclusions and closes this chapter.

\subsection{Emergence of the Brazilian pharmaceutical industry: the reign of public laboratories}

Between the end of the nineteenth century and the first decades of the twentieth century, Brazil faced a serious public health crisis caused by endemic diseases, such as yellow fever, smallpox and typhoid fever. In response to this, the government deployed a series of state-owned institutes to undertake $\mathrm{R} \& \mathrm{D}$ to produce drugs and vaccines to tackle these diseases (Frenkel et al., 1978; Bermudéz, 1992; Ribeiro, 2001). The main public institutes created in this period were the Instituto Bacteriológico (1892), Instituto Vacinológico (1892), Instituto Butantan (1899), Instituto Federal de Soroterapia Federal Manguinhos (1900) (later renamed to Fundação Osvaldo Cruz - FioCruz), Serviço de 
Medicamentos Oficiais do Brasil (1918) and Instituto Biológico (1927). As an unintended result of this public health policy, by 1940s, the Brazilian industry comprised sciencebased organisations, especially from the public sector, which were very active in the research, development and production of high quality vaccines, serum and other biological products.

The construction of a new facility for the Serviço de Medicamentos Oficiais do Brasil, in 1956, eventually became the Instituto de Tecnologia em Fármacos (Farmanguinhos) at FioCruz and this was an important milestone in the public production of drugs in Brazil. Farmanguinhos was designed to research, develop and manufacture chemicalbased solutions for diarrhoea, anaemia, and conditions caused by parasitic worms as well as painkillers, tranquilizers, sedatives and antidepressants. Since then, Farmanguinhos has played a central role as supplier of affordable drugs to the Brazilian public health system.

Between the 1960s and the 1980s, a second wave of expansion of the network of public laboratories was observed. During this period, at least ten state-owned facilities were built throughout the country to produce and deliver cheap essential drugs to the public health system. By 2009, Brazil had 20 state-owned laboratories that manufactured 80 per cent of the vaccines and 30 per cent of the medicines acquired by the Brazilian public health system. However, these laboratories specialized in the formulation of medicines and relied on imports of active pharmaceutical ingredients (API), notably from India and China.

\subsection{Private sector: paradigm shift and catch-up failure}

Until the 1940s, the technological gap between Brazilian private pharmaceutical companies and those from more advanced countries, especially Germany, United States and Switzerland, was not pronounced (Frenkel \& Ortega, 1987; Ribeiro, 2001). Up to that time, pharmaceutical companies had relied mostly on natural sources to search for new active agents. By the end of the 1930s, most of the drugs in the market were derived from plants and microorganisms. When positive activity was identified in a certain substance, then the drug discovery process would be followed through with a serial purification of the crude extracts until the active principle was obtained. Such a method, commonly known as medicinal chemistry, was a limiting factor in the creation of new drugs because it was a slow and labour-intensive process (Drews, 2000; Gershell \& Atkins, 2003). 
However, the picture changed completely after the consolidation of the technological paradigm based on synthetic organic chemistry. The discovery of the Wöhler synthesis in 1828, when Friedrich Wöhler synthesized the organic chemical urea from the inorganic ammonium cyanate, represented a turning point in chemistry (Ramberg, 2000). This breakthrough paved the way for a radical new direction in chemistry as it proved that chemists could synthesize not only the existing molecules but also molecules that did not exist in nature (Yeh \& Lim, 2007).

In the last two decades of the nineteenth century, the chemical industry started transforming radically. The approach to drug discovery was totally revolutionized with advances in the field of organic chemistry. The combination of this new synthetic approach with the more traditional analytical approaches was the basis of the emergence of the modern pharmaceutical and chemical industries (Yeh \& Lim, 2007). The scientific contributions of Paul E. Ehrlich (1854-1915) were fundamental in this process. Ehrlich's findings was crucial to consolidate the principle of 'selective action mechanism' of drugs, which determined a logical basis for the research on new chemical drugs. It was the birth of chemotherapy ${ }^{11}$, which led to the creation of an unprecedented number of new drugs in the course of the twentieth century. By that time, chemistry had reached a degree of maturity that allowed its principles and methods to be applied to problems outside of chemistry itself and pharmacology had become a welldefined scientific discipline in its own right (Drews, 2000).

During the 1950s, public policies encouraging the inflow of foreign direct investments in Brazil had attracted several pharmaceutical MNEs seeking new markets for their products. However, the local industry could not compete with foreign companies, which had started accumulating scientific and technological capabilities in fields related to chemistry much earlier. There was a clear technological gap between them and this has kept increasing since that time.

The entry of pharmaceutical MNEs in Brazil was of such magnitude that, in the late 1950s, it completely changed the local market structure. Between 1958 and 1972, forty-three national firms were acquired by foreign companies, increasing their market share from 30 per cent in 1945 to 70 per cent in 1960 (Bermudez, 1992). The modus operandi of the Brazilian subsidiaries of foreign companies was exclusively based on the

\footnotetext{
${ }^{11}$ Chemotherapy is a term coined by Ehrlich and refers to the treatment of diseases through customized chemical compounds, which have specific biological targets, attacking only the microorganism that causes the disease and not the whole host (Parascandola, 1981).
} 
formulation and commercialization of drugs developed abroad. These companies did not have any local $R \& D$ activity and imported virtually all the required raw materials, especially APIs and intermediates. Thus, the key competitive advantage of these companies was the manufacturing capabilities required for drugs formulation as well as the marketing and distribution capabilities for commercialization.

Nevertheless, by the 1970s, some Brazilian companies had adapted to these conditions and reoriented their core competences towards drug formulation, marketing and distribution. Such reorientation was facilitated by the IPR law of 1969, which did not allow patent protection either for pharmaceutical products or for their respective manufacturing processes. Indeed local companies deployed a business strategy based on the commercialization of branded-copies of existing products. The APIs required for these copies were imported from countries that also did not grant patents to pharmaceutical products at that time (such as Italy, Japan, Spain, Hungary, Bulgaria and Romania). Moreover, the consolidation of the market for branded-copies (also known as similar drugs) was based on aggressive and massive marketing efforts. Between 1971 and 1975, local companies increased spending in marketing, distribution and sales by $400 \%$, while the increase of foreign companies spending stepped up by $218 \%$ (Frenkel et al., 1978).

The Brazilian companies imitated the 'market creation' strategies of MNEs and catching up occurred only in terms of formulation and marketing capabilities. Therefore, the strategy that Brazilian companies have adopted was based on the same core competences of the foreign affiliated companies (i.e. imports of raw materials and focus on drug formulation, marketing and distribution). But while the foreign affiliates were commercializing innovative drugs based on strong scientific and technological capabilities developed in their headquarters, local private companies were allocating more and more resources to marketing expenses, while reducing or eliminating the activities related to R\&D of new pharmaceutical products (ALANAC, 1987). Thus, local private companies became relatively strong in drug formulation and distribution but very weak in terms of in-house innovative capacity for drug development and imitative capacity for API production.

During the mid-1970s and 1980s, the Brazilian Government initiated several industrial policies to tackle the technological retardation of local companies. However, most of them could not exploit the economic opportunities created, either because the incentives were inappropriate or because companies did not have the time to catch up as the 
policy was abandoned after a couple of years due to financial constraints. Furthermore, there was not enough competitive pressure to force companies to integrate vertically in an efficient way. Then, once the protection to the local industry was abolished in the late 1980s, the industry collapsed and almost all the existing API productive capacity was shut down. As a result, at the beginning of the 1990s, the Brazilian pharmaceutical industry was still limited to activities related to drug formulation and marketing, and increasingly dependent on imports of APIs and intermediates.

\subsection{The Brazilian Universal Access Program}

Brazil's first AIDS case was reported in 1982 and, then years later, there were approximately 76,000 living with HIV in the country (Levi \& Vitória, 2002; Nunn, 2009). In a report published in 1993, the World Bank expressed its concern about the spread of the HIV/AIDS epidemic in Brazil. Due to its large population, the significant number of poor people and the precarious state of the healthcare system, experts estimated that there would be nearly 1.2 million people infected by HIV/AIDS by 2000 (The World Bank, 1993). The World Bank stated that an appropriate intervention in the country could help to avoid new infections. Accordingly, a focus on prevention was recommended instead of treatment.

In 1996, Brazil became a trailblazer among developing countries, when it initiated an official and well-structured policy of universal and free access to antiretrovirals through the public health system, named Sistema Unico de Saúde (SUS, or Unified Health System). Indeed, the public commitment to tackle the HIV/AIDS epidemics had begun more than a decade earlier. São Paulo and Rio de Janeiro had created state-level programmes of free drug distribution for sexually transmitted diseases (STD), including AIDS, in 1983 and 1985, respectively. In 1986, the Department of STD, AIDS and Viral Hepatitis was created under the aegis of the Ministry of Health of Brazil (MoH). In 1991, ARV drugs had already been included in the public health system with the distribution of zidovudine capsules (Teixeira, Vitória, \& Barcarolo, 2004).

At least three important elements paved the way for a universal treatment policy in Brazil. First, the Federal Constitution of 1988 recognized the right of free and universal access to health care for the entire population through a national health system. Secondly, an inflow of funds from the World Bank, after a request from the Brazilian Government, provided technical and financial assistance to support the prevention, diagnosis, treatment, and care, surveillance, research, monitoring and evaluation, and 
institutional development. Finally, in late 1995, with the approval of more potent reverse transcriptase inhibitors (RTI) ${ }^{12}$ called lamivudine and the launch of a new class of antiretrovirals, the protease inhibitors $(\mathrm{PI})^{13}$, a new ARV regimem based on the use of multiple drugs acting on different viral targets was consolidated. These regimens are known as highly active antiretroviral therapy (HAART). The combination of drugs slows down the disease progression and prevents the deterioration of the immune system. After that, the mortality rate for AIDS reduced dramatically; this was essential for the launch of a public policy based on universal treatment.

Given these favourable conditions, on November 13, 1996, Brazil passed Law 9,313, which created a large-scale public treatment program, ensuring that all people infected by the HIV virus will have access free of charge for any drug related to his/her treatment. Over time, this approach has proved to be effective not only from the viewpoint of the lives that have been saved, but also as a resource saving strategy, since the treatment of AIDS in its initial stages requires less resource than the intensive repeated hospitalizations of seriously ill patients (Chequer, 2005).

Through this program, Brazil challenged conventional wisdom, because most of the international development agencies were against developing countries implementing treatment programmes, favouring 'cost-effective' prevention over a treatment that often exceeded US\$10,000 per patient per year (PPPY) at the time (Chequer, 2005; Nunn, Da Fonseca, Bastos, \& Gruskin, 2009). Thus, the Brazilian decision was not only critical for the country but also on a wider level, for the 'political economy' of access to ARVs drugs in developing countries (Coriat, 2008; Moatti et al., 2003).

Indeed, Brazil has demonstrated that the combination of prevention and care is critical for halting the AIDS epidemic. However, over time the increasing number of patients and the inclusion of newer patented ARVs imposed some additional challenges for the

\footnotetext{
${ }^{12}$ Reverse-transcriptase inhibitors (RTIs) are a class of antiretroviral drugs used to treat HIV infection or AIDS, and in some cases hepatitis B. RTIs inhibit the activity of reverse transcriptase, a viral DNA polymerase that is required for the replication of HIV and other retroviruses (De Clercq, 2005). It is worth noting that the RTI zidovudine (also known as azidothymidine (AZT)), the first medicine able to slow the replication of the virus and the progression of the disease, was in the market since the late 1980s. However, its efficacy was still limited

${ }^{13}$ Saquinavir was the first Protease inhibitor (PIs) approved for prescription use, in December 1995. In March 1996, two other PIs were also approved (Ritonavir and Indinavir). PIs are a class of antiviral drugs that block activation of an HIV enzyme called protease and prevent the cell from producing new viruses. Other examples of PIs used in the treatment of HIV/AIDS include Tipranavir, Lopinavir + Ritonavir, Fosamprenavir, Darunavir, Atazanavir and Nelfinavir.
} 
Brazilian Government. Due to the rising costs of the program, the $\mathrm{MoH}$ clearly had to contain the health expenditures necessary to ensure the sustainability of the anti-AIDS program. To do so the $\mathrm{MoH}$ started seeking price reductions for high-cost drugs.

One important factor that triggered the Brazilian strategy of price negotiation was the sharp rise in costs due to the high depreciation of the local currency (Brazilian Real BRL) in 1999. This factor alone was the main cause of the 64 per cent rise in the cost of antiretroviral drugs in Brazil between 1998 and 1999. As Figure 3-1 and Figure 3-2 show, 1999 is the only year in the period 1997-2000, when the costs PPPY measured in BRL increases, even though it decreases in dollar. It is also possible to see a sharp increase in the total expenses with ARV drugs in 2009. This had to do with an expansion of the programme with a remarkable increase in the number of patients and with the inclusion of new drugs such as Darunavir and Raltegravir. In spite of the increase in the total expenses, the costs PPPY have decreased steadily until 2013.

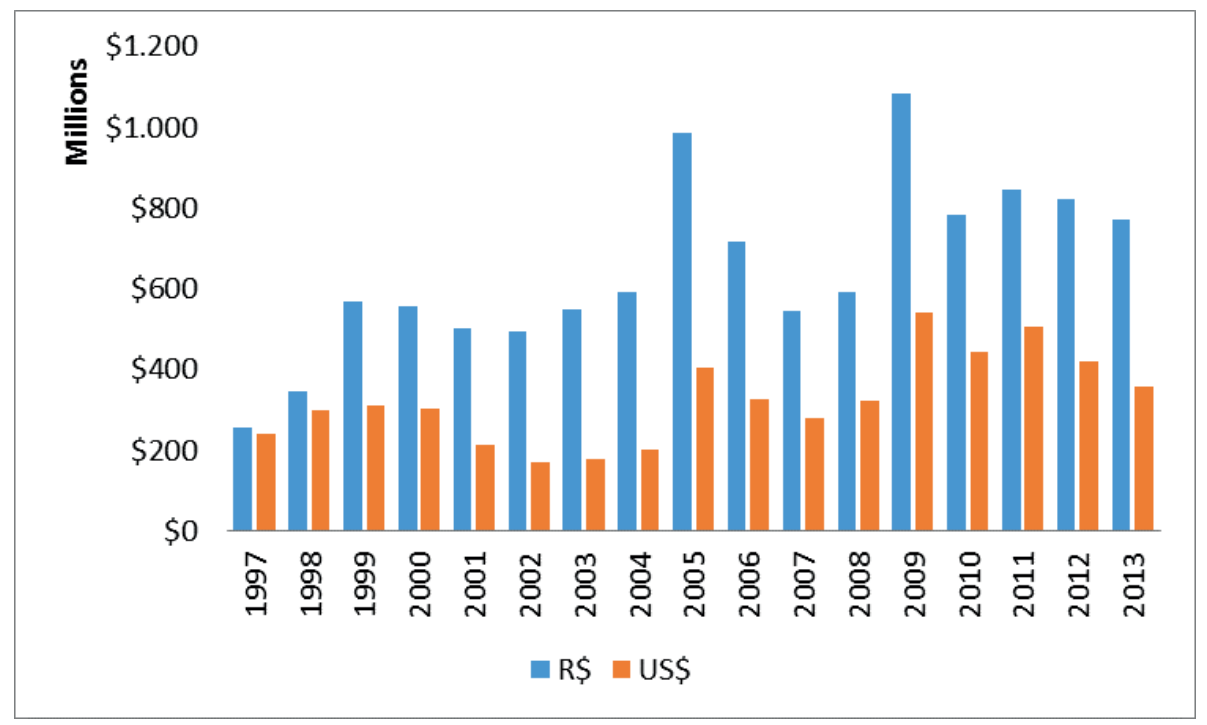

Source: Elaborated by the author based on Galvão (2002); Grangeiro, Teixeira, Bastos, \& Teixeira (2006); and MoH of Brazil, STD/AIDS Department

Figure 3-1: MoH's total expenses with ARV Drugs in Brazil (1997 - 2013) 


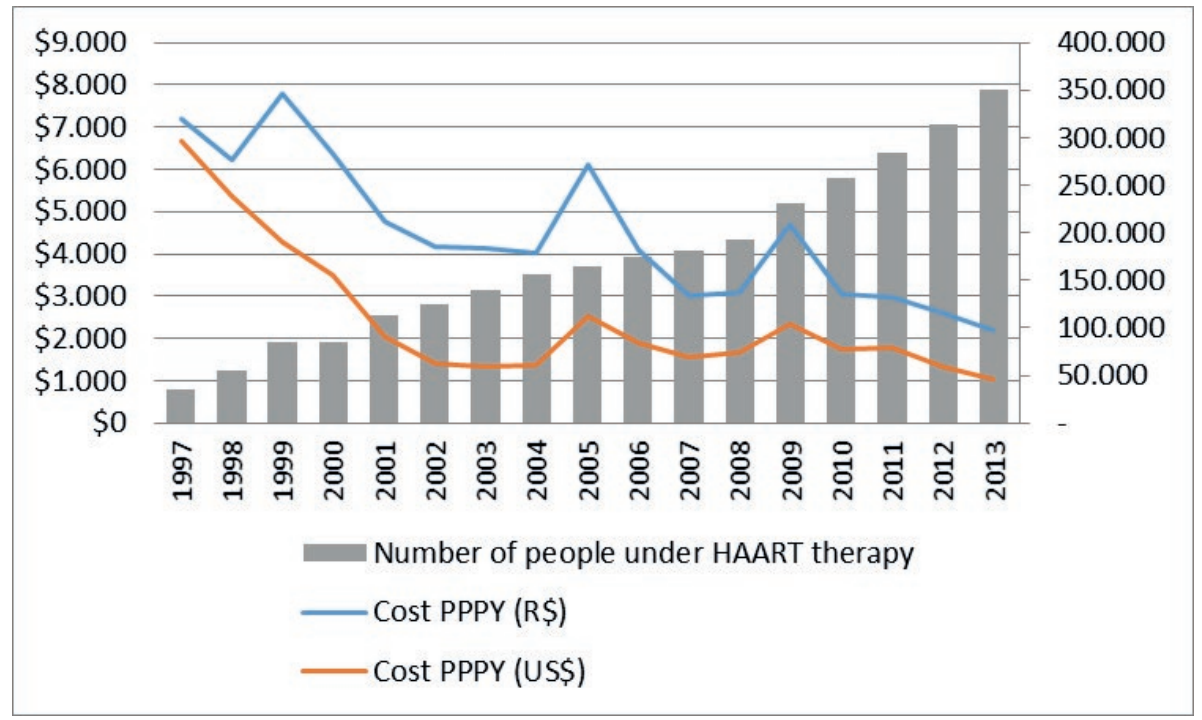

Source: Elaborated by the author based on Galvão (2002); Grangeiro, Teixeira, Bastos, \& Teixeira (2006); and MoH of Brazil, STD/AIDS Department

Figure 3-2 - Number of patients in the STD/AIDS Programme and Cost PPPY Brazil (1997 - 2013)

The Brazilian strategy to reduce prices of ARVs was based on two main pillars, namely (i) the local productions of off-patented ARVs - mainly in state-owned laboratories; and (ii) the use of the threat of compulsory licensing in price negotiations of patented ARVs with pharmaceutical MNEs.

\subsection{Rise of local production of ARV drugs}

The local production of ARV in Brazil started in the first half of the 1990s. In 1993, a small private laboratory named Microbiólogica was the very first local firm able to synthesize zidovudine (AZT), and, in 1994, LAFEPE became the first public laboratory to supply ARV to the Ministry of Health (Cassier \& Correa, 2003; Orsi, Hasenclever, Fialho, Tigre, \& Coriat, 2003). However, it was in 1997 that the cornerstone of local production started taking shape. At that time, Farmanguinhos was mobilized by the MoH to produce off-patented ARVs. Between 1997 and 2002 the volume of production at Farmanguinhos increased sevenfold, notably due to ARV production (Cassier \& Correa, 2003). Of the twelve drugs supplied through the universal access programme at that time, eight were produced locally. 
Nevertheless, neither Farmanguinhos nor other state-owned suppliers of ARVs have mastered the entire drug manufacturing process. They have specialized in the final production phase, i.e. formulation and packaging of drugs. These laboratories do not have manufacturing capabilities to produce their own raw materials and, therefore, depend on suppliers of APIs (Dos Santos, 2010). Due to the lack of competitiveness of local suppliers, more than 90 per cent of the public demand of the APIs needed to produce ARVs are supplied by Indian and Chinese firms (Orsi et al., 2003). However, Farmanguinhos and a handful of private laboratories developed imitative capabilities for reverse engineering the synthesis processes of the different ARVs, including patented second-generation ARVs (such as Efavirenz, Nelfinavir and Lopinavir) (Cassier \& Correa, 2007, 2008). These capabilities became a central component in MoH's strategy of price negotiation with pharmaceutical MNEs, as we will discuss in the following chapters.

\subsection{TRIPS and Compulsory license}

In May 1996, Brazil enacted Law 9,279/96 ${ }^{14}$, which amended its patent laws, bringing them into compliance with TRIPS standards. This law had a significant impact on the local pharmaceutical industry as it introduced the patentability of chemical products and processes, previously non-patentable. The Law 9,279/96 took effect in May 1997; thus, Brazil waived the ten years adaptation period to comply with TRIPS. The premature enforcement of the Brazilian Patent Law created constraints in the local production of ARV drugs because only those molecules that were in the market before 1996 could be copied (Orsi et al., 2003). This was aggravated by two other important decisions: the inclusion of a provision for 'pipeline patents' of pharmaceutical inventions and the exclusion of parallel imports.

Although it was not a part of TRIPS, Brazil introduced a provision for 'pipeline patents' in its IPR law, due to pressure from major pharmaceutical multinationals. This mechanism allowed patent claims for pharmaceutical products to be accepted and approved based on the date of first foreign filing as long as such products were not marketed anywhere. When such patent applications were filed in Brazil, the respective information on the invention had already been available in other countries (e.g. patents, scientific journals). Therefore, they no longer fulfilled the novelty requirement,

\footnotetext{
14 An English version of the Brazilian IP Law is available at http://www.wipo.int/wipolex/en/ text.jsp?file_id=125397
} 
since the information was already in the public domain. In addition to relaxing the definition of 'novelty,' pipeline patents were not examined but simply revalidated by the local authorities (Shadlen, 2009).

Parallel imports refer to products marketed by the patent holder or by other organisation in one country and imported into another country without the approval of the patent owner. The TRIPS agreement in Article 6 states that this practice cannot be challenged under the WTO dispute settlement system and so is effectively a matter of national discretion. The same article of the TRIPS Agreement states that members may adopt the principle of exhaustion of rights at national, regional or international levels. However, the Brazilian legislation permits exhaustion of rights only at the national level, which in practice means that it is impossible to have parallel importation (Oliveira, Bermudez, Chaves, \& Velásquez, 2004). However, as we discuss in the coming paragraphs, in 2003, Brazil amended its IPR law to allow parallel imports if necessary to implement a compulsory license.

On the other hand, the Brazilian Intellectual Property Law includes some flexibilities allowed under TRIPS to cope with the potential negative impact of patents on access to medicines. The main flexibilities implemented in Brazil were compulsory licensing and experimental use of patented inventions. The provisions for compulsory licensing are in Chapter VIII (Section III) of Law No. 9279/96 and the conditions under which a compulsory license can be issued in Brazil are dictated by Articles 68 and 71 of the same.

Article 68 refers to compulsory licenses in case of abuse of economic power, including the case of 'non-exploitation of the object of the patent within the Brazilian territory for failure to manufacture or incomplete manufacture of the product.' ${ }^{15}$ Article 71 allows compulsory license in case of 'national emergency or of public interest' and 'provided that the patent holder or its licensee does not fulfil such need.' In October 1999, the Public Decree No. $3.201{ }^{16}$ was published by the Brazilian Government specifying the rules concerning the granting of compulsory licenses in cases of national emergency and public interest provided in Article 71.

\footnotetext{
15 This is also known as 'local working' condition and it is provided in Article 68, I, $\$ 10$ and $\$ 5$, section II, of the Brazilian Intellectual Property Law (Law No. 9,279 of 1996).

${ }^{16}$ Decree No. 3.201 of October 6, 1999 (Compulsory Licenses in Cases of National Emergency and Public Interest)
} 
Brazil included provisions allowing for experimental use of patented technologies. Article 43, item 2, exempts 'acts carried out by unauthorized third parties for experimental purposes, in connection with scientific or technological studies or researches.' In addition, Law 10,196/2001 has amended Article 43 to include a 'Bolar exemption'. This amendment provided that the patent holder cannot impede 'acts performed by non-authorized third parties, regarding patented inventions, which aim exclusively the production of information, data and test results directed to procure commerce registration, in Brazil or any other country, to allow the exploitation and commercialisation of the patented product.' This provides exemption from claims of patent infringement for those acts of making, using, or selling a patented invention which are reasonably related to seeking regulatory approval to market a drug, provided that no commercial use of a patented invention occurs before the patent expires.

The Brazilian provisions for compulsory licensing resulted in external pressure, especially from the United States Government and from PhRMA. In December 1998, PhRMA requested the United States Trade Representative (USTR) to list Brazil as a Watch List country on its annual 'Special 301' Report ${ }^{17}$. One year later, PhRMA submitted a complaint to the National Trade Estimate Report on Foreign Trade Barriers (NTE), concerning Brazil's limited intellectual property protection. In February 2000, PhRMA requested the USTR to list Brazil on its 2000 'Special 301' Priority Watch List. Finally, in May 1, 2000, the USTR ranked Brazil among the Watch List countries of its 'Special 301' Report, citing the Public Decree No. 3.201 'which contains some problematic provisions related to issuance of pharmaceutical patents.' Finally, in early 2001, the USTR filed a complaint in the WTO Dispute Settlement Body and requested the establishment of a WTO Dispute Settlement panel, concerning article 68 of Brazil's patent law. However, after intense protests by the global AIDS movement and the subsequent negative repercussion, the United States withdrew its complaint (Love, 2007; Nunn et al., 2009).

In 4 September 2003, the Brazilian government introduced an important change in its legal framework regarding the granting of compulsory licenses. The Brazilian President

\footnotetext{
17 Since the mid-1980s, the USTR annually releases its Watch List and Priority Watch List under Section 301 of the Trade Act. The 'Special 301' Report is an annual review of the global state of IPR protection and enforcement. Its main objective is to identify countries that do not provide adequate and effective' protection of IPR or 'fair and equitable market access to United States persons that rely upon intellectual property rights'. By doing so, the US government notifies listed countries that they would impose trade sanctions, that is impose tariffs under their exports, if no further actions are taken to enforce IPR in their territories.
} 
issued Public Decree $n^{\circ} 4.830 / 2003$, which amended the regulations on compulsory license. ${ }^{18}$ Two main changes were introduced: (i) the import of medicines were allowed under compulsory license from countries where the same were not protect by patents; (ii) compulsory licenses and the permission to manufacture patented medicines without the patentee's consent could be granted to private companies. The main goal of this institutional change was to facilitate for imports of generic drugs and/or APIs in case of unsuccessful price negotiations with patent holders.

\subsection{Discussion}

Brazil has an extensive network of state-owned laboratories with a long tradition in drug formulation to supply essential medicines to the public health system. These laboratories, as well as local private companies, specialized in copying products developed abroad. After the new institutional framework for IPR took effect in 1997, the role of these organisations became much more limited.

Although the local IPR framework did not take full advantage of the flexibilities provided in the TRIPS agreement, it included provisions for experimental use and compulsory licensing that were critical for the sustainability of the local programme of universal access to ARV drugs. Therefore, the implementation of such an adequate IPR framework for compulsory licenses paved the way for the Brazilian strategy of price negotiations. This strategy was followed by the $\mathrm{MoH}$ of Brazil on several occasions from 2001-2011 and resulted in different outcomes, including the issuance of compulsory license in 2007. The existence of sufficient manufacturing capacity is deemed as critical for the price reductions obtained in these negotiations. However, the existing literature does not provide an integrative framework to analyse the Brazilian strategy of price negotiation. This is why we needed further research, based on primary and secondary data, to fill this gap.

${ }^{18}$ It amended the Articles 1, 2, 5, 9 and 10 of Decree No. 3.201/1999 


\section{Chapter 4 The Brazilian price negotiation experi- ence with ARV drugs}

\subsection{Introduction}

The sustainability of large-scale health programmes depends on the quantity of drugs that the public authority can afford. In this context, what happens if there are multinational pharmaceutical companies with a monopoly on critical drugs that sell them at high prices? When there is a major disease that calls for patented medicines, the viability of public health programmes may be put at great risk. In this context, one possible solution is that local government will enter into direct price negotiations with the patent holders.

Indeed, Brazil is the most prominent example of a country that has succeeded with the price negotiation strategy and the WHO has defined it as a central component of the 'Brazilian model' for AIDS treatment. Another feature that has marked the Brazilian price-negotiation experience with pharmaceutical MNEs is the use of the compulsory license as a threat by which to obtain a better outcome. For instance, in early 2001, the $\mathrm{MoH}$ publicly threatened to issue compulsory licenses for Nelfinavir and Efavirenz, which were the only two patented ARVs under the anti-HIV/AIDS programme, unless the patent holder agreed to substantially reduce their prices. After months of negotiation, the $\mathrm{MoH}$ accepted price reductions of 59 per cent and 40 per cent for Efavirenz and Nelfinavir, respectively. No compulsory license was issued after this episode.

After this first attempt - considered by many critics as a successful one - the $\mathrm{MoH}$ of Brazil engaged in several other price negotiations backed up by compulsory license threats with mixed outcomes. The first - and only - compulsory license was issued in 2007 after failing to achieve any significant price reduction for Efavirenz with the patent holder. In spite of the Brazilian success, to date there has been no detailed study of the drivers of price negotiation from the Brazilian experience. In addition, there is no extensive research using episodes of price negotiation as the unit of analysis.

In order to contribute to filling this gap, the present chapter aims to analyse the drivers of the Brazilian success, in order to develop an integrative analytical framework (in next chapter) that explains the interrelationships between the possible determinants of price negotiations involving IPR matters. The objective is to identify the systemic drivers of 
the successful free access to ARVs program, refine the conditions lying at the heart of it and re-specify the issues concerning its potential replication in other developing countries, particularly those deprived of industrial capabilities.

Fourteen episodes of price negotiations for ARV drugs between 2001 and 2011 in which IPR issues were involved in the discussion are examined. The case study is constructed using secondary sources of data including official documents, scientific articles, national and international reports, $\mathrm{MoH}$ and Department of STD/AIDS websites and newspaper articles.

The remainder of the chapter is organised as follows. Section 4.2 presents data sources and methodology. Section 4.3 describes a case study on fourteen episodes of price negotiations in Brazil. Finally, preliminary conclusions are presented in Section 4.4.

\subsection{Data and Methods}

Following Yin (1994, 2009, 2012), we construct a descriptive case study of the Brazilian experience of drug price negotiation for its Universal Access Programme to HIV/AIDS treatment through reconstruction of historical events. The purpose of this descriptive effort is to identify characteristics and attributes of these price negotiations as well associations and relationships between actors and other determinants of the observed outcomes. The case study using episodes of price negotiation of ARVs drugs undertaken by the $\mathrm{MoH}$ of Brazil as unit of analysis allows us to construct a general picture of the context, drivers and main obstacles to compulsory licensing of pharmaceutical products.

This methodological approach provides inputs to develop the research design necessary for the analytical research presented in the next chapters. It involves two main steps: first, price negotiation episodes involving IPR matters in Brasil is identified. The search criteria includes negotiations between $\mathrm{MoH}$ and pharmaceutical companies for patented ARVs that involved at least one of the factors listed below:

(i) compulsory license threat

(ii) voluntary license request

(iii) rejection of patent claim

(iv) patent nullification 
From these, fourteen price negotiations, involving six different ARV drugs, are identified, as presented in Table 41 . In some instances, $\mathrm{MoH}$ carried out simultaneous negotiations. These cases are labelled with numbers and letters (e.g. $1 \mathrm{~A}$ and $1 \mathrm{~B}, 2 \mathrm{~A}, 2 \mathrm{~B}$ and $2 \mathrm{C}, 3 \mathrm{~A}, 3 \mathrm{~B}$ and $3 \mathrm{C}$, and $8 \mathrm{~A}$ and $8 \mathrm{~B})$.

\section{Table 4-1: Price negotiations of ARV drugs in Brazil}

\begin{tabular}{|c|c|c|c|c|}
\hline Episode & Drug & Pharmaceutical MNE & Start & End \\
\hline $1 \mathrm{~A}$ & "Efavirenz (Stocrin ${ }^{\oplus}$ ) & Merck \& Co. (USA) & Jan/2001 & Mar/2001 \\
\hline $1 \mathrm{~B}$ & Nelfinavir $\left(\right.$ Viracept $\left.^{\oplus}\right)$ & Roche (Switzerland) & $\operatorname{Jan} / 2001$ & Sep/2001 \\
\hline $2 \mathrm{~A}$ & Efavirenz (Stocrin ${ }^{\oplus}$ ) & Merck \& Co. (USA) & $\mathrm{Jul} / 2003$ & Nov/2003 \\
\hline $2 B$ & Nelfinavir $\left(\right.$ Viracept $\left.^{\oplus}\right)$ & Roche (Switzerland) & $\mathrm{Jul} / 2003$ & Jan/2004 \\
\hline $2 C$ & $\begin{array}{l}\text { Lopinavir/Ritonavir } \\
\text { (Kaletra }^{\oplus} \text { ) }\end{array}$ & $\begin{array}{l}\text { Abbot Laboratories } \\
\text { (USA) }\end{array}$ & $\mathrm{Jul} / 2003$ & Jan/2004 \\
\hline $3 A$ & $\begin{array}{l}\text { Lopinavir/Ritonavir } \\
\left.\text { (Kaletra }{ }^{\oplus}\right)\end{array}$ & $\begin{array}{l}\text { Abbot Laboratories } \\
\text { (USA) }\end{array}$ & Mar/2005 & Oct/2005 \\
\hline $3 B$ & Efavirenz (Stocrin ${ }^{\oplus}$ ) & Merck \& Co. (USA) & Mar/2005 & Mar/2006 \\
\hline $3 C$ & Tenofovir $\left(\right.$ Viread $\left.^{\oplus}\right)$ & Gilead Sciences (USA) & Mar/2005 & May/2006 \\
\hline 4 & Atazanavir (Reyataz $\left.{ }^{\oplus}\right)$ & $\begin{array}{l}\text { Bristol-Myers Squibb } \\
\text { (USA) }\end{array}$ & Nov/2006 & $\mathrm{Dec} / 2006$ \\
\hline 5 & Efavirenz (Stocrin ${ }^{\oplus}$ ) & Merck \& Co. (USA) & Nov/2006 & May/2007 \\
\hline 6 & Tenofovir $\left(\right.$ Viread $\left.^{\oplus}\right)$ & Gilead Sciences (USA) & Apr/2008 & Jul/2007 \\
\hline 7 & Tenofovir $\left(\right.$ Viread $\left.^{\oplus}\right)$ & Gilead Sciences (USA) & Aug/2008 & $\mathrm{Dec} / 2008$ \\
\hline $8 \mathrm{~A}$ & Raltegravir (Isentress ${ }^{\circledR}$ ) & Merck \& Co. (USA) & Sep/2010 & Apr/2011 \\
\hline $8 B$ & Atazanavir $\left(\right.$ Reyataz $\left.^{\circledast}\right)$ & $\begin{array}{l}\text { Bristol-Myers Squibb } \\
\text { (USA) }\end{array}$ & Sep/2010 & Apr/2011 \\
\hline
\end{tabular}

The second step consists of a historical reconstruction of price negotiations. We try to identify the nature of the threat made by $\mathrm{MoH}$, the actors involved, the initial price of the drug, the outcome of the negotiation (i.e. discount, compulsory licensing, voluntary license, status quo), and the magnitude of the price change.

Several types of data, including primary and secondary sources, are used in the construction of this case study. Secondary sources of data include:

- Web portal of the STD, AIDS and Viral Hepatitis Department at MoH of Brazil. Available at: http://www.aids.gov.br/

- Official Gazette of the Federal Government of Brazil (Diário Oficial da União, in Portuguese). Available at: http://portal.in.gov.br/ 
- $\mathrm{MoH}$ of Brazil: administrative documents, proposals, progress reports, and other internal records, available at http://portalsaude.saude.gov.br/

- Newspaper clippings and other articles appearing in the mass media

When secondary sources do not provide sufficient or clear information for the historical reconstruction of the price negotiations, then we use data from primary sources, such as:

- Personal communication (via e-mail) with personnel of both STD/AIDS Department and Department of Science, Technology and Strategic Resources at $\mathrm{MoH}$

- Data requested via the 'Portal for Access to Public Information' (Portal de Acesso à Informação, in Portuguese ${ }^{19}$, available at http://www.acessoainformacao.gov.br/

\subsection{Historical reconstruction of price negotiations of ARV therapies in Brazil (2001 -2011)}

In early 2001, the first episode of price negotiation of ARV drugs in a context involving the possibility of granting compulsory license in Brazil took place. At that time, Nelfinavir and Efavirenz were the only two patented drugs supplied by the Universal Access Programme and they represented about 36 per cent of the MoH's expenditure on antiretrovirals. Then, the $\mathrm{MoH}$ publicly threatened to issue compulsory licenses for these two drugs, which are part of the universal anti-AIDS/HIV access program, unless the patent holder agreed to reduce their prices substantially (Galvão, 2002). After this first experience, compulsory license threat became a common feature of the negotiation strategy of $\mathrm{MoH}$ to reduce prices and/or obtain voluntary licenses of patented ARV drugs. This section describes fourteen negotiation episodes in which price reductions were tied to IPR matters.

\footnotetext{
19 This portal is part of the Access to Information Act (Lei de Acesso à Informação - Federal Law 12,527/2011). This law came into force in May 2012 and guarantees access to financial expenditures and contracts, as well as general data on programmes, actions, projects and other public works at the city, state, and national levels.
} 


\subsubsection{Episode 1A: Price negotiation between the $\mathrm{MoH}$ of Brazil and Merck \& Co. for the drug Efavirenz (Stocrin $\left.{ }^{\circ}\right)-2001$}

The MoH threatened the US-based pharmaceutical company Merck \& Co. that it would license its drug Efavirenz, marketed in Brazil under the brand name Stocrin ${ }^{\circ}$, to the state-owned laboratory Farmanguinhos. Efavirenz is a non-nucleoside reverse transcriptase inhibitor ${ }^{20}$ and, since 1999 , it is offered by the $\mathrm{MoH}$ as part of the antiretroviral therapy against HIV/AIDS. The patent for Efavirenz in Brazil (PI 1100250) was first claimed in 1997 and was automatically granted to Merck Sharp \& Dohme Corp. due to the 'pipeline' provision in the Brazilian IPR law.

In January 2001, Bill Clinton authorized a WTO Dispute Settlement Body against Brazil. Although this dispute concerned compulsory licenses in Brazil in case of lack of local manufacturing facilities (i.e. the 'local working' condition provided in Article 68 of the Brazilian intellectual property law), the USTR officials labelled this complaint as the "Merck case" as it was also a response to the threat made by the $\mathrm{MoH}$ of Brazil (Love, 2007). After enormous pressure from the international NGO community, which saw the US action could harm the Brazilian successful AIDS program, the two countries announced the withdrawal of the US challenge ('t Hoen, 2009; Wade, 2003).

To strengthen their position in the negotiation with Merck, the MoH authorized Farmanguinhos to develop, on a pilot scale, the production technology of Efavirenz, importing a small amount from Indian generic drug suppliers. Although this strategy, commonly known as 'Bolar' provision, respects both TRIPS and the Brazilian IPR Law (see section 3.6 in Chapter 3), it elicited a strong reaction and USA threatened Brazil using its 'Special 301 Report' to impose trade sanctions against Brazilian exports to the USA (Pinheiro, 2006). In March 2001, Farmanguinhos announced that it was carrying out experimental production of Efavirenz in order to 'figure out its costs' (Aith, 2001). After this research, Farmanguinhos announced that it could produce Efavirenz at a unitary price of US\$1.00 - 49 per cent less than Merck's price (Aith, 2001). There was no involvement of local private companies in this process.

\footnotetext{
20 There are two types of reverse transcriptase inhibitors (RTI): the nucleoside reverse transcriptase inhibitors (NRTIs) - e.g. zidovudine, didanosine, zalcitabine, stavudine, lamivudine, abacavir and emtricitabine - and the Non-nucleoside reverse transcriptase inhibitors (NNRTIs) - e.g. nevirapine, delavirdine, efavirenz, dapivirine, etravirine and rilpivirine (De Clercq, 2005).
} 
Just a couple of weeks after Farmanguinhos' announcement, on 29 March, Merck agreed on a price reduction and offered a 59 per cent discount for Efavirenz (US\$ 0,84 per $200 \mathrm{mg}$ capsule instead of $\$ 2.0$ ), as long as the Brazilian government did not issue compulsory licenses for generic production (Cohen \& Lybecker, 2005; Grangeiro et al., 2006).

\subsubsection{Episode 1B: Price negotiation between the MoH of Brazil and F. Hoffmann-La Roche Ltd for the drug Nelfinavir (Viracept ${ }^{\circ}$ ) - 2001}

Nelfinavir (brand name Viracept ${ }^{\circ}$ ) belongs to the class of drugs known as protease inhibitors and was originally developed by Agouron Pharmaceuticals. The drug was licensed to the Swiss company Roche to manufacture and distribute the drug worldwide, barring North America, Canada and Japan. The patent for Nelfinavir in Brazil (PI 1100166) was first claimed in 1997 and was automatically granted to Agouron Pharmaceuticals, Inc. due to the 'pipeline' provision in the Brazilian IPR law.

Nelfinavir was incorporated into the Universal Access Programme in 1998 and caused an immediate increase in public expenditure due to its high cost (Grangeiro et al., 2006). In early 2001, the $\mathrm{MoH}$ started negotiating prices with Roche for the drug Nelfinavir, which accounted alone for US\$ 88 million, or $28 \%$ of the Brazilian expenses with antiretroviral drugs at that time (Mignone \& Madueño, 2001; Rich \& Petersen, 2001). After nine months of negotiation, Roche's best offer was a price reduction of $13 \%$. The $\mathrm{MoH}$ rejected such an offer, as the state-owned laboratory Farmanguinhos was able to provide the same drug for a price that was 40 per cent lower. Given Roche's lack of cooperation, in August 22, 2001, the Brazilian $\mathrm{MoH}$ announced that it had begun the process of issuing a compulsory license to produce Nelfinavir in Farmanguinhos, after stating that the negotiation had ended in deadlock (Rich, 2001).

In 2000, Farmanguinhos' chemists undertook laboratory scale development of the synthesis processes of Nelfinavir (Cassier \& Correa, 2003, 2008; Silva \& Miranda, 2001). The next step was to go over the bioequivalence and bioavailability tests, which are necessary for regulatory approval as a generic drug. According to Farmanguinhos' specialists, these tests take about three months, which means that the laboratory could have been ready to produce the drug by December 2001. Farmanguinhos had a document setting out its synthesis path for Nelfinavir and was able to establish cost-based reference prices (Cassier \& Correa, 2003; Orsi et al., 2003). This was an essential 
component of the $\mathrm{MoH}$ bargaining power during the price negotiations with Roche. The estimated production cost of the drug was US\$ 0.60, with the possibility of reducing to US\$ 0.50 after price negotiations with the Indian supplier of raw materials (Silva \& Miranda, 2001).

After the compulsory license announcement, Roche proposed a price reduction of 35 per cent, which the Brazilian $\mathrm{MoH}$ rejected. After this move, $\mathrm{MoH}$ signalled that it would call off the compulsory license if Roche makes a 'good offer', as in the following statement made by José Serra, the Health Minister at that time, to a local newspaper: 'If Roche comes now with a good offer, then there is no reason to not accept it. However, after Farmanguinhos has already started the production, then there will be no way back.' (Silva \& Miranda, 2001). Paulo Teixeira, the director of Brazil's AIDS program, has even declared what such a 'good offer' should be: 'By producing Nelfinavir here in Brazil we can reduce the price by 40 per cent, so Roche would have to offer at least that.' (Darlington, 2001).

Finally, in August 31, Roche reached an agreement with $\mathrm{MoH}$ to cut the price of Nelfinavir by 40 per cent (Rich, 2001). According to the $\mathrm{MoH}$, this agreement was more advantageous than the compulsory license because the final cost to the public health system would be between 5 per cent and 10 per cent greater due to the royalties that it would have to pay to Roche.

\subsubsection{Episodes 2A, 2B and 2C: Price negotiation between the $\mathrm{MoH}$ of Brazil and Merck \& Co. for the drug Efavirenz (Stocrin ${ }^{\circ}$ ), F. Hoffmann-La Roche Ltd for the drug Nelfinavir (Viracept ${ }^{\circ}$ ), and Abbott Laboratories for the drug Lopinavir/Ritonavir (Kaletra ${ }^{\circ}$ ) - 2003}

In the second half of 2003, the Brazilian $\mathrm{MoH}$ started another round of negotiation for the patented ARV drugs part of the anti-HIV/AIDS program. On 21 July 2003, the Health Minister created the 'Negotiation Group for Acquisition and Production of Antiretroviral Medicines' to start negotiations with Abbott, Merck and Roche, which were the suppliers of Lopinavir/Ritonavir, Efavirenz ${ }^{21}$, Nelfinavir, respectively. The objective of this Negotiation Group was to obtain price discounts for these drugs and

\footnotetext{
${ }^{21}$ At that time, the $\mathrm{MoH}$ had replaced the Efavirenz of $200 \mathrm{mg}$ concentration for a single-daily-pill of $600 \mathrm{mg}$ concentration. Merck Sharp \& Dohme applied for a patent for this new version in 1999 (PI 9908810). However, INPI overruled this patent claim in 2008 due to lack of inventive step.
} 
also establish the basis for voluntary license agreements to allow their local production in public sector-owned laboratories (Costa, 2003). At that time, these were the only three of the 14 drugs supplied under the Universal Access Programme protected by patents. They were responsible for more than 60 per cent of all the MoH's yearly expenditure with ARVs.

The first meeting of the Negotiation Group took place on 1 August 2003. Although the $\mathrm{MoH}$ demanded a 40 per cent discount on each of these three patented ARV drugs, only Abbot offered a marginal price reduction from US\$ 1.50 to US\$ 1.48 (1.3 per cent) (STD/AIDS Department, 2003a). None of the three pharmaceutical companies accepted the terms for a voluntary license agreement. During the meeting, the state-owned laboratory Farmanguinhos presented the production costs of the three drugs, in case Brazil issued compulsory license for them. At that time, a representative of Farmanguinhos claimed that the local production costs of Efavirenz, Nelfinavir and Lopinavir/Ritonavir were, respectively, US\$ 0.87 , US\$ 0.27 and US\$ 0.25 (STD/AIDS Department, 2003a). All the three companies argued that they would evaluate the possibility of reaching an agreement on lower prices after that meeting (STD/AIDS Department, 2003a).

During the second round of negotiations, on 12 August, Merck \& Co did not send any executive to the meeting and requested more time for the head office to evaluate the proposal. In this meeting, Abbott again offered the same 1.3 per cent price drop, while Roche claimed that no discount would be available in 2003 (STD/AIDS Department, 2003b). One week later, in the third meeting, Abbott made a new offer cutting the unitary price of Lopinavir+Ritonavir to US\$1.46, but $\mathrm{MoH}$ also considered this insufficient. Roche did not send any representative to this meeting, while Merck left the meeting claiming that it would evaluate a voluntary license agreement with Farmanguinhos (STD/AIDS Department, 2003c). The three companies would still have until 30 August 2003 to make further offers to the Ministry of Health.

By 30 August, Abbott made a new offer to reduce the price to US\$ 1.40 (6.7 per cent discount) and Roche offered a price cut of 5 per cent (Bacoccina, 2003). Among the three laboratories, Merck was the one that came closest to an agreement with the government. This company requested 60 days to submit a proposal for a voluntary license for Efavirenz (Bacoccina, 2003). In this case, the patentee was to transfer technical information necessary to produce the drug to Farmanguinhos and receive royalties from the MoH. 
Given the unsuccessful outcome of the negotiations, the $\mathrm{MoH}$ decided to extend the deadline for accepting further offers. Moreover, as discussed in Chapter 3, in September 2003, the Government of Brazil amended the regulation on compulsory license via the Public Decree no 4.830/2003. The main goal of this institutional change was to allow for imports of generic drugs and/or APIs from India or China until local laboratories were able to manufacture and supply the drugs to the $\mathrm{MoH}$. A group from the $\mathrm{MoH}$ was sent to India and China to visit local producers to evaluate the existing manufacturing facilities of the three drugs.

The Brazilian move aimed at improving its bargaining position in the ongoing price negotiations and led to strong reactions from pharmaceutical companies. For instance, Abbott said in a statement that it was 'extremely disappointed the Brazilian government has implemented legislation to permit the manufacture or importation of copied versions of Kaletra [Lopinavir/Ritonavir], a drug under patent protection in Brazil, and is concerned about potential patient safety implications.' (Clendenning, 2003)

Only on 18 November 2003, did the $\mathrm{MoH}$ reach an agreement for one of the drugs, when it was announced that Merck's 25 per cent price drop offer for the drug Efavirenz had been accepted (BBC News, 2003; STD/AIDS Department, 2003d). Abbot's best offer for Lopinavir was 11 per cent, while Roche was a 5 per cent discount (STD/AIDS Department, 2003e). On December 8, the Brazilian Health Minister publicly announced that the $\mathrm{MoH}$ was considering granting a compulsory license for the drug Nelfinavir in the coming days. According to him, 'Roche has been absolutely inflexible in the negotiation and not willing to reduce the price of Nelfinavir.' (STD/AIDS Department, 2003f)

Finally, in January 2004, the Brazilian $\mathrm{MoH}$ announced that it had reached an agreement with both Abbott and Roche. The former had reduced the price of Lopinavir by 13.3 per cent, while Roche reduced the price of Nelfinavir by 10 per cent (Grangeiro et al., 2006; STD/AIDS Department, 2004). It is worth noting that the price reductions were considerably more modest than the initial request. Even so, as pointed out by Bermudez, Oliveira, \& Esher (2004), the amendment on the regulation concerning compulsory license played an important role in this outcome. Although Farmanguinhos had already developed the manufacturing process of Efavirenz, Nelfinavir and Lopinavir at laboratory scale, it would not have been able to supply the drug in a short notice in case a compulsory license was granted. Thus, by creating alternative importing possibilities, the institutional change provided by the Public De- 
cree $\mathrm{n}^{\mathrm{O}} 4.830 / 2003$ was crucial to ensure the credibility of the compulsory license threat.

\subsubsection{Episodes 3A, 3B and 3C: Price negotiation between the $\mathrm{MoH}$ of Brazil and Abbott Laboratories for the drug Lopinavir/Ritonavir (Kaletra ${ }^{\circ}$ ), Merck \& Co. for the drug Efavirenz (Stocrin ${ }^{\circ}$ ) and Gilead Sciences Inc. for the drug Tenofovir (Viread $\left.{ }^{\circ}\right)$ - 2005}

In 2005, the costs of the universal access programme were increasing due to a larger number of patients and the growing need for second-line therapies, such as Tenofovir and Atazanavir (see Figure 3-1 and Figure 3-2, in Chapter 3). After approval by the President of Brazil and the $\mathrm{MoH}$, the national STD/AIDS Department started consultations with lawyers, public laboratories and local pharmaceutical companies in order to design a strategy for the voluntary or compulsory licenses aiming at local production of high burden ARV drugs (Possas, 2008). In February 2005, the STD/HIV Department sponsored a technical analysis of the exiting patents (granted and pending) of the ARVs Efavirenz, Nelfinavir, Lopinavir/Ritonavir, Tenofovir and Didanosine entericcoated (Macedo, 2005). ${ }^{22}$ The main recommendations after this technical examination were:

1. To negotiate with the patent holder for voluntary licenses which lead to improved access to ARVs in Brazil

2. To issue compulsory licenses for the patents which the previous negotiation have not been successful

3. To speed up the formation of public-private partnerships to make the local production of these drugs possible in the short term

Following this recommendation, on 14 March 2005, the MoH requested the voluntary license of Lopinavir /Ritonavir (Abbott), Efavirenz (Merck), and Tenofovir (Gilead). By that time these three imported patented drugs represented 63 per cent of the MoH's total expenditure on ARVs (Costa, 2005). The initial deadline for the companies was 4 April, but two months after the initial request, none of the companies had reached an agreement for either voluntary licensing or price reduction of their drugs. It is worth noting that Merck was negotiating the terms of a voluntary license for Efavi-

\footnotetext{
${ }^{22}$ Nonetheless, there was no patent claims for didanosine enteric-coated in the Brazilian IPR Office.
} 
renz to the state-owned laboratory Farmanguinhos since the agreement signed in November 2003.

Given the lack of progress in the negotiations, the debate about issuing compulsory licenses became more intense. Many policymakers as well as other players in the political process believed it would be a mistake to grant compulsory licensing for the three drugs at once, since the reactions from the USA Government and from the pharmaceutical industry would be too big to manage (Possas, 2008). Considering this issue, the Brazilian President and the Health Minister decided to focus on the compulsory license of the association Lopinavir/Ritonavir, which is marketed under the trademark Kaletra ${ }^{\circ}$ by US-based company Abbott Laboratories. Lopinavir/Ritonavir was the most important drug among those in the HAART offered by the universal access program. About 24,000 patients (14 per cent of the total) were taking Lopinavir/Ritonavir, which corresponded to about 30 per cent of all the MoH's expenses with ARV drugs in 2004.

\subsubsection{Episode 3A: Price negotiation between the MoH of Brazil and Ab- bott Laboratories for the drug Lopinavir/Ritonavir (Kaletra ${ }^{\circ}$ - 2005}

On 24 June 2005, Lopinavir/Ritonavir was deemed to be in the public interest by the Health Minister Humberto Costa, providing the legal basis for issuing a compulsory license. The government gave Abbott Laboratories 10 working days to either lower its prices or have a compulsory license issued. Ritonavir was not protected by patents in Brazil while the patent for Lopinavir in Brazil (PI 1100397) was first claimed in 1997 and was automatically granted to Abbott Laboratories Inc. due to the 'pipeline' provision in the Brazilian IPR law.

On 5 July 2005, Abbott offered a price reduction from US\$ 1.17 to US\$ 0.70 per capsule, but the $\mathrm{MoH}$ rejected it because Farmanguinhos could supply a generic version of the drug for US\$ 0.41 (STD/AIDS Department, 2005b). On 8 July, after a nine-hour-long meeting with Abbott's staff, Humberto Costa announced an agreement with Abbott. Under the agreement, Brazil's annual expenses for Lopinavir/Ritonavir would remain unchanged for the next six years, so the price of this drug would be dependent on the number of patients treated. Abbott also agreed to transfer its technology to Farmanguinhos, so it could begin producing a generic version of Lopinavir/Ritonavir when the company's patent expired in 2015. Finally, the agreement also guarantees that Brazilian AIDS patients will have access to a new heat-stable ver- 
sion of Lopinavir/Ritonavir once it gains approval in the United States. This agreement was the very last act of Humberto Costa as Health Minister of Brazil

Local and international organisations, including an official from WHO, opposed this agreement. Alexandre Grangeiro, a former Director of the STD/AIDS Department at the $\mathrm{MoH}$, strongly criticized this agreement and affirmed that it would be even harder to negotiate price reductions with Merck and Gilead after that (Grangeiro, 2005). Finally, on 12 July, the new Brazilian Health Minister, Saraiva Felipe, affirmed that no agreement had been signed with Abbott and that negotiations would continue.

The pressure for a compulsory license from the civil society as well as from international organisations was increasing in the meantime. On 11 August 2005, the National Health Council of Brazil - the top deliberating forum of the Brazilian national health system - approved a resolution recommending the compulsory licenses for Lopinavir produced by Abbott Laboratories. This document revealed that a public-private partnership would be implemented for local production after compulsory licensing the drug, as presented in Table 4-2. While the Council's action does not represent a governmental decision on compulsory licensing, it put further pressure on the $\mathrm{MoH}$ to issue compulsory licenses for Lopinavir/Ritonavir.

Table 4-2: Public-private partnership for local production of Lopinavir/Ritonavir (Episode 3A)

\begin{tabular}{lllll}
\multicolumn{2}{l}{ Synthesis of the API } & & \multicolumn{2}{l}{ Formulation of the ARV } \\
\cline { 1 - 1 } Organisation & $\begin{array}{l}\text { Time to large- } \\
\text { scale production }\end{array}$ & & Organisation & $\begin{array}{l}\text { Time to large- } \\
\text { scale production }\end{array}$ \\
\hline \hline $\begin{array}{l}\text { Cristália (pri- } \\
\text { vate) }\end{array}$ & 3 months & & $\begin{array}{l}\text { Cristália (private) } \\
\text { Farmanguinhos } \\
\text { (public) }\end{array}$ & $\begin{array}{l}6 \text { months, } \\
8 \text { months }\end{array}$ \\
\hline \hline
\end{tabular}

Source: Ministry of Health of Brazil (2005a)

On the other side of the fence, there was also an increasing pressure on the Brazilian Government to not have a compulsory license issued. For instance, Abbott decided to delay plans to invest US\$27 million in a manufacturing facility in Rio de Janeiro while the discussion on a compulsory license over Lopinavir/Ritonavir was unfinished. In addition, the U.S. Representative Mark Steven Kirk proposed to cancel trade preferences for US\$ 2 billion of Brazilian exports. This situation generated an internal conflict between those arguing for the compulsory license and those arguing for renegotiation with the pharmaceutical company amongst the different Ministries (Orsi et al., 2003) 
Finally, Saraiva Felipe, on 10 October 2005, announced a deal with Abbott. The company had agreed to drop the price for Lopinavir/Ritonavir from the current $\$ 1.17$ to $\$ 0.63$ per capsule, beginning in March 2006 (STD/AIDS Department, 2005a, 2005b). In the next meeting of the National Health Council, on 19 October, Saraiva Felipe distributed a Technical Note explaining why no compulsory license had been issued (Ministry of Health of Brazil, 2005b). He put forward several arguments on the political scene to justify his decision, notably the lack of technical capacity in national industry. Saraiva Felipe also claimed that, besides the successful agreement with Abbott, the negotiations with Gilead and Merck was still ongoing. The $\mathrm{MoH}$ has highlighted the risk of Farmanguinhos and Cristália (the laboratories that, respectively, would formulate the drug and manufacture the API) not meeting the regulatory approval on time and, therefore, their need to keep buying from Abbott (Ministry of Health of Brazil, 2005b). Felipe also affirmed that Abbott's offer was better than the best price offered by a generic manufacturer ${ }^{23}$, so he could not justify a compulsory license for imports and, in addition, at that time there was no generic version of Lopinavir+Ritonavir approved by the WHO prequalification programme ${ }^{24}$ (Ministry of Health of Brazil, 2005b).

Although providing short-term benefits - notably a reduction of 46 per cent in the unit price and the prompt introduction of a new, formulation (Meltrex) - the agreement also contained some abusive provisions. Orsi et al. (2003) summarized the main restrictive provisions of the agreement in three points

The Brazilian $\mathrm{MoH}$ committed itself not to issue compulsory licenses for Abbott's intellectual property until 2011. Such a provision is considered 'TRIPS Plus'.

The fixing of the price of both Lopinavir/Ritonavir and of its heat-stable version (brand name Meltrex ${ }^{\circ}$ ) for five years represents a considerable loss of opportunity, as the $\mathrm{MoH}$ of Brazil cannot benefit from natural price reduction trends over this period. The early introduction of the heat-stable formulation in the first stages of treatment as a substitute for the soft- capsule formulation. This will considerably burden the Minis-

\footnotetext{
23 The Indian company Cipla had offered US\$ 0.72 per capsule (Ministry of Health of Brazil, 2005b).

${ }^{24}$ A drug prequalified by WHO does not require regulatory approval by the Brazilian authorities. The first facility approved by WHO for generic versions of Lopinavir/Ritonavir was in February 2009 (the Mylan Laboratories' facility at Maharashtra, India).
} 
try of Health's budget over the mid to long term, as Meltrex ${ }^{\circledast}$ is twice the price of the current version of Stocrin ${ }^{\oplus}$.

Although letters threatening compulsory licensing were also sent in March 2005 to Merck and Gilead Sciences regarding their antiretrovirals Efavirenz and Tenofovir, respectively, the $\mathrm{MoH}$ only held discussions with Abbott from June onwards. After the negotiation with Abbott was concluded, the $\mathrm{MoH}$ turned its attention to pending negotiations with these two companies.

\subsubsection{Episode 3B: Price negotiation between the $\mathrm{MoH}$ of Brazil and Merck \& Co. for the drug Efavirenz (Stocrin ${ }^{\circ}$ ) - 2005 - 2006}

At that time, Merck was negotiating the terms of a voluntary license for Efavirenz to the state-owned laboratory Farmanguinhos since the agreement signed in the previous year. Given the lack of progress in the negotiations, the debate about issuing compulsory licenses became more intense. Merck's strategy was to further delay the voluntary license of Efavirenz and Farmanguinhos had refused to accept this agreement, claiming that the terms offered by the U.S. firm were too restrictive (Chequer, 2012).

In August 2005, the Brazilian National Health Council also recommended the compulsory licenses for Efavirenz and pointed out a model of public-private partnership for local production after compulsory licensing, as presented in Table 4-3.

Table 4-3: Public-private partnership for local production of Efavirenz (Episode 3B)

\begin{tabular}{lllll}
\multicolumn{2}{l}{ Synthesis of the API } & & \multicolumn{2}{l}{ Formulation of the ARV } \\
\cline { 1 - 1 } Organisation & $\begin{array}{l}\text { Time to large- } \\
\text { scale production }\end{array}$ & & Organisation & $\begin{array}{l}\text { Time to large- } \\
\text { scale production }\end{array}$ \\
\hline \hline $\begin{array}{l}\text { NORTEC (pri- } \\
\text { vate) }\end{array}$ & $\begin{array}{l}4 \text { months (process } \\
\text { in small scale al- } \\
\text { ready carried out) }\end{array}$ & & $\begin{array}{l}\text { LAFEPE (public) } \\
\text { Farmanguinhos } \\
\text { (public) }\end{array}$ & $\begin{array}{l}\text { More than } 6 \\
\text { months }\left(1^{\text {st }} \text { half of }\right. \\
2006) .\end{array}$ \\
\hline \hline
\end{tabular}

Source: Ministry of Health of Brazil (2005a)

In the United States, data exclusivity for the molecule had already expired, although key patents on the compound would not begin expiring before 2012. At the same time, the company was trying to obtain support among the economic ministries, especially, the Ministry of Development, Industry, and Trade (MoDIT), and the Ministry of Finance for a proposal to have Merck manufacture certain AIDS drugs locally but have 
them packaged by a state-owned lab. Only after promoting this proposal with the economic ministries would Merck officially negotiate with the $\mathrm{MoH}$ (Danilovich, 2005c).

The company decision to take a hard line, refusing to cooperate with the $\mathrm{MoH}$, was successful at that stage. In order to avoid a shortfall in the supply, in March 2006, the $\mathrm{MoH}$ and Merck signed a contract for the supply of 17.460 .000 pills of Efavirenz $(600 \mathrm{mg})$ until March 2007. At that time, MoH paid the unitary price of US\$ $1.59-$ the same price as of the last agreement (DOU, 2006). Thus, the status quo prevailed; even though the MoH's official position was that the negotiations were still ongoing.

\subsubsection{Episode 3C: Price negotiation between the MoH of Brazil and Gil- ead Sciences Inc. for the drug Tenofovir (Viread ${ }^{\circ}$ ) - 2005 - 2006}

Tenofovir, marketed by Gilead Sciences under the trade name Viread ${ }^{\circ}$, is a nucleoside reverse transcriptase inhibitor, which blocks a critical HIV enzyme. This prevents HIV from replicating and lowers the amount of HIV in the blood. It was first introduced in the Brazilian Universal Access Programme in 2003. Due to its clinical benefits ${ }^{25}$, the number of patients on Tenofovir-based first and second-line HAART regimens had increased sharply since then. In 2005, there were 12,500 being treated with Tenofovir in Brazil, an increase of 83 per cent from the previous year. In the same year, Tenofovir alone accounted for 21 per cent of the MoH's expenses with patented (or 17 per cent of total) ARV drugs. A patent for Tenofovir (PI 9811045) was claimed by Gilead Sciences on 27 July 1998 and it was still under analysis at that time. Thus, only a voluntary technology transfer would be possible until the final decision of the Brazilian Patent Office.

Gilead had made a first offer in May 2005, when the company tried to achieve a $\mathrm{MoH}$ targeted per capsule price, and promised a more reliable supply. In a conversation with John Danilovich, who at that time was the United States Ambassador to Brazil, Gilead's representatives affirmed that they were analysing how to move forward with the $\mathrm{MoH}$ after the negotiation with Abbott (Danilovich, 2005b).

\footnotetext{
${ }^{25}$ The main clinical advantages of Tenofovir includes its better tolerance, the fact that it is also active against hepatitis B, which makes it the treatment of choice for HIV/hepatitis B co-infected patients, it is more robust towards acquisition of resistance-associated mutations, and it can be used during pregnancy.
} 
In August 2005, the Brazilian National Health Council also recommended the compulsory licenses for Tenofovir and revealed that a public-private consortium could produce this drug in case of compulsory licensing, as presented in Table 4-4.

Table 4-4: Public-private partnership for local production of Tenofovir (Episode 3C)

Synthesis of the API

\begin{tabular}{ll}
\hline Organisation & $\begin{array}{l}\text { Time to large- } \\
\text { scale production }\end{array}$ \\
\hline
\end{tabular}

\begin{tabular}{l}
$\begin{array}{l}\text { Genvida } \\
\text { vate) }\end{array}$ \\
\hline
\end{tabular}

Formulation of the ARV

\begin{tabular}{ll}
\hline Organisation & $\begin{array}{l}\text { Time to large- } \\
\text { scale production }\end{array}$ \\
\hline $\begin{array}{l}\text { Farmanguinhos } \\
\text { (public) }\end{array}$ & 8 months \\
\hline
\end{tabular}
(public)

Source: Ministry of Health of Brazil (2005a)

Gilead's strategy was based on the possibility of convincing the $\mathrm{MoH}$ that its approach of providing a more affordable product would be better for $\mathrm{MoH}$ than local production through licensing. At the same time, Gilead's representatives were also presenting the company's offer to other ministries, such as MoDIT, Ministry of Foreign Affairs and Ministry of Finance on an effort to put pressure on the $\mathrm{MoH}$ (Danilovich, 2005b).

This strategy worked as, according to an executive of the company, 'pressure from the US Government and from Brazilian economic ministries was forcing the MoH to moderate its posture.' (Danilovich, 2005b). Finally, in May 2006 the MoH announced an agreement with Gilead on Tenofovir. The company agreed to cut the price from US\$ 7.68 to US\$ 3.80, and the new price would remain constant until 2009 (Nunn et al., 2009; STD/AIDS Department, 2006). However, as shown by Nunn et al. (2007), even after the negotiations, the US\$ 1,327 PPPY price of Tenofovir was higher than the US $\$ 1,186$ average middle-income country price reported to the WHO. Moreover, the same authors affirmed that Gilead's 50 per cent price reduction for Tenofovir in Brazil coincided with the launch of a low-cost generic version of Tenofovir by the Indian generic manufacturer Cipla.

\subsubsection{Episode 4: Price negotiation between the MoH of Brazil and Bris- tol-Myers Squibb for the drug Atazanavir (Reyataz ${ }^{\circ}$ ) 2006/2007}

Atazanavir is a once-daily antiretroviral drug of the protease inhibitor (PI) class. The American pharmaceutical company, Bristol Myers Squibb markets it under the trade name Reyataz. Atazanavir was the first once-daily dose PI and has fewer side effects (especially those regarding the impact on patient's amounts of cholesterol and other 
fatty substances in the blood) than other PIs. There are two patent claims for Atazanavir in Brazil. Patent PI 9701877 was first claimed in 1997 and granted in 2004, while patent PI 9814736 was claimed in 1998 and rejected in 2012 due to lack of inventive step.

Atazanavir was included in the Brazilian programme in 2004, after the $\mathrm{MoH}$ negotiated a price 76.4 per cent lower than the one in the United States. By the end of 2006, about 27,600 patients were being treated with Atazanavir by the Brazilian antiHIV/AIDS program, a 235 per cent increase if compared to 2004. Atazanavir was the most expensive drug in terms of total cost, representing more than one third of the total expenditures with ARVs or 42.2 per cent of the costs of patented ARVs.

Given the increasing number of patients under this drug, and the consequent impact on the budget for ARV acquisition, $\mathrm{MoH}$ asked Bristol Myers for a price reduction and raised to possibility of issuing a compulsory licensing (Beall \& Kuhn, 2012). In December 2006, they signed a new contract for 2007 with a 3 per cent reduction on the price of Atazanavir (DOU, 2006). Under the same agreement, the company agreed on a larger price reduction of 24 per cent for 2008 (STD/AIDS Department, 2007).

\subsubsection{Episode 5: Price negotiation between the $\mathrm{MoH}$ of Brazil and Merck \& Co. for the drug Efavirenz (Stocrin $\left.{ }^{\circ}\right)$}

In November 2006, the MoH of Brazil re-opened price negotiation with Merck \& Co. for Efavirenz, which was one of the most used medicines in the anti-retroviral therapy. About 68,000 patients ( 40 per cent of the total) were under Efavirenz treatment, a rise of 12 per cent as compared to 2004, when its price was reduced for the last time.

At the beginning of the negotiation, Merck offered a minimal discount of 1.25 per cent. After seven meetings with Merck, the company's best offer was a further reduction of 2 per cent (from US\$ 1.57 to US\$ 1.54 per tablet) while the MoH demanded a 60 per cent discount, so that Brazil could get the same price as Thailand (that is US\$ 0.65) (Penna \& Simão, 2007; Simão, 2007). Given Abbott's lack of cooperation, on 25 April, the $\mathrm{MoH}$ published the Decree no. 886/2007 declaring Efavirenz as a drug of public interest. This decree represented a first step towards a compulsory license, unless Merck offered a satisfactory price reduction within seven days. On 27 April, Merck offered a price reduction of 30 per cent (that is US\$ 1.11 per tablet) and a technology transfer agreement for local production by 2010 (two years before the patent expiration) (Penna \& Simão, 2007; Simão, 2007). However, the $\mathrm{MoH}$ of Brazil did not 
accept the offer, claiming that the price was still too high, as the price offered by Indian suppliers pre-qualified by WHO ranged from US\$ 0.44 to US\$ 0.46 . Moreover, according to the $\mathrm{MoH}$, the technology transfer proposal did not state clearly what would be the price in 2010 and that Farmanguinhos had already mastered the technology for local production, thus the agreement would not benefit the country (Guimarães \& Penna, 2007; Penna \& Simão, 2007; Simão, 2007).

Finally, on 4 May 2007, the Brazilian President signed the Decree No 6,108/2007 issuing a compulsory license for the drug Efavirenz. The drug was initially imported from Indian suppliers until local production was arranged. Three local private enterprises were responsible for the development and production of the API - Cristália, Nortec and Globe Química, while two state-owned laboratories were in charge of the formulation and packaging (LAFEPE and Farmanguinhos). After several delays, including the LAFEPE's inability to achieve bioequivalence for its generic version, local production of Efavirenz started only in 2009 at a unitary price of US\$ 0.60 (excluding royalties paid to Merck \& Co.) (Rodrigues \& Soler, 2009).

\subsubsection{Episode 6: Price negotiation between the MoH of Brazil and Gile- ad Sciences Inc. for the drug Tenofovir (Viread ${ }^{\circ}$ ) - 2008}

At the beginning of 2008, more than 31,000 patients were being treated with Tenofovir in the Brazilian public health system. On its own, this drug represented 10 per cent of all the public expenses with antiretroviral drugs and the $\mathrm{MoH}$ started a new price negotiation. However, $\mathrm{MoH}$ pursued a different strategy this time.

In January 2008, the United States and Trademark Office (USPTO) suspended four key patents on Tenofovir after a challenge was filed under the claim of lack of inventive step. ${ }^{26}$ In order to guarantee the supply of the drug during that year, $\mathrm{MoH}$ and Gilead signed a contract in February 2008 fixing a unitary price of US\$3.80 - that was the same price of the previous negotiation in 2006. However, in April 2008, the $\mathrm{MoH}$ of Brazil declared Tenofovir as a drug of public interest and requested prioritized examination for Gilead's patent claim PI 9811045. This step was necessary because a compulsory license can be issued only if the patent is granted. In addition, the possibility to have the patent rejected was a means of pressure in itself. As result, in July 2008, Gilead agreed to amend the existing contract, reducing the unitary price to US\$3.25

\footnotetext{
${ }^{26}$ Later in the same year, USPTO upheld all those patents.
} 
(DOU, 2008a, 2008b). This price cut represented a US\$ 8 million savings for the $\mathrm{MoH}$ of Brazil in that year.

\subsubsection{Episode 7: Price negotiation between the MoH of Brazil and Gile- ad Sciences Inc. for the drug Tenofovir (Viread ${ }^{\bullet}$ ) - 2008}

In August of the same year, the Brazilian Intellectual Property Office (INPI) rejected the patent for Tenofovir under the claim that the drug fails to meet the requirement for inventiveness. ${ }^{27}$ INPI has emphasized that the decision had been "purely technical. However, according to executives from Gilead, officials from INPI admitted that they were facing 'lots of pressure' from the $\mathrm{MoH}$ (Kubiske, 2009). Then, the $\mathrm{MoH}$ and Gilead started negotiating another price reduction for the next year. Reinaldo Guimarães, who at that time was Secretary of Science, Technology and Strategic Supplies at the $\mathrm{MoH}$, made a public statement that, after INPI's decision, MoH would definitively ask for a price 'much lower' than what was currently paid (Formenti, 2008). Finally, a new contract was signed on December fixing the unitary price at US\$2.54, a reduction of 22 per cent (DOU, 2008c).

\subsubsection{Episode 8A and 8B: Price negotiation between the MoH of Brazil and Merck \& Co. for the drug Raltegravir (Isentress), and Bristol- Myers Squibb for the drug Atazanavir (Reyataz ${ }^{\circ}$ )}

In 2008, the Government of Brazil and, more specifically, the $\mathrm{MoH}$, started the consolidation of an institutional framework to support technological capacity building in health-related industries, which were defined as the 'Health Industrial Complex'. ${ }^{28}$ This initiative was part of the Productive Development Policy (Politica de Desenvolvimento Produtivo, in Portuguese), which was the Brazilian Industrial Policy for the triennium 2008-2010. The main components of this institutional framework were:

- Publication of a list of drugs and other products deemed as strategic for the public health system. These drugs would be subject to incentives and other measures from the $\mathrm{MoH}$ towards technology transfer, technological innova-

\footnotetext{
${ }^{27}$ The molecule and its respective antiviral activity are known since 1985.

${ }^{28}$ The pharmaceutical industry has been a priority sector since the launch of the Industrial, Technological and Foreign Trade Policy (Política Industrial, Tecnológica e de Comércio Exterior - PITCE, acronym in Portuguese) in March 2004. The main objective of PITCE was to boost the innovative and export capacity of local firms.
} 
tion and local production aiming to strengthening the Brazilian Health Industrial Complex. ${ }^{29}$

- Introduction of new guidelines for public procurement of medicines and APIs to satisfy the demand of the public health system. Among other changes, it introduced the right of the $\mathrm{MoH}$ to place local manufacturing as a necessary condition for companies to participate in public bidding. ${ }^{30}$

- It was established that the public procurement of patented medicines that are not produced in Brazil could only occur when the federal health authority deems it as being indispensable and demonstrates a justifiable impediment to its production in the country. Otherwise, the Brazilian Government may issue a compulsory license based on the non-exploitation of the object of the patent within the Brazilian territory. ${ }^{31}$

- Introduction of preference to locally manufactured APIs in the state-owned laboratories' procurement of raw materials. ${ }^{32}$

This institutional framework paved the way for the launch, in April 2009, of 11 public-private partnerships for local production of strategic drugs - including their APIs. ${ }^{33}$ These partnerships would be formed between both domestic and foreign manufacturers and state-owned laboratories to locally produce and supply the public health system. In these arrangements, the private company assumes the manufacture of the APIs and supplies them to the public partner, a state-owned laboratory that will formulate the drug. Moreover, private laboratories have to transfer the technology for the production of the drug to public laboratories within five years, while the $\mathrm{MoH}$ guarantees the exclusivity in government purchases of the drug during this period.

This exclusivity in practice means that partners have guaranteed a viable market if the local production of the medicine is successfully developed, as long as (1) the unitary

\footnotetext{
${ }^{29}$ Ordinance no 978 of the Ministry of Health, of 16 May 2008.

${ }^{30}$ Interministerial Ordinance no 128 , of May 29, 2008.

${ }^{31}$ As discussed in Chapter 3 (Section 3.6), Article 38 of the Brazilian IPR law provides for compulsory licensing in case of lack of 'local working' of the invention.

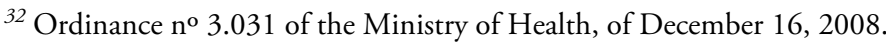

${ }^{33}$ The partnerships to produce strategic drugs are established by Law 10,973/04, known as the Brazilian Innovation Act. This Act allows the Government to contract with private parties in order to create alternative sources for the supply of certain goods, according to the public interest. In addition, the model of public-private partnership to supply key ARVs was under consideration since 2005 (see Episode 3A, 3B and 3C).
} 
price in the first year of the contract must be lower than the unitary price from the previous public tender and (2) this price must reduce gradually during the five years agreement at a minimum rate of 5 per cent a year.

\subsubsection{Episode 8A: Price negotiation between the $\mathrm{MoH}$ of Brazil and Merck \& Co. for the drug Raltegravir (Isentress ${ }^{\circ}$ )}

Raltegravir (brand name Isentress ${ }^{\circ}$ ) was the first in a novel class of antiretroviral drugs known as integrase inhibitors and was approved by the US Food and Drug Administration (FDA) on October 16, 2007 (Temesgen \& Siraj, 2008). Since 2009, Raltegravir was distributed in Brazil as part of the third-line regimen to patients who have developed resistance to other drugs.

In 2009, about 1,000 patients were treated with Raltegravir at a yearly cost of US\$ 6,944. By that time, Merck was selling the same drug for US\$ 1,113 PPPY to lowincome countries. In Brazil, the government started an HIV treatment programme much earlier than the rest of the developing world. As a result, the cohort of people developing resistance and in need of newer medicines is much larger than other countries. For those people already failing on their second-line combination, this unaffordable price can impose a significant barrier to access. Therefore, such a high price for a single drug raised considerable concerns on the economic sustainability of the universal access programme in a context of an increasing number of patients requiring third-line regimens.

In September 2010, the MoH of Brazil announced that an agreement for technology transfer to a public-private consortium was under negotiation with Merck \& Co for the local production of Raltegravir. Although the strategy of seeking voluntary licenses was not new, at this time the $\mathrm{MoH}$ did not make an explicit compulsory license threat for this drug. As mentioned earlier in this section, the institutional framework underlying these public-private partnerships, however, formally provides that compulsory licenses can be issued if the drug deemed as strategic - as Raltegravir - is not manufactured in Brazil.

This licensing agreement would be a public-private partnership where Merck \& Co. would transfer the technology necessary for the production of the API to a local private company (Nortec) and the formulation process to a state-owned laboratory (LAFEPE). After five years, these two organisations would be able to produce and distribute the 
drug to $\mathrm{MoH}$, paying undisclosed royalties to Merck \& Co. until 2019, when the relevant patents expire.

The public-private partnership was formally announced in April 2011. At that time, the $\mathrm{MoH}$ was paying the equivalent of US\$ 5,869 PPY and there was an ongoing price negotiation with Merck \& Co. (GTPI, 2011). In the nine-month contract signed in July 2011, the unitary price of Raltegravir dropped 6.34 per cent, from US\$ 8.04 to US\$ 7.53 (DOU, 2010a, 2011; C.J.B. Batista, personal communication, June 15, 2014). After that, the price for Raltegravir was further reduced three times and the $\mathrm{MoH}$ paid US\$ 6.39 per tablet (that is 4,665 PPY) in its latest purchase in May 2014 (DOU, 2014; C.J.B. Batista, personal communication, June 15, 2014). By the end of the technological transfer process, the $\mathrm{MoH}$ should be able to buy this drug for US\$ 4,000 PPPY (GTPI, 2011), which is aligned with the mandatory yearly discount of at least 5 per cent in this kind of partnership.

\subsubsection{Episode 8B: Price negotiation between the $\mathrm{MoH}$ of Brazil and Bristol-Myers Squibb for the drug Atazanavir (Reyataz ${ }^{\bullet}$ )}

The price negotiation for Atazanavir started in November 2010 but it was suspended because the Science and Technology Secretariat at the MoH was negotiating a technology transfer agreement with Bristol Myers Squibb (GTPI, 2011). Although the agreement was deemed as finalized by December 2010 and formally announced in April 2011, both parties signed the contract only in November 2011 (GTPI, 2013).

In practice, this agreement is a voluntary license in which the patent holder will transfer the technology for API production to Nortec (a local private laboratory) and the technology for formulation to Farmanguinhos. The process of technology transfer started in 2013; it includes the training of personnel, the acquisition of equipment, the manufacturing and distribution of Atazanavir sulfate $200 \mathrm{mg}$ and $300 \mathrm{mg}$ capsules. The local production of Atazanavir is expected to start in 2015, when Farmanguinhos should supply up to 50 per cent of the MoH's demand. By 2017, when the Atazanavir patent expires, Farmanguinhos is expected to be the sole supplier of Atazanavir in Brazil.

After the announcement of the technological transfer agreement, BMS reduced the price of Atazanavir by 6.6 per cent and 21.8 per cent for the formulations with $200 \mathrm{mg}$ and $300 \mathrm{mg}$, respectively (DOU, 2010b; C.J.B. Batista, personal communication, June $15,2014)$. In the first purchase after the signature of the contract, in 2012, the $\mathrm{MoH}$ 
got a discount of 7.6 per cent (price dropped from US\$1.85 to 1.71 per capsule) for the $200 \mathrm{mg}$ concentration. However, the price for the $300 \mathrm{mg}$ was kept at US\$2.80 per capsule, the same of the previous acquisition (DOU, 2012; C.J.B. Batista, personal communication, June 15, 2014). In 2013, the prices for Atazanavir dropped 5.7 per cent and 5 per cent for the $200 \mathrm{mg}$ and $300 \mathrm{mg}$ concentrations, respectively (DOU, 2013; C.J.B. Batista, personal communication, June 15, 2014).

\subsection{Discussion}

This chapter retraced the events surrounding 14 episodes of negotiation between the Brazilian Government and foreign pharmaceutical companies for six different drugs. The case studies provided vivid examples of the critical role of manufacturing capacity on credible threats of compulsory license, as well as the political and economic pressure exerted on countries that choose to pursue this strategy acknowledged in the existing literature.

Indeed, the case studies confirmed that issuing a compulsory license entails negative side effects that may impair the local economy and that the $\mathrm{MoH}$ does take this into account when it negotiates prices. Concerns about these effects were strongly observed in Episodes 3A, 3B and 3C. In these episodes, which both the Ministry of Development, Industry, and Trade and the US Government were actively mobilized by pharmaceutical MNEs to put pressure on $\mathrm{MoH}$ against compulsory licensing.

Although formal bilateral trade sanctions are not allowed under WTO's framework, ${ }^{34}$ these negative side effects are institutionalized as rules of the game and can assume more subtle forms, such as the loss of preferable trade partners or the business sector regarding the country as having a weak patent system that endangers innovation. As discussed earlier, different ministries have different interests and respond to different stakeholders. In Brazil, the MoDIT is in charge of the country's Innovation Policy and it sees a compulsory license as a damage to the 'innovation-friendly' environment that this policy intends to foster. Moreover, MoDIT is under pressure from other economic sectors that believe that compulsory license may cause loss of exports and/or foreign investments. This enables us to understand why the $\mathrm{MoH}$ was keen to accept price reductions instead of issuing compulsory licenses.

\footnotetext{
34 WTO requires that member countries use its multilateral system of settling disputes instead of taking action unilaterally (Abbott \& Reichman, 2007; Monten, 2005; Weissman, 1996)
} 
The Government can also change the rules of the game to improve access outcomes. For instance, the outcome of the episodes $2 \mathrm{~A}, 2 \mathrm{~B}$, and $2 \mathrm{C}$ were directly affected by the institutional change provided by the Public Decree no 4.830/2003. This Public Decree created alternative importing possibilities by allowing parallel imports of the goods from third parties. As there was no sufficient technological capacity to start local production immediately, this change was crucial to enforce the credibility of the compulsory license threat.

In addition, episodes $8 \mathrm{~A}$ and $8 \mathrm{~B}$ were a result of a set of institutional changes implemented by the $\mathrm{MoH}$ to make voluntary license agreements a more attractive alternative to pharmaceutical companies. The $\mathrm{MoH}$ created a legal framework to incentivise local production of 'strategic drugs'. It is worth noting that such a framework explicitly provided for the compulsory license of patented drugs that are not manufactured locally.

Voluntary license agreements for technology transfer, such as observed in episodes 8A and $8 \mathrm{~B}$, can be a win-win solution. The country can benefit from more affordable locally manufactured drugs without bearing the costs associated with a compulsory license. On the other hand, the patent holder can implement more favourable conditions, as for instance the level of royalties, to minimize the market loss. However, such conditions cannot be abusive; otherwise, such voluntary licenses may not improve access to the drug. Although the $\mathrm{MoH}$ officially affirms that this is not the case, confidential terms and unclear contractual arrangements raise doubts whether or not those voluntary licenses are abusive.

It is worth noting that governments may not need to resort to compulsory license if they apply stricter standards in examining patent applications, as observed in episodes 6 and 7. Undeserved patents and unsound IP policy, including implementation of TRIPS Plus provisions, can be detrimental to access to lifesaving medicines. Therefore, governments should define and enforce clear guidelines on what does and does not deserve a patent. 


\section{Chapter 5 When to push for a compulsory license? An Integrative Framework derived from the Bra- zilian experience with ARV drugs}

\subsection{Introduction}

Game theory, with its roots in philosophy, economics and mathematics, is being increasingly applied in a variety of fields. The purpose of game theory is to aid in forecasting the actions that rational individuals or groups (i.e. players) would take to secure the best outcomes for themselves in interdependent strategic interactions. Game theory has been applied in public health policy as for instance, to examine donor kidney sharing (O’Brien, 1988; Roth, Sönmez, \& Ünver, 2004); to analyse the effectiveness of self-regulation on reducing passive smoking in restaurants (Shiell \& Chapman, 2000) and to understand the limitations of voluntary vaccination policies (Bhattacharyya \& Bauch, 2010; Cojocaru, 2008).

In games, individuals make separate, but interactive decisions. This means that the outcome is not just dependent on the strategy chosen by one player, but also on what the opponent does. In real life negotiations, agents usually are not sure about what the other is going to do and they may have contradicting incentives to cooperate or confront. This setting serves to describe many contexts including that of government strategies to improve access to medicines. Therefore, game theory forms the natural framework for the study of drug price negotiations between firms and public agencies.

Theory has three main ends: to lend insight on phenomena, to facilitate predictions and to provide aids for decision-making. Similarly, the use of game theory in this research has three main purposes. First, as an explanatory tool to describe and model how the relevant actors behave in a different set of initial conditions and underlying contexts. In this sense, it can be used as a lens through which to view and learn from episodes of price negotiations and provide causal explanation of the observed negotiations outcomes. Second, as a predictive tool of how the relevant actors will behave when further confronted with situations analogous to the context of price negotiations being analysed in this research. Obviously, the predictive power of a model have many caveats, especially because assumptions and simplifications are intrinsic to modelling much more complex aspects of the real world. Nonetheless, the analysis of how the observed outcomes deviate from the model provides valuable insights to future action. Third, as a prescriptive and normative tool 
not only for the actors directly involved with price negotiations of lifesaving drugs, but also for policy makers and other stakeholders.

Besides this introduction, the chapter is organised as follows. In Section 5.2, we use insights from the game theoretic approach to define the playing field, that is, the relevant actors, their roles and possible actions available to both the $\mathrm{MoH}$ and the pharmaceutical MNE. In Section 5.3, we develop an integrative framework of price negotiations between an Emerging country public agency and an innovating foreign MNE. To illustrate the integrative framework, in Section 5.4 we discuss the episodes of price negotiation between $\mathrm{MoH}$ and Merck \& Co. (i.e. Episodes 1A, 2A, 3B and 5) and derive insights for a more general application using game theory.

\subsection{Defining the playing field}

Drug price negotiations are triggered whenever the price is very high vis-à-vis the capacity to pay of the patient. Although Brazil is commonly classified as an upper-middle income country, the annual cost of treatment for a single drug surpassed the local GDP per capita in some cases (see Error! Reference source not found.). For instance, in 2001, the annual cost Nelfinavir was equivalent to 1.25 times the Brazilian GDP per capita in the same year. Therefore, the MoH's price negotiation strategy was based on contesting the fairness of the price charged by MNEs.

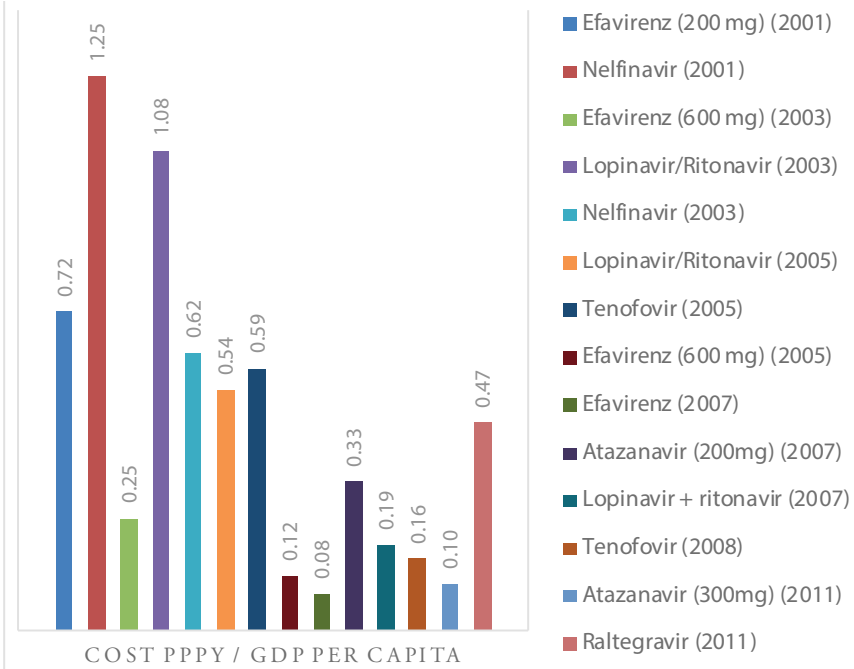

Figure 5-1. Cost per patient per year (PPPY) of selected ARV drugs as ratio of the GDP per capita in Brazil 
Thus, the initial condition for a drug price negotiation is a high drug price to GDP per capita ratio.

Chapter 3 and Chapter 4 identified the main actors involved - directly and indirectly in the MoH's attempts to negotiate the price of ARV drugs. Furthermore, both the $\mathrm{MoH}$ and MNEs establish interactions with other strategic actors in order to secure the best outcome. We refer to this set of actors as the 'Brazilian ecosystem of price negotiations (see Figure 5-2).

\section{Government of}

MNEs' home

country

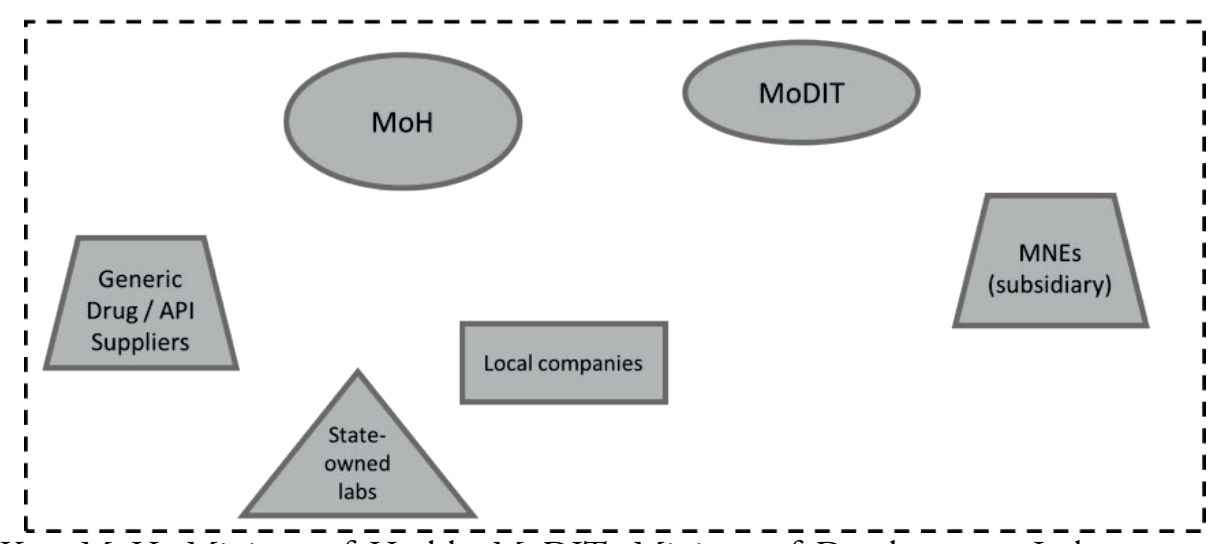

Key: MoH: Ministry of Health; MoDIT: Ministry of Development, Industry, and Trade; MNE: Multinational Enterprise.

Figure 5-2: Brazilian ecosystem of price negotiation

The actors and their respective roles are described in Table 5-1. 
Table 5-1: Actors in the Brazilian Eco-system of price negotiation and their respective roles

\begin{tabular}{|c|c|}
\hline Actor & Role \\
\hline $\mathrm{MoH}$ & $\begin{array}{l}\text { Responsible for buying and supplying ARVs to all people living with } \\
\text { HIV/AIDS in Brazil. The MoH has to negotiate the price of drugs not manufac- } \\
\text { tured by state-owned laboratories to ensure the financial sustainability of the } \\
\text { Universal Access Program. }\end{array}$ \\
\hline MoDIT & $\begin{array}{l}\text { Responsible for the Industrial Policy and for maintaining an innovation- } \\
\text { friendly environment and the trade balance under control. The MoDIT may } \\
\text { exert pressure on the MoH against compulsory license. }\end{array}$ \\
\hline MNES & $\begin{array}{l}\text { Pharmaceutical MNEs supply patented ARVs to the MoH. Once they face } \\
\text { compulsory licenses threats, they may also threaten the host country with } \\
\text { market withdrawal or market retaliation. }\end{array}$ \\
\hline Public Labs & $\begin{array}{l}\text { Responsible for supplying off-patented ARVs to } \mathrm{MoH} \text {. Farmanguinhos has an } \\
\text { important role in the creation of technological capacity via 'reverse engineer- } \\
\text { ing' for product and process development. }\end{array}$ \\
\hline $\begin{array}{l}\text { International } \\
\text { Generic Drug } \\
\text { Suppliers }\end{array}$ & $\begin{array}{l}\text { Companies based in countries that take full advantage of the transitional } \\
\text { period exiting in the TRIPS agreement, notably India. These companies can } \\
\text { manufacture and export generic version of the drug to a country where a } \\
\text { compulsory license is granted. Furthermore, these companies supply most of } \\
\text { the API necessary to formulate off-patented drugs supplied by public labs in } \\
\text { Brazil. }\end{array}$ \\
\hline $\begin{array}{l}\text { Local Compa- } \\
\text { nies }\end{array}$ & $\begin{array}{l}\text { As the public labs do not manufacture APIs, local private companies have to } \\
\text { produce these inputs in case of compulsory licensing. }\end{array}$ \\
\hline $\begin{array}{l}\text { Government of } \\
\text { MNE's host } \\
\text { country }\end{array}$ & $\begin{array}{l}\text { Once the MoH threaten to issue compulsory licenses, patent holders can also } \\
\text { create a strong lobby with their home country's government in order to put } \\
\text { pressure on the developing country, especially in terms of trade retaliation, } \\
\text { withdraw of preferable trade partner status, or regard the country as of weak } \\
\text { patent system and that endangers innovation to affray foreign investors. }\end{array}$ \\
\hline
\end{tabular}

Key: MoH: Ministry of Health; MoDIT: Ministry of Development, Industry, and Trade; MNE: Multinational Enterprise.

MNEs usually differentiate prices of their ARV drugs, like other drugs, taking into account the country's income level and the disease incidence. Nevertheless, MNEs are in a position where they can charge prices that could be considered abusive due to the monopoly conferred by the patent protection of their drugs. Thus, any price negotiation by Brazilian MoH's is a challenge to the MNEs' pricing strategies. Furthermore, as we noted in Chapters 3 and 4, a threat to issue compulsory license for patented ARV drugs is a central component of the MoH's negotiation strategy. However, if we apply the reasoning of game theory, then it is clear that $\mathrm{MoH}$ must secure that it is better off by making a compulsory license threat than being a silent spectator of the patent holder's monopoly. In short, $\mathrm{MoH}$ can make a compulsory license threat if the quantity $\mathrm{MoH}$ can purchase is greater than otherwise.

Once a compulsory license threat is observed, the pharmaceutical MNE has two strategic options: 
The organisation can reduce the price of its drug and, by doing so, adapt its strategy to conform to the definition of 'fair price' established by the $\mathrm{MoH}$.

The organisation does not reduce (significantly) the price of its drug and attempts to convince the other actors, notably the $\mathrm{MoH}$, that the current price is indeed fair due to all the $R \& D$ costs necessary to bring it to the market. This strategy involves mobilization of other strategic actors in order to put pressure on the $\mathrm{MoH}$. If the organisation chooses this option, then it runs the risk of losing the market if $\mathrm{MoH}$ issues a compulsory license for its drug.

Thus, the Pharmaceutical MNE's best response is to agree on a price reduction if the threat is credible and reinforce the status quo otherwise.

\subsection{Determinants of price negotiation outcomes}

The episodes described in Chapter 4 showed that even in the same ecosystem, there could be different outcomes for price negotiations for the same disease. This is summarized in Table 5-2, showing that in 12 out of 14 price negotiation attempts, the $\mathrm{MoH}$ of Brazil was able to get a price discount. However, the magnitude of the discounts varied widely and, in two of these attempts, the discount was tied to a voluntary license agreement. In the remaining two episodes, no agreement was reached and the status quo prevailed in one, while a compulsory license was issued in the other.

Table 5-2. Price negotiations and their respective outcomes

\begin{tabular}{|c|c|c|c|c|c|c|}
\hline & Drug & & MNE & Year & Outcome & $\Delta$ Price \\
\hline $1 \mathrm{~A}$ & Efavirenz & & "Merck \& Co. (USA) & 2001 & Discount & $-59 \%$ \\
\hline 1B & Nelfinavir & & Roche (Switzerland) & 2001 & Discount & $-41 \%$ \\
\hline $2 \mathrm{~A}$ & Efavirenz & & Merck \& Co. (USA) & 2003 & Discount & $-24 \%$ \\
\hline $2 B$ & $\begin{array}{l}\text { Lopinavir } \\
\text { Ritonavir }\end{array}$ & + & Abbot Labs (USA) & 2003 & Discount & $-13 \%$ \\
\hline $2 C$ & Nelfinavir & & Roche (Switzerland) & 2003 & Discount & $-10 \%$ \\
\hline $3 A$ & $\begin{array}{l}\text { Lopinavir } \\
\text { Ritonavir }\end{array}$ & + & Abbot Labs (USA) & 2005 & Discount & $-46 \%$ \\
\hline 3B & Efavirenz & & Merck \& Co. (USA) & 2005 & Status Quo & $0 \%$ \\
\hline $3 C$ & Tenofovir & & Gilead (USA) & 2005 & Discount & $-51 \%$ \\
\hline 4 & Atazanavir & & BMS (USA) & 2006 & Discount & $-7 \%$ \\
\hline 5 & Efavirenz & & Merck \& Co. (USA) & 2006 & $\mathrm{CL}$ & $-62 \%$ \\
\hline 6 & Tenofovir & & Gilead (USA) & 2008 & Discount & $-14 \%$ \\
\hline 7 & Tenofovir & & Gilead (USA) & 2008 & Discount & $-22 \%$ \\
\hline $8 \mathrm{~A}$ & Atazanavir & & Merck \& Co. (USA) & 2010 & VL / Discount & $-8 \%$ \\
\hline $8 \mathrm{~B}$ & Raltegravir & & BMS (USA) & 2010 & VL / Discount & $-28 \%$ \\
\hline
\end{tabular}

Key: $C L=$ Compulsory License,$V L=$ Voluntary License 
On the one hand, the ultimate determinant of $\mathrm{MoH}$ ' bargaining power is the access to alternative suppliers. International generic suppliers are important drivers of bargaining strength if they can supply the concerned drug immediately after a compulsory license being issued. This means that the concerned drug is already part of their product portfolio. However, even when a generic version of the drug is available for imports, two factors limit the role of international generic suppliers. First, there may be concerns about the quality of the product if the same has not being certified by international organisations (such as the WHO prequalification programme) or approved by regulatory agencies from developed countries (such as the Food and Drug Administration, in the United States, or the European Medicines Agency). Second, in Brazil, parallel imports can only be applied in situations in which imports are necessary to implement a compulsory license and such imports are limited to 12 months (Cohen \& Lybecker, 2005; Pinheiro, 2012). Therefore, local technology capacity is also critical and the $\mathrm{MoH}$ has to mobilize local actors - that is, state-owned laboratories and/or private companies - to manufacture the drug, including the APIs. Moreover, local production has not only to be able to produce at low cost but also to meet national regulatory standards of safety and efficacy.

On the other hand, MNEs may respond to a compulsory license threat with market withdrawal of their products or market retaliation, such as reducing investments in manufacturing and/or R\&D. In addition, compulsory licenses may provoke pharmaceutical companies and other industries dependent upon IPR to avoid ventures in that nation and seek a more business-friendly legal climate elsewhere, impacting negatively the flows of foreign direct investment, trade and innovation in the concerned developing country. Therefore, MNEs seek for support from home government and other ministries (notably those that want to avoid the negative impacts on the economic and industrial environment) to deter $\mathrm{MoH}$ from issuing a compulsory license.

Based on the descriptive case studies of the previous section, we summarize the actions taken by the actors in each episode of price negotiation for ARV drugs in Brazil. The results are presented in Table 5-3. 


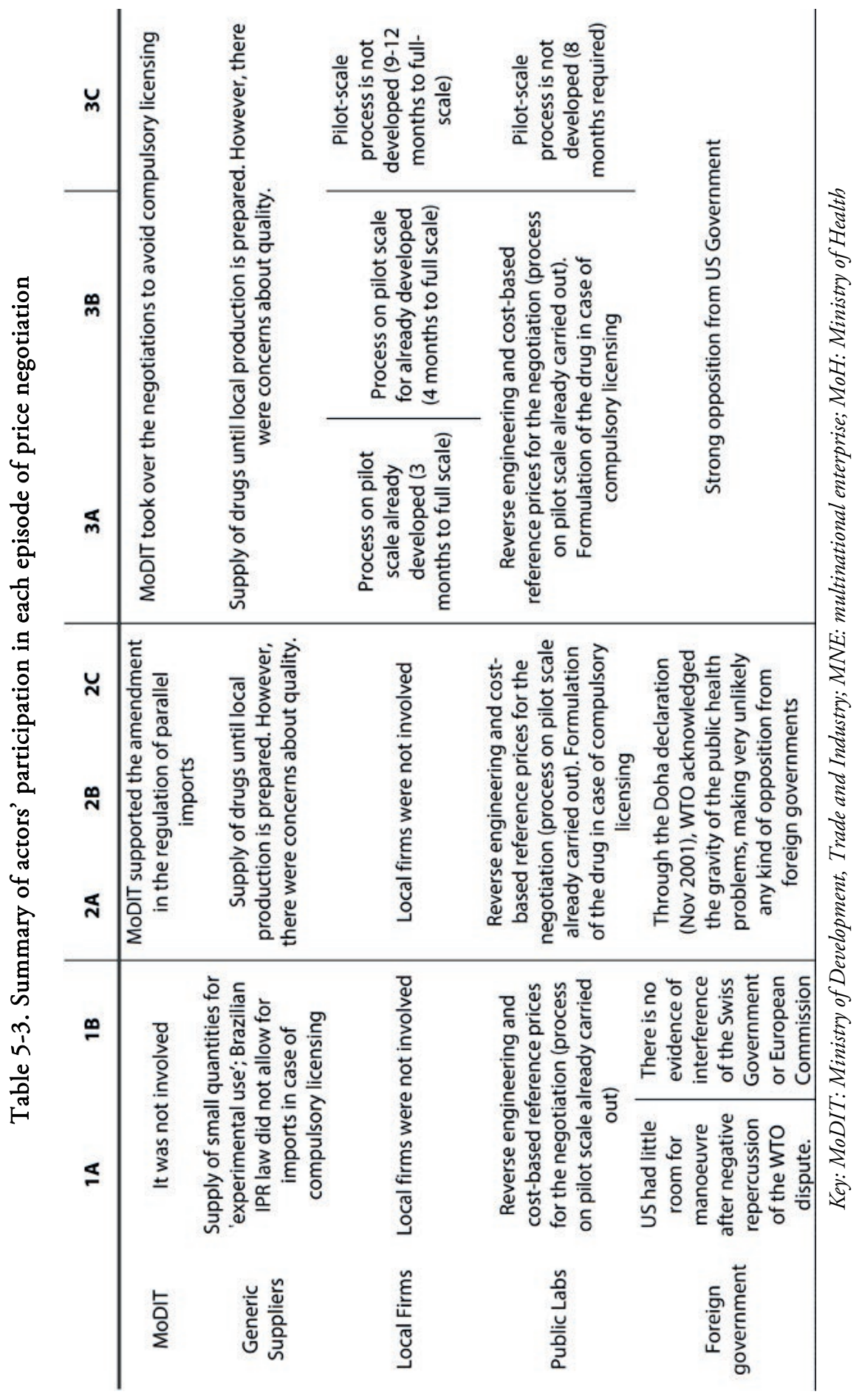




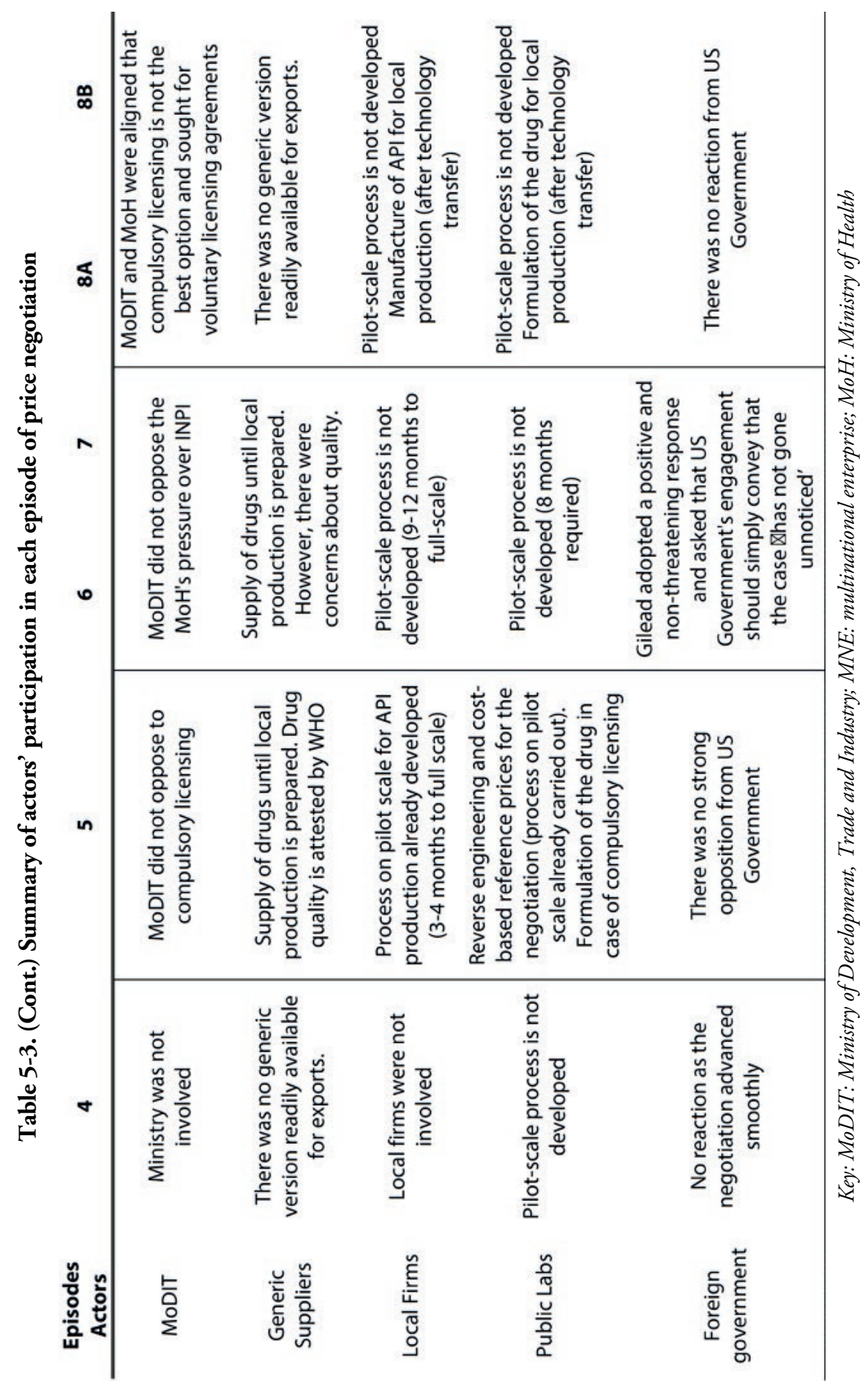


Then, we propose some criteria to categorize the actors according to their respective strength and relative importance in price negotiation episodes. Three strength levels are proposed: weak, medium and high, as presented in Table 5-4.

Table 5-4: Coding criteria for categorisation of actor's relative strength in price negotiations

\begin{tabular}{|c|c|c|c|}
\hline \multirow{2}{*}{ Actor } & \multicolumn{3}{|l|}{ Relative strength } \\
\hline & Weak & Medium & Strong \\
\hline $\begin{array}{l}\text { Generic } \\
\text { Suppliers }\end{array}$ & $\begin{array}{l}\text { If either there is no alter- } \\
\text { native suppliers or the } \\
\text { IPR framework does not } \\
\text { allow parallel imports; }\end{array}$ & $\begin{array}{l}\text { If there is alternative } \\
\text { suppliers, but there is } \\
\text { concerns about quality } \\
\text { (e.g. lack of certification) }\end{array}$ & $\begin{array}{l}\text { If there is alternative } \\
\text { suppliers and the drug } \\
\text { has the quality attest- } \\
\text { ed by an international- } \\
\text { ly recognised organi- } \\
\text { sation }\end{array}$ \\
\hline Local Firms & $\begin{array}{l}\text { Pilot-scale process is not } \\
\text { developed and ar- } \\
\text { rangement for local } \\
\text { production is not set up }\end{array}$ & $\begin{array}{l}\text { Pilot-scale process is not } \\
\text { developed, but ar- } \\
\text { rangement for local } \\
\text { production is set up }\end{array}$ & $\begin{array}{l}\text { Pilot-scale process is } \\
\text { developed }\end{array}$ \\
\hline Public Labs & $\begin{array}{l}\text { Pilot-scale process is not } \\
\text { developed and ar- } \\
\text { rangement for local } \\
\text { production is not set up }\end{array}$ & $\begin{array}{l}\text { Pilot-scale process is not } \\
\text { developed, but ar- } \\
\text { rangement for local } \\
\text { production is set up }\end{array}$ & $\begin{array}{l}\text { Pilot-scale process is } \\
\text { developed }\end{array}$ \\
\hline MoDIT & $\begin{array}{l}\text { If MoDIT is either not } \\
\text { involved or aligned with } \\
\mathrm{MoH}\end{array}$ & $\begin{array}{l}\text { If MoDIT is involved but } \\
\text { did not confront } \mathrm{MoH}\end{array}$ & $\begin{array}{l}\text { If MoDIT is actively } \\
\text { involved to avoid } \\
\text { compulsory licensing }\end{array}$ \\
\hline $\begin{array}{l}\text { MNE's } \\
\text { Home Gov- } \\
\text { ernment }\end{array}$ & $\begin{array}{l}\text { If MNE's home govern- } \\
\text { ments are not involved }\end{array}$ & $\begin{array}{l}\text { If there is no strong } \\
\text { opposition of MNE's } \\
\text { home governments }\end{array}$ & $\begin{array}{l}\text { If there is strong oppo- } \\
\text { sition of MNE's home } \\
\text { governments }\end{array}$ \\
\hline
\end{tabular}

Key: MoDIT: Ministry of Development, Trade and Industry; MNE: multinational enterprise; MoH: Ministry of Health

The above results as given (i.e. as given by Table 5-3 and Table 5-4) allows us to draw inferences on the relative strength of the actors of the ecosystem in terms of their networks with their collaborators, as presented in Table 5-5. We propose that bargaining strengths, in turn, can be achieved through 'outreach' to other actors in the ecosystem to address their concerns. MoH's strength in the negotiation depends on the capacity of International Generic Suppliers, Local Firms and/or Public Labs to supply the concerned drug meeting the deadline, and price and quality standards necessary an efficient compulsory licensing. Thus, the $\mathrm{MoH}$ has to expend outreach efforts towards these actors in order to maximize the quantity that can be supplied if a compulsory license is issued. On the other hand, MNE's strength comes from its own capacity to retaliate and from pressures from MoDIT and its home government (including reprisal 
threats) against compulsory licensing. Therefore, the pharmaceutical MNE has to expend outreach efforts towards MoDIT and its home government in order to maximize the reprisal that the country may face if a compulsory license is issued.

In sum, prior to making a compulsory licensing threat, $\mathrm{MoH}$ has to evaluate both the existence of competent alternative suppliers and the possibility reprisals being issued by other actors in the eco-system. Additionally, a pharmaceutical MNE facing a compulsory license threat has to evaluate the likelihood of its own reprisals as well as reprisal from other actors in deterring $\mathrm{MoH}$ from issuing a compulsory license if the costs outweigh the benefits.

Table 5-5. Actor network strengths in price negotiations

\begin{tabular}{|c|c|c|c|c|c|c|}
\hline \multirow{2}{*}{\multicolumn{2}{|c|}{ Episode / Drug }} & \multicolumn{3}{|c|}{ MoH's strength } & \multicolumn{2}{|c|}{ MNE's strength } \\
\hline & & \multirow{2}{*}{$\begin{array}{l}\begin{array}{l}\text { Generic } \\
\text { Suppliers }\end{array} \\
\text { Weak }\end{array}$} & \multirow{2}{*}{$\begin{array}{l}\text { Local } \\
\text { Firms } \\
\text { Weak }\end{array}$} & \multirow{2}{*}{$\begin{array}{l}\begin{array}{l}\text { Public } \\
\text { Labs }\end{array} \\
\text { Strong }\end{array}$} & \multirow{2}{*}{$\begin{array}{l}\text { MoDIT } \\
\text { Weak }\end{array}$} & \multirow{2}{*}{$\begin{array}{l}\begin{array}{l}\text { Home } \\
\text { Government }\end{array} \\
\text { Weak }\end{array}$} \\
\hline $1 \mathrm{~A}$ & Efavirenz & & & & & \\
\hline $1 B$ & Nelfinavir & Weak & Weak & Strong & Weak & Weak \\
\hline $2 \mathrm{~A}$ & Efavirenz & Medium & Weak & Strong & Weak & Medium \\
\hline $2 \mathrm{~B}$ & Lopinavir+Ritonavir & Medium & Weak & Strong & Weak & Medium \\
\hline $2 C$ & Nelfinavir & Medium & Weak & Strong & Weak & Medium \\
\hline $3 \mathrm{~A}$ & Lopinavir+Ritonavir & Medium & Strong & Strong & Strong & Strong \\
\hline $3 B$ & Efavirenz & Medium & Strong & Strong & Strong & Strong \\
\hline $3 C$ & Tenofovir & Weak & Medium & Medium & Strong & Strong \\
\hline 4 & Atazanavir & Weak & Weak & Weak & Weak & Weak \\
\hline 5 & Efavirenz & Strong & Strong & Strong & Medium & Medium \\
\hline 6 & Tenofovir & Medium & Medium & Medium & Medium & Medium \\
\hline 7 & Tenofovir & Medium & Medium & Medium & Medium & Medium \\
\hline $8 \mathrm{~A}$ & Atazanavir & Weak & Weak & Weak & Weak & Weak \\
\hline $8 B$ & Raltegravir & Weak & Weak & Weak & Weak & Weak \\
\hline
\end{tabular}

Outcomes of any negotiations depend on the relative bargaining strengths of the players. However, we must develop a hypothetical construct that explain how the actors' bargaining power can determine the outcome of price negotiations. To advance in this direction, first, we use the indicators of the relative strengths of the two players (see Table 5-5) to derive explanatory variables for price negotiation outcomes. This yields three central explanatory variables: local capacity, import possibilities and reprisal. 
Second, we propose three categories for these explanatory variables, as presented in Table 5-6.

Table 5-6: Coding criteria for categorisation of explanatory variables

\begin{tabular}{|c|c|c|c|}
\hline Variable & Low & Moderate & High \\
\hline Local capacity & $\begin{array}{l}\max \left(S_{P L}, S_{L F}\right) \\
\text { is weak }\end{array}$ & $\begin{array}{l}\max \left(S_{P L}, S_{L F}\right) \\
\text { is medium }\end{array}$ & $\begin{array}{l}\max \left(S_{P L}, S_{L F}\right) \\
\text { is strong }\end{array}$ \\
\hline $\begin{array}{l}\text { Import possibili- } \\
\text { ties }\end{array}$ & $S_{G S}$ is weak & $S_{G S}$ is medium & $S_{G S}$ is strong \\
\hline Reprisals & $\begin{array}{l}\max \left(S_{M D}, S_{H G}\right) \\
\text { is weak }\end{array}$ & $\begin{array}{l}\max \left(S_{M D}, S_{H G}\right) \\
\text { is medium }\end{array}$ & $\begin{array}{l}\max \left(S_{M D}, S_{H G}\right) \\
\text { is strong }\end{array}$ \\
\hline
\end{tabular}

Key: $S_{P L}$ : strength of public laboratories; $S_{L F}$ : strength of local firms; $S_{G S}$ : strength of generic suppliers; $S_{M D}$ : strength of MoDIT; $S_{H G}$ : strength of MNE's home government

Third, we draw assumptions about how the explanatory variables may affect the expected benefit the actors receive. On the one hand, MoH's objective is to maximize the quantity of the drug that can be purchased by either obtaining a price reduction for the patented drug or issuing a compulsory license. This, in turn, depends on the level of local capacity and import possibilities that will determine the quantity that $\mathrm{MoH}$ can purchase in case of compulsory licensing. These two variables are, to some extent, interchangeable, as $\mathrm{MoH}$ can procure the technology locally or import in case of compulsory licensing. The higher the value of these two variables, the higher the quantity of the drug $\mathrm{MoH}$ can purchase by issuing a compulsory license, and, therefore, the higher will be MoH's bargaining power in the negotiation. On the other hand, MNE's objective is to maximize its profit. Therefore, MNE has to avoid compulsory licensing of its drug while minimizing an eventual price reduction for the same. This, in turn, will depend on the reprisal level that the country is subjected if a compulsory license is issued. As reprisal refers to the possible negative side effects that may entail the issuance of a compulsory license (e.g. investment and trade loss, market withdraw), it has an opposite effect on MoH's bargaining power. Thus, the higher the reprisal, the lower the likelihood of compulsory licensing and the higher the price that $\mathrm{MoH}$ is willing to accept.

In Table 5-7, we present the parameters of the bargaining game for the 14 price negotiations of ARV drugs in Brazil. In this table, we can see that for low reprisal levels, a discount can be obtained and the compulsory license can be avoided even if the availability of alternative suppliers is low. Furthermore, when the reprisal level is moderate, 
the availability of alternative suppliers has to be at least moderate. However, the outcome of negotiations in the presence of high reprisal is ambiguous: moderate and high availability of alternative suppliers led to price discounts (episode 3A and 3C), while the pharmaceutical MNE could avoid a compulsory license without giving a price discount even when the availability of alternative suppliers is high (i.e. episode 3B). In addition, when $\mathrm{MoH}$ and the MNE does not reach an agreement, presence of moderate reprisal is not sufficient to avoid compulsory licensing of the drug (i.e. episode 5).

Finally, Figure 5-2 describes this framework of price negotiation within the Brazilian eco-system. We start with a set of actors with different roles in the ecosystem of price negotiation. The central actors, i.e. $\mathrm{MoH}$ and the pharmaceutical MNE, expend outreach efforts towards supportive actors in order to increase their bargaining strength in the price negotiation. Then, these interactions (and the relative strength of the actors involved) define the initial conditions in which a negotiation takes places. Therefore, the variance in the observed outcomes can be (partially) explained by changes in the actors' relative strength and their capacity to influence the price negotiation (that is, the relative strength of the arrows in Figure 5-2).

Table 5-7. Parameters of the bargaining game

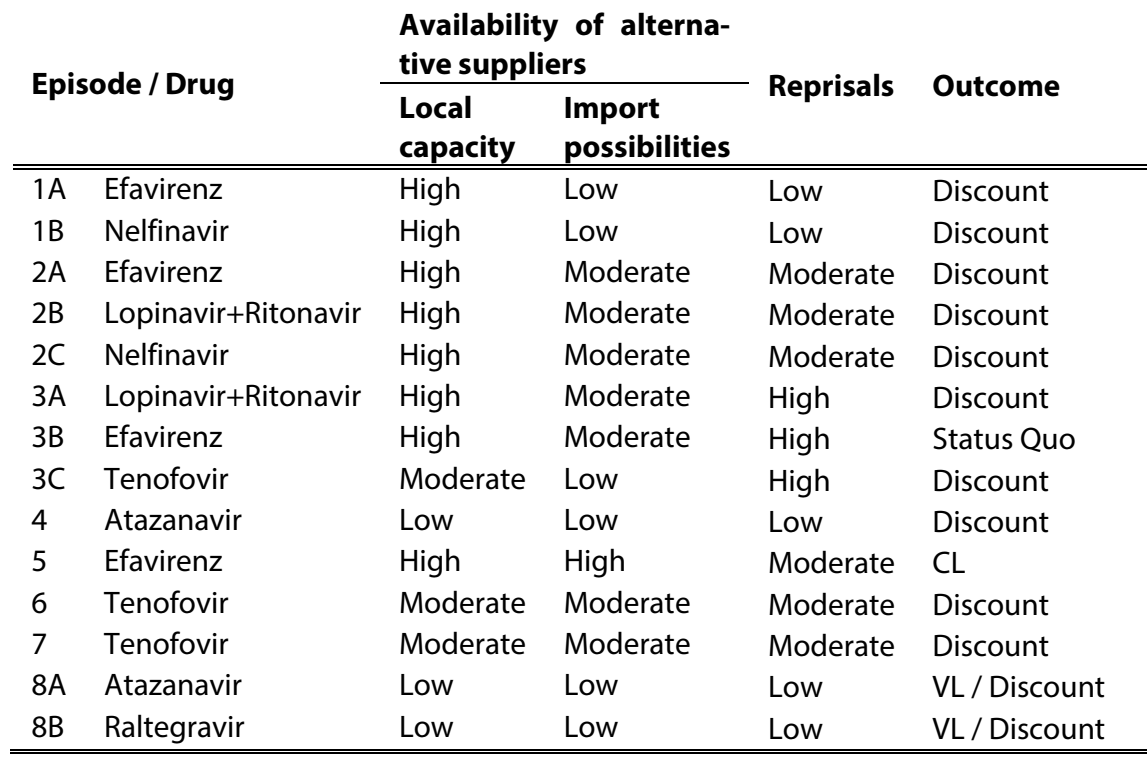

Key: $C L=$ Compulsory License; $V L=$ Voluntary License 


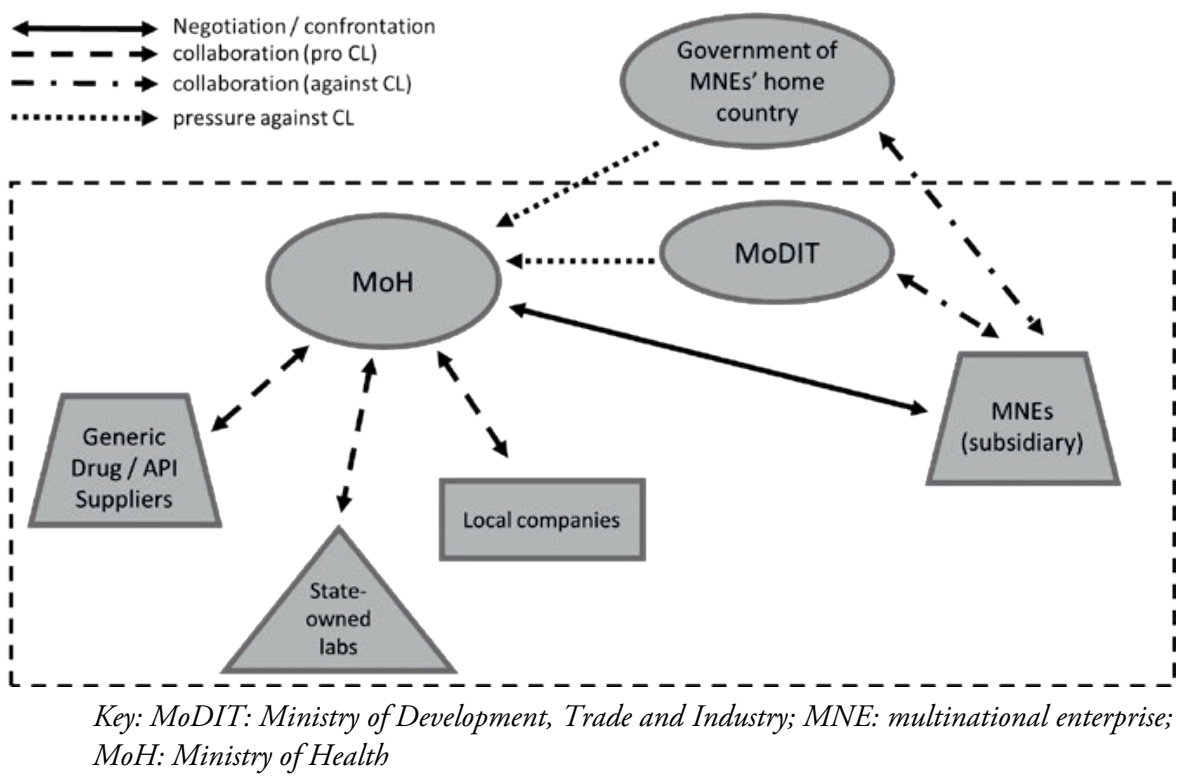

Figure 5-3. Framework of price negotiation within the Brazilian eco-system

\subsection{Illustrating the framework with selected episodes of price negoti- ation}

We now illustrate the above framework through an analysis of the price negotiations between $\mathrm{MoH}$ and Merck \& Co. for the ARV Efavirenz (i.e. Episodes 1A, 2A, 3B and $5)$. These episodes have been chosen because they include all possible outcomes and different values of explanatory variables.

In the first two episodes (Episodes 1A and 2A), Merck's bargaining power was lowered through lack of support from the US government. Whereas, MoH's bargaining power was strengthened by support from the state-owned laboratories, which had developed expertise in Efavirenz production, a critical factor as it would enable local production in case of compulsory licensing. In spite of the local IPR framework do not allow parallel imports, the evidences presented in the technological competences to produce the drug at Farmanguinhos was already sufficient to give credibility to MoH's threat. Merck and $\mathrm{MoH}$ agreed on price reductions of $59 \%$ and $25 \%$ for Efavirenz in episodes $1 \mathrm{~A}$ and $2 \mathrm{~A}$, respectively.

Then tables were turned in 2005 (episode 3B). From the outset, Merck engaged in much strong efforts to persuade MoDIT that a compulsory license was not in the best 
interest of the Brazilian economy. For instance, the company presented investment plans that would be carried out only if a compulsory license was avoided. Only after obtaining support from MoDIT did Merck start conversations directly with $\mathrm{MoH}$. Besides that, the US Government was much more involved in this episode, especially because two other US-based MNEs were also facing compulsory license threat for their ARV drugs. Therefore, in this episode the actors that were against compulsory license played an important role in persuading $\mathrm{MoH}$ to accept Merck's pricing strategy. In fact, at some point, MoDIT took over the negotiation with the pharmaceutical MNEs. Thus, Merck was able to confront $\mathrm{MoH}$ and stall the negotiation until a point that $\mathrm{MoH}$ had to succumb. Therefore, the parties did not reach an agreement for a price reduction and no compulsory license was issued.

But there was another reversal of fortunes in 2007 (episode 5), when Merck adopted the same confrontation strategy as in the previous one. However, this time, Merck's bargaining power was much weaker, especially because the support from US Government was not strong and the company's efforts towards MoDIT did not affect MoH's decision to call for price reduction. Conversely, $\mathrm{MoH}$ was very well positioned for the negotiation because there were prequalified Indian companies able to supply the needed quantity of the drug for just a fraction of the MNE's price. At the same time, local companies organised a supply network to assist state owned labs in the local production of Efavirenz. With its bargaining power at its peak, the Brazilian government issued a compulsory license after rejecting Merck's counteroffer.

The last episode of Merck's failed efforts is also revealing. First, it seemed to have been too sure of the backing of the US government, which failed to materialize. Second, it made a mistake in terms of timing its compromise offer. After the $\mathrm{MoH}$ decided to issue a compulsory license for Efavirenz, Merck offered a last minute 30\% price reduction tied to a technology transfer agreement. However, it was already too late and the Brazilian Government issued a compulsory license in May 2007. MoH imported the drug from India until local production started at Farmanguinhos in 2009. ${ }^{35}$ Therefore, the company lost the market for its product - something that it could have avoided if the company have offered a bigger price reduction in an earlier stage.

\footnotetext{
35 In March 2008, MoH purchased 13.5 million tablets of Efavirenz from an Indian company in order to secure the supply until March 2009, when Farmanguinhos started supplying its own generic version of the drug (Rodrigues \& Soler, 2009).
} 
The negotiation episodes between $\mathrm{MoH}$ and Merck \& Co. suggest that no general legitimization guidelines can be formulated to maximize MNE returns under a confrontation, except that an MNE must re-evaluate its bargaining power at the beginning of every confrontation and not take past victories as an indicator of probable success. This is because bargaining power not only depends on the intrinsic nature of the product and its potential impact, but also on the support provided to the MNE or the local challenger in the MNE's mother country and the emerging country.

In this chapter, the drivers of bargaining outcomes of price negotiations between multinationals and public agencies of developing countries are identified. These drivers are determined by interactions between the actors of the Brazilian eco-system of price negotiation and define the initial conditions in which each negotiation takes place. Given the initial conditions, $\mathrm{MoH}$ and the pharmaceutical MNE must decide the optimal path to follow. However, one or both player may not be perfectly informed about all these conditions or completely aware about how these conditions will affect the other part's (expected) gain with the negotiation. Most of the episodes seems to confirm that the existence of either local manufacturing capacity or import substitution, and the possibility of reprisals from the patent holder or from its host country are the main drivers of price negotiations outcome.

However, neither the individual and joint effects of the drivers of bargaining strength nor what is the role of informational constraints in the outcome of price negotiations are clear. In these negotiations, the final outcome is not entirely determined by the initial conditions or by an individual choice, but rather by interdependent decisions made by the actors involved. This is why game theory seems to be the right analytical tool to further examine the dynamics of price negotiations between a public agency and a pharmaceutical MNE, as we do in the next chapter.I 



\section{Chapter 6 On the dynamics of compulsory license issuance: a game theoretical approach}

\subsection{Introduction}

The general framework developed in the previous chapter helps us to understand the variety of strategies that can be played within an innovation system to improve access to drug via price negotiation. In this chapter, in order to understand the dynamics better, we build a game between the two principal players, namely the public agency and the innovating firm to refine the analysis of the starting conditions under which a compulsory license may be issued.

The game theoretical model has two players: a patent holder, a large pharmaceutical MNE that sells its patented drug to a developing country's government; and the public agency in a developing country that buys this drug and tries to negotiate prices with the patent holder using compulsory licensing as a threat. The model allows us to construct an analytical framework of price negotiation of patented drugs in order to understand the dynamics of the main drivers and obstacles to the issuance of compulsory licenses by developing countries.

Our methodology comprises three steps.

We first review the existing literature and evidence on compulsory licenses in order to have a more complete understanding of the underlying context.

We formulate and solve a game theoretical model of price negotiation between a pharmaceutical company and a public agency in a developing country.

We validate our findings by checking the extent to which the model fits with reality and the findings of the literature (Chapter 7 ).

Our game theoretical model, like all economics models, seeks to simplify rather than represent a complex reality, in order to trace how certain outcomes can emerge. As an instrument of investigation, for analytical tractability, it limits itself to a set of elements most common to different manifestations of the phenomena under study. Further- 
more, in this chapter, the model's purpose is to provide a rationale for the surfacing of outcomes to help fine-tune intuition and provide insights for decision-making.

The remainder of the chapter is organised as follows. Section 6.2 explains the rationale of compulsory license as a flexibility providing option in TRIPS. Section 6.3 presents two models of price negotiation between the public agency and the patent holder of a lifesaving drug - one under complete and the other under incomplete information, where the public agency can use the threat of issuing a compulsory license as a bargaining tool. Section 6.4 provides numerical examples. In Section 6.5, we discuss our results. Section 6.6 concludes the chapter.

\subsection{On the challenges of using compulsory licenses}

After the Doha Declaration and the August 30 Decision, it was expected that the number of compulsory licenses issued by least developed and developing countries would increase over time. However, there were pharmaceutical compulsory license episodes, or even of compulsory license threats (Beall \& Kuhn, 2012). In order to understand why, we carried out a literature survey. Using standard databases (e.g. Google Scholar, Scopus, and Web of Science), we started with several research equations that included the terms 'compulsory license', 'drug', 'medicine' and 'access to medicines'. This yielded a primary corpus that we read to finally select 26 articles that examined why or how countries used compulsory licenses as a policy instrument to improve access to medicines. They confirmed that governments in developing countries view the possibilities for the issuance of a compulsory license to a generic manufacturer as an important source of bargaining strength in price negotiations. Besides the actual announcement of a compulsory license, the authors note that even a threat can have similar effects. The possibility of issuing a compulsory license empowers developing countries to negotiate prices with pharmaceutical companies more aggressively (Abbott \& Reichman, 2007; Beall \& Kuhn, 2012; Benoliel \& Salama, 2010; Bird, 2009; Flanagan \& Whiteman, 2007; Hemphill, 2010; Nattrass, 2008; Shadlen, 2007; Smith, Correa, \& Oh, 2009; WHO, 2006). A careful reading of the corpus reveals that three main factors play an important role on the outcomes of compulsory license threats. These are local manufacturing capacity, import possibilities, and political pressure and retaliation, as shown in Table 6-1

The existence of local manufacturing capacity is a critical element of a developing country's bargaining power vis-à-vis pharmaceutical companies, for only then can it license the technology to local companies. Throughout this dissertation, we adopt a 
broad interpretation of the term 'manufacturing capacity', so that it encompasses not only the physically installed production capacity (i.e. manufacturing facilities, equipment, labour skills, and so on) but also technological capabilities (i.e. skills, knowledge and experience) to produce APIs and formulate them into final consumable drugs. ${ }^{36}$ Then institutional and market linkages are needed to distribute the drug to the end user at an affordable price.

Table 6-1: Factors influencing the issuance of compulsory licenses

\begin{tabular}{|c|c|c|}
\hline Factor & Reasons & Reference(s) \\
\hline \multirow{3}{*}{$\begin{array}{l}\text { Local } \\
\text { manufacturing } \\
\text { capacity }\end{array}$} & $\begin{array}{l}\text { Is a necessary } \\
\text { condition for credible } \\
\text { compulsory license } \\
\text { threats }\end{array}$ & $\begin{array}{l}\text { Abbott \& Reichman (2007); Beall \& Kuhn } \\
\text { (2012); Benoliel \& Salama (2010); Flanagan \& } \\
\text { Whiteman (2007); Kerry \& Lee (2007); Ng \& } \\
\text { Kohler (2008); Ravvin (2008); Shadlen (2007); } \\
\text { Smith et al. (2009); WHO (2006); Yu (2007). }\end{array}$ \\
\hline & $\begin{array}{l}\text { Increases bargaining } \\
\text { strength in price } \\
\text { negotiations }\end{array}$ & $\begin{array}{l}\text { Cohen \& Lybecker (2005); Hemphill (2010); } \\
\text { Roemer-Mahler (2010); WHO (2006). }\end{array}$ \\
\hline & $\begin{array}{l}\text { Necessary for } \\
\text { adequate access to } \\
\text { medicines }\end{array}$ & Liu (2010). \\
\hline $\begin{array}{l}\text { Import } \\
\text { Possibilities }\end{array}$ & $\begin{array}{l}\text { Necessary for credible } \\
\text { compulsory license } \\
\text { whenever domestic } \\
\text { manufacturing } \\
\text { capabilities are absent }\end{array}$ & $\begin{array}{l}\text { Abbott \& Reichman (2007); Beall \& Kuhn } \\
\text { (2012); Bird (2009); Bird \& Cahoy (2008); } \\
\text { Dutfield (2008); Hannah (2011); Kerry \& Lee } \\
\text { (2007); Ng \& Kohler (2008); Yu (2007); Nattrass } \\
\text { (2008). }\end{array}$ \\
\hline \multirow{3}{*}{ Retaliation } & $\begin{array}{l}\text { Moral pressure from } \\
\text { developed countries } \\
\text { and/or patent holders } \\
\text { / Threat of market } \\
\text { withdrawal or market } \\
\text { retaliation }\end{array}$ & $\begin{array}{l}\text { Abbott \& Reichman (2007); Beall \& Kuhn } \\
\text { (2012); Benoliel \& Salama (2010); Bird (2009); } \\
\text { Bird \& Cahoy (2008); Kerry \& Lee (2007); Liu } \\
\text { (2010); Ng \& Kohler (2008); Schüklenk \& } \\
\text { Ashcroft (2002); Shankar et al. (2013); Smith et } \\
\text { al. (2009); Yu (2007). }\end{array}$ \\
\hline & $\begin{array}{l}\text { Lobbying by pharma } \\
\text { majors in WTO }\end{array}$ & $\begin{array}{l}\text { Beall \& Kuhn (2012); Cohen-Kohler (Forman ( } \\
\text { Lipkus (2008); Kuhn \& Beall (2012); Ravvin } \\
\text { (2008); Stiglitz (2008). }\end{array}$ \\
\hline & $\begin{array}{l}\text { Pressure to comply } \\
\text { with TRIPS and WTO }\end{array}$ & $\begin{array}{l}\text { Cohen-Kohler et al. (2008); Shadlen (2009); } \\
\text { Weissman (1996). }\end{array}$ \\
\hline
\end{tabular}

\footnotetext{
${ }^{36}$ We acknowledge that term 'manufacturing capacity' usually has a narrower interpretation in fields, such as economics, business and innovation studies. However, we choose this term for the sake of consistency with the language used in both the Doha Declaration and in the Article 31bis in the TRIPS Agreement.
} 
The existence of local manufacturing capacity is a critical element of a developing country's bargaining power vis-à-vis pharmaceutical companies, for only then can it license the technology to local companies. As discussed in Chapter 2 (see Section 2.3, p. 54), there are many countries without technological capabilities in API production or even in drug formulation. These countries rely on imports to satisfy their demand. Therefore, the availability of the drug in potential exporter countries is critical because several factors (e.g. patent status of the drug in the supplier's country, bilateral agreements, contracts between patent holder and generic suppliers, regulatory barriers, among other institutional arrangements) may prevent the foreign supplier from being able to export the drug under a compulsory license. This means that the use of compulsory license - or of the threat of issuing a compulsory license - is limited by both the existing local manufacturing capacity and importing possibilities.

In addition, the issuance of compulsory licensing may provoke 'economic punishment' from various players against the developing country exercising the TRIPS flexibility. Scholars note that there is considerable pressure from developed countries that actively dissuades less developed ones from granting compulsory licenses (see Table 6-1). Thus, any developing country that threatens to issue a compulsory license, if its demand for drug price reduction is not accepted, must expect to receive counter threats from pharmaceutical firms. This can take the form of not launching new drugs in the developing country in the future, and/or not including the country in clinical trials for drug development. In addition, patent holders can also create a strong lobby with their home country's government in order to put pressure on the developing country, especially in terms of trade retaliation.

Indeed, the use of compulsory licenses invites scrutiny by developed countries' governments willing to defend their multinationals' interests through trade sanctions and other political and diplomatic pressures that may lead to economic loss to the licensing nation (Abbott \& Reichman, 2007; Bird \& Cahoy, 2008; Schüklenk \& Ashcroft, 2002; Shadlen, 2007). For instance, the United States threatened to impose trade sanctions on countries that were considering the issuance of a compulsory license such as South Africa, Thailand and Brazil (Bird, 2009). Furthermore, these countries were included on the USTR's Priority Watch List. It is worth noting that countermeasures taken or threatened by some governments may even cross the line of legality under WTO's framework, which requires that member countries uses WTO's multilateral system of settling disputes instead of taking action unilaterally (Abbott \& Reichman, 2007; Monten, 2005; Weissman, 1996). In fact, more often than not, the political and 
economic pressure put on developing countries triggers internal divisions within local governments (e.g. Trade Ministry versus Health Ministry) and makes them adopt a conservative attitude towards the use of TRIPS flexibilities (Bird, 2009; Possas, 2008). Therefore, in any consideration of a compulsory license issuance, developing country governments are forced to weigh the welfare loss that can result from retaliation by the government of the patent holder, against the welfare gain to local public health.

Ultimately, the issuance of compulsory licenses may industries highly dependent upon IPR to seek a more innovation-friendly legal climate elsewhere, impacting negatively investment flows, trade and innovation in the concerned developing country. For example, when Thailand issued a compulsory license for a HIV/AIDS drug. In response, a drug manufacturer withdrew pending applications for anti-AIDS drugs particularly effective in tropical climates; and in Egypt another company decided to slam the brakes' on a state-of-the-art production facility in the country due to its weak intellectual property enforcement (Bird, 2009; Bird \& Cahoy, 2008; Castellano, 2005).

The challenges raised in this section characterize what Joseph Stiglitz defined as the 'inflexibilities of the TRIPS flexibilities'. According to him

[TRIPS flexibilities] are designed to make it difficult to issue compulsory licenses even for life saving generic medicines. If the WTO really were interested in making sure people had access to generic medicines, the set of procedures would look very different. (...) As it is, not only do the rules make it difficult for developing countries to get access to these vital medicines at prices that they can afford, but the United States exacerbates the problem by coming down hard on any country that attempts to use a compulsory license. (...) So, it is not just how the rules were designed but also the way they are being implemented that has made it more difficult to get access to these generic medicines.' (Stiglitz, 2008, p. 1717).

According to the above, the sanction costs that developing countries may be subject to in case a compulsory license is granted, can be very detrimental. Nonetheless, compulsory license is a legitimate tool and has been employed extensively by more developed countries, such as the United States and Canada; there is always a cost of issuing a compulsory license for developing countries, especially in terms of political and economic sanctions. So whenever possible, the developing country will prefer to negotiate 
a price drop to issuing a compulsory license; depending on its bargaining position and/or how the developing country weigh the risks, costs and benefits of compulsory licensing, it may prefer even to accept the status quo.

To summarize, the threat of issuing a compulsory license is used as an instrument by some public agencies in developing countries to bring about drug price reductions in negotiations with patent holders. The credibility of the threat is determined by the local manufacturing capacity and access to imports. The cost of reprisals on the local industry is an element that has to be integrated in all calculations by developing countries engaging in price negotiations with patent holders. As of now, there is no analytical framework that integrates these diverse elements to explain their joint impact on the probability of the use of compulsory licenses as a policy instrument or the probability of success of a price negotiation that is backed up by a compulsory license threat. In response to this gap, we propose the following game theoretical model.

\subsection{A game theoretic model of drug price negotiations ${ }^{37}$}

To understand the dynamics of drug price negotiation between a developing country and a foreign multinational, we first consider the context of complete information, when all features of the game are common knowledge to the patent holder and the public agency. Then we examine outcomes under incomplete information, when the patent holder does not know the true value of all the parameters influencing the choices of the public agency.

\subsubsection{Game under complete information}

Suppose that in a developing country, a multinational company, an original innovator holding a drug patent, is the sole supplier of a drug, which is bought by the local public health agency for a major health burden. Let the public health agency of the developing country be given by $D C$ and the foreign patent holder by $P H$.

The public health agency $D C$ has a fixed amount of funds $B$ to spend on drug provision that we will refer to as its budget. Furthermore, suppose that the patent holder $P H$ has negotiated a price $p_{0}$ and is currently supplying $q_{0}=\frac{B}{p_{0}}$ to $D C$. But the quantity,

\footnotetext{
${ }^{37}$ This section draws substantially on Ramani \& Urias (2015)
} 
$q_{0}$, is not sufficient for the public health programme to reach the poorer sections of society. For simplicity, we assume that the foreign patent holder can produce any finite amount of the drug at the constant average cost of production $c$.

In this context, the public agency, $D C$, has the choice of either accepting the status-quo or initiating a price negotiation. Note that such negotiation refers solely to public procurement prices for a specific patented medicine at the national level and 'spillovers' of this negotiation over the supply chain to final pharmacy retail prices are not considered. When a negotiation starts, $D C$ informs the patent holder $P H$ that unless $P H$ reduces the price of its branded drug from $p_{0}$ to price $p_{1}<p_{0}$, the government of $D C$ will issue a compulsory license and procure the technology to be manufactured by local firms or import it from the international market. For instance, $p_{1}$ could be the lowest price at which $\mathrm{PH}$ sells the branded drug in a different market or $p_{1}$ could be the lowest price at which a generic version can be imported. The patent holder $P H$ can respond to such a threat in one of three ways. ${ }^{38}$

PH can accept the large price drop to $p_{1}<p_{0}$, then the game ends.

I. $\quad \mathrm{PH}$ can refuse to give the large price drop to $p_{1}<p_{0}$, and instead make a counter-offer of a smaller price drop to $p_{2}$, where $p_{1}<p_{2} \leq$ $p_{0}$.

$\mathrm{PH}$ can refuse to give a large price drop and continue to reinforce the status quo.

When $P H$ responds as per (ii) or (iii) above, $D C$ can either accept $P H$ s proposal or issue a compulsory license.

\subsubsection{The payoff structure}

The objective of $D C$ is to maximize the quantity of the drug that it is able to buy, and thus, its payoff at price $p_{i}$ is the quantity of the drug that can be bought given its budget. The goal of $P H$ is to maximize its profit, and therefore, its payoff is given by the profit associated with the sale of the quantity $q_{i}$ at price $p_{i}$, namely $\pi_{i}=$ $\pi_{i}\left(p_{i}, q_{i}\right)$. Moreover, given the fixed budget $B$ of the public agency $D C$, its payoff increases as the price of the drug decreases, i.e.:

\footnotetext{
${ }^{38}$ In response to compulsory license threats, pharmaceutical companies have also made voluntary licenses available, but we did not include this option in the model for simplification. For the same reason, we did not consider the possible impact of parallel imports (when allowed by law) on the negotiation dynamics.
} 


$$
p_{1}<p_{2}<p_{0} \Leftrightarrow q_{1}>q_{2}>q_{0}
$$

By the same logic, since $B=p_{i} . q_{i}$ the profit of $P H$ decreases as the price decreases, i.e.:

$p_{1}<p_{2}<p_{0} \Leftrightarrow \pi_{1}<\pi_{2}<\pi_{0}$.

At the start of the game, $P H$ charges the negotiated price $p_{0}$ with corresponding payoffs $q_{0}=\frac{B}{p_{0}}$ and $\pi_{0}=\pi_{0}\left(p_{0}, q_{0}\right)$ to $D C$ and $P H$ respectively. The same payoffs hold if $P H$ insists on the status quo and $D C$ accepts the same.

Viewing the stakes from the $D C$ s perspective, if $D C$ issues a compulsory license, then it has to ensure that the minimum target of the public health programme is met by finding alternative sources of drug supply. To do so, $D C$ must either buy the drug from local firms or import it from the international market, depending on who can offer the drug at a lower price, which in turn will affect final market prices. It also has to bear the costs of possible reprisal, $R$, from the government of the patent holder's country, which reduces its budget for drug procurement from $B$ to $B-R$. We assume that that reprisal will have actual direct costs that can only be taken from the budget of the drug ${ }^{39}$. Let $\alpha_{L}$ and $\alpha_{F}$ be the indicators of manufacturing capacity of local and foreign generic producers respectively, where $0 \leq \alpha_{L} \leq 1$ and $0 \leq \alpha_{F} \leq 1$. ${ }^{40}$ This means that if either $\alpha_{L}$ or $\alpha_{F}$ is equal to 1 , the drug can be offered at the lowest possible price, $p_{1}$. Conversely, if $\alpha_{L}$ and $\alpha_{F}$ are both equal to 0 , there is no alternative source of drugs. Then the drug price under compulsory licensing is given by:

$p_{C L}=\min \left(p_{L}, p_{F}\right)=\frac{p_{1}}{\max \left(\alpha_{L}, \alpha_{F}\right)}$.

Finally, given that the reprisal $R$ represents a burden on the developing country's budget, under compulsory licensing the payoff of $D C$ is:

$$
q_{C L}=\frac{B-R}{p_{c l}}=\frac{(B-R) \cdot \max \left(\alpha_{L}, \alpha_{F}\right)}{p_{1}} .
$$

In Equations 3 and 4, local capacity and import possibilities carry the same weight. Therefore, in case of compulsory license granting, DC will opt for local manufacturing only if the local price is lower than the price of an imported generic. Obviously, if there is no generic version available for imports, then $D C$ s bargaining power will be function of only its manufacturing capacity. ${ }^{41}$

\footnotetext{
${ }^{39}$ A reprisal can assume very informal and subtle ways that are not always measurable in economic (or other monetary) terms. Therefore, we opted for an oversimplification of the dynamic in order to explore its implications better.

${ }^{40}$ The indicator $\alpha_{F}$ refers not only to the international manufacturing capacity, but also to the availability of the drug for export to the country demanding the drug.

${ }^{41}$ As India complied with TRIPS in 2005, Indian generic manufacturers are no longer able to supply low-cost and high-quality generics of drugs introduced after this date until the patents pertaining to
} 
This interaction is represented in Figure 1 assuming that all parameters of the game are common knowledge to the two players.

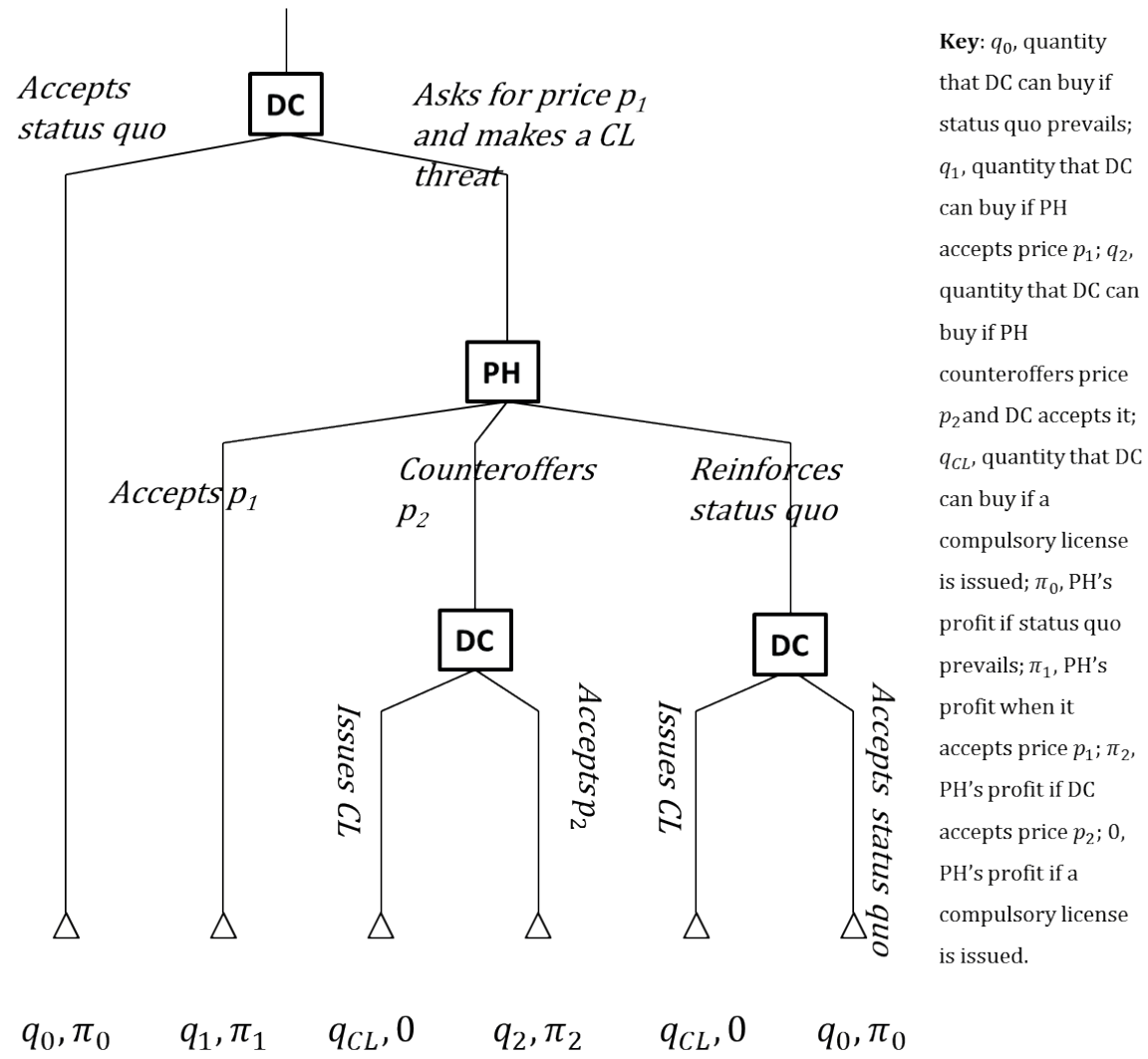

Figure 6-1. Extensive form of the game under complete information

\subsubsection{Game outcomes under complete information}

Applying the standard approach of game theory, the most probable moves along the game tree of the two players $D C$ and $P H$, also referred to as the sub-perfect Nash equilibrium of the game, is indicated in Result 1. It presents the moves of players, which are rational given their anticipation of how the other player will respond. The equilibrium or most probable play is one such that no player has incentive to change his strat-

the drugs expire (see Chapter 2, section 2.3). In addition, some voluntary license agreements between generic manufactures and patent holders frequently come with geographical restriction for exporting and other limitations that hamper the full effect of generic competition ('t Hoen, Berger, Calmy, \& Moon, 2011). 
egy given what the other player is doing - implying a convergence around a strategy profile.

Result 1: DC will consider issuing a compulsory license only if reprisal $R$ is below an upper limit $\bar{R}$ and alternative supply capabilities $\max \left(\alpha_{L}, \alpha_{F}\right)$ are above a minimum limit $\underline{\alpha}$. However, a compulsory license will never be issued under complete information because PH will counteroffer a price $p_{2}$ such that it is in the interest of DC to accept it.

We begin by noting that the public agency, $D C$, will not issue a compulsory license if quantity after a compulsory license $\left(q_{C L}\right)$ is less than the current quantity $\left(q_{0}\right)$ available, i.e. if:

$\frac{\mathrm{B} \cdot \mathrm{p}_{1}}{\mathrm{p}_{0} \cdot(\mathrm{B}-\mathrm{R})} \geq \max \left(\alpha_{L}, \alpha_{F}\right)$

The right side of equation (5) assumes its minimum value when $\max \left(\alpha_{L}, \alpha_{F}\right)=0$. In this case, the above equation will always be true. Therefore, given the continuity of the functions on both sides of the equation, there always exists a small enough value $\underline{\alpha}=$ $\frac{B}{B-R} \cdot \frac{p_{1}}{p_{0}}$ such that if the $\max \left(\alpha_{L}, \alpha_{F}\right)<\underline{\alpha}$, the above equation holds and $D C$ prefers the status-quo.

Similarly, the right side of equation (5) assumes its maximum value when $\max \left(\alpha_{L}, \alpha_{F}\right)=1$. Here equation (5) holds whenever $R=B \cdot\left(1-\frac{p_{1}}{p_{0}}\right)$. Again by continuity of functions, there exists a high enough reprisal value $\bar{R}=B \cdot\left(1-\frac{p_{1}}{p_{0}}\right.$. $\left.\frac{1}{\max \left(\alpha_{L}, \alpha_{F}\right)}\right)$ such that for $R>\bar{R}$ equation (5) is true.

Thus, $D C$ will consider issuing a compulsory license if and only if the expected reprisal is not too high, i.e. if $R<\bar{R}$, and there is sufficient local manufacturing capacity or imports from alternative sources, i.e. $\max \left(\alpha_{L}, \alpha_{F}\right)>\underline{\alpha}$. However, even under such circumstances, $P H$ can propose a price reduction to $p_{2}$ just small enough so that $D C$ can buy at least the same under $p_{2}$ as after issuing a compulsory license and thereby avoid the risk of having a compulsory license being issued. Price $p_{2}$ can be easily found because:

$q_{2} \geq q_{C L} \Leftrightarrow \frac{B}{p_{2}} \geq \frac{B-R}{p_{c l}} \Leftrightarrow p_{2} \leq \frac{B}{B-R} \cdot \frac{p_{1}}{\max \left(\alpha_{L}, \alpha_{F}\right)}$

Therefore, the highest possible price that $P H$ can offer such that $q_{2}=q_{C L}$ is $p_{2}=\frac{B}{B-R} \cdot \frac{p_{1}}{\max \left(\alpha_{L}, \alpha_{F}\right)}$. At $p_{2}$, for $P H$ the payoffs are higher than at $p_{1}$ and for $D C$ 
there is no incentive to issue a compulsory license. Thus, in the complete information context a compulsory license can always be avoided. Moreover, according to equation (6), PH will accept to lower prices to $p_{1}$, i.e. $p_{2}=p_{1}$, if and only if $R=0$ and $\max \left(\alpha_{L}, \alpha_{F}\right)=1$. Indeed, the lower the expected reprisal and the higher the manufacturing capacity, the larger is the price drop acceptable to the patent holder.

However, in reality there have been instances when compulsory licenses have been issued. Could this be due to informational constraints? We turn to this question now.

\subsubsection{Game under incomplete information about possible reprisals}

A reading of the existing literature indicates that the factor on which there is likely to be asymmetric information is the degree of reprisal from the government of the patent holder whenever a compulsory license is issued. For instance, if we rearrange (4), we obtain $q_{C L}=\frac{B}{p_{C L} \cdot\left(\frac{B}{B-R}\right)}$. We can interpret the term $p_{C L} \cdot\left(\frac{B}{B-R}\right)$ as the $D C$ s reservation price, that is, the maximum price that $D C$ is willing to pay not to issue a compulsory license. The reservation price depends on reprisal $R$, which, in the game under incomplete information, is $D C$ s private information. Higher the reprisal, higher the maximum price that $D C$ is willing to pay. The patent holder does not know how $D C$ calculates such cost as this may include not only economic variables (such as share of exports on GDP, share of exports to the US in the total exports, United States Trade Representative listing etc.) but also more 'imprecise' political variables (such as political inclination of the current government, local political context etc.).

Suppose that the reprisal expected by $D C$ in case a compulsory license is granted can be high, say $R^{H}$, or low, say $R^{L}$, with $R^{H}>R^{L}$. In this case, $D C$ can be one of two types. Either it can be of type $D C^{H}$, i.e. from a developing country that is a high reprisal target with a high reservation price of $p_{C L} \cdot\left(\frac{B}{B-R^{H}}\right)$; Or $D C$ can be of type $D C^{L}$ i.e. belonging to a low reprisal target country with a low reservation price of $p_{C L} \cdot\left(\frac{B}{B-R^{L}}\right)$.

Now the drug price negotiation game under incomplete information starts with the move by nature ${ }^{42}$ (represented by $N$ ), which chooses $D C$ s type. Nature chooses the developing country to be a high-reprisal type $D C^{H}$ with probability $\gamma$, and a low-

\footnotetext{
42 Following the framework proposed by Harsany $(1967,1968 \mathrm{a}, 1968 \mathrm{~b})$ a game with incomplete information can be modelled by introducing Nature as a player. Nature assigns a random variable to each player, which gives the probability of the player being of a particular type.
} 
reprisal type $D C^{L}$ with probability $(1-\gamma)$ and this is common knowledge to both players. The public agency, $D C$ of either type, makes the second move either accepting status quo or launching a price negotiation. In the latter case, DC makes compulsory licensing threat and demands $\mathrm{PH}$ to lower price from $p_{0}$ to $p_{1}$ or face the risk of a possible issue of compulsory license. The third move consists of the response of $P H$, to either decline DC's request and reinforce the status quo or make a counter offer of a smaller price drop to $p_{2}$, calculated according to type so that $D C$ has no incentive to issue a compulsory license. ${ }^{43}$ In the fourth and last move of the game, $D C$ decides whether to accept $P H$ 's move or issue a compulsory license. This game is presented in Figure 6-2.

We start with an extreme case ${ }^{44}$ by supposing that if nature chooses $D C$ to be of $D C^{H}$ , it means that $R^{H}>\bar{R}$. Then we know from the previous section, that $D C^{H}$ will never issue a compulsory license, preferring status quo to launching a price negotiation as $R^{H} \geq \bar{R}$ implies that $q_{0}>q_{C L}^{H}$. However, is it in the interest of $D C^{H}$ to bluff by launching a price negotiation with the threat of compulsory license issue? How will the probable outcomes change? In order to identify the probable outcomes of a sequential game under incomplete information, we consider mixed or probabilistic strategies for all players as per the standard approach. Let $\beta$ be the probability with which the public agency, whether $D C^{H}$ or $D C^{L}$ chooses to initiate a price negotiation and $(1-\beta)$ the probability with which it accepts the status-quo. Similarly, let $P H$ consider the randomized strategy, whereby with probability $\delta$, it proposes counter-offer $p_{2}$, and with probability $(1-\delta)$ it upholds the status-quo. We now prove that compulsory licensing is possible under incomplete information by a low reprisal developing country target via three results.

\footnotetext{
${ }^{43}$ Accepting $p_{1}$ will never be optimal for $\mathrm{PH}$ whenever $R>0$. Therefore, we omitted this choice for the sake of simplification.

${ }^{44}$ It must be noted that the results can be easily extended to other cases where $\bar{R}>R^{H}>R^{L}>0$.
} 


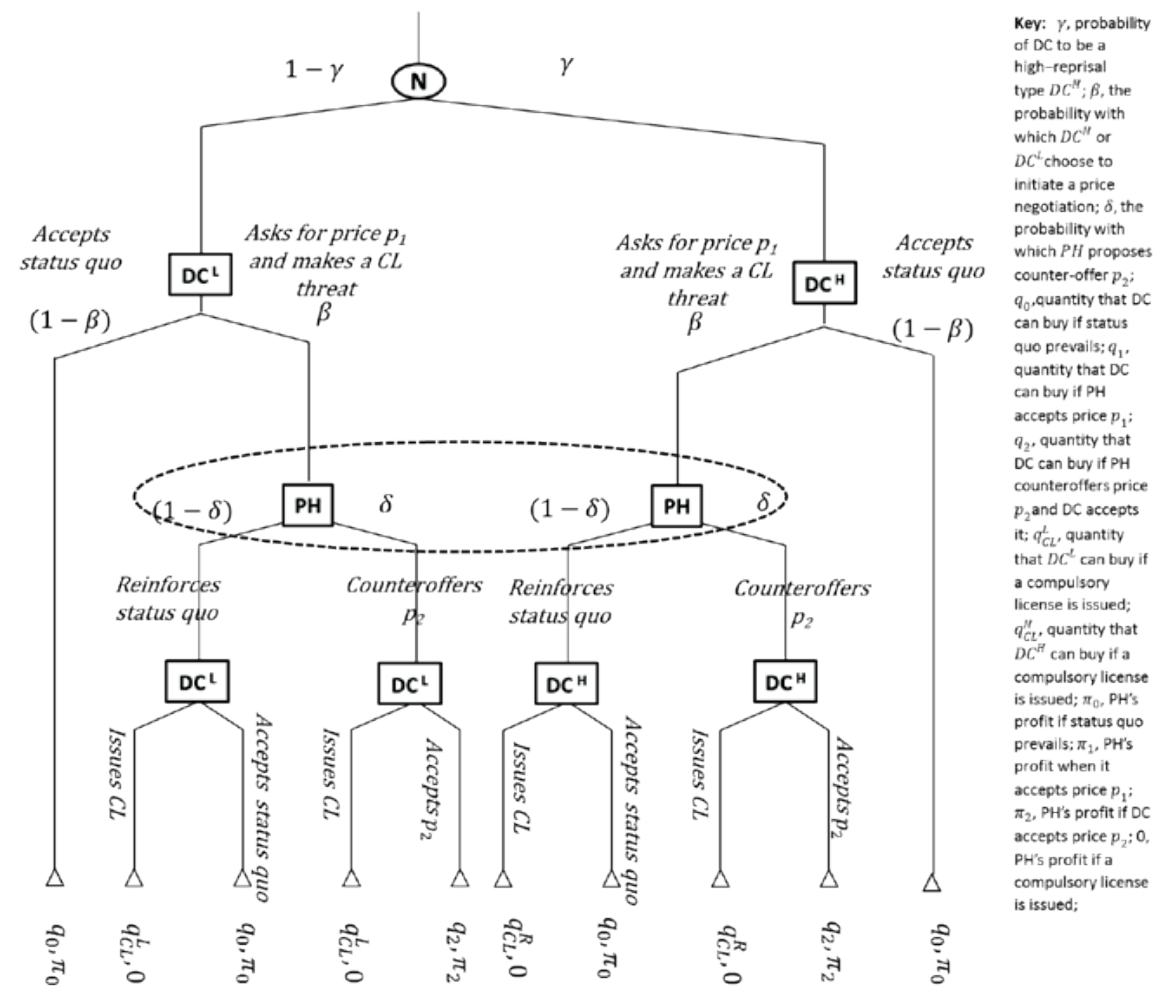

Figure 6-2. Extended Game under incomplete information

Result 2: Whatever its type, $D C^{L}$ or $D C^{H}$, a developing country will always initiate a price negotiation under the given payoff structure.

The payoff of $D C$ associated with the issuance of a compulsory licence varies according to its type as follows:

$$
\begin{gathered}
q_{0}<q_{C L}^{L}=\frac{B-R^{L}}{p_{c l}}=\frac{B-R^{L}}{p_{1}} \cdot \max \left(\alpha_{L}, \alpha_{F}\right) \\
q_{0}>q_{C L}^{H}=\frac{B-R^{H}}{p_{c l}}=\frac{B-R^{H}}{p_{1}} \cdot \max \left(\alpha_{L}, \alpha_{F}\right)
\end{gathered}
$$

If nature chooses $D C$ to be of type $D C^{L}$, then given that expected reprisals are low, $D C^{L}$ will always choose to initiate negotiation for price reduction (i.e. $\beta=1$ ). On the other hand, $D C^{H}$ will choose its strategy, i.e. the probability of initiating price negotiation $\beta$, so as to maximize its expected payoff: 


$$
\begin{gathered}
\max _{\beta}\left[(1-\beta) \cdot q_{0}+\beta \cdot \delta \cdot q_{2}+\beta \cdot(1-\delta) \cdot q_{0}\right] \\
\Rightarrow \max _{\beta}\left[q_{0}+\beta \cdot \delta \cdot\left(q_{2}-q_{0}\right)\right]
\end{gathered}
$$

Since $q_{2}>q_{0}$, for all values of $\delta$, the expected payoff of $D C^{H}$ increases in $\beta$. Therefore, to maximize payoff, $D C^{H}$ will always choose $\beta=1$, i.e. $D C^{H}$ will always initiate a price negotiation.

Result 3: Even if a price negotiation is initiated, the beliefs of PH about DC's type do not change as there is no learning.

Now, according to the conditional probability (i.e. by Bayes' law) determined by the game tree (Figure 2), whenever a price negotiation is initiated, the probability that it comes from type $D C^{H}$ is $\frac{\gamma \cdot \beta}{(1-\gamma)+\gamma \cdot \beta}$, while the probability it is from type $D C^{L}$ is $\frac{(1-\gamma)}{(1-\gamma)+\gamma \cdot \beta}$. However from result 1 , we know that $\beta=1$; and hence the beliefs of $P H$ remain unchanged.

Result 4: A compulsory license will be issued only if the belief-payoff configuration is such that $\pi_{2}<\gamma \cdot \pi_{0}$ and nature chooses $D C=D C^{L}$.

Recall that $P H$ believes that $D C$ is of type $D^{H}$ and $D C^{L}$ with probability $\gamma$ and $(1-\gamma)$ respectively. Thus, $P H$ chooses $\delta$, the probability of making the counter-offer $p_{2}$, so as to maximize its expected payoff, i.e.:

$$
\begin{aligned}
\max _{\delta}\left[\delta \left[(1-\gamma)\left(\pi_{2}\right)\right.\right. & \left.\left.+(\gamma)\left(\pi_{2}\right)\right]+(1-\delta) .\left[(1-\gamma)(0)+(\gamma)\left(\pi_{0}\right)\right]\right] \\
& \Rightarrow \max _{\delta}\left[\gamma \cdot \pi_{0}+\delta \cdot\left(\pi_{2}-\gamma \cdot \pi_{0}\right)\right]
\end{aligned}
$$

Clearly, when $\pi_{2}>\gamma \cdot \pi_{0}$, the expected payoff of $P H$ is increasing in $\delta$ implying that $P H$ will attribute the highest probability $\delta=1$ to the counteroffer $p_{2}$. By construction $p_{2}$ offers better payoffs to both $D C^{H}$ and $D C^{L}$ as compared to issuing a compulsory license or the status quo. And hence it will be accepted. Similarly, when $\pi_{2}<\gamma \cdot \pi_{0}$, $P H$ will affirm the status-quo. Here, it is in the interest of $D C^{L}$ to issue a compulsory license, while for $D C^{H}$ it is better to accept the status quo.

Note that $\pi_{2}$ represents the certain payoffs for $P H$ from taking the safe route of proposing a lower price $p_{2}$, while $\gamma . \pi_{0}$ is the expected payoff from pursuing the risky path of refusing to lower the drug price. Consequently, result 4 indicates that whenever the certain returns from the safe route exceeds the expected payoffs from the risky 
route (i.e. $\pi_{2}>\gamma \cdot \pi_{0}$ ), $P H$ will follow the safe route of making a counter offer. Thus, result 4 demonstrates that if the patent holder is handicapped by incomplete information, then even if it takes a bold stand on the basis of rational expectations and rejects a demand to lower drug prices, the true state of the world could be such that the bet does not pay off and a compulsory license is issued.

\subsection{Numerical examples}

For a better understanding of the dynamics of the game presented in the previous section, we developed numerical solutions for the equilibrium as the parameters vary. Table 6-2 shows the starting conditions for the game.

Table 6-2: Fixed parameters for the numerical examples

\begin{tabular}{|c|c|c|}
\hline Parameter & Variable & Value \\
\hline Budget & $B$ & $\$ 1.000 .000$ \\
\hline Initial price & $p_{0}$ & $\$ 250$ \\
\hline Initial quantity & $Q_{0}$ & 4.000 \\
\hline Lowest price of the drug & $p_{1}$ & $\$ 125$ \\
\hline Highest quantity & $Q_{1}$ & 8.000 \\
\hline Average production cost & $c$ & $\$ 100$ \\
\hline Initial profit & $\pi_{0}$ & 600.000 \\
\hline Profit when accepts $\mathrm{p} 1$ & $\pi_{1}$ & 200.000 \\
\hline
\end{tabular}

\subsubsection{Complete information}

In the game with complete information, we want to demonstrate how the negotiation outcome and the respective agreed price vary according to different reprisal and manufacturing capacity levels. First, based on Result 1 (see Section 6.3.3)and for the parameters given by Table 6-2, we can easily see that when the reprisal level $R \geq \bar{R}=$ 500.000 , the compulsory license threat is not credible and, therefore, the developing country will accept the status quo regardless of the existing manufacturing capacity. Conversely, when the manufacturing capacity $\max \left(\alpha_{L}, \alpha_{F}\right) \leq \underline{\alpha}=0,5$, the developing country will accept the status quo regardless of the expected reprisal. These conditions are depicted in Figure 6-3 and Figure 6-4 below. 


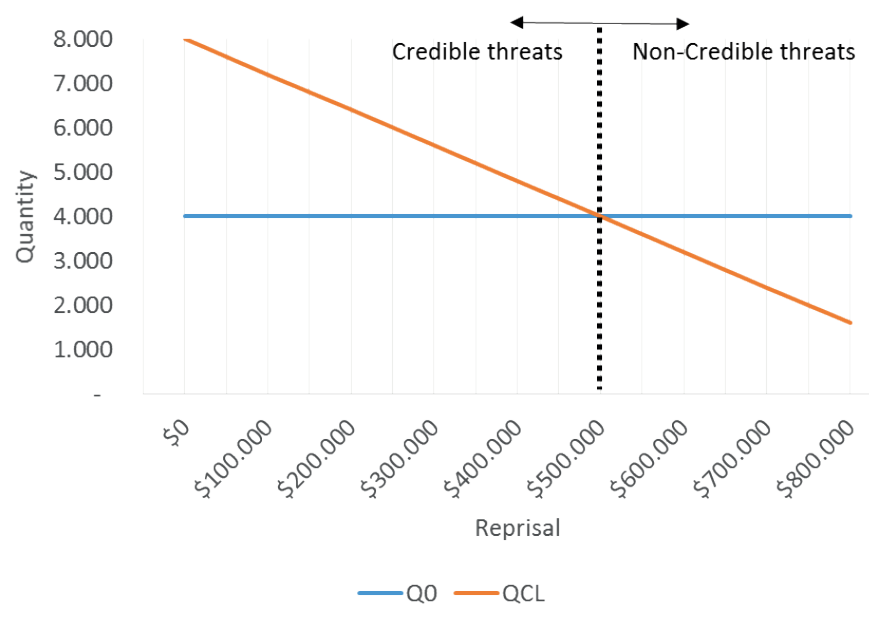

Figure 6-3: Quantity obtained under compulsory license for different reprisal levels $\max \left(\alpha_{L}, \alpha_{F}\right)=1$

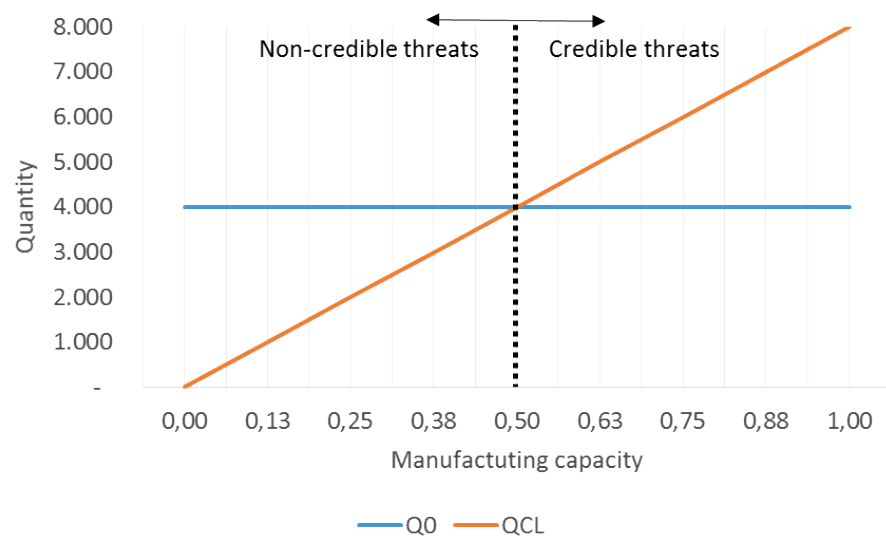

Figure 6-4: Quantity obtained under compulsory license for different levels of manufacturing capacity $R=\mathbf{0}$

For the rest of this exercise, we will use the five different reprisal levels (see Table 6-3) and five values for the level of manufacturing capacity (see Table 6-4). 
Table 6-3: Different reprisal values used in this exercise

Variable

Value

\begin{tabular}{ll}
\hline \hline$R_{1}$ & 0 \\
$R_{2}$ & $\$ 125.000$ \\
$R_{3}$ & $\$ 250.000$ \\
$R_{4}$ & $\$ 375.000$ \\
$R_{5}$ & $\$ 499.000$ \\
\hline \hline
\end{tabular}

Table 6-4: Different manufacturing capacity values used in this exercise

\begin{tabular}{cl} 
Variables & Value \\
\hline \hline $\max \left(\alpha_{L}, \alpha_{F}\right)_{1}$ & 0,510 \\
$\max \left(\alpha_{L}, \alpha_{F}\right)_{2}$ & 0,626 \\
$\max \left(\alpha_{L}, \alpha_{F}\right)_{3}$ & 0,750 \\
$\max \left(\alpha_{L}, \alpha_{F}\right)_{4}$ & 0,875 \\
$\max \left(\alpha_{L}, \alpha_{F}\right)_{5}$ & 1,00 \\
\hline \hline
\end{tabular}

In Table 6-5, we present the results of a comparative static analysis of the impact of changes in these variables on the quantity that the developing country can procure after a compulsory license is granted. As specified in the model, manufacturing capacity and reprisal have a joint influence on a country's bargaining strength. Therefore, the maximum quantity that can be obtained under compulsory license occurs when the reprisal is minimal and the manufacturing capacity is highest. It is interesting to see that intermediary values of reprisal and manufacturing capacity affect the credibility of the threat. For instance, when the reprisal is very high, as in $R_{5}$, the compulsory license threat is non-credible even for high levels of manufacturing capacity (e.g. $\left.\max \left(\alpha_{\mathrm{L}}, \alpha_{\mathrm{F}}\right)_{4}=0.875\right)$. Conversely, when the level of manufacturing capacity is low, even low reprisal levels are not sufficient to make the threat being credible. The grey areas in Table 6-5 denotes the scenarios in which the compulsory license is credible (that is, if a compulsory license is issued, then the developing country can procure a greater quantity of a drug than the amount that is currently procured). 
Table 6-5: Quantity obtained under compulsory license for different levels of both reprisal and manufacturing capacity

\begin{tabular}{cccccc} 
& $\boldsymbol{R}_{\mathbf{1}}$ & $\boldsymbol{R}_{\mathbf{2}}$ & $\boldsymbol{R}_{\mathbf{3}}$ & $\boldsymbol{R}_{\mathbf{4}}$ & $\boldsymbol{R}_{\mathbf{5}}$ \\
\hline \hline $\max \left(\boldsymbol{\alpha}_{L}, \boldsymbol{\alpha}_{\boldsymbol{F}}\right)_{\mathbf{1}}$ & 4.080 & 3.570 & 3.060 & 2.550 & 2.044 \\
$\max \left(\boldsymbol{\alpha}_{L}, \boldsymbol{\alpha}_{\boldsymbol{F}}\right)_{\mathbf{2}}$ & 5.008 & 4.382 & 3.756 & 3.130 & 2.509 \\
$\operatorname{ax}\left(\boldsymbol{\alpha}_{L}, \boldsymbol{\alpha}_{\boldsymbol{F}}\right)_{\mathbf{3}}$ & 6.000 & 5.250 & 4.500 & 3.750 & 3.006 \\
$\max \left(\boldsymbol{\alpha}_{L}, \boldsymbol{\alpha}_{\boldsymbol{F}}\right)_{\mathbf{4}}$ & 7.000 & 6.125 & 5.250 & 4.375 & 3.507 \\
$\max \left(\boldsymbol{\alpha}_{L}, \boldsymbol{\alpha}_{\boldsymbol{F}}\right)_{\mathbf{5}}$ & 8.000 & 7.000 & 6.000 & 5.000 & 4.008 \\
\hline \hline
\end{tabular}

In Table 6-6, we do a similar analysis to check the patent holder responses to a compulsory license threat for different levels of manufacturing capacity and reprisal. The grey areas refer to the scenarios in which the compulsory license threat is credible and, therefore, the patent holder has to reduce the drug price to avoid losing the market. The greater the quantity that the developing country can procure under compulsory license, the lower will be the price $\left(p_{2}\right)$ counteroffered by the patent holder.

Table 6-6: Patent holder's optimal counteroffer $\left(\boldsymbol{p}_{2}\right)$ to avoid compulsory license

\begin{tabular}{cccccc} 
& $\boldsymbol{R}_{\mathbf{1}}$ & $\boldsymbol{R}_{\mathbf{2}}$ & $\boldsymbol{R}_{\mathbf{3}}$ & $\boldsymbol{R}_{\mathbf{4}}$ & $\boldsymbol{R}_{\mathbf{5}}$ \\
\hline \hline $\max \left(\boldsymbol{\alpha}_{\mathbf{L}}, \boldsymbol{\alpha}_{\boldsymbol{F}}\right)_{\mathbf{1}}$ & 245,10 & 250,00 & 250,00 & 250,00 & 250,00 \\
$\max \left(\boldsymbol{\alpha}_{\boldsymbol{L}}, \boldsymbol{\alpha}_{\boldsymbol{F}}\right)_{\mathbf{2}}$ & 199,68 & 228,21 & 250,00 & 250,00 & 250,00 \\
$\max \left(\boldsymbol{\alpha}_{\boldsymbol{L}}, \boldsymbol{\alpha}_{\boldsymbol{F}}\right)_{\mathbf{3}}$ & 166,67 & 190,48 & 222,22 & 250,00 & 250,00 \\
$\max \left(\boldsymbol{\alpha}_{\boldsymbol{L}}, \boldsymbol{\alpha}_{\boldsymbol{F}}\right)_{\mathbf{4}}$ & 142,86 & 163,27 & 190,48 & 228,57 & 250,00 \\
$\max \left(\boldsymbol{\alpha}_{\mathbf{L}}, \boldsymbol{\alpha}_{\boldsymbol{F}}\right)_{\mathbf{5}}$ & 125,00 & 142,86 & 166,67 & 200,00 & 249,50 \\
\hline \hline
\end{tabular}

Table 6-7 presents the impact of this dynamics on the patent holder's profit. Following Result 1 (see section 6.3.3), the patent holder can obtain positive profits in all instances when a price reduction is agreed upon. Therefore, under complete information, the patent holder will always be better off by offering a price discount than it would be in case of compulsory license (when the profit would be zero, given the model assumptions). 
Table 6-7: Patent holder's profit

\begin{tabular}{cccccc} 
& $\boldsymbol{R}_{\mathbf{1}}$ & $\boldsymbol{R}_{\mathbf{2}}$ & $\boldsymbol{R}_{\mathbf{3}}$ & $\boldsymbol{R}_{\mathbf{4}}$ & $\boldsymbol{R}_{\mathbf{5}}$ \\
\hline \hline $\max \left(\boldsymbol{\alpha}_{L}, \boldsymbol{\alpha}_{F}\right)_{\mathbf{1}}$ & 592.000 & 600.000 & 600.000 & 600.000 & 600.000 \\
$\max \left(\boldsymbol{\alpha}_{L}, \boldsymbol{\alpha}_{F}\right)_{\mathbf{2}}$ & 500.000 & 561.800 & 600.000 & 600.000 & 600.000 \\
$\max \left(\boldsymbol{\alpha}_{L}, \boldsymbol{\alpha}_{F}\right)_{\mathbf{3}}$ & 400.000 & 475.000 & 550.000 & 600.000 & 600.000 \\
$\max \left(\boldsymbol{\alpha}_{L}, \boldsymbol{\alpha}_{F}\right)_{\mathbf{4}}$ & 300.000 & 387.500 & 475.000 & 562.500 & 600.000 \\
$\max \left(\boldsymbol{\alpha}_{L}, \boldsymbol{\alpha}_{F}\right)_{\mathbf{5}}$ & 200.000 & 300.000 & 400.000 & 500.000 & 599.200 \\
\hline \hline
\end{tabular}

The Table 6-8 summarizes the sub game-perfect equilibrium strategies under complete information for different levels of reprisal and manufacturing capacity. In game theory, a strategy for a player is a complete plan of action and must specify a feasible action for the player in every contingency in which the player might be called on to act. This is why we specified the moves of the patent holder (and a subsequent response of the developing country) even when the developing country accepts the status quo in the beginning. As discussed before, no compulsory license is issued under incomplete information.

Table 6-8: Sub game-Perfect Nash Equilibrium for different reprisal and manufacturing capacity levels

\begin{tabular}{|c|c|c|c|c|c|}
\hline & 0 & 125.000 & 250.000 & 375.000 & 500.000 \\
\hline 0,5 & $\begin{array}{l}\text { (1) DC accepts } \\
\text { the status quo; } \\
\text { (2) PH reinforc- } \\
\text { es the status } \\
\text { quo; (3) DC } \\
\text { accepts. }\end{array}$ & $\begin{array}{l}\text { DC accepts the } \\
\text { status quo; (2) } \\
\text { PH reinforces } \\
\text { the status quo; } \\
\text { (3) DC accepts. }\end{array}$ & $\begin{array}{l}\text { DC accepts the } \\
\text { status quo; (2) } \\
\text { PH reinforces } \\
\text { the status quo; } \\
\text { (3) DC accepts. }\end{array}$ & $\begin{array}{l}\text { DC accepts the } \\
\text { status quo; (2) } \\
\text { PH reinforces } \\
\text { the status quo; } \\
\text { (3) DC accepts. }\end{array}$ & $\begin{array}{l}\text { DC accepts the } \\
\text { status quo; (2) } \\
\text { PH reinforces } \\
\text { the status quo; } \\
\text { (3) DC accepts. }\end{array}$ \\
\hline
\end{tabular}

(1) DC makes (1) DC makes

$\mathrm{CL}$ threat; (2) $\mathrm{CL}$ threat; (2)

PH counterof- PH counterof-

$\mathbf{0 , 6 2 5}$ fers the price fers the price \$200; (3) DC \$229; (3) DC accepts. accepts,

(1) DC makes (1) DC makes (1) DC makes

$\mathrm{CL}$ threat; (2) $\mathrm{CL}$ threat; (2) $\mathrm{CL}$ threat; (2)

PH counterof- $\mathbf{P H}$ counterof- $\mathbf{P H}$ counterof-

$\mathbf{0 , 7 5}$ fers the price fers the price fers the price \$167; (3) DC \$190; (3) DC \$222; (3) DC accepts. accepts. accepts.
DC accepts the DC accepts the status quo; (2) status quo; (2) PH reinforces $\mathbf{P H}$ reinforces the status quo; the status quo; (3) DC accepts. (3) DC accepts. 


\begin{tabular}{|c|c|c|c|c|c|}
\hline & 0 & 125.000 & 250.000 & 375.000 & 500.000 \\
\hline 0,875 & $\begin{array}{l}\text { (1) DC makes } \\
\mathrm{CL} \text { threat; (2) } \\
\text { PH counterof- } \\
\text { fers the price } \\
\text { \$143; (3) DC } \\
\text { accepts. }\end{array}$ & $\begin{array}{l}\text { (1) DC makes } \\
\mathrm{CL} \text { threat; (2) } \\
\text { PH counterof- } \\
\text { fers the price } \\
\text { \$163; (3) DC } \\
\text { accepts. }\end{array}$ & $\begin{array}{l}\text { (1) DC makes } \\
C L \text { threat; (2) } \\
\text { PH counterof- } \\
\text { fers the price } \\
\$ 190 ; \quad \text { (3) DC } \\
\text { accepts. }\end{array}$ & $\begin{array}{l}\text { (1) DC makes } \\
\mathrm{CL} \text { threat; (2) } \\
\text { PH counterof- } \\
\text { fers the price } \\
\text { \$229; (3) DC } \\
\text { accepts. }\end{array}$ & $\begin{array}{l}\text { DC accepts the } \\
\text { status quo; (2) } \\
\text { PH reinforces } \\
\text { the status quo; } \\
\text { (3) DC accepts. }\end{array}$ \\
\hline 1 & $\begin{array}{l}\text { (1) DC makes } \\
\text { CL threat; (2) } \\
\text { PH accepts; }(3) \\
\text { DC accepts }\end{array}$ & $\begin{array}{l}\text { (1) DC makes } \\
\mathrm{CL} \text { threat; (2) } \\
\text { PH counterof- } \\
\text { fers the price } \\
\$ 143 ; \text { (3) DC } \\
\text { accepts. }\end{array}$ & $\begin{array}{l}\text { (1) DC makes } \\
\mathrm{CL} \text { threat; (2) } \\
\text { PH counterof- } \\
\text { fers the price } \\
\$ 167 \text { (3) DC } \\
\text { accepts. }\end{array}$ & $\begin{array}{l}\text { (1) DC makes } \\
\mathrm{CL} \text { threat; (2) } \\
\text { PH counterof- } \\
\text { fers the price } \\
\$ 200 ; \quad \text { (3) DC } \\
\text { accepts. }\end{array}$ & $\begin{array}{l}\text { DC accepts the } \\
\text { status quo; (2) } \\
\text { PH reinforces } \\
\text { the status quo; } \\
\text { (3) DC accepts. }\end{array}$ \\
\hline
\end{tabular}

\subsubsection{Incomplete information}

For the game under incomplete information, we restrict the analysis to two reprisal levels, that is $R^{L}=125.000$ and $R^{H}=500.000$ being the expected reprisal for $D C^{L}$ and $D C^{H}$, respectively. All the other parameters remain the same as in Table 6-2. Therefore, as we noted in the previous section, a compulsory license threat made by $D C^{H}$ is non-credible for any given level of manufacturing capacity.

Then we analyse how the outcome of the price negotiations change as we vary the level of manufacturing capacity and the patent holder's beliefs about DC's type, that is $\gamma$. As explained on section 6.3.3, the patent holder will prefer to reinforce status quo whenever its expected payoff associated with this strategy is greater than the expected payoff of counter offering a lower price $p_{2}$. According to the Result 2 (see Section 6.4.4), this will happen when

$$
\gamma>\gamma^{*}=\frac{\pi_{2}}{\pi_{0}}
$$

Table 6-9 shows the values that $\gamma^{*}$ assumes for different manufacturing capacity leves, given the other parameters used in this numerical example. The Figure 6-5 presents the interaction between the patent holder's expected payoff of reinforcing the status quo and its belief $\gamma$ that DC if of type $D C^{H}$. In this figure we can see, as it was already shown in preposition 2, that the expected payoff of reinforcing the status quo has a positive relationship with the belief $\gamma$. 
Table 6-9: Values for manufacturing capacity level and beliefs $\left(\gamma^{*}\right)$

\begin{tabular}{llll} 
Manufacturing capacity & $\boldsymbol{\pi}_{\mathbf{2}}$ & $\boldsymbol{\pi}_{\mathbf{0}}$ & $\boldsymbol{\gamma}^{*}$ \\
\hline \hline $\max \left(\alpha_{L}, \alpha_{\mathrm{F}}\right)=0,625$ & 562.500 & 600.000 & 0,938 \\
$\max \left(\alpha_{L}, \alpha_{\mathrm{F}}\right)=0,75$ & 475.000 & 600.000 & 0,792 \\
$\max \left(\alpha_{L}, \alpha_{\mathrm{F}}\right)=0,875$ & 387.500 & 600.000 & 0,646 \\
$\max \left(\alpha_{L}, \alpha_{\mathrm{F}}\right)=1$ & 300.000 & 600.000 & 0,500 \\
\hline \hline
\end{tabular}

In addition, the Figure 6-5 shows how the patent holder's expected payoffs vary according to both its belief in the developing country type (that is, $\gamma$ ) and the level of manufacturing capacity. As presented in section 6.3.3, the counteroffer $p_{2}$.is a function of both the reprisal and the manufacturing capacity. Since the reprisal is fixed in this exercise, in this chart we presented $p_{2}$.as a function of only $\max \left(\alpha_{L}, \alpha_{F}\right)$.

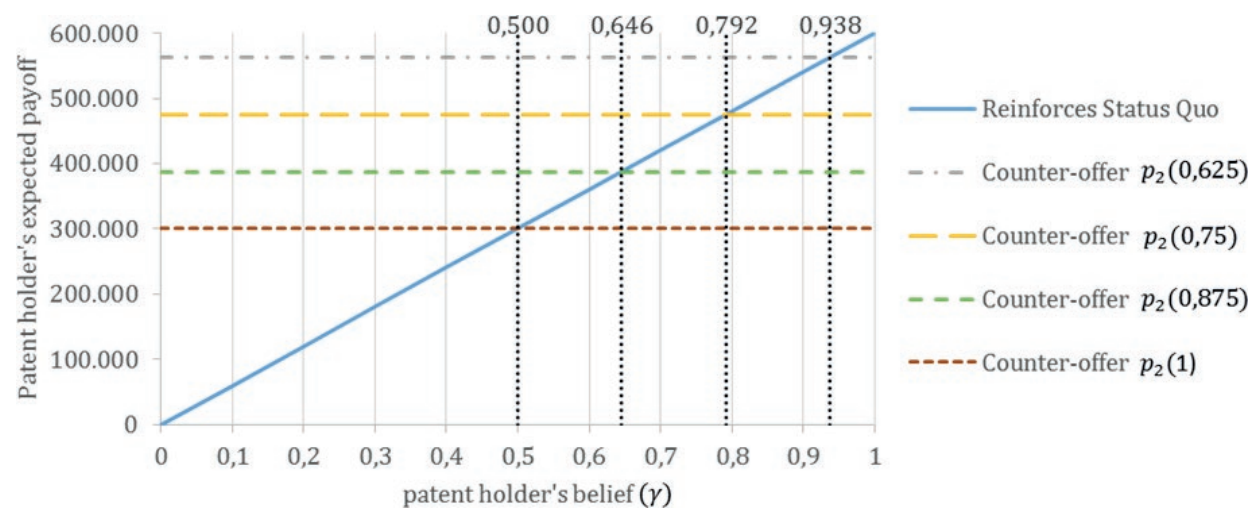

Figure 6-5: Patent holder's expected payoffs according to its belief and to the level of manufacturing capacity

One can clearly see that whenever $\boldsymbol{\gamma} \leq \mathbf{0 , 5}$, the patent holder's expected payoff associated with counter offering $\boldsymbol{p}_{2}$.is greater than the expected payoff associated with reinforcing the status quo for all the four levels of manufacturing capacity considered in this exercise. Therefore, in this circumstance, the patent holder and the developing country will agree on a price reduction. Conversely, the patent holder will reinforce the status quo whenever $\boldsymbol{\gamma}>\mathbf{0}, \mathbf{9 3 8}$. In this case, the negotiation outcome will depend on the developing country's type. For beliefs in the interval $\mathbf{0}, \mathbf{5}<\boldsymbol{\gamma} \leq \mathbf{0 , 9 3 8}$, the patent holder's decision will depend on the existing level of manufacturing capacity. The different possible outcomes for the given values employed in this numerical example are presented in more detail in Table 6-10. 
Table 6-10: Outcome of the game under incomplete information

\begin{tabular}{|c|c|c|c|c|}
\hline Beliefs $\gamma$ & $\begin{array}{l}\max \left(\alpha_{L}, \alpha_{F}\right) \\
=0,625\end{array}$ & $\begin{array}{l}\max \left(\alpha_{L}, \alpha_{F}\right) \\
=0,75\end{array}$ & $\begin{array}{l}\max \left(\alpha_{L}, \alpha_{F}\right) \\
=0,875\end{array}$ & $\max _{=1}\left(\alpha_{L}, \alpha_{F}\right)$ \\
\hline$\gamma \leq \mathbf{0}$ & $\begin{array}{l}P H \text { rejects } p_{1} \\
\text { and } \\
\text { counteroffers } \\
p_{2}=229 \\
D C \text { accepts } p_{2} \\
\text { regardless of } \\
\text { its type }\end{array}$ & $\begin{array}{l}P H \text { rejects } p_{1} \\
\text { and } \\
\text { counteroffers } \\
p_{2}=190 \\
D C \text { accepts } p_{2} \\
\text { regardless of } \\
\text { its type }\end{array}$ & $\begin{array}{l}P H \text { rejects } p_{1} \\
\text { and } \\
\text { counteroffers } \\
p_{2}=163 \\
D C \text { accepts } p_{2} \\
\text { regardless of } \\
\text { its type }\end{array}$ & $\begin{array}{l}P H \text { rejects } p_{1} \\
\text { and } \\
\text { counteroffers } \\
p_{2}=143 \\
D C \text { accepts } p_{2} \\
\text { regardless of } \\
\text { its type }\end{array}$ \\
\hline $0,5<\gamma \leq 0.646$ & $\begin{array}{l}P H \text { rejects } p_{1} \\
\text { and } \\
\text { counteroffers } \\
p_{2}=229 \\
D C \text { accepts } p_{2} \\
\text { regardless of } \\
\text { its type }\end{array}$ & $\begin{array}{l}P H \text { rejects } p_{1} \\
\text { and } \\
\text { counteroffers } \\
p_{2}=190 \\
D C \text { accepts } p_{2} \\
\text { regardless of } \\
\text { its type }\end{array}$ & $\begin{array}{l}P H \text { rejects } p_{1} \\
\text { and } \\
\text { counteroffers } \\
p_{2}=163 \\
D C \text { accepts } p_{2} \\
\text { regardless of } \\
\text { its type }\end{array}$ & $\begin{array}{l}P H \text { rejects } p_{1} \\
\text { and reinforces } \\
\text { status quo } \\
D C \text { accepts } \\
\text { status quo if its } \\
\text { type is } D C^{H} \\
\text { and issue } C L \text { if } \\
\text { of type } D C^{L}\end{array}$ \\
\hline $0,65<\gamma \leq 0,792$ & $\begin{array}{l}P H \text { rejects } p_{1} \\
\text { and } \\
\text { counteroffers } \\
p_{2}=229 \\
D C \text { accepts } p_{2} \\
\text { regardless of } \\
\text { its type }\end{array}$ & $\begin{array}{l}P H \text { rejects } p_{1} \\
\text { and } \\
\text { counteroffers } \\
p_{2}=190 \\
D C \text { accepts } p_{2} \\
\text { regardless of } \\
\text { its type }\end{array}$ & $\begin{array}{l}P H \text { rejects } p_{1} \\
\text { and reinforces } \\
\text { status quo } \\
D C \text { accepts } \\
\text { status quo if its } \\
\text { type is } D C^{H} \\
\text { and issue } C L \text { if } \\
\text { of type } D C^{L}\end{array}$ & $\begin{array}{l}P H \text { rejects } p_{1} \\
\text { and reinforces } \\
\text { status quo } \\
D C \text { accepts } \\
\text { status quo if its } \\
\text { type is } D C^{H} \\
\text { and issue } C L \text { if } \\
\text { of type } D C^{L}\end{array}$ \\
\hline $0,79<\gamma \leq 0,938$ & $\begin{array}{l}P H \text { rejects } p_{1} \\
\text { and } \\
\text { counteroffers } \\
p_{2}=229 \\
D C \text { accepts } p_{2} \\
\text { regardless of } \\
\text { its type }\end{array}$ & $\begin{array}{l}P H \text { rejects } p_{1} \\
\text { and reinforces } \\
\text { status quo } \\
D C \text { accepts } \\
\text { status quo if its } \\
\text { type is } D C^{H} \\
\text { and issue } C L \text { if } \\
\text { of type } D C^{L}\end{array}$ & $\begin{array}{l}P H \text { rejects } p_{1} \\
\text { and reinforces } \\
\text { status quo } \\
D C \text { accepts } \\
\text { status quo if its } \\
\text { type is } D C^{H} \\
\text { and issue } C L \text { if } \\
\text { of type } D C^{L}\end{array}$ & $\begin{array}{l}P H \text { rejects } p_{1} \\
\text { and reinforces } \\
\text { status quo } \\
D C \text { accepts } \\
\text { status quo if its } \\
\text { type is } D C^{H} \\
\text { and issue } C L \text { if } \\
\text { of type } D C^{L}\end{array}$ \\
\hline $0,94<\gamma \leq 1$ & $\begin{array}{l}P H \text { rejects } p_{1} \\
\text { and reinforces } \\
\text { status quo } \\
D C \text { accepts } \\
\text { status quo if its } \\
\text { type is } D C^{H} \\
\text { and issue } C L \text { if } \\
\text { of type } D C^{L}\end{array}$ & $\begin{array}{l}P H \text { rejects } p_{1} \\
\text { and reinforces } \\
\text { status quo } \\
D C \text { accepts } \\
\text { status quo if its } \\
\text { type is } D C^{H} \\
\text { and issue } C L \text { if } \\
\text { of type } D C^{L}\end{array}$ & $\begin{array}{l}P H \text { rejects } p_{1} \\
\text { and reinforces } \\
\text { status quo } \\
D C \text { accepts } \\
\text { status quo if its } \\
\text { type is } D C^{H} \\
\text { and issue } C L \text { if } \\
\text { of type } D C^{L}\end{array}$ & $\begin{array}{l}P H \text { rejects } p_{1} \\
\text { and reinforces } \\
\text { status quo } \\
D C \text { accepts } \\
\text { status quo if its } \\
\text { type is } D C^{H} \\
\text { and issue } C L \text { if } \\
\text { of type } D C^{L}\end{array}$ \\
\hline
\end{tabular}




\subsection{Discussion of results}

The game theoretic model developed in this chapter is aligned with both the literature and the findings in Chapters 4 and 5. That is, the use of compulsory licenses threats in price negotiations depends on the existence of local manufacturing capacity, the availability of import substitutes and political and economic pressures from the government of the patent holder in the post-compulsory license period. The greater the local industrial strengths and import possibilities, and the lower the expected reprisal from the patent holder's government, the stronger is the role of compulsory licensing.

Local manufacturing capacity and availability of generics for imports are substitute factors. In essence, if a country decides to issue a compulsory license, then it has to ensure that there is an alternative supplier for the desired drug. Such an alternative supplier may be either a local actor, provided that it has the required technological capabilities to produce APIs and the final formulation, or an international supplier, provided that it has the technological capacity to produce the drug and that there are no legal or regulatory impediments to the supplier's export decision.

Two contexts were considered, with and without informational constraints. The informational constraint considered was the degree of reprisal against the developing country should a compulsory license be issued for a specific drug. The developing country was assumed to be aware of this, but not the patent holder. The resolution of the game indicated that when all players are completely informed about the parameters of the bargaining process, a compulsory license can be avoided, as there is a price, lower than the existing one that yields higher payoffs than the status quo for the developing country and a compulsory license issuance for the patent holder. Thus, compulsory licenses are issued only under incomplete information, by a low reprisal target country with strong local manufacturing capabilities or access to imports, and when the probability of the developing country being a low reprisal target is low enough for the patent holder to take a risk.

The game with perfect information depicts the best possible scenario for both developing countries and patent holders, assuming the compulsory license threat is credible. When all players are perfectly informed, a developing country would be able to obtain a price reduction such that the quantity it can afford under the new price is greater than the original quantity and also greater than the quantity it would get under compulsory license. Furthermore, by reaching an agreement with the patent holder, the 
government would send a signal to existing and potential investors that it respects the needs and interests of industries sensitive to IPR. On the other hand, the patent holder would not lose the monopoly rights in that specific market. In addition, by avoiding compulsory licensing in a given country the patent holder does not incentivize other countries doing the same.

This point was made clear in a declaration made by the Chief Executive Officer of one of the main American pharmaceutical companies: 'If I don't provide our products in Africa, governments will license our intellectual property to others who can. Governments will intervene. Make no mistake, they will do that. [...] If Africa does it, why not China? Why not India? Why not Latin America? ${ }^{25}$ However, the very same company faced compulsory licenses for at least one of its drugs for HIV/AIDS in the last few years. So why would a company end up with an outcome that is worse than a negotiated price?

A major concern of the innovation-based pharmaceutical industry has been over parallel imports and the effect that price discrimination in favour of least developed countries would have on the motivation for mid-income countries to pay higher prices. Pharmaceutical MNEs are unlikely to be concerned if their drugs are sold at slightly above manufacturing costs in the poorest countries of the world. However, they would be very concerned if this sent a signal that mid-income countries such as Brazil, Argentina, China, and even India, should be able to pay prices near the manufacturing cost. Based on our framework, we argue that to avoid such a contamination effect, the pharmaceutical companies rely excessively on their lobby power over the governments of both their home countries and the developing countries in order to make the status quo prevail or to give a marginal price discount in some markets. When such a lobby fails, a compulsory license may be issued. In the incomplete information game, the fact that the patent holder cannot foresee the retaliation costs expected by the developing country is an attempt to capture this feature of reality.

The games developed in this chapter shed light on the complexity involved to the issuance of a compulsory license by developing countries. Although compulsory license can be an effective tool for lowering drug prices, there are other important variables that must be considered in order to evaluate in which extent it can be used. By definition, a model cannot take into account all variables marking reality and thus variables such as political will and technological change were absent. It is acknowledged that modelling

\footnotetext{
${ }^{45}$ As quoted in London (2004).
} 
the adverse impact of a compulsory license as a retaliation cost to be directly subtracted from the government's budget may be over simplifying reality. But then we could also argue that trade retaliation as well as lower investment in IPR-sensitive industries may have a negative impact on the country's economic performance, which in turn may lead to lower resources for health programmes.

\subsection{Preliminary conclusions}

In any country, the availability of drugs for public health programmes depends on the quantity of drugs that the State is able to buy given its health budget and existing drug prices. Sometimes, the high prices of patented medicines puts the sustainability of public health programmes at great risk. In such cases, public agencies may enter into price negotiations with the patent holder and weigh the possibilities of threatening to use compulsory licensing as a bargaining tool.

Our results indicate that while the use of threats may be useful under situations of informational constraints, compulsory licensing should not be considered as a tool to promote long-term sustainable access to critical medicines. They are at most a shortterm fix for market conditions that exclude patients from receiving the right treatment. Compulsory licensing is a legitimate tool to improve access to patented technologies and it has been used by developed countries such as the United States and Canada even in the last century, to improve access to medicines for their citizens. In the new millennium, the incidence of compulsory license issuance has been increasing, and yet our recognition of this trend is not matched by a better understanding of its determinants and impact. Thus, the present chapter developed a game theoretical representation of the price negotiation process, a compulsory licensing game, between a public agency of a developing country and a patent holder to attempt to provide insight.

A survey of the economics literature on compulsory licensing to improve access to medicine and a descriptive case study on the Brazilian experience (see Chapters 4 and 5) revealed that variables, such as local manufacturing capacity, access to imports and magnitude of expected reprisal from the country of the patent holder, determined the credibility of compulsory licenses as a tool. Thus, the game theoretical model used these variables as indicators of the bargaining powers of the patent holder and the public agency of a developing country. The bargaining strength of the public agency was derived from its access to alternative sources of drugs either through its own manufacturing capacity or through imports. The patent holder, on the other hand, derives its 
bargaining strengths not only through its manufacturing and innovation capabilities, but also through potential reprisals from its government on the developing country. To the best of our knowledge, this is the first attempt to create a framework that integrates the factors considered as critical by the existing literature on compulsory license of lifesaving drugs.

The game theoretical model demonstrated that a compulsory license would not be issued under complete information. However, under informational constraints a compulsory license could be issued if the developing country has sufficient local manufacturing capabilities or access to imports. The informational constraint considered was the degree of reprisal against the developing country in the aftermath of compulsory license, assumed to be known only to the public agency but not the patent holder.

Although the model has certain limitations, we show that there are several political, economic and institutional constraints that makes the developing countries' search for more affordable medicines very challenging, and the current IPR system is only one of them. IPR may be an obstacle for more affordable medicines only if there is an alternative manufacturer capable to supply the drug at a lower price. When such alternative manufacturing capacity does not exist, the access to critical medicines in the developing world is compromised regardless of the patent status of the drug. Thus, developing countries must pursue capacity building strategies in order to strengthen their bargaining position vis-à-vis pharmaceutical companies, and institutional changes that facilitate the issuance of compulsory license for export must be made to benefit the countries for which such strategies are not an option. These contributions are relevant to two main streams of literature: the political economy of IPR and use of TRIPS flexibilities and the political economy of improving access to medicines. 


\section{Chapter 7 Price negotiations of ARVs: Using game theory to explain the Brazilian Model}

\subsection{Introduction}

As we have been discussing throughout this monograph, some countries have tried to improve access to critical patented medicines by negotiating prices with the respective patent holders. Many instances of this negotiation strategy included compulsory license threats when a satisfactory agreement on the drug price was not reached. In addition, as presented in Chapters 3 and 4, Brazil is frequently acclaimed as the most successful example of a country that mobilized such a strategy and the $\mathrm{MoH}$ of Brazil was able to reduce the price of ARV drugs through direct bargaining in many instances.

To understand the rationale of this play further, the previous chapter developed a game theoretic model of bargaining between $\mathrm{MoH}$ and a patent holder. Our objective in $\mathrm{f}$ the current chapter is to test and validate this game-theoretical conceptual framework with the Brazilian experience on price negotiation of ARV drugs. In order to validate the model against actual experience, we first derive propositions from our conceptual framework. Then, these propositions are further refined into three testable hypotheses. In a next step, the hypotheses are cross-checked against a case study based on 14 instances of price negotiations related to ARV drugs in Brazil. The validation process is effectuated using both primary data (interviews and online survey responses) and secondary sources (e.g. public documents). Finally, the hypotheses are tested using a pattern-matching method.

We rely on multiple sources of evidence to classify the episodes in terms of the magnitude of the expected reprisal in case a compulsory license issuance, the patent holders' belief on the expected reprisal and presence of information constraints regarding the expected reprisal. Then, we use these classifications to validate the propositions with the case studies. The model is mostly confirmed by the case studies, as the propositions explain eleven of the fourteen negotiation episodes. However, the model cannot capture all the aspects of real world interactions. To overcome this limitation, the detailed case studies provide richer information on the drivers and determinants of the outcomes of the price negotiations carried out by the $\mathrm{MoH}$ of Brazil that complement the model findings. In addition, the case studies provide alternative explanations for the episodes not explained by the model. 
Besides this Introduction, the chapter includes another five sections. Section 7.2 presents the methodology and the data sources used in this research. In Section 7.3, we present the proposition and hypotheses of the research. In section 7.4, we confront the real episodes of price negotiation for ARV drugs in Brazil with the model to check which proposition explain the outcomes and test the hypotheses. The main results are discussed in Section 7.5, while Section 7.6 concludes the chapter.

\subsection{Data and methods}

\subsubsection{Methodology}

The validation of our theoretical findings follows five steps. First, we derive propositions about characteristics of drug price negotiations from the game theoretic model developed in chapter 6. Secondly, we translate the propositions into hypotheses, which are formulated as expected patterns given the presence or absence of certain conditions. Thirdly, we construct a case study on the Brazilian experience in price negotiations for ARV drugs. Fourth, we define some criteria for valid and reliable measurement of the relevant variables. We try to use quantitative indicators whenever these are available; otherwise, we rely on 'qualitative methods' (such as using 'multiple sources of evidence'). Finally, we test the hypotheses by comparing the observed pattern with the expected pattern. In other words, we compare the predicted outcome to what happened in reality (empirically based pattern).

As defined by Yin (1994), a case study is an empirical inquiry that is suitable for studying complex social phenomena, especially for research on a contemporary phenomenon and when boundaries between a phenomenon and its context are not clearly evident. This exactly fits the conditions of our enquiry. Moreover, we opted for the case study method rather than a large-scale statistical analysis for two reasons. First, there are no secondary sources of data on the parameters of our theoretical model, though proxies can be formulated from existing data for some of them. Second, the number of observations of compulsory license threats in Brazil and in the world is not sufficiently high to justify a statistical analysis. Nevertheless, we pooled a variety of data drawn from primary and secondary sources to make our case. Therefore, the purpose of our case study is to examine the validity of a set of theoretical propositions rather than generalize them to the population as in statistical research. 
Our case study on the Brazilian experience in the price negotiations of ARV drugs has, as a unit of analysis, 14 episodes of price negotiations that took place between 2001 and 2011. One important issue in case studies is the criteria for interpreting the findings and the logic linking the data to the hypotheses. The data analysis technique used in this chapter is 'pattern matching', which can be interpreted as a hypotheticdeductive logic of theory-testing and validity construction ((Hak \& Dul, 2010a, 2010 b). In order to establish that the case study reflects the theoretical realm, we need to have, first, an 'expected or conceptual pattern' (a hypothesis) suggested by the propositions with expected relationships between the variables of interest. Secondly, an 'observed or operational pattern' (empirically based pattern of measured values) that reflects observed interdependencies between the measures of the variables of interest. Finally, a clear criteria to decide whether these patterns match (i.e. the result confirms the hypothesis) or do not match (i.e. the result is a disconfirmation of the hypothesis) (Hak \& Dul, 2010a; Trochim, 1985). Therefore, pattern matching is a non-statistical test of the correctness of the hypothesis and it is essential that the expected pattern be precisely specified before the matching takes place (Hak \& Dul, 2010a).

\subsubsection{Data sources}

Several types of data, including primary and secondary sources, were used in the construction of this case study. Primary data were obtained from 26 semi-structured and exploratory interviews with academics, politicians, lawyers, activists and businesspersons familiar with the Brazilian experience in price negotiation for ARV drugs (see Table 7-1). The interviews were not recorded. Instead, notes were taken and they were written up immediately afterwards. The analysis of these expert interviews did not build on formalized coding protocols. More important was to check statements related to informational constraints, drivers of bargaining position, obstacles faced and alternatives for the future.

The selection of the first subjects to be interviewed was based on bibliographic research in online newspapers, academic journals and on the website of the $\mathrm{MoH}$ in Brazil. Furthermore, we also used a 'snowball sampling' technique, asking interviewed people to give referrals to other possible subjects. These interviews were conducted in Portuguese, between January and March 2012. 
Table 7-1 Interview profiles

Actor

Semi-structured interviews

Exploratory

Total

interviews

interviews

Academics

4

0

4

FioCruz / Farmanguinhos

1

2

3

Ministry of Health

Public agencies and autarkies

1

4

STD/ AIDS Department

1

2

3

2

1

3

Local private companies

MNEs

2

0

NGOs

2 13

13

$2 \quad 2$

13

Total

$13 \quad 26$

The interview approach was used to validate, seek exceptions and clarify theoretical and methodological issues and identify explanations based on the respondent's personal opinion and experience (Kvale, 1996). We mixed two distinct approaches, employing both semi-structured and exploratory interviews. This choice is justified by several variations in the circumstances in which interviews took place, such as the background of the person interviewed, the time available for the interview and personal knowledge of the subject.

The semi-structured interviews were neither an open conversation nor a highly structured questionnaire (Kvale, 1996). Indeed, they were conducted according an interview guide that focused on certain themes and included suggested questions in order to:

- Validate the episodes of price negotiation previously identified;

- Identify additional episodes of price negotiation;

- Validate the conceptual framework based on game theory we have developed;

- Validate the propositions we have derived from the above mentioned conceptual framework;

- Gather information on the role of compulsory licensing in price negotiation as well as the Brazilian experience on this topic; 
Gather information on tools, other than compulsory license, which may be used to bargain, ensure price reduction and promote the sustainability of universal access programmes to lifesaving drugs.

The exploratory interviews were more open, i.e. less structured. In these cases, we introduced the problem we were dealing with and we followed up on the subject's answers. This approach allowed us to locate new information, opinions and common knowledge about new angles on the topic, which were not covered in the interview guide

After summarizing the interviews results, we also submitted an online survey to all the interviewed subjects to validate and clarify the main drivers of the capacity of the Brazilian government to reduce the price of ARV drugs that were raised during the interviews. The main idea was to reduce the importance of personal opinion and to obtain a greater level of generalization on those issues. The rate of response was 21 out 26 $(81 \%)$.

Secondary sources of data included official documents, scientific articles, national and international reports, $\mathrm{MoH}$ and Department of STD/AIDS websites and newspaper articles. These sources were very helpful not only to supplement interviews, but also to provide additional understanding of the broader context surrounding each episode of price negotiation.

\subsection{Propositions and hypotheses}

Based on the results of the previous chapter, we had demonstrated the following propositions:

\section{PROPOSITION 1: Under complete information,}

If the expected reprisal is very high, (that is $R>\bar{R}$ ), andlor there is neither sufficient local manufacturing capacity nor imports from alternative sources, (that is $\max \left(\alpha_{L}, \alpha_{F}\right)<\underline{\alpha}$ ), the compulsory license will not be credible and the status quo prevails with the drug price remaining at $p_{0}$.

If the compulsory license is credible, then the patent holder and the developing country will agree on a price discount. The lower the reprisal and the lower the price under compulsory license, the higher the price drop. 
A compulsory license is never issued.

\section{PROPOSITION 2: Under incomplete information}

If the patent holders strongly believe that the developing country is a low reprisal target (that is, $\gamma<\frac{\pi_{2}}{\pi_{0}}$ ), then the patent holder and the developing country will agree on a price discount.

If the patent holders strongly believe that the developing country is a high reprisal target (that is, $\gamma>\frac{\pi_{2}}{\pi_{0}}$ ), then the patent holder will affirm the status-quo. In this case, a lowreprisal-target country will issue a compulsory license, while a high-reprisal-target country will accept the status quo.

From the two propositions above, we can derive the main hypotheses to test in our case study, as follows.

H1. A compulsory license is never issued under complete information.

$\mathrm{H} 2$. The price will not change if a generic version of the drug cannot be imported and there is insufficient local manufacturing capacity for the drug.

H3. For a given value of the expected reprisal, the higher levels of local capacity to procure drugs from alternative sources, the lower the negotiated price for the drug.

Hypotheses 1 and 2 assume the form of necessary conditions. If a necessary condition is observed, this does not guarantee that the predicted outcome will occur (which would imply that the condition is "sufficient") but solely that the outcome has become possible. Therefore, hypothesis 1 implies that incomplete information is a necessary condition for compulsory license, while hypothesis 2 implies that the existence of alternative suppliers is necessary condition for price reductions.

On the other hand, hypothesis 3 is a probabilistic condition as it expresses a probabilistic relation between concepts. That is, for higher levels of the value of local manufacturing capacity at the drug level, the average level of the price offered by the patent holder will be lower. Therefore, hypothesis 3 assumes that manufacturing capacity at the drug level causes price reduction but without insisting on a deterministic relation between the two variables in terms of absolute magnitude of change. 


\subsection{Validating the model against actual episodes of price negotiations}

\subsubsection{Explaining the cases with the propositions}

Is this subsection we use 'multiple sources of evidence' to classify the episodes in terms of magnitude of the expected reprisal in case a compulsory license issuance (i.e. either high reprisal or low reprisal), the patent holder's belief on the type of the developing country (i.e. either high reprisal target or low reprisal target), and completeness of information (i.e. either complete or incomplete information). Then, we confront the outcome of these episodes to the model's dynamics and check which proposition(s) explain the real outcome (if any).

\subsubsection{Episodes $1 A$ (Efavirenz) and $1 B$ (Nelfinavir)}

The $\mathrm{MoH}$ was negotiating prices for the drugs Nelfinavir and Efavirenz, which were marketed in Brazil by the companies Hoffmann La Roche (Switzerland) and Merck \& Co. (United States), respectively. Secondary data indicates that the United States government was under considerable pressure from the international community after the settlement panel at WTO (KHN, 2001; Love, 2007). According to a US official 'familiar with the issue', the United States had no objections to the production of Nelfinavir and Efavirenz under Brazilian national emergency law and there was no indication of retaliation from Switzerland or the European Union (Astor, 2001; KHN, 2001)

Therefore, it seems reasonable to assume that in Episodes 1A and 1B the patent holders could not rely on the likelihood of retaliation by their home governments. Furthermore, the Brazilian $\mathrm{MoH}$ had publicly announced its reservation price. Therefore, these episodes seem to match the game scenario under complete information with reprisal $R=0$.

The excerpt below corroborates this result:

'There are at least two episodes of price negotiation in the Brazilian experience that fits with the case of complete information, low or no reprisal, and strong bargaining position of the developing country. One of these cases was in 2001, during the price negotiation with Merck and Roche for Efavirenz and Nelfinavir, respectively.'(Interview - Academics [2]).

Although for both Efavirenz and Nelfinavir there was a more affordable generic version in India, the $\mathrm{MoH}$ could not import these drugs. At that time, the Brazilian legal and 
institutional framework on compulsory licensing did not allow imports for the licensed technologies from other sources than the patent holder. In practice, this meant that Brazil, to issue a compulsory license for the purchase of ARVs in the international market, would have to buy these medicines only from the patent owner or a third party authorized by it. Thus, the $\mathrm{MoH}$ was unable to import medicines from countries that did not grant patents for pharmaceutical products and processes and were able to supply generic versions of ARV drugs more affordable than the patented counterparts (Bermudez et al., 2004). This feature weakens Brazil's bargaining power and, therefore, the best price that the $\mathrm{MoH}$ could get was related only to the local technological capacity. In our game theoretical model, this is equivalent to $\alpha_{F}=0$.

Validation 1: Under these conditions, the actual outcome of Episodes 1A and 1B can be explained by Proposition 1.2.

\subsubsection{Episodes 2A (Efavirenz), 2B (Lopinavir + Ritonavir) and 2C (Nelfinavir)}

The $\mathrm{MoH}$ was again negotiating prices for the drugs Nelfinavir and Efavirenz, and the drug Lopinavir+Ritonavir, which were marketed by Hoffmann La Roche (Switzerland) and Merck \& Co. (United States), and Abbott Laboratories (United States), respectively. According to Richard Virden, who was the Foreign Service Officer at the US Embassy in Brazil, although the final outcome was hard to predict, there were sufficient indications that Brazil was 'prepared to issue compulsory licenses and import [the drugs] if price negotiations are not concluded to its satisfaction' (Virden, 2003). He also pointed out that international admiration of the Brazilian Universal Access Programme and the emergency status that the WTO has conferred upon the AIDS epidemic 'make it likely that the [Government of Brazil] will employ compulsory licensing to assure the supply of AIDS drugs unless the desired price reductions are negotiated'(Virden, 2003). In addition, Merck Communications Director João Sanches stated that lower-level staff of the $\mathrm{MoH}$ affirmed that the Brazilian Government preferred a negotiated solution to the imposition of compulsory licensing under the Public Decree no 4.830/2003. He also admitted that 'at this time, the least painful road for Merck to take would be to negotiate a smaller price reduction or agree to voluntary licensing.' (Virden, 2003).

Given the above, Episodes 2A, 2B, and 2C were characterized as one of incomplete information, where the patent holders strongly believe that Brazil is a low reprisal target (that is, $\gamma<\frac{\pi_{2}}{\pi_{0}}$ ). In addition, interviews suggest that the Government of Brazil 
was expecting reprisals in case a compulsory license was issued (that is $0<R \leq \bar{R}$ ), as shown in the excerpt below.

In 2003, all the elements needed for a compulsory license were set up: all the pertinent ministries were aligned, Farmanguinhos had already developed the technical capability to formulate the drug, there was a supplier from India, and the legislation had been amended to make imports under compulsory licensing possible. However, the Minister of Health did not put the compulsory license forward and accepted the counter offer made by the patent holders. Indeed the price reduction was greater than at the one made at the start of negotiation, but the outcome was still far from what was possible to pay under compulsory license. At the final meeting among MoH's staff, compulsory licensing was compared to an atomic bomb: it is important to possess an atomic bomb just to threaten other countries, but you cannot use it because the political cost outweigh the benefits' (Interview with STD/AIDS Department [2])

Validation 2: Under these conditions, Proposition 2.1 explains the actual outcomes of episodes $2 \mathrm{~A}, 2 \mathrm{~B}$, and $2 \mathrm{C}$.

However, there are also indications of uncertainty regarding local manufacturing capacity. As pointed out by Virden (2003), imports from an alternative supplier 'would likely be a temporary measure until the state-owned lab can begin internal production. Whether Brazil can actually start up production of these pharmaceuticals as cheaply as Brazilian officials seemingly assume is not a foregone conclusion.'

\subsubsection{Episodes 3A (Lopinavir + Ritonavir), 3B (Efavirenz) and 3C (Tenofovir)}

The $\mathrm{MoH}$ was negotiating prices for the drugs Efavirenz and Lopinavir+Ritonavir. Official communications between the US Embassy in Brasilia and officers of the US Government reveal that, from their point of view the Brazilian 'motivation for pressing on voluntary licensing is unclear' (Danilovich, 2005a). In addition, they also indicate that ${ }^{~}[\mathrm{~d}]$ espite $\mathrm{MoH}$ demands, none of the companies have yet entered into voluntary license negotiations with the ministry. All acknowledged that the issue is as much political as economic making the eventual outcome difficult to predict.' (Danilovich, 2005b). Based on these observations, Episode 3A, 3B, and 3C are classified as one of incomplete information.

In this episode, the $\mathrm{MoH}$ decided to prioritize the negotiation with Abbott Laboratories (Danilovich, 2005c; Possas, 2008)(Danilovich, 2005c; Possas, 2008). This can be 
interpreted as a signal that the threat for Lopinavir/Ritonavir was credible, from the Abbott Laboratories' (the patent holder's) perspective, such that it expected to face a compulsory license if the price was not reduced. However, this may have also signalled to Merck that the $\mathrm{MoH}$ would not issue a compulsory license for Efavirenz because, as pointed out by Possas (2008), it would be difficult to handle the pressure from the US Government.

Therefore, in Episode 3A, the Government of Brazil was a low reprisal target $(0<R<\bar{R})$ and so was the patent holder's belief about the country's type (that is, $\left.\gamma<\frac{\pi_{2}}{\pi_{0}}\right)$. On the other hand, in Episode $3 \mathrm{~B}$, the Government of Brazil expected a high reprisal in case of compulsory licensing $(R \geq \bar{R})$ and the patent holder had the right belief about the country's type that is, $\gamma>\frac{\pi_{2}}{\pi_{0}}$.

Indeed, the analysis of the context, as well as interviews corroborate with Brazil being a reprisal target. For instance, Eloan Pinheiro, who was Director of Farmanguinhos at that time and actively engaged in the price negotiations of ARV drugs, affirmed that Brazil did not issue a compulsory license due to the economic pressures it was facing (Pinheiro, 2006, 2012). Such pressures became even greater after the agreement with Abbott, when the US Embassy in Brazil recommended that Brazil should stay on the USTR Priority Watch List, but be downgraded to the Watch List if negotiations with Merck and Gilead Sciences (episodes 3B and 3C, respectively) reach a mutually satisfactory conclusion prior to the Special 301 announcement (Linehan, 2006). Excerpts from the interviews point in the same direction

'[The agreement] occurred after Brazil had already announced a compulsory license for Kaletra, but it was called off after Abbott's CEO participation in a last minute counteroffer. If the cost-benefit ratio associated to compulsory licensing is taken into account, it may be worth accepting a higher price. At the time, there were no versions pre-qualified at WHO, what could create concerns related to the quality of the drug provided under compulsory license (as happened in Thailand) and, thus damaging the public image of the public health program”. (Interview with STD/AIDS Department [3]).'

'Saraiva Felipe, who was just empowered as Health Minister, was really willing to issue a compulsory license for Kaletra after several failed attempts of price negotiations. The presidential decree was already written in the case of Kaletra, but when it came to the crunch, the compulsory license was called off. It was decided that the MoDIT would lead the last 
negotiation instead of the Ministry of Health. After the meeting with Abbot, the MoDIT accepted the company's offer. This decision was taken because, primarily, Dilma Rousseff was concerned about retaliations. Carlos Patriota, the Brazilian ambassador in Washington, was being pushed by the White House and the U.S. Senate against compulsory licensing. They were threatening to retaliate against Brazil in trade if the compulsory license was effectuated. And secondly, there was no generic version pre-qualified by WHO, even though there was one version undergoing.' (Interview with STD/AIDS Department [1])

Validation 3: Therefore, while Episode 3A can be better explained by Proposition 2.1, the Episode 3B matches with the outcome of Proposition 2.2.

Even so, Episode 3A and 3B brings to attention some elements that are not captured in the model, such as belief updating and manufacturing capacity as source of informational constraint. We could see that Abbott Laboratories were not certain about the $\mathrm{MoH}$ 's reservation price. However, in this real episode there were many additional rounds, such that the patent holder was able to offer a price reduction, which was finally accepted. It means that in reality the player can update their beliefs according to the different moves of the opponent. Moreover, the company was able to make a last minute offer even after the compulsory license was announced. Nonetheless, it is not clear whether the threat was a bluff and whether this is why the $\mathrm{MoH}$ retracted from issuing a compulsory license.

Additional interviews also raised the possibility that the $\mathrm{MoH}$ was bluffing on the existing manufacturing capacity in the state-owned laboratories. Thus, this can also be a source of informational constraint.

'Some people have pointed out (like Jarbas Barbosa ${ }^{46}$, for instance) that there was no local capacity to manufacture Lopinavir/Ritonavir in 2005. That is why there was no compulsory licensing and Brazil accepted a higher price in addition to TRIPS plus provisions (e.g. waiving the right to issue compulsory license for this drug in the future) in that negotiation.' (Interview with NGO [1]).

In fact, Jarbas Barbosa wrote an article in a local newspaper questioning the capacity of Farmanguinhos to manufacture the drugs:

\footnotetext{
46 Author's note: Jarbas Barbosa was the Secretary (Vice Minister) for Health in the Ministry of Health of Brazil between 2003 and 2006.
} 
'In this case, for the three most high-cost patented ARVs, Farmanguinhos, in theory, masters the technology of only one ${ }^{47}$. What would we do with the other two? Should we do a bet with an uncertain outcome about or capacity to develop the technology? (...) About the local production capacity, it is important to clarify that Brazil does manufacture almost none of off-patented $A R V$ s. The raw material is imported and only the formulation is done locally. Should not be more appropriate (and safer for patients) to give more priority to master all the technology of production? Thus, we would certainly be more prepared when there was the need to issue a compulsory license.' (Barbosa da Silva Jr., 2006)

Finally, the negotiation with Merck regarding the drug Efavirenz took more than one year. Thus, the MoH's dwindling stocks of the drug in question also weakened its bargaining power in Episode 3B. This additional feature, which is not captured by the model, helps to explain why the status quo prevailed at that time.

The $\mathrm{MoH}$ was negotiating prices for the drug Tenofovir, which was marketed in Brazil by the company Gilead Sciences (United States). Gilead's International Vice President stated that despite he believed on the credibility of the threat, the "pressure from the USG [US Government] and from Brazilian economic ministries was forcing the $\mathrm{MoH}$ to moderate its posture'. Therefore, in Episode 3C, the Government of Brazil was a subject to a reprisal $\mathrm{R}(0<R<\bar{R})$ and so the patent holder's belief about the country's type was, $\gamma<\frac{\pi_{2}}{\pi_{0}}$.

Indian companies introduced the first generic versions of Tenofovir in the market in 2006 (Médecins Sans Frontières, 2006), few months before MoH and Gilead announced an agreement on price reduction. In addition, a local private laboratory was able to supply the API for a generic version of Tenofovir within nine to twelve months after compulsory licensing, while Farmanguinhos would need eight months to master the formulation process of the drug. However, as there was no prior pilot-scale development of the drug, there is no evidence of an estimate price of a local produced generic of Tenofovir.

The same executive from Gilead Science reported that the MoH's strategy of pushing for either voluntary or compulsory licensing could be a way to boost the development of the local pharmaceutical industry via the production of generics. So, the company presented a proposal to the $\mathrm{MoH}$ designed to address reliability of supply and price,

${ }^{47}$ Author's note: he is referring to Efavirenz. 
the two concerns the ministry had also pointed out as underlying its interest in licensing local production of Tenofovir. Moreover, the executive signalled that the company was willing to work with the local government 'to develop a plan for development of an $R \& D$ based pharmaceutical industry in Brazil.'

Validation 4: Therefore, the outcome of this negotiation can be explained by Proposition 2.1.

However, the company's decision to reduce the price of the drug can be a way to avoid local capacity building for its drug, and this feature is not captured in our model. One former Director of the STD/AIDS Department has acknowledged this possibility during the interviews:

'[T] he patent holder may reduce its prices just to make the local production less attractive' (Interview with STD/AIDS Department [2])

\subsubsection{Episode 4 (Atazanavir)}

The $\mathrm{MoH}$ was negotiating prices for the drug Atazanavir, which was marketed in Brazil by the companies Bristol-Myers Squibb (BMS) from the United States. A generic equivalent for Atazanavir was first approved by the FDA - and automatically prequalified by WHO - only in February 2008 (Nunn et al., 2009). In spite of the absence of either a generic version for imports or sufficient technological capacity for immediate local production, Brazil was able to negotiate a price considerably lower than other middle-income countries (Cuba, Peru and Dominican Republic. US\$ 6.20, US\$ 4.87 and US\$ 4.82 per tablet, respectively).

Validation 5: Therefore, none of our propositions explains the outcome of this negotiation. Due to the lack of alternative suppliers, according to Proposition 1.1, the status quo should prevail.

One possible alternative explanation was the shortages for the drug in early 2005, which may have increased the bargaining power of the $\mathrm{MoH}$ in this negotiation. In this case, a compulsory license could be a way to create technological capacity for this drug in the medium term, ${ }^{48}$ while the Ministry of Health would keep buying from the patent holder for the initial price in the meantime. So, as pointed out in Validation 4 (Episode 3C,) by reducing the price, the patent holder makes local production less

\footnotetext{
${ }^{48}$ It would take between 12 and 24 months for a local company to be able to manufacture the drug (Interview with FioCruz / Farmanguinhos [1], and Local company [1])
} 
attractive. In addition, the significance of the Brazilian market for the company was also an important factor according a former Director of BMS in the interview.

'BMS did not face much trouble because the company's strategy was to be part of the solution of the HIVIAIDS problem in Brazil, to be part of the public policy of universal access to ARVs. Excluding African countries, Brazil has the best price of Atazanavir in the world. The Ministry of Health of Brazil was one of the best customers of the company, with large volumes, paying cash and without delays. There was no reason to create trouble with a customer like that. It was wise to establish a cooperative approach.' (Interview with MNE [1])

\subsubsection{Episode 5 (Efavirenz)}

The MoH was negotiating prices for the drugs Efavirenz with Merck \& Co. (United States). The document analysis and interviews suggested, on the one hand, that the Government of Brazil was taking into account the possibility of facing reprisals in case of compulsory licensing, and, on the other hand, it was willing to do so if the patent holder does not come up with a minimum price requirement during the negotiation (that is, . $0<R<\bar{R}$ ).

This was clear in an interview with one person closely involved with this negotiation:

'The Ministry of Industry, Development and Trade was also involved in negotiation because compulsory license is regulated by WTO and it has to ensure that the compulsory license will not be against TRIPS and other trade agreements. Everything was prepared for the compulsory license [of Efavirenz]. Brazil could even accept a price above the one paid in Thailand. The Ministry of Health was paying US\$ 1.59 per tablet but was willing to pay US\$ 1.00 per pill-although it has never declared that openly. Thailand had already issued three compulsory licenses by that time, but the country faced retaliations. Therefore, it is important to take this possibility into account when pushing for a compulsory license.' (Interview with STD/AIDS Department [3])

Interviews and documents suggest that Merck \& Co. was relying on the US Government capacity to put pressure on Brazil against compulsory licensing. For instance, the Merck representative manifested that the company had suggested to the US Embassy that Brazil should be retained on the Priority Watch list for that year (Sobel, 2007). In our game theoretical model, this is equivalent to say that the patent holder had a strong belief that Brazil was a high reprisal target (that is, $\gamma>\frac{\pi_{2}}{\pi_{0}}$ ). 
In a correspondence with the US Government in February 2007, Clifford Sobel (former US Ambassador in Brazil) affirmed that a compulsory license had ceased to be a major concern as '[a]ll of the U.S. pharmaceutical companies that were previously faced with this threat have either reached an accord with the GOB, or in the case of the one remaining firm that hasn't [Merck], believe their situation is relatively secure.' (Sobel, 2007)

In addition, the documentation analysis and interview findings corroborate with the assumption the patent holder was not completely informed about the reprisal level expected by the Government of Brazil (that is, there was incomplete information about the country's type).

'Merck did not believe that Brazil would issue a compulsory license. There was a strong alignment between Lula and Bush at that time. Merck hoped the US Government would give support, but it did not. Clifford Sobel was supporting Merck's decision, but he jumped off the boat as soon as he realized that the White House would not help. Merck believed that Brazil would not issue a compulsory license.' (Interview with MNE [1])

'The 'Big Pharma' companies have a strong influence on their government and use this influence to create political pressure on developing countries willing to issue compulsory license. However, this lobby may fail, leading pharmaceutical companies to a misleading position that, in turn, may create the conditions for a compulsory license.' (Interview with FioCruz / Farmanguinhos [1])

"Merck believed that Brazil was bluffing. It was a "chicken game", because the compulsory license was not the optimal solution for both sides. However, they reached such an impasse that they could not step back anymore.' (Interview with Local Company [1])

Validation 6: Therefore, the outcome of this negotiation matches with the one expected in the model under these circumstances (that is, Proposition 2.2).

There are elements not captured by the model that may also play a role in determining the outcome. This includes other sources of informational constrains, changes in beliefs according to the outcome of past negotiations and other manoeuvres of the pharmaceutical MNEs to avoid a compulsory license being issued.

The interview excerpts below suggest the information about local technological capacity may also be not perfect for one or both players. 
"Merck "tested" the credibility of the threat. Perhaps the political will of the Government was clear, but the technological capacity was not.' (Interview with local company [2]) 'There was imperfect information in the compulsory licensing process. However, such asymmetry of information may be regarding manufacturing capacity. Even the government was not sure of the real capacity (for instance, they thought that LAFEPE would be able to produce Efavirenz, but, at the end, LAFEPE was not)' (Interview with Academics [1]).

'Someone at Merck under evaluated the timing of the negotiation andlor made a mistake regarding the price range that the government was willing to accept. (...) The Ministry of Health also made a mistake by pushing too hard: at the end, it had to keep buying from Merck and import from India while local companies were not able to supply the drug.' (Interview with MNE [2])

The interview excerpts below refer to the possibility of the outcome being affected by changes in the patent holder's beliefs due to the outcome of past negotiations.

'This should be a game with repetition because the actors can learn with the past negotiation outcomes.' (Interview with Academics [2])

'As the time passes by the credibility of the threat reduces if the compulsory license is not issued.' (Interview with Academics [1])

'Merck has always been intransigent. They thought that the compulsory license would not be issued, because they based the decision on past negotiation experiences.' (Interview with STD/AIDS Department [1])

The patent holder also tries to implement other manoeuvres to avoid a compulsory license being issued, as suggested below.

'Merck was convinced that Brazil would not issue a compulsory license for Efavirenz. It was clear that the company was stalling negotiation, because they knew that MoH's stocks of Efavirenz would last only until August 2007. Therefore, Merck knew that if we kept the negotiation ongoing, then we would not have time to import from India.' (Interview with STD/AIDS Department [3])

'[At the last minute] Merck offered a price reduction and voluntary licensing agreement solely to delay a decision in favour of compulsory licensing. The technology transfer process was first offered in 2001, but Merck was always making new requests, making additional excuses. In 2005-2006, the Ministry of Health tried to move the technology transfer for- 
ward but, at the end, they concluded it was a hoax, as the company was willing to delay the transfer until the patent expiration.' (Interview with STD/AIDS Department [1])

\subsubsection{Episodes 6 and 7 (Tenofovir)}

In episode 6, the $\mathrm{MoH}$ was negotiating prices for Tenofovir after declaring the drug as 'of public interest'. Additionally, in episode 7, the negotiations started after INPI rejected Gilead's patent claim, though the company was still appealing the INPI's decision. For this reason, we classified both episodes as 'complete information'.

In 2008, there were high-quality generic versions of Tenofovir available for US\$ 0.43 per unit in India ${ }^{49}$. However, since 2006, Gilead had been offering voluntary license agreements to any interested generic manufacturer in India. These voluntary licenses impose restrictions so that, for example, manufacturers cannot export to middleincome countries such as Brazil, China and South Africa, manufacturers must purchase API from Gilead itself or from a Gilead licensee, among other restrictive clauses (Ford, Gray, \& Venter, 2008; Médecins Sans Frontières, 2008). This strategy allowed Gilead to limit the generic competition as the majority of Indian generic manufacturers capable of producing the product (including Matrix, Ranbaxy, Hetero, Aurobindo and Emcure) have accepted those terms. One major Indian generic manufacturer - Cipladid not enter into an agreement with Gilead. However, this company could face additional obstacles to export a generic version of Tenofovir to Brazil because the drug was not pre-qualified by the WHO. Therefore, Cipla's generic of Tenofovir would have to be approved by the Brazilian regulatory authorities, a process that could take up to 12 months. This could be a plausible explanation for why, in episode 7, $\mathrm{MoH}$ accepted to pay more to Gilead for Tenofovir than $\mathrm{MoH}$ would pay if procured the drug from Cipla.

Validation 7: Episodes 6 and 7 can be partially explained by proposition 1.2. However, as $\mathrm{MoH}^{\prime}$ strategy involved rejecting the drug patent rather than compulsory licensing, there are aspects not captured in the model.

As INPI rejected the patent for Tenofovir, the Brazilian Government had no impediment to support local public and private laboratories to produce the drug. Executives of the company even acknowledged that INPI's decision pointed to generic production of Tenofovir in Brazil. In April 2009, almost three months before INPI rejected Gile-

\footnotetext{
${ }^{49}$ For instance, the generic version of Tenofovir produced by Indian laboratory Matrix was already pre-qualified by WHO (Médecins Sans Frontières, 2008).
} 
ad's appeal, the $\mathrm{MoH}$ announced two public-private consortia for local production of a generic version of Tenofovir (Galvão, 2009).

After the INPI became final, a report from Gilead's executives to the US Embassy Officer in Brazil pointed out why the company granted a price discount. In this report, the company manifested its intention to continue a 'positive relationship' with the $\mathrm{MoH}$ and find a 'constructive path forward' because the company intends to seek new patents in Brazil and do not want to 'hold patients hostage' as a result of the Tenofovir patent rejection (Kubiske, 2009).

\subsubsection{Episodes $8 A$ (Raltegravir) and $8 B$ (Atazanavir)}

The $\mathrm{MoH}$ was negotiating prices for the drugs Atazanavir and Raltegravir with BristolMyers Squibb and Merck \& Co., respectively. The first generic of Raltegravir was introduced only in In July 2013, by the Indian company Hetero Drugs (Médecins Sans Frontières, 2013). However, up to 1 July 2014, there was no WHO-prequalified generic version of Raltegravir. On the other hand, for the drug Atazanavir, there are two Indian companies with generic versions prequalified by the WHO: Emcure Pharmaceutical (since 2008) and Mylan Laboratories (since 2010). However, both companies have entered in agreements with Bristol-Myers Squibb that limits the distribution of Atazanavir sulfate $200 \mathrm{mg}$ and $300 \mathrm{mg}$ capsules to sub-Saharan Africa and India. ${ }^{50}$ Alternatively, since 2012, the Indian company Hetero Drugs reports a price 2.5 times cheaper than what the $\mathrm{MoH}$ was paying for Atazanavir in Brazil. ${ }^{51}$ However, this version had not been pre-qualified by WHO, which limits the MoH's capacity to procure Atazanavir from Hetero in case a compulsory license is granted.

In addition, neither state-owned laboratories nor local private companies had mastered the technology to produce these drugs by reverse engineering. Therefore, the $\mathrm{MoH}$ of Brazil there were no alternative suppliers for these drugs in case of compulsory license unable to procure this drug from these suppliers.

\footnotetext{
${ }^{50}$ In February 2006, Bristol-Myers Squibb entered in a full technology transfer agreement for Atazanavir with generic companies Aspen PharmaCare (South Africa) and Emcure Pharmaceuticals (India). In June 2011, Bristol-Myers Squibb signed an immunity-from-suit agreement with Matrix Laboratories Limited, a Mylan Company.

${ }^{51}$ In January 2011, the Indian Patent office rejected patent applications related to Atazanavir due to lack of inventive steps, allowing the entry of other generic manufacturers in this market.
} 
Validation 8: The model explains neither the drivers of these technology transfer agreements nor the subsequent price discounts.

The agreement between Merck and the $\mathrm{MoH}$ is part of the company's decision to no longer offer standardized price discounts across middle-income countries, starting from 2011. According to the company, these countries will have to negotiate discounted prices on a case-by-case basis. In addition, the strategy of granting a voluntary license to the Brazilian partners may be interpreted as a defensive move to avoid compulsory license in the future. Merck pursued a similar move in India, when the company entered into an agreement with the generic manufacturer Cipla, which was pushing the Indian government for a compulsory licensing of the same.

BMS's monopoly led to another shortage of Atazanavir in 2011 and several patients had to change treatment regimens. ${ }^{52}$ Civil society groups then urged the government to issue a compulsory license due to health emergency, as allowed in the Brazilian IPR (Médecins Sans Frontières, 2012). Therefore, the voluntary license agreement and the price discounts may have been an alternative to avoid the grant of a compulsory license that would build local capacity in the medium-term. In this sense, a voluntary license agreement is more reasonable from the patent holder point of view as it can define the conditions and restrictions for the process of technology transfers, royalties, markets and distribution, among other strategic factors.

Moreover, the absence of an alternative supplier was not the only reason for the $\mathrm{MoH}$ accepting voluntary license agreements instead of issuing compulsory licenses. For instance, in 2012, Alexandre Padilha, who was the Health Minister of Brazil at that time, declared that such technological transfers would not affect the inflows of foreign investments and would have a positive impact on the Brazilian trade balance, as it will allow for import substitution (Vieira, 2012). During the interviews with high-level staff from the $\mathrm{MoH}$ of Brazil, it was clear that a voluntary license was perceived as more investor-friendly than a compulsory license, as seen in the excerpts below.

'As of now, compulsory license is not a priority. The objective of the current policy is to not banalize the use of compulsory licensing. It has to be a health emergency; it is rather an exceptional situation. It cannot be the standard approach to provide more affordable drugs. (...) By fostering public-private partnerships, the Brazilian government is introducing a

\footnotetext{
${ }^{52}$ As discussed in Episode 4, a shortage of Atazanavir also occurred in 2005.
} 
cooperative framework that does not have the political cost associated with compulsory licenses. The patent holder may have some privileges by starting a partnership with a local organisation - especially because it is known that a compulsory license may be issued when needed. It is worth noting that voluntary licenses are more likely for products with patents about to expire. However, the policy should not extend the patent holder's monopoly beyond the time of patent protection (...) This said, it is indeed possible that the compulsory license issued in 2007 influenced these companies to accept voluntary licensing agreements, as they know that Brazil can issue father compulsory licenses if necessary.' (Interview with $\mathrm{MoH}$ [1])

'Currently, there is no discussion of compulsory licensing within the Brazilian Government. Compulsory license is a move that brings several negative outcomes, especially in the perspective of both foreign investors and governors. The current priority is to seek voluntary license agreements instead of compulsory licenses. The government is not explicitly using compulsory licensing threat in these voluntary licensing agreements, but it does not guarantee that there will not be a compulsory license for these drugs either. There are many patents about to expire and companies are trying to create a more friendly relationship with the Ministry of Health as part of their strategy for when they lose the monopoly.' (Interview with $\mathrm{MoH}[2]$ )

'At this moment there is no discussion of further compulsory licenses in Brazil. The Ministry of Health only signed voluntary licenses with both Merck (Raltegravir) and BMS (Atazanavir) because these companies will lose the monopoly after five years of the public-private partnerships and they are obliged to reduce the prices yearly. This is in the contract. The public policy has to be as friendly to foreign companies as to local companies, as long as they are doing what the policy is asking for.' (Interview with $\mathrm{MoH}$ [3])

It is worth discussing that there are concerns about the impact of granting voluntary licenses on improved access to medicines, because the patent holder may impose restrictive conditions on the licensee and extend the monopoly power while the technology transfer is not fully implemented. Thus, even though these voluntary license agreements include clauses for price reduction, Brazilian civil society groups continue to demand transparency over their contractual terms and conditions, particularly since it involves a state-owned laboratory.

The terms of the voluntary license for Raltegravir are deemed as confidential and, therefore, have not been disclosed to the public. We requested information about this partnership through the Access to Information Act ${ }^{53}$, but our request was rejected.

${ }^{53}$ Law $12.527 / 2011$ 
Thus, it is not possible to evaluate whether or not abusive terms have been included while the technology transfer is taking place or even when the royalties are paid later on.

In December 2013, the Working Group for Intellectual Property (Grupo de Trabalho sobre Propriedade Intelectual - GTPI, in the Portuguese acronym) had access to the contract of the voluntary license for Atazanavir through the Access to Information Act. After analysing the contract, GTPI concluded that the negotiation and implementation of the agreement was flawed and identified points that can potentially damage the public health system (GTPI, 2013). The main concerns raised by GTPI (2013) were:

- The contract signed in Brazil expressly prohibits the formulation of fixed-dose combinations. This term is not aligned with international treatment guidelines, which indicate that Atazanavir has to be boosted with Ritonavir. The fixed-dose combination of Atazanavir with Ritonavir facilitates treatment compliance. Therefore, Brazil is at risk of having to pay too much to make a product that is to be replaced shortly after the end of the agreement.

- Farmanguinhos can market and distribute the drug solely within the Brazilian territory.

- The parts not only negotiated a high royalty rate ( $4.5 \%$ of the net sales) but also include a 'double royalty provision'. Both Farmanguinhos and Nortec must pay royalties to BMS for the final product and for the API, respectively. This term sounds abusive, especially taking into account that BMS had entered into royalty-free technology transfer agreements with laboratories in South Africa and India in the past.

- The contract establishes that the MoH is obliged to buy Atazanavir from BMS for five years counting after the approval of the local version by the Brazilian regulatory authority. However, the register for Farmanguinhos' version of Atazanavir was approved by ANVISA only in January 2014 and it is not clear whether the agreement lasts until the patent expires, or until the period of five years is over. This means that Brazil may have a contractual obligation to purchase the product from BMS until 2019, even after the patent expiration in the country in 2017.

\subsubsection{Testing the predictability of the model trough 'pattern-matching'}

presents the observed values observed values of the variables that explain the outcomes according to the conceptual framework presented in the previous subsection 


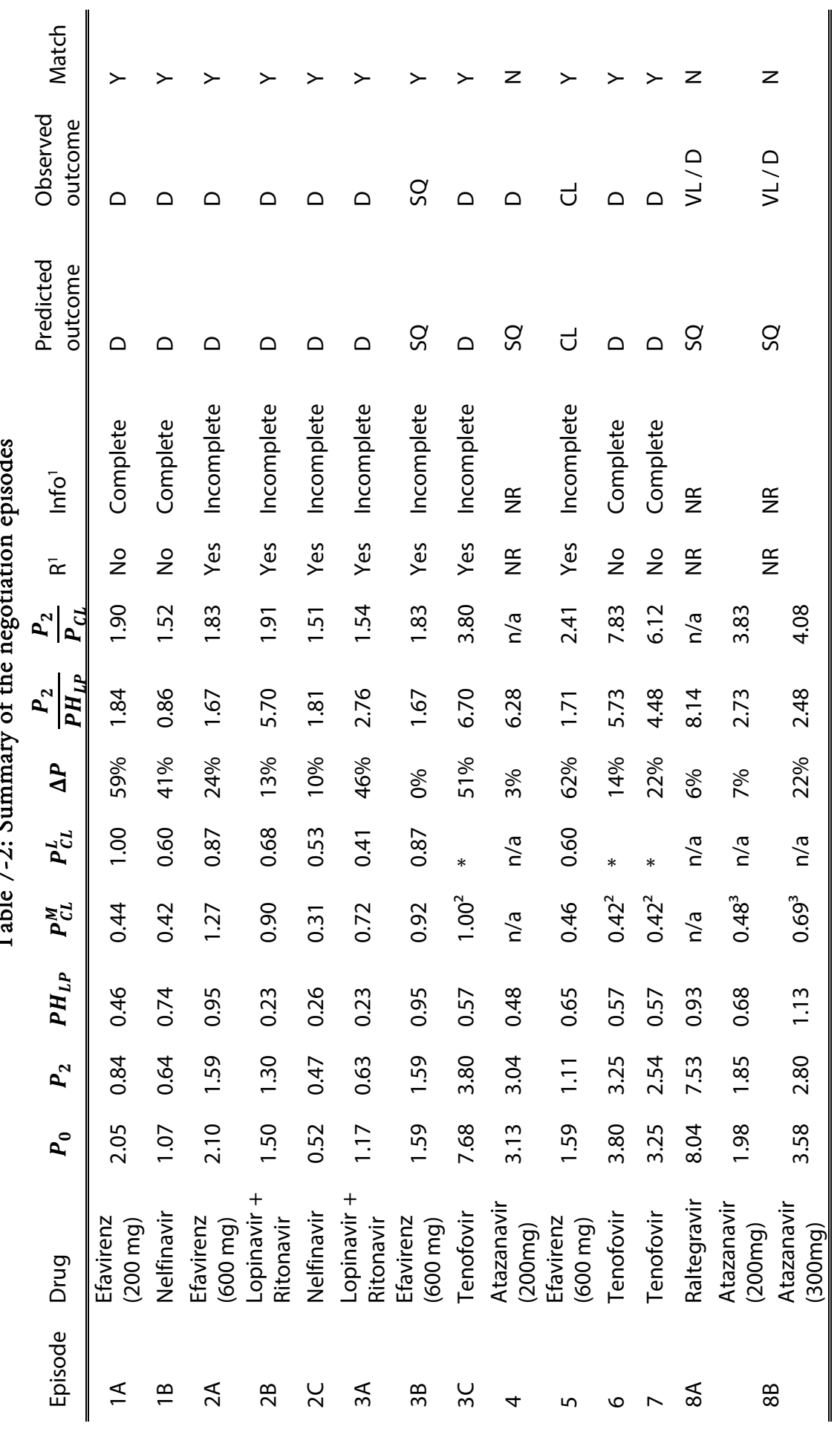


Key: $\boldsymbol{P}_{\mathbf{0}}$ : Initial price; $\boldsymbol{P}_{\mathbf{2}}$ : PH's best offer; $\boldsymbol{P} \boldsymbol{H}_{\boldsymbol{L} \boldsymbol{P}}$ : PH's lowest price; $\boldsymbol{P}_{\boldsymbol{C L}}^{\boldsymbol{M}}$ : cheapest imported generic version; $\boldsymbol{P}_{\boldsymbol{C} \boldsymbol{L}}^{\boldsymbol{L}}$ : price if locally produced; $\boldsymbol{R}$ : Retaliation; Info: information; D: discount; SQ: statusquo; CL: compulsory license; VL: voluntary license; NR: not relevant

* A local consortium comprised by a private company (GENVIDA) and Farmanguinhos was willing to produce Tenofovir, however there was not estimate costs for the local generic version of the drug.

${ }^{1}$ Reprisal and Information were marked as 'NR - not relevant' in episodes where there were no alternative suppliers. According to Proposition 1, under these conditions, prices will not change regardless of the reprisal level or the information status.

${ }^{2}$ Price of generic copies that were not readily available as the product was neither approved in Brazil nor prequalified by the WHO

${ }^{3}$ Generic manufacturers were unable to export to Brazil due to contractual arrangements with the patent holder

To test the necessary conditions is essential that for each single observation in the domain the proposition holds true. In Table 7-3, we test hypothesis 1, that is, if incomplete information is a necessary condition for the issuance of a compulsory license in price negotiations. Following Braumoeller and Goertz (2000), we checked if (i) incomplete information is always observed when a compulsory license occurs; and (ii) compulsory license does not occur in events when complete information is observed.

Table 7-3: Testing H.1

Compulsory License Other Outcomes

\begin{tabular}{lll}
\hline \hline Complete Information & 0 & 4 \\
Incomplete Information & 1 & 6 \\
Information Not Relevant & 0 & 3 \\
\hline \hline
\end{tabular}

Result 1: Based on the above, we cannot reject the hypothesis 1 that compulsory license is never issued under complete information.

In Brazil, Episode 5 is the only instance of compulsory licensing and we collected several sources of evidence that accounts for an incomplete information scenario. Although necessary conditions can be tested in a single instance (see Dion, 1998; Dul \& Hak, 2008; Nock, Michel, \& Photos, 2007), we cannot be sure that the underlying proposition can be generalized for other instances of compulsory license. Therefore, a replication strategy that includes compulsory license incidence in other countries is necessary to check whether our result also applies for broader domains. Analogously, Table 7-4 presents the test for hypothesis 2 . In the episodes $4,8 \mathrm{~A}$, and $8 \mathrm{~B}$ there was no local manufacturing capacity and Brazil was not able to import the drug from third 
parties in case of granting a compulsory license. Therefore, for all levels of expected reprisal the status quo should prevail, as presented in Proposition 1.1. However, the $\mathrm{MoH}$ was able to negotiate discounts in all these cases.

Result 2: Therefore, the hypothesis that the price will not change if a generic version of the drug cannot be imported and there is insufficient local manufacturing capacity for the drug (H2) must be rejected

Table 7-4: Testing H.2

\begin{tabular}{lll} 
Episode & $\begin{array}{l}\text { Availability of alternative } \\
\text { suppliers }\end{array}$ & $\begin{array}{l}\text { Observed } \\
\text { Outcome }\end{array}$ \\
\hline \hline $1 \mathrm{~A}$ & Yes & $\mathrm{D}$ \\
$1 \mathrm{~B}$ & Yes & $\mathrm{D}$ \\
$2 \mathrm{~A}$ & Yes & $\mathrm{D}$ \\
$2 \mathrm{~B}$ & Yes & $\mathrm{D}$ \\
$2 \mathrm{C}$ & Yes & $\mathrm{D}$ \\
$3 \mathrm{~A}$ & Yes & $\mathrm{D}$ \\
$3 \mathrm{~B}$ & Yes & $\mathrm{SQ}$ \\
$3 \mathrm{C}$ & Yes & $\mathrm{D}$ \\
4 & No & $\mathrm{D}$ \\
5 & Yes & $\mathrm{CL}$ \\
6 & Yes & $\mathrm{D}$ \\
7 & Yes & $\mathrm{D}$ \\
$8 \mathrm{~A}$ & No & $\mathrm{VL} / \mathrm{D}$ \\
$8 \mathrm{~B}$ & No & $\mathrm{VL} / \mathrm{D}$ \\
\hline \hline
\end{tabular}

Hypothesis 2 and the measurement for the underlying variables account for manufacturing capacity at the drug level. The rejection of such a hypothesis does not mean that manufacturing capacity is not important. It means that it is possible to negotiate a price for patent drugs and get a price reduction even in the absence of readily available manufacturing capacity for that specific drug(s). This is clear in episodes 3C, 6 and 7, when a local public-private consortium announced that it could manufacture the concerned drug within 12 months. This suggests that the existence of a 'general capacity to manufacture' is already sufficient for obtaining price reductions. 
It would be desirable to differentiate the bargaining strength of a country in price negotiations of patented drugs in terms of the degree of the existing manufacturing capacity. Therefore, we now turn to hypothesis 3 in order to check whether there is a difference in the average price of drugs with a greater level of local manufacturing capacity than otherwise.

As one can see in Table 7-5, the MoH of Brazil paid, in average, 5.6 times the lowest international price for the drugs for which a minimum limit of manufacturing capacity was absent. This difference is more than three times greater than the average difference in the episodes of price negotiation where a minimum limit of manufacturing capacity was present.

Table 7-5: Testing H.3

Episodes where a minimum level of manufacturing capacity was present

\begin{tabular}{|c|c|c|c|c|c|c|c|c|c|}
\hline Episode & $1 \mathrm{~A}$ & $1 \mathrm{~B}$ & $2 \mathrm{~A}$ & $2 \mathrm{~B}$ & $2 C$ & $3 A$ & $3 A$ & 5 & Average \\
\hline $\begin{array}{l}\text { Best offer of the patent } \\
\text { holder vis-à-vis the cheapest } \\
\text { alternative }\end{array}$ & 1.9 & 1.5 & 1.8 & 1.9 & 1.5 & 1.5 & 1.8 & 2.4 & 1.8 \\
\hline
\end{tabular}

Episodes where a minimum level of manufacturing capacity was absent

\begin{tabular}{|c|c|c|c|c|c|c|c|c|c|}
\hline Episode & $3 C$ & $4 \mathrm{~A}$ & $4 B$ & 6 & 7 & $8 \mathrm{~A}$ & $8 B$ & 7C & Average \\
\hline $\begin{array}{l}\text { Best offer of the patent } \\
\text { holder vis-à-vis the cheapest } \\
\text { alternative }\end{array}$ & 3.80 & 6.3 & 4.8 & 7.8 & 6.1 & 3.8 & 4.1 & 8.1 & 5.6 \\
\hline
\end{tabular}

Result 3: Based on the data presented in Table 7-5, we cannot reject the hypothesis that for a given value of the expected reprisal, the higher levels of local capacity to procure drugs from alternative sources, the lower the negotiated price for the drug $(\mathrm{H} 3)$.

One possible rival explanation for such difference in the average price could be the availability of generic drugs for imports. However, as one can see in Table 7-6 no generic version was available for imports in episodes $1 \mathrm{~A}$ and $1 \mathrm{~B} .{ }^{54}$ In addition, only in Episode 5 was there a generic version that was pre-qualified by the WHO. This not only imposed restrictions for imports of such goods due to regulatory constraints, but also could have raised concerns on their quality. Therefore, this evidence does not seem

\footnotetext{
${ }^{54}$ Although there were Indian generic versions for these drugs in the market, as discussed in Chapter 3, the Brazilian legal framework did not allow for imports of compulsory licensed good at that time.
} 
to be sufficient to undermine the importance of the existence of a minimum level of manufacturing capacity in the most successful price negotiations.

Table 7-6: Availability of generic ARVs during price negotiations between $\mathrm{MoH}$ and patent holders

\begin{tabular}{lll} 
Episode & $\begin{array}{l}\text { Generic version available } \\
\text { for imports }\end{array}$ & $\begin{array}{l}\text { WHO-prequalified } \\
\text { generics }\end{array}$ \\
\hline \hline $1 \mathrm{~A}$ & No & No \\
$1 \mathrm{~B}$ & No & No \\
$2 \mathrm{~A}$ & Yes & No \\
$2 \mathrm{~B}$ & Yes & No \\
$2 \mathrm{C}$ & Yes & No \\
$3 \mathrm{~A}$ & Yes & No \\
$3 \mathrm{~B}$ & Yes & No \\
$3 \mathrm{C}$ & Yes & No \\
4 & No & No \\
5 & Yes & Yes \\
6 & Yes & No \\
7 & Yes & No \\
$8 \mathrm{~A}$ & No & No \\
$8 \mathrm{~B}$ & No & No \\
\hline \hline
\end{tabular}

\subsection{Discussion of results}

Table 7-7 summarizes the propositions (if any) that explain each episode of price negotiation, according to the validation exercise presented in section 7.4.1.

Proposition 1.2 indicates that if the compulsory license is credible and the agents are completely informed, then the patent holder and the developing country will agree on a price discount. This proposition can explain the outcomes of the negotiation episodes 1A, 1B, 6, and 7, which were characterized as negotiations with complete information. Nonetheless, the model fails in predicting the magnitude of the price drop in episodes $1 \mathrm{~A}, 6$, and 7 . This may indicate that patent holder's decisions may be influenced by factors that are not captured by the model.

Proposition 2.1 explains the outcomes of episodes 2A, 2B, 2C, 3A and 3C, in which there is incomplete information and the patent holders strongly believe that the devel- 
oping country is a low reprisal target. As expected, the respective patent holders and the $\mathrm{MoH}$ agreed on a price discount in this instance. Proposition 2.2 explains the episodes $3 \mathrm{~B}$ and 5 , in which there is incomplete information and the patent holders strongly believe that the developing country is a high reprisal target. In this scenario, the patent holder affirms the status-quo and a high-reprisal-target country accepts the status quo - as in episode $3 \mathrm{~B}$ - while a low-reprisal-target country issues a compulsory license - as in episode 5 .

Table 7-7: Results derived from validating the propositions with the cases Validation Episode(s) Proposition Observations

\begin{tabular}{|c|c|c|c|}
\hline 1 & $1 \mathrm{~A} ; 1 \mathrm{~B}$ & Proposition 1.2 & $\begin{array}{l}\text { The price discount in Episode } 1 \mathrm{~A} \text { was even greater } \\
\text { than the one predicted by the model. This may } \\
\text { indicate the patent holder's decision may have } \\
\text { alternative drivers that are not captured in the model. }\end{array}$ \\
\hline 2 & $2 \mathrm{~A} ; 2 \mathrm{~B} ; 2 \mathrm{C}$ & Proposition 2.1 & $\begin{array}{l}\text { There are also indications of uncertainty regarding } \\
\text { local manufacturing capacity. }\end{array}$ \\
\hline 3 & $3 B$ & $\begin{array}{l}\text { Propositions } \\
\qquad 2.1 \\
\\
\text { Propositions } \\
2.2\end{array}$ & $\begin{array}{l}\text { There are some elements that are not captured in the } \\
\text { model, such as belief updating, manufacturing } \\
\text { capacity as source of informational constraint, and } \\
\text { spillovers from simultaneous negotiations. }\end{array}$ \\
\hline 4 & $3 C$ & $\begin{array}{l}\text { Propositions } \\
2.1\end{array}$ & $\begin{array}{l}\text { Local public-private consortium had not mastered the } \\
\text { technology yet and there was no import substitutes. } \\
\text { The company's decision to reduce the drug price } \\
\text { could be a way to avoid local capacity building for its } \\
\text { drug, and this feature is not captured in our model. }\end{array}$ \\
\hline 5 & 4 & None & $\begin{array}{l}\text { MoH was willing to build local manufacturing capacity } \\
\text { to avoid further drug shortages. The company's } \\
\text { decision to reduce the drug price could be a way to } \\
\text { avoid local capacity building for its drug, and this } \\
\text { feature is not captured in our model. }\end{array}$ \\
\hline 6 & 5 & Proposition 2.2 & $\begin{array}{l}\text { There are elements not captured by the model that } \\
\text { may also play a role in determining the final outcome. } \\
\text { This includes other sources of informational } \\
\text { constrains, changes in the beliefs according to the } \\
\text { result of past negotiation, other manoeuvres of the } \\
\text { patent holder to avoid a compulsory licensing. }\end{array}$ \\
\hline
\end{tabular}




\begin{tabular}{ccc}
\hline \hline 6roposition 1.2 & $\begin{array}{c}\text { Local public-private consortium had not mastered the } \\
\text { technology yet and there was obstacles to import a } \\
\text { generic from India. This can explain the high prices } \\
\text { paid by MoH even after the patent rejection of the } \\
\text { drug. }\end{array}$ \\
\hline $8 \mathrm{AA} ; 8 \mathrm{~B} \quad$ None $\quad \begin{array}{l}\text { The strategy of granting a voluntary license to the } \\
\text { Brazilian partners may be interpreted as a defensive } \\
\text { move to avoid compulsory license in the future. From } \\
\text { the perspective of the Government of Brazil, voluntary } \\
\text { license is seen as more investor-friendly than } \\
\text { compulsory license. }\end{array}$ \\
\hline
\end{tabular}

In these seven episodes with incomplete information, interviews and document analysis suggest that there may be other sources of informational constraints. The information about the actual level of manufacturing capacity is stressed as being possibly imperfect to both the patent holder and the $\mathrm{MoH}$. This seems especially true in regards to the time taken from the drug development after issuing a compulsory license until the drug can be supplied to patients.

According to proposition 1.1, when there is neither sufficient local manufacturing capacity nor imports from alternative sources - as in episodes $4,8 \mathrm{~A}$ and $8 \mathrm{~B}$ - the compulsory license will not be credible and the drug price will not change. However, in these instances, the $\mathrm{MoH}$ was able to obtain price discounts - sometimes combined with voluntary license agreements - in spite of the absence of alternative suppliers. Therefore, there are no propositions that explain the outcome of these price negotiations. As discussed earlier, from the patent holder's perspective, to agree with a price discount could be a better option than to motivate the creation of local capacity via compulsory license - given the existence of general absorptive capacity and technological capabilities to do so. An alternative explanation for those discounts may be because the governmental pressure on multinational pharmaceutical companies had the effect of enforcing their own declared Corporate Social Responsibility policies to make medicines more available in the developing world, as acknowledged by Flanagan \& Whiteman (2007).

Table 7-8: Results derived from pattern matching to test the hypotheses

\begin{tabular}{lll} 
Result & Hypothesis & Test result \\
\hline \hline Result 1 & H.1 & Not rejected \\
Result 2 & H.2 & Rejected \\
Result 3 & H.3 & Not rejected \\
\hline \hline
\end{tabular}


Table 7-8 summarizes the results of the hypothesis testing presented in section 7.4.2. One interesting result of this chapter is that, based on the Brazilian experience on price negotiations of ARV drugs, we cannot reject the hypothesis (H.1) that incomplete information is a necessary condition for compulsory license (Result 1). The compulsory license for the drug Efavirenz in 2007 (Episode 5) is the very only case of compulsory license issuance in Brazil.

This case study provides evidence that issuing a compulsory license was not MoH's optimal choice and it was willing to accept an intermediate price. The patent holder would also be better off by accepting a price discount instead of losing the market after compulsory licensing. However, there are also indications that the patent holder was not expecting to face a compulsory license, that is, the pharmaceutical MNE did not believe that the threat was credible - something that could have been avoided if the agent was completely informed. Although our case study shows that the presence if informational constraints was determinant for that outcome, it is not possible to generalize this result to a broader spectrum of cases. Therefore, further qualitative research is necessary to check whether this feature apply to other national experiences.

As proposition 1.1 fails to explain the price discounts observed in three negotiations, we rejected the hypothesis (H.2) that price will not change if there is insufficient local manufacturing capacity for the drug and a generic for the same cannot be imported (Result 2). In the model we developed in the previous chapter and, therefore, in the propositions and hypothesis derived from it, we used a drug-level measurement of manufacturing capacity (either local or for imports). However, our results show that lower levels of local manufacturing capacity can be enough to bring drug prices down in negotiations with patent holders. As discussed in Chapters 4 and 5, the existence of manufacturing capacity in small scale (laboratorial or pilot) was a relevant source of bargaining strength in price negotiations. Nonetheless, even when such laboratorial or pilot-scale capacity was absent, the $\mathrm{MoH}$ of Brazil was able to obtain price discounts. This can be an indication that the existence of local absorptive capacity and prior knowledge base for API and drug production play a role in this context. Skills in fine and organic chemistry cumulated locally, especially at Farmanguinhos' research facilities, in previous experiences on reverse engineering for API production and drug formulation created absorptive capability and prior knowledge bases for the local development of other ARV drugs. Therefore, the 'capacity to create manufacturing capacity' can be a source of bargaining strength and, therefore, a driver of price reductions, as suggested by interview statement bellow: 
'The simple fact that Brazil masters the technology and knowledge necessary for API and drug production has resulted in price reductions. Actually, the patent holder may reduce its prices just to make the local production less attractive and, therefore, avoid the creation of local productive capacity.' (Interview with STD/AIDS Department [2]).

Another interview suggests that the existing level of technological capacity in Brazil is sufficient to produce ARV drugs, even though the process can take time. In addition, developing countries may have other motivations to issue a compulsory license - even when there are no immediate substitutes - notably the promotion of local industry. From the perspective of the patent holder, it may be a better option to reduce price than to run the risk of triggering a capacity building process for its drug.

'The issue of technological capacity is complex. Brazil does have technological capacity to produce ARV drugs, including the APIs. However, there are many steps involved, such as drug deformulation, development of an alternative synthesis route, regulatory approval to ensure that the generic drug has the same quality and efficiency, as does the original drug. This process is not straightforward. This is not like an electrical power that you just have to plug into the wall socket. The capacity building takes times. Considering only the production of the API, the entire process can take up to 18 months until large scale production commences.' (Interview with Local Company [1]).

Finally, we cannot reject the hypothesis (H.3) that higher levels of local capacity to procure drugs from alternative sources tend to generate lower prices in negotiations. Result 3 suggest that the $\mathrm{MoH}$ of Brazil was able to negotiate better prices - when compared to the lowest international price - for drugs when manufacturing capacity in small scale was previously developed (i.e. Efavirenz, Nelfinavir, and Lopinavir). The time required to introduce the generic drug in case of compulsory license granting can be the explanation for such difference. In this case, the 'higher' the existent manufacturing capacity, the faster can local production commences and the greater the country's bargaining strength in the negotiation.

Based in these results, it is possible to construct a typology for the episodes of price negotiation, which is presented in 
Table 7-9. Typology of price negotiations after the validation exercise

\begin{tabular}{llll}
\multicolumn{2}{c}{ Episode / Drug } & Outcome & Type of outcome \\
\hline \hline 1A & Efavirenz & Discount & \\
1B & Nelfinavir & Discount & \\
2A & Efavirenz & Discount & Credible threat (D) \\
2B & Lopinavir+Ritonavir & Discount & \\
2C & Nelfinavir & Discount & \\
3A & Lopinavir+Ritonavir & Discount & Non-credible threat \\
\hline 3B & Efavirenz & Status Quo & Disincentive to enter \\
\hline 3C & Tenofovir & Discount & \\
4 & Atazanavir & Discount & Credible threat (CL) \\
\hline 5 & Efavirenz & CL & \\
\hline 6 & Tenofovir & Discount & \\
7 & Tenofovir & Discount & \\
8A & Atazanavir & VL / Discount & \\
$8 B$ & Raltegravir & VL / Discount & \\
\hline
\end{tabular}

Key: $C L=$ Compulsory License VL = Voluntary License

Episodes $1 \mathrm{AB}, 2 \mathrm{~A}, 2 \mathrm{~B}, 2 \mathrm{C}$, and $3 \mathrm{~A}$ were classified as a 'credible threat (D)'. In these instances, the actors that could oppose a compulsory license had little to moderate capacity to influence the outcome of the negotiation. On the other hand, most of the actors that were supportive of a compulsory license were strongly involved in the process. The exceptions were local firms that did not have technological capacity to produce these drugs locally.

Episode 3B was classified as a 'non-credible threat'. As opposed to Episode 3A, in this case there was strong opposition from both MoDIT and the US Government. Moreover, the negotiation lasted for over one year and the $\mathrm{MoH}$ was running out of stock for the drug. All these factors considerably reduced the credibility of the threat, even though it was possible to produce the drug locally.

Episodes 3C and 4 were classified as a 'disincentive to enter' because the patent holder agreed with a discount even when a compulsory license was not very likely due to absence alternative suppliers able to produce the drug in a short notice. However, companies 
decided to give a price discount in an attempt to build a good relationship with the $\mathrm{MoH}$ and not give incentives to the creation of a local capacity to produce these drugs.

Episode 5 was classified as 'credible threat (CL)'. All the fundamental conditions were set for a compulsory license (that is, interministerial alignment, high-quality import substitutes were available, local manufacturing capacity, little external pressure), but the patent holder did not cooperate. When the patent holder did not meet the MoH's reservation price and the conditions were favourable (that is, low expected reprisal and presence of alternative suppliers), then a compulsory license was issued. This is exactly what happened in Episode 5, when the patent holder's best offer was still 2.41 times greater than the cheapest alternative to Strocrin ${ }^{\circledR}$ (Efavirenz). There was technological development at pilot scale for Efavirenz, and the $\mathrm{MoH}$ was able to import the drug from an Indian generic manufacturer while state-owned laboratories could not produce at full scale. Therefore, given these conditions, the MoH's best response was indeed to issue a compulsory license for Efavirenz, as in fact happened in May 4, 2007.

Episodes 6,7, and 8A, and 8B were classified as 'industrial policy' because these negotiations took place under a context of starting local production of the drugs. In Episode 6 and 7, the MoH requested a decision from the Brazilian Patent Office, which is subordinate to MoDIT, regarding the patents for the drug Tenofovir. In the meantime, $\mathrm{MoH}$ and other Ministries were setting up the Industrial Policy that would announce local production of Tenofovir by two local consortia. The announcement of public-private partnerships to manufacture Tenofovir locally took place less than one month after INPI rejected Gilead's appeal. On the other hand, Episodes $8 \mathrm{~A}$ and $8 \mathrm{~B}$ were explicitly conducted under the terms of this industrial policy and the resulting voluntary licensing agreements were conditioned to price discounts while the technology transfer was not finished.

\subsection{Preliminary conclusions}

In this chapter, we provided a game theoretical explanation for the Brazilian Ministry of Health's strategy as well as for the wide variation of the results obtained from it. Our model assumed that the patent holder is not completely informed on the reprisal level, which the Brazilian Government expects to in case a compulsory license is granted. The presence of informational constraints is important to capture features that are common in real-world interactions. Even so, models are simplifications of reality, which can be used to fine-tune intuition and discover new ways of thinking about old problems. Thus, we carried out an explanatory case study on 14 episodes of negotiation 
between the Brazilian Government and foreign pharmaceutical companies for six different drugs. By doing so, we were able to consider some complex aspects of the reality that was not included in the model.

The evidence collected for the case study suggests that the $\mathrm{MoH}$ of Brazil was willing to accept higher prices for patented drug than what it could obtain under compulsory licenses. This was to avoid the negative impact that a compulsory license can cause in the economy. In addition, for the patent holder to give a price reduction is always a better choice than to lose the entire market - especially when the market has a considerable size, as is the case of Brazil. Therefore, accepting a price reduction was perceived as a better outcome for both sides and, even so, there was an instance of compulsory license granting in Brazil. However, in the model developed in Chapter 6, the MoH's reservation price is private information. Thus, when the patent holder does not meet MoH's request, then a compulsory license can be issued.

This complementary analysis was especially valuable for the episodes that the model could not provide an explanation. More qualification to the importance of local manufacturing capacity was provided. It seems that the presence of a general prior knowledge base for API production and drug formulation can be an important driver of price reductions. This opposes our modelling strategy, as we developed a drug-level based measurement for manufacturing capacity. Nonetheless, our findings suggest the accumulation of knowledge and experience on the production development of a specific drug tends to lead to lower prices (relative to the international price) for the same.

It is worth noting that the existing literature is silent about the patent holder's strategies to stall price negotiations. The case study on the Brazilian experience with ARV drugs reveals that patent holders use negotiations as a ploy to gain time or a better outcome. This strategy includes the offering of voluntary licenses that do not concretize, delaying meetings and including extensive protocols to formalize agreements (such as transferring the decision to the headquarters, for instance). The patent holder seems to benefit from longer negotiations because its bargaining power improves as the MoH's stocks for the drug reduces.

Finally, the case studies also pointed out the need for further refinements and extensions of the model in order to include, for instance, voluntary license agreements, other orders of play, time preferences, and belief updates and revisions. The development of a more general model for drug price negotiation can be an important asset for the understanding of the dynamics of such a problematic issue. 


\section{Chapter 8 Policy Implications}

\subsection{Policy recommendations}

In terms of policy recommendations, the central point of this dissertation is that developing countries must work to build their 'bargaining strengths' rather than focus on whether or not to increase the use of compulsory licenses as a means to improve access to medicines through international trade. Following upon this point, our research calls for two main lines of action for public policy. First, governments must implement an adequate IPR framework to avoid undeserved patents and an unsound patent policy. Second, governments must invest in technological capacity building, using other TRIPS flexibilities if necessary.

\subsubsection{Implementation of an appropriate IPR framework}

Any IPR system must ensure that adequate incentives are provided for innovation, but at the same time guard against lowering access to lifesaving drugs. We detail the associated challenges further.

\subsubsection{Setting higher patentability criteria to avoid undeserved patents such as ever- greening}

Governments may not need to depend upon compulsory licenses if they apply stricter standards in examining patent applications. Undeserved patents and an unsound IP policy, including implementation of TRIPS Plus provisions, can be detrimental to access to lifesaving medicines. Therefore, governments should define and enforce clear guidelines on what does and does not deserve a patent. Moreover, it is hard to guarantee that such guidelines are adequately applied for every case. Therefore, IP laws should allow - and public policy should encourage - third parties to challenge the validity of both pending patent applications ('pre-grant opposition') and granted patents ('patent challenge').

Innovative pharmaceutical companies are increasingly deploying various legal instruments to extend their monopoly privileges for their main products. This strategy, usually referred as 'evergreening', may involve a skilled addition of new patents to the main patents of the innovative product (for instance, composition patents, patents for new polymorphs, new use or new formulations) or filling new patents that are usually just slight modifications of old drugs and do not provide significant therapeutic advantages (Bansal, Sahu, Bakshi, \& Singh, 2009; Dwivedi, Hallihosur, \& Rangan, 2010). 
Some countries have adopted strict patentability criteria during patent examination to fight against 'evergreening'. For instance, the IPR law in India prevents patents on a new form or use of existing drug products created through minor modifications to previously existing products that do not demonstrate improved efficacy (Rajkumar \& Kesselheim, 2013). Other developing countries, such as Argentina and the Philippines, have amended their IPR framework to restrict the patentability of certain categories of pharmaceutical inventions, especially of patents for polymorphs, formulations and additional uses of existing compounds (Amin \& Kesselheim, 2012).

\subsubsection{Incorporating all TRIPS flexibilities and safeguards in the local IPR laws and making their use workable}

Several developing countries did not take full advantage of TRIPS flexibilities and safeguards when they enacted their local IPR laws (see Oliveira et al., 2004; for a review of Latin America and Caribbean countries and Nkomo, 2010; for a review of African countries). Some countries did not incorporate all of the mechanisms allowed for by the TRIPS Agreement, such as provisions for compulsory licensing, parallel imports and/or research exemption, or did not take full advantage of the transitional periods that they were eligible to use. Another major problem is that some countries have implemented so stringent and complicated provisions that they are mostly unworkable.

These countries should revise their IPR laws so that they implement patent legislations that are sensitive to public health needs and facilitate access to patented medicines. In addition, as noted by Nkomo (2010), many developing countries are not fully aware or lack legal expertise to incorporate and implement TRIPS flexibilities. Therefore, they must seek to develop the legal, technical and institutional capabilities that are necessary to use these flexibilities once they are implemented. In this sense, South-South cooperation with countries that have more experience in this field, such as Brazil and India, could be a valuable instrument to speed up this process.

\subsubsection{Industrial policy for strengthening manufacturing and industrial capabilities according to technological capacity}

The use of compulsory licenses to obtain more affordable drugs is subject to the existence of alternative suppliers. These suppliers, in turn, must have the technological competences to produce and deliver the concerned drug at low prices while meeting high quality and safety standards. Drugs that are not protected by patents in countries with a strong pharmaceutical industry can be imported in case of compulsory licensing 
without additional obstacles. Countries that made full use of the transitional period allowed in TRIPS, such as India, or where the patent was not granted, for instance because the claimed invention was considered not new or not inventive, are in a position to export these drugs without having to rely on the Paragraph 6 system. However, if the concerned drug is patented, then a compulsory license for local production is the most workable alternative in the current international IPR system.

Countries without a strong pharmaceutical sector may become hostage to the pricing and licensing strategies of pharmaceutical MNEs unless they devote time and resources to build their 'bargaining strengths'. Therefore, public policy for technological capacity building in pharmaceuticals may become an important interface of health policy and national security. However, countries differ in terms of the actual development stage of the indigenous pharmaceutical sector. The knowledge base necessary for the production of APIs differs from the one necessary for pharmaceutical formulation. APIs are the core components of drugs, both in terms of therapeutic value and technological complexity. The manufacture of APIs begins with the development of the production process, with the objective of achieving economic efficiency and profitability, using bench and pilot scales to define the optimal parameters, and the development of engineering design for scaling up. Although the knowledge base required for this productive step is fairly diffused and codified, it requires a strong base of tacit knowledge and cumulative skills. Such knowledge and skills had to be acquired by training in synthetic organic chemistry, especially in fields related to fine chemicals, and through trial-anderror experimentation and learning by doing. Pharmaceutical formulation refers to the preparation of the pharmaceutical products in the form in which they are marketed for use (tablets, capsules, injections, among others). It is a purely manufacturing process, in which different chemical substances, including the API and generally, but not necessarily, excipients (i.e. inactive ingredients), are combined to produce a final drug product. It is typically a physical transformation process, which involves activities such as granulation, drying, blending and compressing treatments and with few modifications in the chemical properties of the API. The technological complexity associated with pharmaceutical formulation is typically lower than in API manufacturing, so is the value added. Thus, the type and magnitude of the policy intervention must consider these features. 


\subsubsection{Countries with technological capacity in both API production and pharmaceuti- cal formulation}

When manufacturing capabilities are well developed, as in countries like China and India, policy should provide incentives for the private sector to start developing capacity in bench and pilot-scale for high cost drugs and/or drugs for conditions with a high disease burden. Ideally, this should involve forecasting activities (such as technology monitoring, scenarios and roadmaps) to gather and interpret information on changing population health patterns, newly introduced drugs and promising patents and drugs in the pipeline of research-based pharmaceutical companies so that the health policy can anticipate the direction and pace of changes.

For instance, in the case of HIV/AIDS, there are several new ARVs already patented in India (e.g. Elvitegravir, Etravirine, Maraviroc, Raltegravir, Rilpivirine, Tenofovir alafenamide fumarate) or which patent application is still pending (e.g. Cobicistat, Dolutegravir). Some of them, such as Raltegravir and Etravirine, are recommended by WHO as part of third-line treatment regimens. Considering that treatment failure of the initial HAART regimen is relatively common and, with the scale-up of initial treatment, more people living with HIV/AIDS are likely to develop drug resistance, the demand for new drugs that are part of third-line HAART regimens as well as drugs needed for salvage therapy ${ }^{55}$ tends to increase.

Policy makers must anticipate these trends and encourage the private sector to use other TRIPS flexibilities, such as research and Bolar exemptions, to do pharmaceutical deformulation (also known as 'reverse engineering') for those drugs considered of high health impact for the country. By doing so, the country will be in better position to negotiate lower prices with pharmaceutical companies (or the private sector to negotiate attractive voluntary licenses for generics), or to issue compulsory licenses when no agreement is arrived at. In addition, the private sector, along with organised civil society groups, should be encouraged to be active in pre and post-grant opposition of patents in order to correct eventual misguidance in the patent policy.

\footnotetext{
55 Salvage therapy refers to treatment regimens given to save or rescue a patient who has failed two or more ARV regimens.
} 


\subsubsection{Countries with technological capacity in drug formulation, but limited capacity in API production}

Industrial policy in countries with limited technological capacity in API production, such as Brazil, Argentina and South Africa, should promote the strengthening of capabilities in duplicative and creative imitations (Kale \& Little, 2007; Kim, 1997) to build technological capacity in process $\mathrm{R} \& \mathrm{D}$. This can be done in public-private centres of excellence that specialize in pharmaceutical deformulation for product development and scaling up of manufacturing processes. This strategy can be particular efficient, as in the pharmaceutical industry reverse engineering is one of the most effective methods of learning and acquiring technical knowledge of process and product innovations developed by other organisations (Levin, 1988).

Pharmaceutical deformulation can determine the original drug's formulation parameters, which are not required to be revealed by the inventor (Bansal \& Koradia, 2005). These parameters include the quantitative composition of the innovator product (including all 'functional' excipients) the solid-state characterization of the API, and the manufacturing process (Koradia, Chawla, \& Bansal, 2005). Pharmaceutical deformulation is a science-based and cost-effective strategy for accelerating generic product development and can be carried out under research exemption provisions in the case of drugs that are still patent-protected.

These centres should be a locus of technology expertise in process selection, development and scaling-up of organic syntheses for the commercial manufacture of APIs. They must have solid competence in process engineering that enables them to optimize and validate processes demonstrated at bench scale, maximize product quality and yield, minimize process costs and ensure that health and safety regulations are met before moving to full-scale manufacturing. In addition, these centres could become knowledge hubs, providing training, consultancy and technology transfer to industrial partners that would be responsible for manufacture and commercialization. This strategy would permit the delivery of a manufacturing-ready process, allowing the best routes to be identified before making significant investment in equipment and reducing the risk to the partners involved.

This policy, in turn, calls for developing chemical synthesis skills, which are the core competence for reverse engineering APIs. It is worth noting that duplicative and creative imitation is often intricate in the case of reverse engineering pharmaceuticals. Copying of technical knowledge involves translation, adaptation and reconstruction of 
technologies, in a process that can involve more than mere duplication, so that it produces tacit knowledge and, sometimes, improvements in products and/or processes.

In the case of reverse engineering pharmaceutical $R \& D$, the public and codified knowledge available in the patent and in the literature may not be sufficient on its own to produce a reverse engineered product. Therefore, reverse engineering requires skilled and experienced scientists, chemists and chemical engineers, as well as cumulative expertise through experimentation and learning by doing. Information available in patents are often either incomplete because the description either gives limited information on the steps involved or is so broad that it is the optimal conditions of the manufacturing process cannot be determined without experimentation. Moreover, the patent often describes a technology in its earlier phase of development and does not include any further improvement made by the inventor during and after the process of scaling up and market introduction. In addition, newer molecules that still have clinical trials data under protection do not have standards available in a national or international pharmacopeia ${ }^{56}$. Therefore, the process of reverse engineering had to reconstruct references for these molecules in order to ensure the same quality, efficacy and safety as the original drug. This reconstruction and discovery of alternative synthesis routes are essentially creative imitation activities that may lead to process innovation, by improving cost efficiency and reducing impurities.

The above implies that the acquisition of an existing knowledge base and tacit competencies to expedite technological learning is critical. This could be done through, at least, two different (and perhaps complementary) alternatives. First, these centres of excellence could start with gradual reverse engineering. The chemical synthesis of a drug involves several steps (for instance, the ARV ritonavir has 17 synthesis steps), so it is possible to start with the last step of the synthesis and move upstream once this step is successfully reproduced and knowledge and competences are developed and internalized. This can be done gradually until the process is complete and all the chemical synthesis steps, from the raw materials to the final molecule, can be replicated. Second, South-South cooperation for R\&D personnel exchange, technical assistance, technology transfer and direct investment can be valuable forms for acquisition of tacit

\footnotetext{
${ }^{56}$ Pharmacopeia is an official compendium publication containing directions and procedures for the identification, analysis and specifications for the determination of pharmaceutical substances, excipients, and dosage forms. There are national and international pharmacopoeias, like the United States Pharmacopeia, the Chinese pharmacopeia, the Europe Union Pharmacopeia, and the International Pharmacopeia, which is issued by the WHO.
} 
knowledge. However, it is worth noting that both the alternatives are subjected to the availability of skilled human resources, as it is necessary for a minimum level of absorptive capacity to enable individuals to access and acquire existing bodies of knowledge and to increase their competencies through the development of new capabilities and the strengthening of the existing ones.

Furthermore, the demand for the API can be small. For example, the daily dose of the ARV Emtricitabine is a capsule of 200 milligrams. Therefore, only 200 kilograms of this input is required to treat 1 million people living with HIV/AIDS. This means that economies of scale that are essential to supply low cost generic drugs are out of reach for smaller countries and, consequently, generic companies may not have enough incentives to invest in developing a generic version for this specific market. An option to address this problem would be South-South cooperation for pooled procurement strategies - coupled with compulsory licenses if necessary - in countries with small markets (Abbott, 2011; Abbott \& Reichman, 2007; Bird, 2009; Shadlen, 2007)

\subsubsection{Countries with capacity in neither API production nor drug formulation}

According to the WHO, there are more than 40 countries, mostly LDCs in Africa, with limited or no competence in drug formulation and API production, relying on imports of finished products to satisfy their demand (WHO, 2004). The promotion of centres of excellence for reverse engineering could also be valuable for these countries. However, the approach of gradual reverse engineering would have to start with the formulation of imported APIs and excipients and, then, gradually be extended into more intricate operations, through backward integration, until the synthesis of chemical components.

Due to the low level of absorptive capacity, foreign direct investment (FDI) and joint ventures can be an essential component of the catching up strategy in pharmaceuticals in these countries. Some authors have advocated for south-south cooperation to promote knowledge transfer (for tacit knowledge accumulation), joint ventures and FDI in order to attract foreign generic producers from countries like India, China and Brazil to establish local production facilities in LDCs. A local producer in such a territory could take advantage of the extended transitional period allowed by TRIPS to LDCs and become a supplier of low-cost generics to other developing countries (Abbott \& Reichman, 2007; UNCTAD, 2011). The export of low cost generics could be done without the need for compulsory licenses in case of countries that still do not grant patents for pharmaceuticals or to a large area if countries decided to rely on this TRIPS flexibility. 
However, the obstacles and challenges to implement this kind of policy are immense. First, many LDCs have ignored the transitional period and already have implemented IPR legislation that allows the granting of patents for pharmaceutical products and processes (Thorpe, 2002; UNCTAD, 2011). Second, some LDCs have also signed FTAs with developed nations and included IPR provisions that limit their ability to take advantage not only of the extended transitional period but also other TRIPS flexibilities (WHO, 2006). Third, the majority of LDCs lack the main prerequisites for investment in the pharmaceutical sector, which, according to UNCTAD (2011), include:

- Human capital in the form of a diverse critical mass of skilled human resource that is required regardless of whether an organisation is involved in pharmaceutical R\&D or only in drug formulation;

- Basic infrastructure, especially reliable power and clean water, that is necessary for good practices of manufacturing and to ensure that both the factory and its outputs meet an acceptable quality standard;

A functioning national drug regulatory authority to ensure quality, safety and efficacy of the products. The adherence to external quality standards, such as the WHO good manufacturing practices, WHO pre-qualification programmes and standards of drug regulatory authorities from developed countries are necessary when production targets export markets.

- Transport and logistical infra-structure to allow for timely and cost-effective access to key inputs, especially imported APIs and raw materials

The costs and technical complexity of reverse engineering newer drugs are higher, as, for instance, some second and third-line ARVs. Thus, generic manufacturers have to invest resources and develop technical expertise to learn how to manufacture these drugs with the same safety and efficacy of the innovative counterparts. Furthermore, their production facilities have to meet the highest international standards of good manufacturing practices, as for instance those required by WHO's prequalification program. There are not many companies in the developing world that are able to bear such costs.

In addition, South-South cooperation in R\&D, technology transfer and FDI in pharmaceuticals has to be strengthened. The high scale production of generic drugs, especially the new ones, involve high levels of tacit knowledge that may require substantial external assistance to be absorbed by the new entrants. Such a capability building process is long drawn out and costly, which means that there are few chances that fragile 
economies would be able to commit to the needed investments on their own. Moreover, there is no reason to believe that the research-based pharmaceutical industry from the developed world would be willing to collaborate in a large-scale capacity building process towards production of off-patent drugs in any country - even in the least developed ones. This just increases the potential role that South-South FDI and technology transfer can play in such capacity building strategies.

The challenges and obstacles are enormous and will demand several years - if not decades - to be overcome. Nevertheless, this does not mean that nothing should or can be done. Market forces on their own will not provide incentives for investment in the pharmaceutical sector in these countries. Therefore, public policy and multilateral efforts are necessary to promote capacity-building strategies aimed at improving access to medicines.

\subsection{Emerging countries: a new pharmacy of the developing world?}

In 2005, the Indian Patent Act was amended in order to comply with the TRIPS agreement. The changed IPR framework, which started granting patents for pharmaceutical products for the first time in more than three decades, is likely to affect India's position as 'pharmacy of the developing world'.

The transition period granted to LDCs under TRIPS Article 66.1, and extended until 1 July 2021 gives some hope that it is still possible to build a competitive industry producing safe, effective and affordable generic medicines for the developing world. In this context, Bangladesh emerges as a potential supplier of low cost generics because, among all the countries classified as an LDC, it is the only country with an adequate pharmaceutical manufacturing capability. In addition, the Bangladeshi IPR framework allows patent protection only for the process of producing a pharmaceutical product but not for pharmaceutical products (van Duzer, 2003). It also has provisions for compulsory licensing when the demand for the patented product is not being met to an adequate extent and on reasonable terms (van Duzer, 2003).

However, many challenges must be overcome to attract investment in building productive capacity in Bangladesh and provide foreign assistance to the domestic industry to acquire the skills to develop new generic drugs. Ala (2013) found that the main vulnerabilities of the Bangladeshi pharmaceutical industry are related to R\&D, international competitiveness and production of APIs. According to him, local pharmaceutical firms 
have not been able to develop considerable technical and scientific capability and a higher level of regulation handling capability. Most of the local pharmaceutical firms in Bangladesh have technological capacity only in drug formulation and import APIs mainly from India and China (Ala, 2013; Gehl Sampath, 2007; van Duzer, 2003). Moreover, the few firms in Bangladesh that are capable of producing APIs have a limited product portfolio and are able to perform only the last few steps in the synthesis process (Gehl Sampath, 2007). In general, the country does not have the imitative capacity to reverse engineer patented drugs and is presently struggling to build capacity in the more knowledge-intensive processes of producing APIs in order to develop competing generic products (Gehl Sampath, 2007; van Duzer, 2003). Some local firms are trying to secure technological capabilities in order to venture into API production and reverse engineering. However, they are precluded by a lack of adequate scientific and physical infrastructure, which includes missing human resources, the lack of capabilities to conduct bioequivalence tests and the incapacity of domestic R\&D institutes and universities in assisting the firms to develop the necessary chemical synthesis skills (Gehl Sampath, 2007).

Given the important role that a strong pharmaceutical industry in countries like Bangladesh can play in terms of improving access to high quality medicines in the developing world, more attention in terms of international cooperation should be devoted to this cause. This is especially true when we consider that TRIPS Article 66.2 provides that 'developed country Members shall provide incentives to enterprises and institutions in their territories for the purpose of promoting and encouraging technology transfer to least-developed country Members in order to enable them to create a sound and viable technological base'. On the one hand, one could argue that the TRIPS transition period has not been used effectively by the Bangladeshi pharmaceutical industry to develop the technological capabilities necessary to produce and export safe, effective and affordable generic medicines. On the other hand, the expected process of transfer of technology has not materialized and significant work remains to be done to ensure an effective implementation of Article 66.2.

\subsection{Medicines of the future: a note on biopharmaceuticals}

The importance of capacity building strategies may be even more critical for drugs based on biotechnology (that is, biopharmaceuticals). Due to their intrinsic technological features and the specific regulatory requirements associated with the approval of these drugs, even after the patent expiration there are few alternative substitutes (also 
known as biosimilars). The development and production of biosimilar drugs must be based on local scientific and technological capabilities for the development, operation and maintenance of production processes to very high quality standards. This is critical because the characteristics of the drug (including its safety and efficacy) are very sensitive to the production process, what is also known as 'product-process paradigm'. As the main features of the production process are kept in secrecy by the originators and are subject to extended 'data exclusivity' protection by the regulatory authorities, the scientific and technological barriers, the financial resources required, and the time-tomarket associated with the development of biosimilars are considerably higher than those required to develop traditional small molecule generic drugs.

For instance, there are only 19 regulatory approvals (concerning seven active substances) for marketing authorization of biosimilar drugs in the European Union. Moreover, some off-patented biopharmaceuticals, such as Etanercept, Rituximab, Trastuzumab and Cetuximab, do not have biosimilar competitors approved for commercialization in the region yet. Thus, as a limited number of competitors are introduced in the market, the expected price reduction after the patent expiration tends not only to be smaller but also to take longer when compared to small molecule drugs based on chemical synthesis. As governments around the world try to rein in healthcare expenses, promotion of biosimilars can play a major role in reducing this budgetary burden. This is especially important if we consider that biopharmaceuticals are majorly used for conditions for which the burden of disease is rapidly increasing worldwide, i.e. chronic and life-threatening diseases such as cancer, multiple sclerosis and rheumatoid arthritis. However, the ability of governments to negotiate prices or even issue compulsory licenses is likely to be very limited while the technological competence to produce biopharmaceuticals is majorly located in developed countries.

\subsection{Lessons from Brazil}

Since the mid-1980s, the Brazilian Government has been able to provide free ARVs treatment to its population and, since 1996, it has deployed a universal coverage program. Such a universal access programme has two main pillars:

The manufacturing capacity of state-owned laboratories, which supply low-cost offpatented ARVs. These organisations have specialized in drug formulation and, in general, depend on import of APIs from countries, such as India and China. 
The ability of the MoH to negotiate price reductions for the patented ARVs. This negotiation process involves compulsory license threats based on the technological capabilities of state owned laboratories, especially Farmanguinhos.

\subsubsection{IPR framework}

IPR policy is also an important line of public intervention. On the one hand, it is necessary to have an adequate legal framework for compulsory licenses. In the Brazilian experience, such a framework evolved since the $\mathrm{MoH}$ made the first compulsory license threat. On the other hand, a basic question that emerges is whether the grant of the patent is justified in the first place. Therefore, governments can avoid the various costs associated with both the patent monopolies and with the grant of compulsory licenses if they apply more diligent standards in examining patent applications (Correa, 2006b).

Three out of the six drugs analysed in this chapter (that is, Nelfinavir, Efavirenz and Lopinavir+Ritonavir) have patents granted under the 'pipeline mechanism' in the Brazilian IPR law of 1997. This mechanism, which is considered a TRIPS-plus clause, allowed the granting of patents for pharmaceutical products based on the date of first foreign filing. Without this mechanism, the grace period for these drugs would have expired and, therefore, they would no longer fulfil the novelty requirement. So, unlike India, Brazil not only waived the ten years of adaptation provided by the TRIPS Agreement, but also included a TRIPS plus provision which created intellectual property barriers to accessing affordable medicines that could be in the public domain. If such a provision had been avoided, then the $\mathrm{MoH}$ could have saved a considerable amount of resources by buying then from generic suppliers from the date these drugs were first introduced.

In addition, there is a worldwide trend toward relaxation of patent requirements by patent offices and courts, and many patent examiners overlook novelty and inventivestep problems in pharmaceutical inventions (Mándi, 2003). The MoH of Brazil could have avoided paying patent-monopolistic prices for three drugs if INPI have applied more stringent patentability standards. The drug Tenofovir, in turn, had its main patents overruled by the Brazilian patent office in 2008 - almost 10 years after the initial deposit - due to lack of inventive steps. If the analysis of patent claims was faster and linked to public policies priorities, then the MoH would not have had to pay monopolistic prices for about six years. Additionally, the drug Atazanavir had its patents rejected in other countries also due to lack of inventive steps, such as in India. Nonetheless, the Brazilian patent office decided to grant one patent for this drug (PI9701877-5), 
though one additional patent for Atazanavir was rejected due to lack of inventive step (PI 9814736-6). Finally, in 2012, the Brazilian court nullified the patent for Lopinavir after one local company challenged its validity in 2009. Thus, a more strict and stringent patents policy would have saved the MoH's resources and have improved access to these drugs.

\subsubsection{Industrial Policy}

Given the paramount role of local manufacturing capacity, one possible line of action for public policy is to support technological capacity building. This is even more critical for newer ARVs, which are protected by patents in India. In the past, Farmanguinhos has played the role of centre of excellence for drug deformulation, but this is no longer part of its mission at this moment. Brazil has not mastered the technological routes to produce newer anti-HIV drugs such as Atazanavir, Raltegravir, Maravoric, Darunavir, Etravirine and Enfuvirtide. As there is an increasing demand for these therapies, it is necessary long term planning to create technologies and to develop capabilities in advance.

However, the increasing complexity associated with the development of newer drugs along with obstacles to import patented drugs from India exposed the Brazilian fragilities in API production to the world. The patent status of a drug cannot be seen as an independent aspect of access to medicines. If there is no manufacturing capacity, the patent status of the drug is not very relevant. For instance, in 2008, the Brazilian IPR Office rejected a patent for Tenofovir, one of the most commonly used ARV drugs, claiming lack of novelty. However, three years later, the Brazilian Ministry of Health was still paying around six times the price of the cheapest generic version available in the international market because there was no alternative supplier. Although the Indian IPR Office had not granted patents for Tenofovir, the patent holder had signed voluntary license agreements with several Indian companies prior to the local patent office's final decision. These agreements did not allow Indian companies to export the drug to medium income countries, including Brazil. Until 2010, there was only one Indian generic manufacturer producing Tenofovir that had not accepted those terms, but this company could not export to Brazil because at that time it did not have the drug prequalified by the WHO. Thus, given the absence of local suppliers and regulatory 
obstacles to imports, the Brazilian bargaining position was not strong enough to negotiate a price closer to the cheapest alternative. ${ }^{57}$

Even compulsory licenses may not be the optimal solution for access to the medicines. For instance, the $\mathrm{MoH}$ granted a compulsory license to Efavirenz in 2007 and the local production of the drug started in 2009. Since then, the price of the generic manufactured version has remained constant while the price of the cheapest imported alternative has reduced by 77 per cent (see Table $8-1$ ). Therefore, even though this compulsory license improved access to the drug, such improvement was less than it could be due to the lack of competiveness of local producers. This difference was evident in 2010, when 40 per cent of MoH's demand for Efavirenz was met by a generic version imported from India due to 'exceptional circumstances'. In that year, the price Efavirenz produced by Farmanguinhos was almost five times the price of the Indian generic.

Table 8-1: Price comparison of Efavirenz after compulsory licensing in Brazil (US\$ 2007 constant)

\begin{tabular}{llll} 
Year & Best generic price $^{1}$ & CL price (Imported) $^{\mathbf{2}}$ & $\begin{array}{l}\text { CL } \\
\text { (Farmanguinhos) }^{2}\end{array}$ \\
\hline \hline 2007 & 0.47 & 0.46 & \\
2008 & 0.42 & 0.30 & \\
2009 & 0.27 & & 0.69 \\
2010 & 0.17 & 0.14 & 0.69 \\
2011 & 0.14 & & 0.69 \\
2012 & 0.12 & & 0.69 \\
2013 & 0.11 & & 0.69 \\
\hline \hline
\end{tabular}

Sources: ${ }^{1} \mathrm{MSF} ;{ }^{2} \mathrm{MoH}$ of Brazil, STD/AIDS Department

The current priority of the Brazilian industrial policy is to use public procurement to support import substitution of strategic drugs through public-private partnerships. This policy has its merits, notably fostering the resurgence of the local API industry and investing in modern machinery, equipment and facilities for state-owned laboratories. However, local production has to be carefully examined in terms of its relative competitiveness.

\footnotetext{
${ }^{57}$ It is worth noting that between 2008 and 2011, the Brazilian Ministry of Health was able to get a 40 per cent price drop for Tenofovir, even though the final price was still considerably higher than the generic alternatives available in India.
} 
Once more, Tenofovir provides an interesting example. In 2010, $\mathrm{MoH}$ could have imported a generic version from the Indian company Cipla, as it had just gotten WHO's prequalification approval. However, $\mathrm{MoH}$ choose to continue purchasing from the innovator company, Gilead Sciences, for a price more than seven times higher than Cipla's generic. Already in 2009, MoH announced two public-private consortia of local companies (Blanver, Nortec and Cristália) and state-owned laboratories (FUNED and LAFEPE) for local production of a generic of Tenofovir. In 2011, these consortia delivered the first batch of local produced Tenofovir to the $\mathrm{MoH}$, at a price more than eleven times higher than the Indian generic. In addition, the consortium reduced the price only after two years, and by the minimum level stipulated by the contract with $\mathrm{MoH}$, that is 5 per cent - while the price of Cipla's drug fell 30 per cent in the same period. This is summarized in Table 8-2.

\begin{tabular}{lllll}
\multicolumn{4}{l}{ Table 8-2: Price comparison of Tenofovir after PPP for local production in Brazil } \\
Supplier & Year & Price (R\$) & Price (US\$) & Cipla's price \\
\hline \hline Gilead & 2010 & 4,02 & 1,75 & 0,24 \\
FUNEDE / LAFEPE & 2011 & 4,02 & 2,55 & 0,23 \\
FUNEDE / LAFEPE & 2012 & 4,02 & 2,35 & 0,18 \\
FUNEDE / LAFEPE & 2013 & 3,82 & 1,87 & 0,17 \\
\hline \hline
\end{tabular}

Sources: MoH of Brazil, STD/AIDS Department

It may yet be too early to evaluate the real impact of this policy in terms of technological capacity creation. This process is complex and it takes time to see the returns from the investment made. However, it is unclear whether the incentives provided by this public policy are repeating the previous mistakes of import substitution policies. The market exclusivity and the modest mandatory price reduction can generate accommodation. If that is the case, then the side effect will be reduced access to medicines not only in the short but also in the long run. Local production of drugs, including APIs, can also be important for knowledge accumulation. However, this should not be an excuse for lack of competitiveness and high prices for patients.

Ironically, it seems that the 'Brazilian model' is much more efficient in terms of the MoH's ability to reduce prices of patented ARV drugs, then in terms of issuing compulsory licenses and implementing other means to foster local production of these drugs. 


\section{Chapter 9 Concluding remarks}

Some lifesaving patented medicines have been out of the reach of patients due to high costs. Price negotiations between public health agencies and pharmaceutical MNEs have been shown to be a valuable strategy for countries seeking to improve access to these drugs. In addition, some countries have successfully used compulsory license threat in price negotiations with pharmaceutical majors to leverage price discounts.

The overarching question of this research was to investigate the circumstances under which a developing country will be able to use compulsory licenses in price negotiations, and the conditions under which such threats will be successful in reducing the price of lifesaving drugs. It is also important to identify the drivers of bargaining outcomes of price negotiations between pharmaceutical MNEs and public agencies of developing countries and understand how these drivers, individually and jointly, determine the outcomes.

Furthermore, Brazil was taken as the country to be examined as it is widely acknowledged as a leading user of this strategy. Thus, Brazil forms a natural choice for further analysis to gain insight on how the threat of compulsory licensing can be used to negotiate price reductions with innovator pharmaceutical companies. This, in turn, allow us to refine the conditions lying at the heart of this strategy, and to re-specify the issues concerning its replication in least developed and developing countries.

The research approach employed in this dissertation is summarized in Figure 9-1 below.

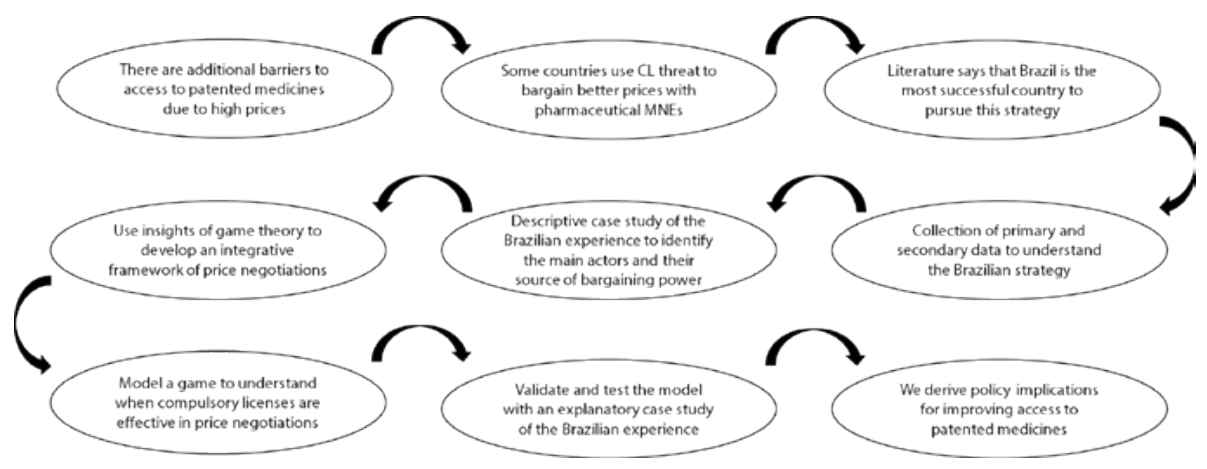

Figure 9-1: Research approach 


\subsection{Summary of findings}

There is much interplay between health status, economic growth, and development. Healthier workers are more productive and greater life expectancy increases the incentives to invest in schooling, which in turn, also leads to greater productivity. Better nutrition, housing and sanitation, among other factors associated with socio-economic development have a critical impact on the health status of a population.

Several international agreements, including the Universal Declaration of Human Rights, insist that the highest attainable standards of physical and mental health as a fundamental right of every human being. The right to health means that States must provide the necessary conditions for everyone to be as healthy as possible. This implies access to timely, acceptable, and affordable health care of the appropriate quality.

Health expenditure is also an important determinant of health status, however many critical medicines and other medical goods and services are out of the reach of patients. There are many barriers to access to medicines, but lack of financial resources is the most important of them. This means that neither the poor nor their governments can afford to purchase these essential goods. The scenario can become even more critical in the case of patented technologies. Although IPR provide a valuable incentive for R\&D of new drugs, the monopolistic structure granted by patents tends to generate higher prices for new treatments.

From the above arguments, it is clear that, when there is a major disease that calls for patented medicines, the health status of the population that cannot afford the treatment may be put at great risk. In this context, the purpose of this thesis was to examine the options that are available to government seeking to ensure the right to health of the poor. By way of answer, in Chapter 2, we show that the literature on access to medicines acknowledged the use of compulsory licenses as the main solution for this problem. In addition, recent events suggest that the threat to issue a compulsory license can be used to leverage price discounts in negotiations between developing countries and pharmaceutical companies. This is likewise confirmed in the economics literature, but the existing body of knowledge does not provide sufficient evidence to identify the appropriate conditions for a developing country to make a compulsory license threat (or actually issue one), and to understand when such threats can result in price reductions for the vital drug concerned. The present research fills this gap and its central results con- 
tribute to two streams of literature, namely the political economy of IPR and the use of TRIPS flexibilities; and the political economy of improving access to medicines.

The use of use of compulsory license threats in price negotiations is as a central component of the 'Brazilian model' for AIDS treatment, which is widely acclaimed as the most successful anti-HIV/AIDS public programme in the developing world. In Chapter 3, we presented a brief historical review of the public health programme that provides free-of-charge drug cocktails to people living with HIV/AIDS in Brazil. We stressed the dual role of state-owned laboratories in this health policy. First, these laboratories are responsible for manufacturing low-cost off-patented ARVs to $\mathrm{MoH}$. Second, the technological capacity for reverse engineering, notably at Farmanguinhos, is a central component of the Brazilian strategy of the price negotiations of patented drugs backed up by compulsory license threats.

In Chapter 4, we designed a detailed case study basing it upon 14 episodes of negotiation between the Brazilian Government and foreign pharmaceutical companies for six different ARV drugs. We use data from a wide range of secondary sources to describe the central elements and dynamics of each episode of price negotiation carried out by the $\mathrm{MoH}$ of Brazil. A major contribution of the chapter is a more precise understanding of the drivers of bargaining strength in these negotiations. Earlier studies, such as Ford et al., (2007) and Nunn et al. (2009), stress that Brazil was losing bargaining power because of its sequential compulsory license threats that were never carried out. However, our results show that not issuing compulsory licenses cannot be taken as an indicator of bargaining power. According to our analysis, it is the level of technological capability, availability of import substitutes and internal and external pressure against compulsory licensing that ultimately determine bargaining strength.

Moreover, to date there is no integrative analytical framework that explains the interrelationships between the determinants of compulsory license issuance to obtain more affordable drugs. Based in this case study, in Chapter 5, we used a game theoretical reasoning to analyse the price negotiations of ARV drugs in Brazil. In this framework, a set of actors interact within an ecosystem in order to influence the outcome of the negotiation according to their distinct interests. In the same ecosystem, there can be different outcomes for price negotiations for the same disease. This variance can be explained by changes in the bargaining strength of Brazil's $\mathrm{MoH}$ in different negotiation episodes. 
Drawing upon the analytical representation of price negotiation within the Brazilian anti-HVI/AIDS programme, in Chapter 6, we formulated and solved a game theorybased model of price negotiation between the two main actors of the above-mentioned framework, that is, an innovator pharmaceutical company and a public agency in a developing country. The model confirms that the role of compulsory licenses to leverage price discounts depends on the existence of local manufacturing capacity, the availability of import possibilities and the expected political and economic pressures from the patent holder's home government in the post-compulsory license period. The greater the local industrial strengths and import possibilities, and the lower the expected retaliation from the patent holder's government, the stronger is the role of compulsory licensing. In addition, the model indicates that compulsory licensing is likely to be issued only under incomplete information. Under complete information, the patent holder can always offer a price drop that the developing country accepts and thereby avoid compulsory licensing. However, under informational constraints a compulsory license could be issued, as a mistake resulting from risk-taking on the part of the patent holder about the 'retaliation support' it would receive from its own government against the developing country. Even so, for a compulsory license to be issued, it is necessary that the developing country has sufficient local manufacturing capabilities or access to imports.

The results of the model are validated with an explanatory case study on the Brazilian experience in price negotiations for ARV drugs. To do so, in Chapter 7, we derived propositions about the characteristics of drug price negotiations and formulate hypotheses about the most probable outcomes. Then, we implemented an empirically based pattern-matching exercise to test the hypotheses. The evidence collected for the case study suggests that the $\mathrm{MoH}$ of Brazil was willing to accept higher prices for patented drugs than what it could obtain under compulsory licenses. This was to avoid the negative impact that a compulsory license can cause in the economy. In addition, it is a better choice for the patent holder to give a price reduction than to lose the entire market - especially when the market has a considerable size, as it is in the case of Brazil. Therefore, accepting a price reduction was perceived as a better outcome for both sides. Even so, there was an instance of granting a compulsory license in Brazil. Our research approach reveals that the presence of informational constraints is indeed crucial to understand why Brazil issued its only compulsory license in one instance of price negotiation. We also find that Brazil was able to pay lower prices for the drug for which it had built technological capacity at laboratorial or pilot scale in the early 2000s (that is, Efavirenz, Nelfinavir and Lopinavir). For newer drugs introduced after 2004, MoH 
was paying considerably more than the price of the generic versions (when available). This was because of the obstacles for local production - due to the absence of local capacity even at a small scale - and for imports.

It is worth noting that our game theoretical model could not fully explain the outcome of some negotiations, as in cases classified as 'disincentive to enter' (i.e. episodes $3 \mathrm{C}$ and 4) and 'industrial policy' (episodes 6,7A and 7B). In these episodes, there was neither local manufacturing capacity even at laboratorial scale nor exporters of attested high-quality generics. Therefore, according to the model, the $\mathrm{MoH}$ of Brazil was not supposed to obtain the discounts that it actually did. This conclusion calls for further qualification on the importance of local manufacturing capacity. The existence of production capacity for a specific drug is not a necessary condition to obtain price reductions for the same. Alternatively, the existence of absorptive capacity for reverse engineering can be enough to bring prices down. However, when local actors have already mastered the production process to make a generic version of the drug, then it is likely that the negotiation will result in a more significant price reduction than otherwise. Thus, it is not only the current level of manufacturing capacity that influences the country's ability to reduce prices of patented drugs, but also the country's imitation capabilities that can 'create' manufacturing capacity in the future.

This point makes evident the need qualify the term manufacturing capacity as well as to define objective indicators for its measurement. As pointed out by Correa (2002), in the paragraph 6 system of the TRIPS Agreement it is not clear whether the term 'manufacturing capacity' refers to the general capacity to manufacture drugs and/or APIs or to the capacity to manufacture a particular drug. For instance, a country may have manufacturing capacity to produce APIs or end products in general, but lack the equipment, technology or other resources necessary to produce a particular drug (Correa, 2002). In response, we propose four levels of manufacturing capacity, in Figure 9-2, that influence a country's bargaining strengths while negotiating the price of specific drugs with pharmaceutical companies. 


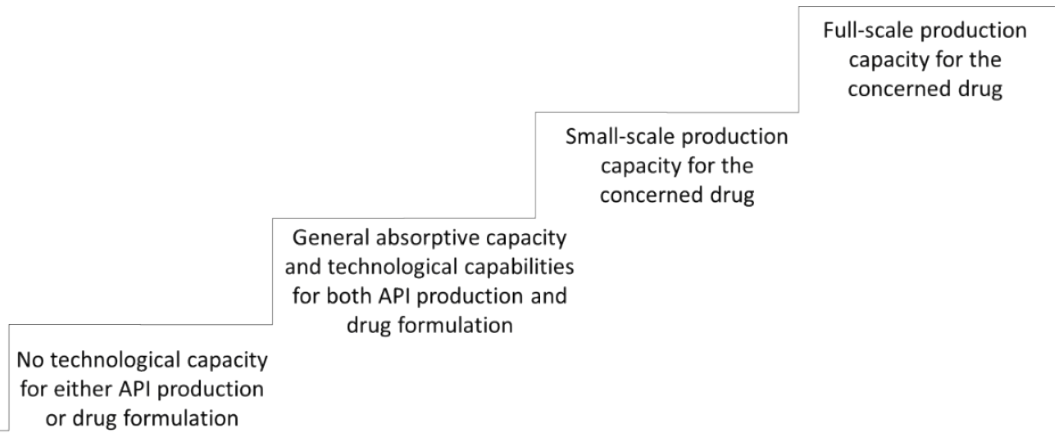

Figure 9-2: Levels of manufacturing capacity for drug production

First, there are countries where there is very limited or no competence for the production of APIs or even bulk drugs. According to WHO (2004), in 2004, there were more than 120 countries in this condition. These countries rely on imports to satisfy their demand and, therefore, the use of compulsory licenses to get affordable generics is conditioned to availability in the international market. Regarding import of drugs under compulsory licenses, availability is the crucial issue. This means that the existence of manufacturing capacity to provide the requested quantity of the drug in a short time frame is necessary for credible compulsory license threats. However, this may not be sufficient as many generic manufacturers have agreements with innovative pharmaceutical companies that impose geographical restrictions that limit the exporting possibilities of certain drugs.

The other three levels concern countries with manufacturing capacity for active ingredients and finished products. General absorptive capacity and technological capabilities for drugs and API production refer to the local availability of the resources needed to manage all phases of product development, including skills, knowledge and experience, and institutional structures and linkages. The existence of small-scale capacity for a specific drug implies that the country already masters the production development process such that the techno-economic viability is ensured. Finally, capacity for fullscale production refers to the availability of the resources used to produce the required quantity of the drug at a given level of efficiency, whilst ensuring its efficacy and safety. This level of manufacturing capacity can be available only in countries where the concerned drug is not protected by patents.

Following these results, the central recommendations of this research for improving access to medicines is not to promote the massive use of compulsory licenses, but to 
assist developing countries in pursuing capacity-building strategies in order to strengthen their bargaining position vis-à-vis pharmaceutical companies in price negotiations. The policy recommendations that immediately derive from this are that developing countries must work to build their bargaining strengths, as it is discussed in Chapter 8 .

One line of action is the construction of excellence centres for drug deformulation. Using other flexibilities provided by the TRIPS Agreement, such as research and Bolar exemptions, these centres could create local manufacturing capacity - even if only in laboratorial scale - to strengthen the bargaining power of developing countries. In addition, these centres could accelerate the introduction of generic versions in case of compulsory licensing. South-South cooperation in R\&D, technology transfer and FDI in pharmaceuticals has to be strengthened. This is particularly crucial because drug discovery is now going to be increasingly based on generic technologies, such as biotechnology and nanotechnology, in which the developing countries have a greater technological gap than in synthetic chemistry. Thus, the least developed and developing countries must increasingly pool and share knowledge, technology and products to build bargaining strengths.

Both least developed and developing developed countries need to make the best use of their industrial policy to build industrial and technology capabilities in pharmaceuticals. Given the obvious economic and technological constraints, it is not reasonable to claim that every country must pursue this goal. Middle-income countries, such as $\mathrm{Ar}$ gentina, Brazil, China, India and South Africa may have more autonomy to implement capacity-building policies, but the same may not hold true for most of the LDCs. Moreover, the focus cannot be limited to technological capabilities but has to include capabilities for process scale-up. LDCs can first work towards building technological capabilities in formulation and initiate institutional changes to facilitate the import of the cheap generic versions of patented drugs under compulsory licenses.

Our analysis demonstrates that the current IPR system is only one hurdle among other political, economic and institutional constraints that make the developing countries' quest for more affordable medicines very challenging. For instance, for the six drugs investigated in this research, the $\mathrm{MoH}$ of Brazil could have avoided paying patentmonopolistic prices for up to five of them if the national IPR framework was more appropriate to the health needs of the population. Thus, a more strict and stringent patent policy would have saved the MoH's resources. Moreover, in Brazil, the huge patent backlog also must be addressed. INPI took ten years to judge the patent applica- 
tion of Tenofovir. Although the patent was overruled, the patent holder benefited from provisional protection and the $\mathrm{MoH}$ had unnecessarily to pay monopolistic prices for more than six years. Therefore, there is a need for capacity building in the patent bureaucracy to speed up the process of patent examination and to implement more strict patentability criteria in such examinations.

In addition, IPR may not be an obstacle for more affordable medicines, if there are no alternative sources for low cost generics of the concerned drug. The price negotiation between $\mathrm{MoH}$ and Gilead Sciences for Tenofovir in 2009, for instance, points in this direction. In this episode, even after the Tenofovir patent rejection, the $\mathrm{MoH}$ had to pay monopolistic prices to the innovator company due to lack of local capacity and import alternatives. In Brazil, the current industrial policy aims to increase local technological capabilities for API production through public-private partnerships along with public procurement to overcome this weakness. However, local production must be carefully assessed in terms of competiveness; otherwise, higher prices may exclude patients from treatment - as it seems to be the case of Efavirenz and Tenofovir. Moreover, partnerships that involve technological transfer for patented drugs can be a winwin solution as long as they do not include abusive provisions, which may hinder access to the concerned drug in the medium run.

Local capacity building is difficult, takes time and is subject to external pressure. Therefore, there is an urgent need to facilitate the issuance of compulsory licenses to export vital drugs to LDCs. In this regard, making the use of compulsory licenses for exports under the Paragraph 6 System smoother is likely to yield a high impact even in the short run. Institutional changes in this direction would benefit not only the least developed countries, but all countries that do not have sufficient manufacturing capacity for a given drug. Just changing the resolutions of the August 30 decision is not enough. While least developed and developing are subject to political and economic pressure from both companies and their home governments, it is very unlikely that they will take full advantage of the existing TRIPS flexibilities to get more affordable drugs either by issuing compulsory licenses or by bargaining for price discounts with the patent holder. 


\subsection{Limitations of the research and areas for further investigation}

\subsubsection{The negotiation game}

By definition, a model is a simplification of reality. The case study based on real contexts provided a better understanding of the main drivers and obstacles to the use of compulsory licenses and pointed to factors that are not part of the model. Many other variables can influence the outcome of drug price negotiations, such as the level of drug stocks, adequacy of both the IP law and regulatory framework, and market size. Moreover, other players can actively participate in these negotiations and influence its result, for instance other State Ministries - in Brazil, notably MoDIT - NGOs and civil society, generic manufacturers and other governments.

In our model, the patent holder has only one round to make a counter-offer, while in reality those price negotiations have many rounds and take several months to conclude. It is possible that players can update and revise their beliefs as they reach each sequential round. Thus, the model can be further extended to include this dynamic and check whether it affects the probable outcomes. Moreover, the $\mathrm{MoH}$ often negotiates prices using compulsory license threats for more than one drug at the same time. In Episode $3 \mathrm{~B}$, document analysis and interviews have shown that this factor had a direct impact on the negotiation with Merck \& Co.

In addition, the patent holder is not completely informed about the retaliation level expected if the $\mathrm{MoH}$ grants a compulsory license. However, both the document analysis and the interviews suggest there might be other sources of informational constraints. For instance, patent holders may not be perfectly informed about the level of manufacturing capacity and, therefore the actual cost of local production. In fact, this information may not be available even to the $\mathrm{MoH}$. For instance, the local production of Efavirenz started about one year after the original plan and both LAFEPE and Farmanguinhos - the two state-owned laboratories in charge of local production faced several delays until they met the regulatory requirements to register a generic version of the drug.

The model can be further refined in at least three ways. First, to include the different levels of manufacturing capacity presented in the previous section rather than the simple drug level measurement used in the current model. As discussed earlier in this chapter, different levels of manufacturing capacity likely have different impacts on the nego- 
tiation outcome. Therefore, it would be a major improvement if the model could capture this attribute from the reality.

Second, major pharmaceutical companies sell their products in different markets and the outcome of the price negotiation in one country may affect the negotiation in another one. Such spillovers, which are not included in the model, can even affect the order of play in this price negotiation game. For instance, in April 2007, Abbott announced that it would reduce the price of Lopinavir/Ritonavir capsules and tablets to $\$ 1,000$ PPPY in 45 low and low-middle income countries, including Brazil. In July 2007, the Government of Brazil accepted Abbott's offer to supply Lopinavir/Ritonavir at a unitary price of US\$ 0.47 , which was even lower than the cheapest generic version available worldwide. Abbott's strategy followed the Thai Ministry of Public Health's decision to issue a compulsory license for Lopinavir/Ritonavir after failing to achieve any significant price reduction in January of the same year. Thus, the decision to cut price in other developing countries aimed at avoiding other compulsory licenses in those markets as well as improving the company's image, which had deteriorated after the Thai decision. ${ }^{58}$ Merck \& Co. also played first in the voluntary license described in Episode 7A and, as discussed earlier, this strategy might be related to the possibility of a compulsory license in India.

Third, in some episodes, the patent holder offers a voluntary license agreement to the $\mathrm{MoH}$. However, the model does not consider the possibility of the patent holder granting voluntary licenses to the developing country. Although the factors affecting the developing country's bargaining position (i.e. alternative suppliers and likelihood of retaliation) may be the same for requesting either voluntary licenses or price discounts, it is not clear when each of these strategies is optimal not only for the developing country but also for the patent holder. Therefore, more research is needed to clarify the motivations behind this strategy vis-à-vis price reductions as well as the real impact that these agreements may have on access to medicines.

\footnotetext{
${ }^{58}$ After the decision of the Thai Government, Abbott undertook an aggressive lobbying campaign to block the compulsory licensing. The company announced that they would withhold registration of all new medicines from Thailand, stating the country ignores the patent system. Abbott also requested that the US government pressure Thailand for allegedly 'stealing' their intellectual property; in response, the US government downgraded Thailand's trade status to a country with poor intellectual property protection (Ford et al., 2007).
} 


\subsubsection{Articulating supply and demand}

This research analyses the issue of access to medicines from the perspective of the supply of affordable medicines. However, we must acknowledge that even if the challenges in the supply side are overcome, still there are obstacles in the demand side. In lowincome countries and countries where the public health system cannot supply essential medicines to the poorest, isolated policies to promote manufacturing capacity are not likely to have a major impact on access. In these countries, given the extreme context of financial constraints, patients may take the necessary medicines only if they are offered free of charge. Even when this is the case, access to medicines may be jeopardized due to lack of availability and acceptability. Therefore, public policies should foster institutional arrangements that can tackle simultaneously all dimensions of access to medicines.

\subsubsection{Validation with experience of other countries}

Building on Beall \& Kuhn (2012), we identified 33 compulsory license threat episodes in 19 nations (see Ramani \& Urias, 2015). To understand the real circumstances behind each of these negotiation episodes would require a detailed qualitative study with key informants in order to capture factors and details that are not publicly available. A venue for future research could be a validation exercise of the model through interviewing people with experiential knowledge of these negotiations.

\subsubsection{Future innovation: biotechnology and biosimilars}

The increasing financial burden related to public spending on biopharmaceuticals in both developed and developing countries coupled with the intrinsic technological and regulatory idiosyncrasies associated with the approval of biosimilars lead to some loaded questions. There is a need to identify what major advances in science and technology, such as in characterization and evaluation of proteins, are necessary to accelerate the regulatory approval of biosimilar drugs and reduce the need for high cost clinical trials. This issue is critical to define what regulatory pathways are available to facilitate the introduction of follow-on drugs, while maintaining high standards of quality, safety and efficacy for biosimilars as for originator biological drugs. In addition, more research is necessary to understand how science and technology policy can be oriented to achieve these goals and the potential implications of public policies to promote technological capacity building in both developed and developing countries in this context. 


\subsection{Final remarks}

We have largely answered the main question of this research by identifying and analysing the drivers of price negotiation between research-based pharmaceutical MNEs and public agencies in developing countries.

To be able to use compulsory licensing in price negotiations of lifesaving drugs effectively, a developing country must have an appropriate IPR framework that provides for the use of TRIPS flexibilities. If that is the case, then the country must ensure that the drug quantity that can be obtained is greater than otherwise. This, in turn, implies the need of alternative suppliers for the concerned drug. The existence of a local alternative supplier is subject to the country's technological capacity to produce and supply a low cost version of the drug, while meeting high quality standards. The substitution of the patented drug by an imported version, on the other hand, depends not only of the technological competences of the supplier, but also on the patent status of the drug in the exporting country. If the drug is patented in the exporting country, then the likelihood of successful use of compulsory licensing threat can be significantly reduced. This because Paragraph 6 system of TRIPS for compulsory licensing for exports imposes very restrictive conditions that are not attractive to private generic manufacturers.

Confrontation is essentially a bargaining game, but bargaining power is determined by the contextual specificities of the time and the game is usually conducted under incomplete information, with the local challenger and the MNE not being fully aware of the bargaining power of the other.

In addition, a country willing to issue a compulsory license - or simple to threat to use this TRIPS flexibility - must consider the possible side effects that come along. More importantly, it has to handle the internal and external pressure that can arise from this strategy. The model that we developed and the validation with the Brazilian experience provide insights that, in some circumstances, the pressure is strong enough to outrun the benefits of reducing the costs of the concerned drug.

These results reaffirm the view that the current institutional framework provided by the TRIPS Agreement and legitimized by both the Doha Declaration and the August 30 decision gives some freedom to the least developed and developing countries to issue compulsory licenses. Clearly, compulsory licensing cannot and should not be a mechanism for sustainable drug access in the developing world, but rather a short-term 
fix for market conditions that exclude patients from receiving the right treatment. Moreover, they must be limited to vital drugs (e.g. antiretrovirals), differentiating these from 'life-style' drugs (e.g. sildenafil), so that they are not placed in the same basket of needs. Nevertheless, the analysis also clearly indicates that the existing political, diplomatic and economic pressure exerted by pharmaceutical companies and their supportive home governments are still barriers to the widespread use of compulsory licenses to provide more affordable drugs. These pressures can be subtle or even informal, but they are institutionalized as part of the rules of the game and play a strong enforcement role in constraining the available options to countries willing to issue compulsory licenses. 



\section{Chapter 10 Valorisation}

The main results, practical findings, and policy recommendations of this dissertation can be relevant for a wide target audience: scientific, technical, business, institutional and governmental audiences as well as the general public at large.

Effective communication, dissemination and exploitation of the results of this research are an essential part of the its success to reach the maximum social value creation. In addition, it is necessary to exployt a wide range of tools to reach such a diverse target audience. This tools includes publications in peer-reviewed journals (open acesses whever feasible), specialist website and presentations in scientific conferences and seminars (scientific community); commercial, financial and industrial publications (business organizations), popular newspapers, magazines, blogs, social media, and the Internet (the general public); reports and policy briefs (international organisations and policy makers).

In short, the social value created in this dissertation can be presented in three different, though connected, dimensions.

\subsection{Guidance for policy makers}

The topic of this dissertation is highly relevant in terms of public policy. Chapter 8 is entirely devoted to discuss the policy implications of the results presented along this book. The main call for action at the national level refers to the need of building 'bargain strengths' in low and middle-income countries. To be able to negotiate better prices for patented medicines, local governments must have access to technological capabilities that are necessary either to manufacture the concerned drug or to develop its productive process.

We acknowledge the existence of a wide variance in the actual development stage of the pharmaceutical industry in the developing world. Thus, different industrial policy approaches are suggested so that they can be more suitable for these different initial conditions. Although, this research does not provide a ready recipe for policy formulation and implementation, it does address an important topic and provide general guidelines to solve (or alleviate) the problem at hand. 


\subsection{Orientation for business strategy}

Research-based pharmaceutical companies can also benefit from the results of this research. First, these companies can use the integrative framework developed in this dissertation to fine tune their strategy when negotiating prices with governments. Compulsory licensing is never an optimal solution for the patent holder. Therefore, companies should address the sources of informational constrains and find the best response in terms of price reduction that they can offer without losing the market.

In additional, corporations themselves are also observed to hold the view that they should go beyond their traditionally defined responsibilities to take up some of the social responsibilities. Moreover, affordable access to medicines in developing countries, through the cooperation of the pharmaceutical industry is a focal area of the MDGs and is include as part of the MDG 8.

Engaging in price negotiation strategies with developing countries can be seen as robust intiatives in terms of CSR initiatives and brand trust and reputation, which in turn may create economic value for shareholders and social value for consumers.

\subsection{Raising Awareness}

The pharmaceutical industry invest heavily in $\mathrm{R} \& \mathrm{D}$ of products that may have a significant positive impact on individual and collective health. In many instances, pharmaceutical innovation makes the difference between live and death. For some dome diseases, such as HIV/AIDS, even though they do not provide a cure, pharmaceutical products provide signifcant improvement not only in the life expanctancy in the quality of living of those extra years gained. However, many people - most of them in low and middle-income countries - cannot enjoy the benefits from breakthrough drugs simply because they cannot affor these products.

This research raises awareness not only of this important problem, but also of one of its causes and possible alternatives to solve or alleviate it. As pointed by Kingdon (2013), the chances for a problem to raise on the governmental agenda increase if a solution is attached to the it. In addition, the same author says that the chances for a problem to raise on decision-making agenda are dramatically increased if a solution is attached to it. Therefore, this research can make a real contribution to this topic outside the academic world. To realize this potential, it is necessary - though far from being sufficient 
- to disseminate the results of this dissertation and to establish of a continuos dialogue with the scientific community, business sector, policy-makers and the general public.

In additional, we joint the voices that call for changes in the institutional framework concerning compulsory licensing. The limitations imposed by the Paragraph 6 system constrain not only the existing possibilities for the use of compulsory licensing in price negotiations but also the design of policies to address this problem in the developing world. Therefore, our attempt to raise awareness to this topic may have relevant implactions in terms of social value creation. 


\section{References}

Abbott, F. M. (2011). Trends in Local Production of Medicines and Related Technology Transfer. World Health Organization. Retrieved from http://papers.ssrn.com/sol3/papers.cfm?abstract_ id $=1971924$

Abbott, F. M., \& Reichman, J. H. (2007). The Doha Round's Public Health Legacy: Strategies for the Production and Diffusion of Patented Medicines under the Amended TRIPS Provisions. Journal of International Economic Law, 10(4), 921 -987. http://doi.org/10.1093/jiel/jgm040

Acemoglu, D., \& Johnson, S. (2007). Disease and Development: The Effect of Life Expectancy on Economic Growth. Journal of Political Economy, 115(6). Retrieved from http://219.219.114.96/ cufe/upload_files/other/4_20140528031741_55_Acemoglu\%202007.pdf

Aith, M. (2001, November 24). Far-Manguinhos ajuda a baixar valor. Folha de São Paulo. Retrieved from http://www1.folha.uol.com.br/fsp/cotidian/ff2408200117.htm

Aksan, A.-M., \& Chakraborty, S. (2014). Mortality versus morbidity in the demographic transition. European Economic Review, 70, 470-492. http://doi.org/10.1016/j.euroecorev.2014.06.011

Ala, M. U. (2013). A Firm-level Analysis of the Vulnerability of the Bangladeshi Pharmaceutical Industry to the TRIPS Agreement: Implications for R\&D Capability and Technology Transfer. Procedia Economics and Finance, 5, 30-39. http://doi.org/10.1016/S2212-5671(13)00006-3

ALANAC. (1987). Uma estratégia para vencer a dependência. Revista Brasileira de Tecnologia. Brasília. Revista Brasileira de Tecnologia, 18(3).

Amador, J. M. M. (2012). Aplicabilidad del derecho internacional general dentro del mecanismo de solución de controversias de la OMC: el caso del derecho a la salud. Anuario Colombiano de Derecho Internacional-ACDI, 5, 93-121.

Amin, T., \& Kesselheim, A. S. (2012). Secondary Patenting Of Branded Pharmaceuticals: A Case Study Of How Patents On Two HIV Drugs Could Be Extended For Decades. Health Affairs, 31(10), 2286-2294. http://doi.org/10.1377/hlthaff.2012.0107

Anabwani, G. M. (2002). Drug development: a perspective from Africa. Paediatric and Perinatal Drug Therapy, 5(1), 4-11.

Astor, M. (2001, August 23). Brazil to Strip Patent on AIDS Drug. Washington Post. Retrieved from http://www.washingtonpost.com/wp-dyn/world/A51205-2001Aug23.html

Attaran, A. (2004). How Do Patents And Economic Policies Affect Access To Essential Medicines In Developing Countries? Health Affairs, 23(3), 155-166. http://doi.org/10.1377/hlthaff.23.3.155

Attaran, A., \& Gillespie-White, L. (2001). Do Patents for Antiretroviral Drugs Constrain Access to AIDS Treatment in Africa? JAMA: The Journal of the American Medical Association, 286(15), 1886 -1892. http://doi.org/10.1001/jama.286.15.1886

Augier, L., \& Yaly, A. (2013). Economic growth and disease in the OLG model: The HIV/AIDS case. Economic Modelling, 33, 471-481. http://doi.org/10.1016/j.econmod.2013.04.033

Babovic, S., \& Wasan, K. M. (2011). Impact of the trade-related aspects of intellectual property rights (TRIPS) agreement on India as a supplier of generic antiretrovirals. Journal of Pharmaceutical Sciences, 100(3), 816-821. http://doi.org/10.1002/jps.22326 
Bacoccina, D. (2003, September 4). Brasil muda lei para facilitar quebra de patentes. Retrieved December 12, 2013, from http://www.bbc.co.uk/portuguese/noticias/story/2003/09/030904_denizemp.shtml

Baker, B. K. (2008). Ending Drug Registration Apartheid: Taming Data Exclusivity and Patent/Registration Linkage. American Journal of Law \& Medicine, 34, 303.

Bansal, A. K., \& Koradia, V. (2005). The role of reverse engineering in the development of generic formulations. Retrieved from http://www.pharmtech.com/pharmtech/Article/The-Role-ofReverse-Engineering-in-the-Development/ArticleStandard/Article/detail/173676

Bansal, I. S., Sahu, D., Bakshi, G., \& Singh, S. (2009). Evergreening - A Controversial Issue in Pharma Milieu. Journal of Intellectual Property Rights, 14(4), 299-306.

Barbosa da Silva Jr., J. (2006, December 28). A questáo do acesso aos anti-retrovirais. Folha de São Paulo. São Paulo -SP, Brasil. Retrieved from http://wwwl.folha.uol.com.br/fsp/opiniao/ fz2812200608.htm

Barro, R. (1996). Health and Economic Growth. Retrieved from http://scholar.harvard.edu/barro/ publications/health-and-economic-growth

Bass, N. A. (2002). Implications of the TRIPs Agreement for Developing Countries: Pharmaceutical Patent Laws in Brazil and South Africa in the 21st Century. George Washington International Law Review, 34, 191.

BBC News. (2003, November 18). New anti-HIV drug deal for Brazil. Retrieved December 13, 2013, from http://news.bbc.co.uk/2/hi/americas/3281683.stm

Beall, R., \& Kuhn, R. (2012). Trends in Compulsory Licensing of Pharmaceuticals Since the Doha Declaration: A Database Analysis. PLoS Med, 9(1), e1001154. http://doi.org/10.1371/ journal.pmed.1001154

Benoliel, D., \& Salama, B. (2010). TOWARDS AN INTELLECTUAL PROPERTY BARGAINING THEORY: THE POST-WTO ERA. Retrieved from http://works.bepress.com/ daniel_benoliel/1

Bermudez, J. (1992). Remédio: saúde ou indústria? A produçäo de medicamentos no Brasil; (Pharmaceuticals: health or industry? The production of medicines in Brazil). Rio de Janeiro: Relume Dumar.

Bermudez, J., Oliveira, M. A., \& Esher, Á. (2004). Acceso a medicamentos: derecho fundamental, papel del estado; Access to drugs: fundamental right, role of the state. Escola Nacional de Saúde Pública. Retrieved from http://bases.bireme.br/cgi-bin/wxislind.exe/iah/online/?IsisScript=iah/iah.xis \&src=google\&base=LILACS\&lang=p\&nextAction=lnk\&exprSearch=426500\&indexSearch=ID

Bermudez, J., \& 't Hoen, E. (2010). The UNITAID Patent Pool Initiative: Bringing Patents Together for the Common Good. The Open AIDS Journal, 4, 37-40. http://doi.org/ $10.2174 / 1874613601004020037$

Bhattacharyya, S., \& Bauch, C. T. (2010). A game dynamic model for delayer strategies in vaccinating behaviour for pediatric infectious diseases. Journal of Theoretical Biology, 267(3), 276-282. http://doi.org/10.1016/j.jtbi.2010.09.005

Bird, R. C. (2009). Developing Nations and the Compulsory License: Maximizing Access to Essential Medicines While Minimizing Investment Side Effects. Journal of Law, Medicine and Ethics, 37, 209.

Bird, R. C., \& Cahoy, D. R. (2008). The Impact of Compulsory Licensing on Foreign Direct Investment: A Collective Bargaining Approach. American Business Law Journal, 45(2), 283. 
Bloom, D. E., \& Canning, D. (2000). Policy forum: public health. The health and wealth of nations. Science (New York, N.Y.), 287(5456), 1207, 1209.

Bloom, D. E., \& Canning, D. (2003). The health and poverty of nations: from theory to practice. Journal of Human Development, 4(1), 47-71.

Bloom, D. E., Canning, D., \& Sevilla, J. (2004). The Effect of Health on Economic Growth: A Production Function Approach. World Development, 32(1), 1-13. http://doi.org/10.1016/j.worlddev.2003.07.002

Boulet, P., Perriens, J., Renaud-Théry, F., \& Velasquez, G. (2000). Pharmaceuticals and the WTO TRIPS Agreement: Questions and Answers. Geneva, Switzerland: UNAIDS/WHO. Retrieved from http://apps.who.int/medicinedocs/pdf/whozip18e/whozip18e.pdf

Buske, L. (2002). Drug prices stable but total spending rises by $15 \%$. Canadian Medical Association Journal, 167(4), 390-390-a.

Cameron, A., Ewen, M., Ross-Degnan, D., Ball, D., \& Laing, R. (2009). Medicine prices, availability, and affordability in 36 developing and middle-income countries: a secondary analysis. The Lancet, 373(9659), 240-249. http://doi.org/10.1016/S0140-6736(08)61762-6

Cassier, M., \& Correa, M. (2003). Patents, innovation and public health: Brazilian public-sector laboratories' experience in copying AIDS drugs. In Economics of Aids Aid and Access in Developing Countries, Ed. ANRS (pp. 89-107). Retrieved from http://193.144.75.244/epip/documentos/ Cassier's\%20paper.pdf

Cassier, M., \& Correa, M. (2007). Propriedade intelectual e saúde pública: a cópia de medicamentos contra HIV/Aids realizada por laboratórios farmacêuticos brasileiros públicos e privados-DOI: 10.3395/reciis. v1i1. 38pt. Revista Eletrônica de Comunicação, Informação \& Inovação Em Saúde, 1(1). Retrieved from http://www.reciis.icict.fiocruz.br/index.php/reciis/article/viewArticle/38

Cassier, M., \& Correa, M. (2008). Scaling up and reverse engineering: Acquisition of industrial knowledge by copying drugs in Brazil. In B. Coriat, The Political Economy of HIVIAIDS in Developing Countries: TRIPS, Public Health Systems and Free Access. Edward Elgar Publishing.

Castellano, R. A. (2005). Patent Law for New Medical Uses of Known Compounds and Pfizer's Viagra Patent. IDEA: The Intellectual Property Law Review, 46, 283.

Centre for Pharmaceutical Management. (2000). Defining and Measuring Access to Essential Drugs, Vaccines, and Health Commodities: Report of the WHO-MSG consultative meeting. FerneyVoltaire, France. Retrieved from http://projects.msh.org/seam/reports/measuring_access_ Dec2000.pdf

Chakrabarti, G. (2014). Need of Data Exclusivity: Impact on Access to Medicine. Journal of Intellectual Property Rights, 19, 325-336.

Chami, G., \& Wasswa-Kintu, S. (2011). Compulsory licensing of generic drugs remains mired in quagmires. Canadian Medical Association Journal, cmaj-109.

Chaudhuri, S. (2010). R\&D for development of new drugs for neglected diseases in India. International Journal of Technology and Globalisation, 5(1), 61-75. http://doi.org/10.1504/IJTG. 2010.033666

Chequer, P. (2005). Aids 20 anos: esboço histórico para entender o programa brasileiro”. Retrieved from http://sistemas.aids.gov.br/congressoprev2006/20_anos_do_PN.htm

Chequer, P. (2012, March 14). Interview with Pedro Chequer. 
Clemens, B., \& Douglas, T. J. (2012). To What Degree Can Potable Water Foster International Economic Development and Sustainability? What Role Does Health Play? Organization Management Journal, 9(2), 83-89.

Clendenning, A. (2003, September 3). Brazil Starts Patent Breaking AIDS Drugs. The Associated Press. New York. Retrieved from http://www.apnewsarchive.com/2003/Brazil-Starts-PatentBreaking-AIDS-Drugs/id-547349bc2fcd12d9405818c337846fe4

Cohen, J. C., \& Lybecker, K. M. (2005). AIDS Policy and Pharmaceutical Patents: Brazil's Strategy to Safeguard Public Health. World Economy, 28(2), 211-230. http://doi.org/10.1111/j.14679701.2005.00668.x

Cohen-Kohler, J. C., Forman, L., \& Lipkus, N. (2008). Addressing legal and political barriers to global pharmaceutical access: Options for remedying the impact of the Agreement on TradeRelated Aspects of Intellectual Property Rights (TRIPS) and the imposition of TRIPS-plus standards. Health Economics, Policy and Law, 3(03), 229-256. http://doi.org/10.1017/S17441 33108004477

Cohen, W. M., Nelson, R. R., \& Walsh, J. P. (2000). Protecting Their Intellectual Assets: Appropriability Conditions and Why U.S. Manufacturing Firms Patent (or Not). National Bureau of Economic Research Working Paper Series, No. 7552. Retrieved from http://www.nber.org/papers/ w7552

Cojocaru, M.-G. (2008). Dynamic equilibria of group vaccination strategies in a heterogeneous population. Journal of Global Optimization, 40(1-3), 51-63. http://doi.org/10.1007/s10898007-9204-7

Commission on Macroeconomics and Health. (2001). Macroeconomics and Health: Investing in Health for Economic Development. World Health Organization.

Coriat, B. (2008). The Political Economy of HIV/AIDS in Developing Countries: TRIPS, Public Health Systems and Free Access. Edward Elgar Publishing.

Correa, C. M. (2002). Implications of the Doha Declaration on the TRIPS Agreement and public health. World Health Organization, Essential Drugs and Medicine Policy Geneva. Retrieved from http://wwwlive.who.int/entity/medicines/areas/policy/WHO_EDM_PAR_2002.3.pdf

Correa, C. M. (2006a). Implications of bilateral free trade agreements on access to medicines. Bulletin of the World Health Organization, 84(5), 399-404. http://doi.org/10.1590/S0042-96862006 000500021

Correa, C. M. (2006b). Pharmaceutical inventions: when is the granting of a patent justified? International Journal of Intellectual Property Management, 1(1), 4-21.

Costa, H. PORTARIA No 1360/GM de 21 de julho de 2003., Pub. L. No. No 1360/GM (2003). Retrieved from http://dtr2001.saude.gov.br/sas/PORTARIAS/Port2003/GM/GM-1360.htm

Costa, H. (2005, June 27). Statement of Dr. Humberto Costa, Minister of Health of Brazil, about Compulsory Licensing of the Lopinavir-ritonavir combination | Department of STD, AIDS and Viral Hepatitis. Retrieved January 21, 2014, from http://www.aids.gov.br/en/noticia/statementdr-humberto-costa-minister-health-brazil-about-compulsory-licensing-lopinavirriton

Cullen, D. (2007). Data Protection: The New IP Frontier - An Overview of Existing Laws and Regulations. Journal of Generic Medicines: The Business Journal for the Generic Medicines Sector, 5(1), 9-25. http://doi.org/10.1057/palgrave.jgm.4950087

Danilovich, J. (2005a, March 24). Brazil threatens compulsory licensing of AIDS pharmaceuticals, again. Retrieved from http://search.wikileaks.org/plusd/cables/05BRASILIA804_a.html 
Danilovich, J. (2005b, June 3). Ambassador meets with U.S. pharmaceutical firms threatened with licensing. Retrieved from http://search.wikileaks.org/plusd/cables/05BRASILIA1507_a.html

Danilovich, J. (2005c, October 13). Abbott and GoB reach deal to avoid compulsory license. Retrieved from http://www.wikileaks.org/plusd/cables/05BRASILIA2729_a.html

Danzon, P. M. (1997). Price Discrimination for Pharmaceuticals: Welfare Effects in the US and the EU. International Journal of the Economics of Business, 4(3), 301-322. http://doi.org/ $10.1080 / 758523212$

Danzon, P. M., \& Chao, L.-W. (2000). Cross-national price differences for pharmaceuticals: how large, and why? Journal of Health Economics, 19(2), 159-195. http://doi.org/10.1016/S01676296(99)00039-9

Danzon, P. M., Mulcahy, A. W., \& Towse, A. K. (2013). Pharmaceutical Pricing in Emerging Markets: Effects of Income, Competition, and Procurement. Health Economics, n/a-n/a. http://doi.org/10.1002/hec.3013

Danzon, P. M., \& Towse, A. (2003). Differential Pricing for Pharmaceuticals: Reconciling Access, $\mathrm{R} \& \mathrm{D}$ and Patents. International Journal of Health Care Finance and Economics, 3(3), 183-205. http://doi.org/10.1023/A:1025384819575

Darlington, S. (2001, August 23). Brazil makes demands in Roche AIDS drug dispute. Reuters. Retrieved from http://ww1.aegis.org/news/re/2001/RE010823.html

Dawkins, J. (2005). Corporate responsibility: The communication challenge. Journal of Communication Management, 9(2), 108-119. http://doi.org/10.1108/13632540510621362

De Clercq, E. (2005). Antiviral drug discovery and development: Where chemistry meets with biomedicine. Antiviral Research, 67(2), 56-75. http://doi.org/10.1016/j.antiviral.2005.05.001

DiMasi, J. A., Hansen, R. W., \& Grabowski, H. G. (2003). The price of innovation: new estimates of drug development costs. Journal of Health Economics, 22(2), 151-185.

DiMasi, J. A., \& Paquette, C. (2004). The economics of follow-on drug research and development. Pharmacoeconomics, 22(2), 1-14.

Dion, D. (1998). Evidence and Inference in the Comparative Case Study. Comparative Politics, 30(2), 127. http://doi.org/10.2307/422284

Dionisio, D. (2010). Needs-driven rather than market-driven rules to spread access to medicines in poor countries. Translational Biomedicine, 1(1). Retrieved from http://imed.pub/ojs/index.php/ transbiomed/article/view/167

Dos Santos, R. S. L. (2010). Sustentabilidade do programa nacional de DST/AIDS: análise da capacidade de oferta e preços dos medicamentos antiretrovirais (Master's Dissertation). Universidade Federal do Rio de Janeiro, Rio de Janeiro, Brasil.

DOU. (2006, April 28). EXTRATO DE INEXIGIBILIDADEDE LICITAÇÃO No 10/2006. Diário Oficial Da União, p. 88. Brasília.

DOU. (2008a, February 27). EXTRATO DE CONTRATO No 1/2008. Diário Oficial Da Uniāo, p. 64. Brasília.

DOU. (2008b, July 24). EXTRATO DE TERMO ADITIVO No 1/2008. Diário Oficial Da União, p. 120. Brasília.

DOU. (2008c, December 31). EXTRATO DE INEXIGIBILIDADE DE LICITAÇĀO № 30/2008. Diário Oficial Da União, p. 191. Brasília.

DOU. (2010a, January 22). EXTRATO DE CONTRATO № 66/2009. Diário Oficial Da União, p. 141. Brasília. 
DOU. (2010b, January 29). EXTRATO DE CONTRATO N³9/2010. Diário Oficial Da União, p. 100. Brasília.

DOU. (2011, July 27). EXTRATO DE CONTRATO No 132/2011. Diário Oficial Da União, p. 144. Brasília.

DOU. (2012, March 28). EXTRATO DE INEXIGIBILIDADE DE LICITAÇÃO No 13/2012. Diário Oficial Da União, p. 61. Brasília.

DOU. (2013, April 4). EXTRATO DE CONTRATO No 27/2013. Diário Oficial Da União, p. 101. Brasília.

DOU. (2014, May 15). EXTRATO DE CONTRATO No 47/2014 - UASG 250005. Diário Oficial Da Uniāo, p. 141. Brasília.

Drews, J. (2000). Drug Discovery: A Historical Perspective. Science, 287(5460), 1960-1964. http://doi.org/10.1126/science.287.5460.1960

Dul, J., \& Hak, T. (2008). Case study methodology in business research. Routledge. Retrieved from http://books.google.nl/books?hl=en\&lr=\&id=2UqvbjtpO8sC\&oi=fnd\&pg=PP2\&dq=Case+Stud $\mathrm{y}+$ Methodology+in+Business+Research\&ots=A3vNDeHEoG\&sig=IySSZZJCJuKkK7gR5UkFh $4 \mathrm{ThT} 2 \mathrm{~s}$

Dutfield, G. (2008). Delivering Drugs to the Poor: Will the TRIPS Amendment Help. American Journal of Law \& Medicine, 34, 107.

Dwivedi, G., Hallihosur, S., \& Rangan, L. (2010). Evergreening: A deceptive device in patent rights. Technology in Society, 32(4), 324-330. http://doi.org/10.1016/j.techsoc.2010.10.009

Ehrlich, I., \& Lui, F. T. (1991). Intergenerational trade, longevity, and economic growth. Journal of Political Economy, 1029-1059.

El-Said, H., \& El-Said, M. (2007). TRIPS-Plus Implications for Access to Medicines in Developing Countries: Lessons from Jordan-United States Free Trade Agreement. The Journal of World Intellectual Property, 10(6), 438-475. http://doi.org/10.1111/j.1747-1796.2007.00330.x

Fanti, L., \& Gori, L. (2013). Endogenous fertility, endogenous lifetime and economic growth: the role of child policies. Journal of Population Economics, 27(2), 529-564. http://doi.org/ $10.1007 / \mathrm{s} 00148-013-0472-\mathrm{x}$

Fanti, L., Gori, L., \& Tramontana, F. (2012). Endogenous lifetime, accidental bequests and economic growth. Decisions in Economics and Finance, 37(1), 81-98. http://doi.org/10.1007/s10203012-0138-2

Ferrán Catalá-López, Anna García-Altés, Álvarez-Martín, E., Gènova-Maleras, R., \& MorantGinestar, C. (2010). Does the development of new medicinal products in the European Union address global and regional health concerns? Population Health Metrics, 8(1), 34. http://doi.org/10.1186/1478-7954-8-34

Flanagan, W., \& Whiteman, G. (2007). "AIDS is Not a Business": A Study in Global Corporate Responsibility - Securing Access to Low-cost HIV Medications. Journal of Business Ethics, 73(1), 65-75. http://doi.org/10.1007/s10551-006-9198-y

Ford, N., Gray, A., \& Venter, W. F. (2008). Tough choices: Tenofovir, tenders and treatment. Southern African Journal of HIV Medicine, 9(1), 8. http://doi.org/10.7196/sajhivmed.21

Ford, N., Wilson, D., Chaves, G. C., Lotrowska, M., \& Kijtiwatchakul, K. (2007). Sustaining access to antiretroviral therapy in the less-developed world: lessons from Brazil and Thailand. AIDS, 21(Suppl 4), S21-S29. http://doi.org/10.1097/01.aids.0000279703.78685.a6 
Formenti, L. (2008, September 2). Inpi nega patente ao anti-retroviral Tenofovir. O Estado de São Paulo. Retrieved from http://www.estadao.com.br/noticias/geral,inpi-nega-patente-ao-antiretroviral-tenofovir, 234768,0 .htm

Francisco, M. (2012). Compulsory license bandwagon gains momentum. Nature Biotechnology, 30(9), 814-814. http://doi.org/10.1038/nbt0912-814a

Frenkel, J., \& Ortega, J. A. (1987). A integração necessária entre tecnologia e saúde. Revista Brasileira de Tecnologia. Brasilia, 18(3).

Frenkel, J., Reis, J. A., Araújo Jr, J. T., Naidin, L. C., Lobão, R. S., \& Fonseca, M. S. (1978). Tecnologia e competição na indústria farmacêutica brasileira [Technology and competition in the Brazilian pharmaceutical industry]. Rio de Janeiro, Brazil: Financiadora de Estudos e Projetos.

Frost, L. J., \& Reich, M. (2009). Access: How Do Good Health Technologies Get to Poor People in Poor Countries?. Bibliomotion, Inc.

Galvão, A. (2009, April 2). Governo decide usar PPPs para produzir 24 fármacos no país. Valor Econômico. São Paulo -SP, Brasil. Retrieved from http://www.valor.com.br/arquivo/ 614961/governo-decide-usar-ppps-para-produzir-24-farmacos-no-pais

Galvão, J. (2002). Access to antiretroviral drugs in Brazil. The Lancet, 360(9348), 1862-1865. http://doi.org/10.1016/S0140-6736(02)11775-2

Gehl Sampath, P. (2005). Economic aspects of access to medicines after 2005: product patent protection and emerging firm strategies in the Indian pharmaceutical industry. Retrieved from http://wwwlive.who.int/entity/intellectualproperty/studies/PadmashreeSampathFinal.pdf

Gehl Sampath, P. (2007). Innovation and Competitive Capacity in Bangladeshs Pharmaceutical Sector. United Nations University, Maastricht Economic and social Research and training centre on Innovation and Technology. Retrieved from http://ideas.repec.org/p/unm/unumer/ 2007031.html

Gershell, L. J., \& Atkins, J. H. (2003). A brief history of novel drug discovery technologies. Nature Reviews Drug Discovery, 2(4), 321-327. http://doi.org/10.1038/nrd1064

Global Forum for Health Research. (2000). The 10/90 Report on Health Research 2000. Geneva, Switzerland: Global Forum for Health Research. Retrieved from http://announcementsfiles. cohred.org/gfhr_pub/assoc/s14791e/s14791e.pdf

Goenka, A., Liu, L., \& Nguyen, M.-H. (2014). Infectious diseases and economic growth. Journal of Mathematical Economics, 50, 34-53. http://doi.org/10.1016/j.jmateco.2013.10.004

Gold, E. R., \& Morin, J.-F. (2012). Promising Trends in Access to Medicines. Global Policy, 3(2), 231-237. http://doi.org/10.1111/j.1758-5899.2011.00110.x

Grabowski, H. (2002). Patents, Innovation and Access to New Pharmaceuticals. Journal of International Economic Law, 5(4), 849-860. http://doi.org/10.1093/jiel/5.4.849

Grangeiro, A. (2005, July). MINISTÉRIO INVENTA E ABBOTT PATENTEIA A NEGOCIAÇÃO. Retrieved June 1, 2015, from http://agenciaaids.com.br/home/artigos/ artigo_detalhe/119\#.VWym0EbqHm5

Grangeiro, A., Teixeira, L., Bastos, F. I., \& Teixeira, P. (2006). Sustainability of Brazilian policy for access to antiretroviral drugs. Revista de Saúde Pública, 40, 60-69. http://doi.org/10.1590/ S0034-89102006000800009 
Greve, J. (2008). Healthcare in developing countries and the role of business: a global governance framework to enhance the accountability of pharmaceutical companies. Corporate Governance: The International Journal of Business in Society, 8(4), 490-505. http://doi.org/10.1108/ 14720700810899220

Grover, A., Citro, B., Mankad, M., \& Lander, F. (2012). Pharmaceutical Companies and Global Lack of Access to Medicines: Strengthening Accountability under the Right to Health. The Journal of Law, Medicine \& Ethics, 40(2), 234-250. http://doi.org/10.1111/j.1748-720X.2012. 00661.x

GTPI, (Grupo de Trabalho sobre Propriedade Intelectual ). (2011, April 19). Carta de Preocupaçóes do GTPI a respeito das Parcerias Público-Privadas anunciadas pelo governo. Retrieved from http://www.deolhonaspatentes.org.br/media/file/Notas\%20GTPI\%20-

\%202011/Carta\%20GTPI_Preocupa\%C3\%A7\%C3\%B5es_Final_Site.pdf

GTPI, (Grupo de Trabalho sobre Propriedade Intelectual ). (2013, December 17). Civil society demands a response from the government in relation to the contract of ARV drug atazanavir. Grupo de Trabalho sobre Propriedade Intelectual. Retrieved from http://www.deolhonaspatentes.org.br/media/file/notas\%20GTPI\%202013/release\%20atazanavir _final\% $20 \% 28$ english $\% 29 . p d f$

Guennif, S., \& Ramani, S. V. (2012). Explaining divergence in catching-up in pharma between India and Brazil using the NSI framework. Research Policy, 41(2), 430-441. http://doi.org/ 10.1016/j.respol.2011.09.005

Guimarães, R., \& Penna, G. (2007, May 18). SOBRE O LICENCIAMENTO COMPULSÓRIO. Valor Econômico. São Paulo -SP, Brasil. Retrieved from http://www.agenciaaids.com. $\mathrm{br} /$ noticias/interna.php?id=7561

Hak, T., \& Dul, J. (2010a). Pattern matching. In A. J. Mills, G. Durepos, \& E. Wiebe (Eds.), Encyclopedia of Case Study Research: L - Z; Index. SAGE.

Hak, T., \& Dul, J. (2010b). Theory-Testing With Cases. In A. J. Mills, G. Durepos, \& E. Wiebe (Eds.), Encyclopedia of Case Study Research (Vol. 2). SAGE.

Hannah, E. N. (2011). NGOs and the European Union: Examining the Power of Epistemes in the EC's TRIPS and Access to Medicines Negotiations. Journal of Civil Society, 7(2), 179-206. http://doi.org/10.1080/17448689.2011.573669

Hansen, C. W. (2013). Life expectancy and human capital: Evidence from the international epidemiological transition. Journal of Health Economics, 32(6), 1142-1152.

Harsanyi, J. C. (1967). Games with Incomplete Information Played by "Bayesian” Players, I-III Part I. The Basic Model. Management Science, 14(3), 159-182.

Harsanyi, J. C. (1968a). Games with Incomplete Information Played by "Bayesian” Players Part II. Bayesian Equilibrium Points. Management Science, 14(5), 320-334.

Harsanyi, J. C. (1968b). Games with incomplete information played by’Bayesian'players, Part III. The basic probability distribution of the game. Management Science, 14(7), 486-502.

Hartsough, K., Rosan, D. E., \& Sachs, L. (2006). Benchmarking AIDS: Evaluating Pharmaceutical Company Responses to the Public Health Crisis in Emerging Markets. Bangkok, Thailand: APCOM (Asia Pacific Coalition on Male Sexual Health). Retrieved from http://www.apcom.org/idsdocument/benchmarking-aids-evaluating-pharmaceutical-company-responses-public-healthcrisis 
Hemphill, T. A. (2010). Pharmaceutical patent expropriation and technology strategy: strategic options to compulsory licensing. Technology Analysis \& Strategic Management, 22(1), 19-41. http://doi.org/10.1080/09537320903438039

He, Y., Lam, T. H., Jiang, B., Li, L. S., Sun, D. L., Wu, L., ... Hu, F. B. (2014). Changes in BMI Before and During Economic Development and Subsequent Risk of Cardiovascular Disease and Total Mortality: A 35-Year Follow-up Study in China. Diabetes Care, 37(9), 2540-2547.

Hickson, K. (2014). The GDP Value of Twentieth-Century Health Improvements in Developed Economies: Initial Estimates for England. Review of Income and Wealth, 6O(2), 385-399.

Hoebert, J., Laing, R., \& Stephens, P. (2011). Pharmaceutical Consumption. In G. WHO, The world medicines situation 2011. Geneva, Switzerland: WHO. Retrieved from http://www.who.int/entity/health-accounts/documentation/world_medicine_situation.pdf?ua=1

Hotez, P. J., Molyneux, D. H., Fenwick, A., Ottesen, E., Ehrlich Sachs, S., \& Sachs, J. D. (2006). Incorporating a Rapid-Impact Package for Neglected Tropical Diseases with Programs for HIV/AIDS, Tuberculosis, and Malaria. PLoS Med, 3(5), e102. http://doi.org/10.1371/journal.pmed.0030102

IFPMA. (2013). Developing World Health Partnerships Directory. Geneva, Switzerland: International Federation of Pharmaceutical Manufacturers \& Associations. Retrieved from http://partnerships. ifpma.org/pages/uploads/Modules/Resources/ifpma_partnerships_directory_publication_final.pdf

Isaakidis, P., Swingler, G. H., Pienaar, E., Volmink, J., \& Ioannidis, J. P. A. (2002). Relation between burden of disease and randomised evidence in sub-Saharan Africa: survey of research. BMJ, 324(7339), 702. http://doi.org/10.1136/bmj.324.7339.702

Kale, D., \& Little, S. (2007). From Imitation to Innovation: The Evolution of R\&D Capabilities and Learning Processes in the Indian Pharmaceutical Industry. Technology Analysis \& Strategic Management, 19(5), 589-609. http://doi.org/10.1080/09537320701521317

Kerry, V. B., \& Lee, K. (2007). TRIPS, the Doha Declaration and Paragraph 6 decision: what are the remaining steps for protecting access to medicines. Globalization and Health, 3(3). Retrieved from http://www.biomedcentral.com/content/pdf/1744-8603-3-3.pdf

KHN. (2001, August 23). Brazil Intends to Break Patent on Roche's Nelfinavir to Produce Drug Locally. Retrieved from http://khn.org/morning-breakout/dr00006553/

Kiddell-Monroe, R. (2014). Access to Medicines and Distributive Justice: Breaching Doha's Ethical Threshold. Developing World Bioethics, 14(2), 59-66. http://doi.org/10.1111/dewb.12046

Kim, L. (1997). Imitation to Innovation: The Dynamics of Korea's Technological Learning. Harvard Business Press.

Koradia, V. S., Chawla, G., \& Bansal, A. K. (2005). Comprehensive Characterisation of the Innovator Product: Targeting Bioequivalent Generics. Journal of Generic Medicines: The Business Journal for the Generic Medicines Sector, 2(4), 335-346. http://doi.org/10.1057/palgrave. jgm.4940086

Kubiske, L. (2009, August 17). BRAZIL: PATENT DENIED, GOB PAVES WAY FOR GENERIC PRODUCTION OF IMPORTANT HIV DRUG. Retrieved from http://www.wikileaks.org/ plusd/cables/09BRASILIA1017_a.html

Kuhn, R., \& Beall, R. F. (2012). The time for pharmaceutical compulsory licensing has expired. Nature Medicine, 18(8), 1168-1168. http://doi.org/10.1038/nm0812-1168

Kuznets, S. (1975). Population trends and modern economic growth-notes towards a historical perspective. Retrieved from http://www.popline.org/node/520695

Kvale, S. (1996). Interviews: an introduction to qualitative research interviewing. SAGE. 
Lane, C. (1998). European companies between globalization and localization: a comparison of internationalization strategies of British and German MNCs. Economy and Society, 27(4), 462-485. http://doi.org/10.1080/03085149800000030

Lassen, L. C., \& Thomsen, M. K. (2007). Global health: the ethical responsibility of the pharmaceutical industry. Dan Med Bull, 54, 35-6.

Leach, B., Paluzzi, J. E., \& Munderi, P. (2005). Prescription for Healthy Development: Increasing Access to Medicines. Earthscan.

Lee, J.-Y., \& Hunt, P. (2012). Human Rights Responsibilities of Pharmaceutical Companies in Relation to Access to Medicines. The Journal of Law, Medicine \& Ethics, 40(2), 220-233. http://doi.org/10.1111/j.1748-720X.2012.00660.x

Levi, G. C., \& Vitória, M. A. A. (2002). Fighting against AIDS: the Brazilian experience. Aids, 16(18), 2373-2383.

Levin, R. C. (1988). Appropriability, R\&D Spending, and Technological Performance. The American Economic Review, 78(2), 424-428.

Levin, S. R. (1987). Improving distribution of pharmaceuticals in developing countries: A case study of The Gambia project. The Journal of Technology Transfer, 11(2), 1-8. http://doi.org/10.1007/ BF02174374

Lichtenberg, F. R. (2011). Pharmaceutical Companies' Variation Of Drug Prices Within And Among Countries Can Improve Long-Term Social Well-Being. Health Affairs, 30(8), 15391544. http://doi.org/10.1377/hlthaff.2010.0891

Liese, B. H., Houghton, N., \& Teplitskaya, L. (2014). Development assistance for neglected tropical diseases: progress since 2009. International Health, 6(3), 162-171. http://doi.org/10.1093/ inthealth/ihu052

Linehan, P. (2006, February 21). BRAZIL'S SPECIAL 301 RECOMMENDATION. Retrieved from http://www.wikileaks.org/plusd/cables/06BRASILIA367_a.html

Liu, W. (2010). Approaches to Ensuring Access to Pharmaceuticals under the New China's Patent Law. Journal of Intellectual Property Rights, 15, 228-234.

López-Casasnovas, G., \& Soley-Bori, M. (2014). The Socioeconomic Determinants of Health: Economic Growth and Health in the OECD Countries during the Last Three Decades. International Journal of Environmental Research and Public Health, 11(1), 815-829. http://doi.org/10.3390/ijerph110100815

Love, J. P. (2007). Recent examples of the use of compulsory licenses on patents. Knowledge Ecology International, 8.

Lu, Y., Hernandez, P., Abegunde, D., WHO, G., \& Edejer, T. (2011). The world medicines situation 2011. Medicine Expenditures. World Health Organization, Geneva. Retrieved from http://www.who.int/entity/health-accounts/documentation/world_medicine_situation.pdf?ua=1

Lv, Z., \& Zhu, H. (2014). Health Care Expenditure and GDP in African Countries: Evidence from Semiparametric Estimation with Panel Data. The Scientific World Journal, 2014. Retrieved from http://www.hindawi.com/journals/tswj/2014/905747/abs/

Macdonald, S. (2003). Increased drug spending is creating funding crisis, report says. BMJ: British Medical Journal, 326(7391), 677.

Macedo, M. F. (2005). Análise de patentes de medicamentos arv candidatas a licenciamento pelo Ministério da Saúde (Patent analysis of ARV drugs that are candidates for compulsory license by the Ministry of Health) (Technical Report) (p. 39). Brasília: Ministry of Health of Brazil. 
Mackie, J. E., Taylor, A. D., Daar, A. S., \& Singer, P. A. (2006). Corporate social responsibility strategies aimed at the developing world: perspectives from bioscience companies in the industrialised world. International Journal of Biotechnology, 8(1), 103-118.

Mándi, A. (2003). Protection and Challenge of Pharmaceutical Patents. Journal of Generic Medicines: The Business Journal for the Generic Medicines Sector, 1(1), 72-82. http://doi.org/10.1057/palgrave.jgm.4940019

Mansfield, E. (1986, February 1). Patents and Innovation: An Empirical Study [research-article]. $\begin{array}{llll}\text { Retrieved November } & 19, & \text { 2013, }\end{array}$ http://pubsonline.informs.org/doi/abs/10.1287/mnsc.32.2.173

Mansfield, E., Schwartz, M., \& Wagner, S. (1981). Imitation Costs and Patents: An Empirical Study. The Economic Journal, 91(364), 907-918. http://doi.org/10.2307/2232499

Mazumdar, M., \& Banerjee, D. S. (2012). On price discrimination, parallel trade and the availability of patented drugs in developing countries. International Review of Law and Economics, 32(1), 188-195. http://doi.org/10.1016/j.irle.2012.01.001

Médecins Sans Frontières. (2006). Untangling the web of antiretroviral price reductions: 9th Edition.

Médecins Sans Frontières. (2008). Untangling the web of antiretroviral price reductions: 11th Edition.

Médecins Sans Frontières. (2012). Untangling the web of antiretroviral price reductions: 15th Edition. Geneva, Switzerland: MSF - Médecins Sans Frontières.

Médecins Sans Frontières. (2013). Untangling the web of antiretroviral price reductions: 16th Edition. Geneva, Switzerland: MSF - Médecins Sans Frontières.

Mignone, R., \& Madueño, D. (2001, August 22). Brasil quebra patente de remédio contra Aids. Folha de São Paulo. Retrieved from http://www1.folha.uol.com.br/folha/ciencia/ult306u46 64.shtml

Ministry of Health of Brazil. (2005a). THE SUSTAINABILITY OF UNIVERSAL ACCESS TO ANTIRETROVIRAL MEDICINES IN BRAZIL. Brasília.

Ministry of Health of Brazil. (2005b, November 11). Nota Técnica. Ministry of Health of Brazil. Retrieved from http://www.aids.gov.br/noticia/no-inicio-do-mes-de-agosto-o-conselho-nacionalde-saude-emitiu-resolucao-352-leia-abaixo-rec

Moatti, J.-P., Barnett, T., Coriat, B., Souteyrand, Y., Dumoulin, J., \& Flori, Y.-A. (2003). Economics of AIDS and access to HIV-AIDS care in developing countries: issues and challenges. Agence nationale de recherches sur le SIDA (ANRS). Retrieved from http://eprints.lse.ac.uk/23789/

Monten, L. M. (2005). Inconsistency between Section 301 and TRIPS: Counterproductive with Respect to the Future of International Protection of Intellectual Property Rights, The. Marquette Intellectual Property Law Review, 9, 387.

Moon, S., Bermudez, J., \& 't Hoen, E. (2012). Innovation and Access to Medicines for Neglected Populations: Could a Treaty Address a Broken Pharmaceutical R\&D System? PLoS Med, 9(5), e1001218. http://doi.org/10.1371/journal.pmed.1001218

Moran, M. (2005). A Breakthrough in R\&D for Neglected Diseases: New Ways to Get the Drugs We Need. PLoS Med, 2(9), e302. http://doi.org/10.1371/journal.pmed.0020302

Moran, M., Guzman, J., Chapman, N., Abela-Oversteegen, L., Howard, R., Farrell, P., \& Luxford, J. (2013). Neglected Disease Research and Development: The Public Divide. Australia: Policy Cures. Retrieved from http://www.policycures.org/downloads/GF_report13_all_web.pdf 
Morel, C. M., McGuire, A., \& Mossialos, E. (2011). The Level Of Income Appears To Have No Consistent Bearing On Pharmaceutical Prices Across Countries. Health Affairs, 30(8), 15451552. http://doi.org/10.1377/hlthaff.2010.0317

Moreno-Macías, L., Palma-Solís, M., \& Zapata-Vázquez, R. E. (2013). The impact of public expenditure on undernourishment distribution in Mexico. Global Health Promotion, 20(3), 25-37.

Murthy, V. N., \& Okunade, A. A. (2014). Population health status and economic growth in Chinese provinces: some policy implications. Applied Economics Letters, 21(6), 377-382.

Naidu, S., \& Chand, A. (2013). Does central government health expenditure and medical technology advancement determine economic growth rates in the Pacific island countries? Asia-Pacific Journal of Business Administration, 5(3), 234-245. http://doi.org/10.1108/APJBA-01-2013-0005

Nattrass, N. J. (2008). The (political) economics of antiretroviral treatment in developing countries. Trends in Microbiology, 16(12), 574-579. http://doi.org/10.1016/j.tim.2008.08.012

Ng, E., \& Kohler, J. C. (2008). Finding Flaws: The Limitations of Compulsory Licensing for Improving Access to Medicines - An International Comparison. Health Law Journal, 16, 143.

Nicol, D., \& Owoeye, O. (2013). Using TRIPS flexibilities to facilitate access to medicines. Bulletin of the World Health Organization, 91(7), 533-539.

Nkomo, M. (2010). The Under-Utilization of TRIPS Flexibilities by Developing Countries: The Case of Africa. In WIPO-WTO COLLOQUIUM PAPERS (p. 125). Retrieved from http://www.wto.int/English/tratop_e/trips_e/wipo_wto_colloquium_aug11_e.pdf\#page=139

Nock, M. K., Michel, B. D., \& Photos, V. I. (2007). Single-case research designs. In D. McKay (Ed.), Handbook of research methods in abnormal and clinical psychology (pp. 337-350).

Novignon, J., Olakojo, S. A., \& Nonvignon, J. (2012). The effects of public and private health care expenditure on health status in sub-Saharan Africa: new evidence from panel data analysis. Health Economics Review, 2, 22. http://doi.org/10.1186/2191-1991-2-22

Nunn, A. S. (2009). The Politics and History of AIDS Treatment in Brazil. Springer.

Nunn, A. S., Da Fonseca, E. M., Bastos, F. I., \& Gruskin, S. (2009). AIDS Treatment In Brazil: Impacts And Challenges. Health Affairs, 28(4), 1103-1113. http://doi.org/10.1377/hlthaff. 28.4.1103

O’Brien, B. J. (1988). A game-theoretic approach to donor kidney sharing. Social Science \& Medicine, 26(11), 1109-1116. http://doi.org/10.1016/0277-9536(88)90186-4

OECD. (2013). Health at a Glance 2013. OECD Publishing. Retrieved from http://www.oecdilibrary.org/social-issues-migration-health/health-at-a-glance-2013_health_glance-2013-en

Oliveira, M. A., Bermudez, J., Chaves, G. C., \& Velásquez, G. (2004). Has the implementation of the TRIPS Agreement in Latin America and the Caribbean produced intellectual property legislation that favours public health? Bulletin of the World Health Organization, 82(11), 815-821.

Orsi, F., Hasenclever, L., Fialho, B., Tigre, P., \& Coriat, B. (2003). Intellectual Property Rights, Anti-AIDS Policy and Generic Drugs. Lessons from the Brazilian Public Health Program. In J.P. Moatti, T. Barnett, B. Coriat, Y. Souteyrand, J. Dumoulin, \& Y.-A. Flori (Eds.), Economics of AIDS and access to HIV-AIDS care in developing countries: issues and challenges. Agence nationale de recherches sur le SIDA (ANRS). Retrieved from http://eprints.lse.ac.uk/23789/

Osuji, O. K., \& Umahi, O. T. (2012). Pharmaceutical companies and access to medicines - social integration and ethical CSR resolution of a global public choice problem. Journal of Global Ethics, 8(2-3), 139-167. http://doi.org/10.1080/17449626.2012.702678 
Owoeye, O. A. (2014). Patents and the obligation to protect health: examining the significance of human rights considerations in the protection of pharmaceutical patents. Journal of Law and Medicine, 21(4), 900-919.

PARASCANDOLA, J. (1981). THE THEORETICAL BASIS OF PAUL EHRLICHS CHEMOTHERAPY. Journal of the History of Medicine and Allied Sciences, 36(1), 19.

Penna, G., \& Simão, M. (2007, May 14). Nota de Esclarecimento. Ministry of Health of Brazil. Retrieved from http://www.deolhonaspatentes.org.br/media/file/Casos/Brasil/nota_esclarecimento_pndstaids.pdf

Pinheiro, E. (2006). A Conversation with Eloan Pinheiro. Knowledge Ecology Studies, 2.

Pinheiro, E. (2012, February 11). Interview with Eloan Pinheiro.

Plahte, J. (2012). Is the pneumococcal vaccine Advance Market Commitment motivating innovation and increasing manufacturing capacity? Some preliminary answers. Vaccine, 30(14), 2462-2466. http://doi.org/10.1016/j.vaccine.2012.01.046

Possas, C. (2008). Compulsory licensing in the real world: the case of ARV drugs in Brazil. In B. Coriat (Ed.), The Political Economy of HIVIAIDS in Developing Countries: TRIPS, Public Health Systems and Free Access. Edward Elgar Publishing.

Preston, S. H. (1975). The changing relation between mortality and level of economic development. Population Studies, 29(2), 231-248.

Rajkumar, R., \& Kesselheim, A. S. (2013). Balancing access and innovation: India's supreme court rules on imatinib. JAMA, 310(3), 263-264. http://doi.org/10.1001/jama.2013.7336

Ramani, S. V., Dutta, A., \& Urias, E. (2014, November 14). IBSA and access to medicines in developing countries: A systemic disease based enquiry. Unpublished, Maastricht, Netherlands.

Ramani, S. V., \& Urias, E. (2015). Access to Critical Medicines: When are compulsory licenses effective in price negotiations? Social Science \& Medicine, 135, 75-83. http://doi.org/ 10.1016/j.socscimed.2015.04.023

Ramberg, P. J. (2000). The Death of Vitalism and The Birth of Organic Chemistry: Wohler's Urea Synthesis and the Disciplinary Identity of Organic Chemistry. Ambix, 47(3), 170-195. http://doi.org/10.1179/amb.2000.47.3.170

Ramiah, I., \& Reich, M. R. (2006). Building effective public-private partnerships: Experiences and lessons from the African Comprehensive HIV/AIDS Partnerships (ACHAP). Social Science \& Medicine, 63(2), 397-408. http://doi.org/10.1016/j.socscimed.2006.01.007

Ravvin, M. (2008). Incentivizing Access and Innovation for Essential Medicines: A Survey of the Problem and Proposed Solutions. Public Health Ethics, 1(2), 110-123. http://doi.org/10.1093/ phe/phn017

Renton, A., Wall, M., \& Lintott, J. (2012). Economic growth and decline in mortality in developing countries: An analysis of the World Bank development datasets. Public Health, 126(7), 551-560. http://doi.org/10.1016/j.puhe.2012.03.011

Ribeiro, M. A. . (2001). Public health and chemical-pharmaceutical companies. História. Ciência. Saúde-Manguinhos, 7(3), 607-26.

Rich, J. L. (2001, September 1). Roche Reaches Accord on Drug With Brazil. The New York Times.

Retrieved from http://www.nytimes.com/2001/09/01/business/roche-reaches-accord-on-drugwith-brazil.html 
Rich, J., \& Petersen, M. (2001, August 23). Brazil Will Defy Patent on AIDS Drug Made by Roche. The New York Times. Retrieved from http://www.nytimes.com/2001/08/23/business/ 23DRUG.html

Ridge, D., \& Arachne, J. (1997). From pharmaceuticals to alternative treatments for HIV/AIDS: What is the potential? Health Care Analysis, 5(4), 275-282. http://doi.org/10.1007/BF02 678525

Ridley, D. D. B. (2005). Price differentiation and transparency in the global pharmaceutical marketplace. PharmacoEconomics, 23(7), 651-658. http://doi.org/10.2165/00019053-2005 2307000002

Ritter, G. S. (2010). Are Drug Companies Living Up to Their Human Rights Responsibilities? The Merck Perspective. PLoS Med, 7(9), e1000343. http://doi.org/10.1371/journal.pmed.1000343

Rivers, P. A., Hall, N. G., \& Frimpong, J. (2006). Prescription drug spending: contribution to health care spending and cost containment strategies. Journal of Health Care Finance, 32(3), 8-19.

Rodrigues, W. C. V., \& Soler, O. (2009). Compulsory licensing of efavirenz in Brazil in 2007: contextualization. Revista Panamericana de Salud Pública, 26(6), 553-559. http://doi.org/ 10.1590/S1020-49892009001200012

Roemer-Mahler, A. (2010). Business strategy and access to medicines in developing countries. Global Health Governance, 4(1). Retrieved from http://blogs.shu.edu/ghg/files/2011/11/RoemerMahler_Business-Strategy-and-Access-to-Medicines-in-Developing_Fall-2010.pdf

Roffe, P. (2004). Bilateral agreements and a TRIPS-plus world: the Chile-USA Free Trade Agreement. Quaker International Affairs Programme Ottawa,, Canada. Retrieved from http://qunodru-

pal.283elmp01.blackmesh.com/sites/default/files/resources/Bilateral\%2BAgreements\%2Band\%2 BTRIPS\%2Bplus\%2BEnglish.pdf

Roffe, P., \& Spennemann, C. (2006). The impact of FTAs on public health policies and TRIPS flexibilities. International Journal of Intellectual Property Management, 1(1), 75-93.

Roth, A. E., Sönmez, T., \& Ünver, M. U. (2004). Kidney Exchange. The Quarterly Journal of Economics, 119(2), 457-488. http://doi.org/10.1162/0033553041382157

Rozek, R. P., \& Rainey, R. L. (2001). Broad-Based Compulsory Licensing of Pharmaceutical Technologies. The Journal of World Intellectual Property, 4(4), 463-480. http://doi.org/10.1111/ j.1747-1796.2001.tb00122.x

Savoie, B. (2007). Thailand's Test: Compulsory Licensing in an Era of Epidemiologic Transition. Virginia Journal of International Law, 48, 211.

Schüklenk, U., \& Ashcroft, R. E. (2002). Affordable Access to Essential Medication in Developing Countries: Conflicts Between Ethical and Economic Imperatives. Journal of Medicine and Philosophy, 27(2), 179-195. http://doi.org/10.1076/jmep.27.2.179.2989

Sebbag, R. (2007). [Drug access in poor countries]. Bulletin de l'Academie nationale de medecine, 191(8), 1601-1602.

Sell, S. K. (2001). Trips and the Access to Medicines Campaign. Wisconsin International Law Journal, 20, 481 .

Sell, S. K. (2007). TRIPS-Plus Free Trade Agreements and Access to Medicines. Liverpool Law Review, 28(1), 41-75. http://doi.org/10.1007/s10991-007-9011-8 
Shadlen, K. C. (2007). The Political Economy of AIDS Treatment: Intellectual Property and the Transformation of Generic Supply. International Studies Quarterly, 51(3), 559-581. http://doi.org/10.1111/j.1468-2478.2007.00464.x

Shadlen, K. C. (2009). The Politics of Patents and Drugs in Brazil and Mexico: The Industrial Bases of Health Policies. Comparative Politics, 42(1), 41-58.

Shah, A. K., Warsh, J., \& Kesselheim, A. S. (2013). The Ethics of Intellectual Property Rights in an Era of Globalization. The Journal of Law, Medicine o Ethics, 41(4), 841-851. http://doi.org/10.1111/jlme.12094

Shankar, R., Kinsey, E., Thomas, P., Hooper, J., \& Tejani, S. (2013). Securing IP and Access to Medicine: Is Oncology the Next HIV?. IMS Consulting Group. Retrieved from http://www.imshealth.com/deployedfiles/imshealth/Global/Content/Home\%20Page\%20Conte nt/High-

Growth\%20Markets/Securing_IP_and_Access_to_Medicine_in_Emerging\%20Markets.pdf

Shiell, A., \& Chapman, S. (2000). The inertia of self-regulation: a game-theoretic approach to reducing passive smoking in restaurants. Social Science \& Medicine, 51(7), 1111-1119. http://doi.org/10.1016/S0277-9536(00)00018-6

Silva, S. C., \& Miranda, L. (2001, August 24). Serra pode voltar atrás na quebra de patente da Roche. $O$ Estado de São Paulo. Retrieved from http://www.anvisa.gov.br/hotsite/genericos/noticias/ 2001/240801.htm\#2

Simão, M. (2007, July 7). NOTA DE ESCLARECIMENTO. STD/AIDS Department. Retrieved from http://www.aids.gov.br/noticia/resposta-materia-sem-estardalhaco-publicada-na-edicao-de29-de-junho

Smith, R. D., Correa, C. M., \& Oh, C. (2009). Trade, TRIPS, and pharmaceuticals. The Lancet, 373(9664), 684-691. http://doi.org/10.1016/S0140-6736(08)61779-1

Snyder, C. M., Begor, W., \& Berndt, E. R. (2011). Economic Perspectives On The Advance Market Commitment For Pneumococcal Vaccines. Health Affairs, 30(8), 1508-1517. http://doi.org/ 10.1377/hlthaff.2011.0403

Sobel, C. (2007, February 16). BRAZIL: SPECIAL 301 RECOMMENDATION. Retrieved from http://search.wikileaks.org/plusd/cables/07BRASILIA294_a.html

STD/AIDS Department. (2003a, August 1). Saúde quer reduzir custos de medicamentos para o tratamento da aids. Retrieved December 12, 2013, from http://www.aids.gov.br/noticia/saudequer-reduzir-custos-de-medicamentos-para-o-tratamento-da-aids

STD/AIDS Department. (2003b, August 13). Laboratórios mantêm preços de medicamentos para aids. Retrieved December 11, 2013, from http://www.aids.gov.br/noticia/laboratorios-mantemprecos-de-medicamentos-para-aids

STD/AIDS Department. (2003c, August 20). Laboratório pode conceder licença para produção de medicamentos para aids. Retrieved December 12, 2013, from www.aids.gov.br/noticia/ laboratorio-pode-conceder-licenca-para-producao-de-medicamentos-para-aids

STD/AIDS Department. (2003d, November 18). Preço do Efavirenz cai 25\%. Retrieved December 13, 2013, from http://www.aids.gov.br/noticia/preco-do-efavirenz-cai-25

STD/AIDS Department. (2003e, November 19). Governo consegue desconto em outro remédio contra a aids. Retrieved December 13, 2013, from http://www.aids.gov.br/node/39528

STD/AIDS Department. (2003f, December 8). Remédio pode ter patente quebrada. Retrieved December 13, 2013, from http://www.aids.gov.br/node/38946 
STD/AIDS Department. (2004, January 15). Saúde fecha acordo com laboratórios de anti-retrovirais. Retrieved December 13, 2013, from http://www.aids.gov.br/noticia/saude-fecha-acordo-comlaboratorios-de-antiretrovirais

STD/AIDS Department. (2005a, October 12). Após três meses de negociações. Retrieved May 20, 2015, from http://www.aids.gov.br/noticia/apos-tres-meses-de-negociacoes-o-ministro-da-saudesaraiva-felipe-informou-nesta-terca-feira

STD/AIDS Department. (2005b, October 12). Valor pago pode quase dobrar com o remédio substituto. Depois de muita negociação e ameaça de quebra de patente, governo e laboratório Abbott acertaram valor do Kaletra | Departamento de DST, Aids e Hepatites Virais. Retrieved May 20, 2015, from http://www.aids.gov.br/noticia/valor-pago-pode-quase-dobrar-com-oremedio-substituto-depois-de-muita-negociacao-e-ameaca-de

STD/AIDS Department. (2006, May 10). Medicine against HIV to cost 51\% less for Brazil | Department of STD, AIDS and Viral Hepatitis. Retrieved May 20, 2015, from http://www.aids.gov.br/en/noticia/medicine-against-hiv-cost-51-less-brazil

STD/AIDS Department. (2007, January 5). Destrinchando os poucos números divulgados pelo Ministério da Saúde. Retrieved May 20, 2015, from http://www.aids.gov.br/ noticia/destrinchando-os-poucos-numeros-divulgados-pelo-ministerio-da-saude-conclui-se-que-ogasto-d

Stenberg, K., Axelson, H., Sheehan, P., Anderson, I., Gülmezoglu, A. M., Temmerman, M., ... Bustreo, F. (2014). Advancing social and economic development by investing in women's and children's health: a new Global Investment Framework. The Lancet, 383(9925), 1333-1354. http://doi.org/10.1016/S0140-6736(13)62231-X

Stéphenne, J. (2011). Vaccines As A Global Imperative-A Business Perspective. Health Affairs, 30(6), 1042-1048. http://doi.org/10.1377/hlthaff.2011.0338

Stiglitz, J. E. (2008). Economic Foundations of Intellectual Property Rights. Duke Law Journal, 57, 1693.

Still, R. R., \& Hill, J. S. (1984). Adapting consumer products to lesser-developed markets. Journal of Business Research, 12(1), 51-61. http://doi.org/10.1016/0148-2963(84)90037-7

Strulik, H., \& Weisdorf, J. (2014). How child costs and survival shaped the industrial revolution and the demographic transition. Macroeconomic Dynamics, 18(01), 114-144.

Sturchio, J. L. (2008). Business engagement in public programs: the pharmaceutical industry's contribution to public health and the millennium development goals. Corporate Governance: The International Journal of Business in Society, 8(4), 482-489. http://doi.org/10.1108/ 14720700810899211

Swift, R. (2011). The relationship between health and GDP in OECD countries in the very long run. Health Economics, 20(3), 306-322.

Teece, D. J. (1986). Profiting from technological innovation: Implications for integration, collaboration, licensing and public policy. Research Policy, 15(6), 285-305. http://doi.org/10.1016/00487333(86)90027-2

Teixeira, P. R., Vitória, M. A., \& Barcarolo, J. (2004). Antiretroviral treatment in resource-poor settings: the Brazilian experience. Aids, 18, S5-S7.

Thai White Paper I, M. of P. H. and N. H. S. O., Thailand. (2007). Facts and Evidences on the 10 Burning Issues Related to the Government Use of Patents on Three Patented Essential Drugs in Thailand. Retrieved from http://www.moph.go.th/hot/White\%20Paper\%20CL-EN.pdf 
Theodosiou, M., \& Katsikeas, C. S. (2001). Factors Influencing the Degree of International Pricing Strategy Standardization of Multinational Corporations. Journal of International Marketing, 9(3), $1-18$.

The World Bank. (1993). Brazil - AIDS and STD Control Project (No. 11734) (pp. 1-126). The World Bank. Retrieved from http://documents.worldbank.org/curated/en/1993/10/734651/ brazil-aids-std-control-project

The World Bank. (2012a). World Development Indicators: Health expenditure per capita (current US\$) [Data file]. Retrieved April 13, 2015, from http://data.worldbank.org/indicator/ SH.XPD.OOPC.TO.ZS

The World Bank. (2012b). World Development Indicators: Health expenditure, total (\% of GDP) [Data file]. Retrieved April 13, 2015, from http://data.worldbank.org/indicator/ SH.XPD.TOTL.ZS

The World Bank. (2012c). World Development Indicators: Out-of-pocket health expenditure (\% of total expenditure on health) [Data file]. Retrieved April 13, 2015, from http://data.worldbank.org/indicator/SH.XPD.PCAP

't Hoen, E. (2002). TRIPS, pharmaceutical patents, and access to essential medicines: a long way from Seattle to Doha. Chicago-Kent Journal of Intellectual Property, 3, 27.

't Hoen, E. (2009). The Global Politics of Pharmaceutical Monopoly Power: Drug Patents, Access, Innovation and the Application of the WTO Doha Declaration on TRIPS and Public Health. AMB Publishers.

't Hoen, E., Berger, J., Calmy, A., \& Moon, S. (2011). Driving a decade of change: HIV/AIDS, patents and access to medicines for all. Journal of the International AIDS Society, 14(1), 15. http://doi.org/10.1186/1758-2652-14-15

't Hoen, E., \& Passarelli, C. A. (2013). The role of intellectual property rights in treatment access: challenges and solutions. Current Opinion in HIV and AIDS, 8(1), 70-74. http://doi.org/10.1097/COH.0b013e32835b6e5a

Thorpe, P. (2002). Implementation of the TRIPS agreement by Developing Countries (No. Study Paper 7). UK Commission on Intellectual Property Rights. Retrieved from http://www.iprcommission.org/papers/pdfs/study_papers/sp7_thorpe_study.pdf

Trochim, W. M. K. (1985). Pattern Matching, Validity, and Conceptualization in Program Evaluation. Evaluation Review, 9(5), 575-604. http://doi.org/10.1177/0193841X8500900503

Trotter, A. (2012). Enforcement Costs: Some Humanitarian Alternatives to Stronger Patent Rights. Medico-Legal Journal, 80(1), 22-32. http://doi.org/10.1258/mlj.2011.011036

UN. (2014). United Nations Millennium Development Goals - Goal 8: Develop a global partnership for development. Retrieved April 17, 2015, from http://www.un.org/millenniumgoals/global.shtml

UNCTAD, - United Nations Conference on Trade and Development. (2011). Investment in pharmaceutical production in the least developed countries. Geneva, Switzerland: United Nations. Retrieved from http://unctad.org/en/Docs/diaepcb2011d5_en.pdf

Van Duzer, T. (2003). TRIPS and the pharmaceutical industry in Bangladesh: Towards a national strategy. Centre for Policy Dialogue (CPD). Retrieved from https://ideas.repec.org/p/pdb/opaper/24.html 
Velasquez, G. (2014). The Right to Health and Medicines: The Case of Recent Multilateral Negotiations on Public Health, Innovation and Intellectual Property. Developing World Bioethics, 14(2), 67-74. http://doi.org/10.1111/dewb.12049

Venkitachalam, L., Wang, K., Porath, A., Corbalan, R., Hirsch, A. T., Cohen, D. J., ... Magnuson, E. A. (2012). Global Variation in the Prevalence of Elevated Cholesterol in Outpatients With Established Vascular Disease or 3 Cardiovascular Risk Factors According to National Indices of Economic Development and Health System Performance. Circulation, 125(15), 1858-1869. http://doi.org/10.1161/CIRCULATIONAHA.111.064378

Versantvoort, C., Maliepaard, M., \& Lekkerkerker, F. (2008). Generics: what is the role of registration authorities. Neth J Med, 66(2), 62-6.

Vieira, I. (2012, November 30). Produção nacional de antirretroviral para tratamento do HIV começa em 2015. Retrieved June 20, 2014, from http://noticias.uol.com.br/saude/ultimasnoticias/redacao/2012/11/30/producao-nacional-de-antirretroviral-para-tratamento-do-hivcomeca-em-2015.htm

Virden, R. (2003, September 26). NEW DECREE TO FACILITATE IMPORTATION OF COPIED DRUGS THROUGH COMPULSORY LICENSING. Retrieved from http://search.wikileaks.org/plusd/cables/03BRASILIA3122_a.html

Viswanathan, N. K., \& Dickson, P. R. (2007). The fundamentals of standardizing global marketing strategy. International Marketing Review, 24(1), 46-63. http://doi.org/10.1108/02651 330710727187

Vollmer, S., Harttgen, K., Subramanyam, M. A., Finlay, J., Klasen, S., \& Subramanian, S. V. (2014). Association between economic growth and early childhood undernutrition: evidence from 121 Demographic and Health Surveys from 36 low-income and middle-income countries. The Lancet Global Health, 2(4), e225-e234.

Wade, R. H. (2003). What strategies are viable for developing countries today? The World Trade Organization and the shrinking of "development space." Review of International Political Economy, 10(4), 621-644. http://doi.org/10.1080/09692290310001601902

Weilbaecher, A. (2009). Diseases Endemic in Developing Countries: How to Incentive Innovation. Annals of Health Law, 18, 281.

Weissman, R. (1996). Long, Strange Trips: The Pharmaceutical Industry Drive to Harmonize Global Intellectual Property Rules, and the Remaining WTO Legal Alternatives Available to Third World Countries. University of Pennsylvania Journal of International Economic Law, 17, 1069.

WHO. (2000). Global comparative pharmaceutical expenditures. Geneva, Switzerland: World Health Organization. Retrieved from http://apps.who.int/medicinedocs/documents/s18569en/ s18569en.pdf

WHO. (2004). The world medicines situation - 2004. Geneva: World Health Organization.

WHO. (2005). Access to Medicines: Intellectual property protection: impact on public health. World Health Organization Drug Information, 19(3), 236-41.

WHO. (2006). Public Health-Innovation and Intellectual Property Rights: Report of the Commission on Intellectual Property Rights, Innovation and Public Health. World Health Organization.

WHO. (2011). The World Medicines Situation - 2011. Geneva, Switzerland: World Health Organization. Retrieved from http://apps.who.int/medicinedocs/en/m/abstract/Js20052en/

Winsbury, R. (1999). HIV vaccine development: would more (public) money bring quicker results? AIDS Analysis Africa, 10(1), 11-3. 
WTO. (2006, September). TRIPS and pharmaceutical patents: obligations and exception. Retrieved from http://www.wto.org/english/tratop_e/trips_e/factsheet_pharm02_e.htm\#art31

Yeh, B. J., \& Lim, W. A. (2007). Synthetic biology: lessons from the history of synthetic organic chemistry. Nature Chemical Biology, 3(9), 521-525. http://doi.org/10.1038/nchembio0907-521

Yin, R. K. (1994). Case Study Research, Design awl Methods (1st ed.). Beverly Hills, CA: Sage.

Yin, R. K. (2009). Case Study Research: Design and Methods (4th ed., Vol. 5). SAGE.

Yin, R. K. (2012). Applications of Case Study Research (3rd ed., Vol. 34). SAGE.

Yu, P. (2007). The International Enclosure Movement. Indiana Law Journal, 82, 827-907. 


\section{Annexes}

\section{A.1 List of key informants interviewed}

Table A 1: List of key informants interviewed

\begin{tabular}{|c|c|c|c|c|c|}
\hline Informant & Position & $\begin{array}{l}\text { Gen- } \\
\text { der }\end{array}$ & Date & Place & Type \\
\hline Academic [1] & Post-doc & Female & $05 / 03 / 12$ & $\begin{array}{l}\text { São Paulo - SP } \\
\text { (Brazil) }\end{array}$ & Semi-structured \\
\hline Academic [2] & Professor & Female & $31 / 01 / 12$ & $\begin{array}{l}\text { Rio de Janeiro - } \\
\text { RJ (Brazil) }\end{array}$ & Semi-structured \\
\hline Academic [3] & Post-doc & Male & $27 / 02 / 12$ & $\begin{array}{l}\text { São Paulo - SP } \\
\text { (Brazil) }\end{array}$ & Semi-structured \\
\hline Academic [4] & Post-doc & Female & $05 / 03 / 12$ & $\begin{array}{l}\text { São Paulo - SP } \\
\text { (Brazil) }\end{array}$ & Semi-structured \\
\hline $\begin{array}{l}\text { FioCruz / } \\
\text { Farmanguinhos } \\
\text { [1] }\end{array}$ & $\begin{array}{l}\text { Former- } \\
\text { Director }\end{array}$ & Female & $11 / 02 / 12$ & Skype & Semi-structured \\
\hline $\begin{array}{l}\text { FioCruz/ } \\
\text { Farmanguinhos } \\
\text { [2] }\end{array}$ & $\begin{array}{l}\text { IPR Coordi- } \\
\text { nator }\end{array}$ & Female & $16 / 02 / 12$ & $\begin{array}{l}\text { Rio de Janeiro - } \\
\text { RJ (Brazil) }\end{array}$ & Exploratory \\
\hline $\begin{array}{l}\text { FioCruz/ } \\
\text { Farmanguinhos } \\
\text { [3] }\end{array}$ & Researcher & Male & $16 / 02 / 12$ & $\begin{array}{l}\text { Rio de Janeiro - } \\
R J \text { (Brazil) }\end{array}$ & Exploratory \\
\hline Local company [1] & $\begin{array}{l}R \& D \text { Direc- } \\
\text { tor }\end{array}$ & Male & $09 / 02 / 12$ & $\begin{array}{l}\text { Cosmópolis - SP } \\
\text { (Brazil) } \\
\text { Taboão da }\end{array}$ & Semi-structured \\
\hline Local company [2] & CEO & Male & $09 / 02 / 12$ & $\begin{array}{l}\text { Serra - SP } \\
\text { (Brazil) }\end{array}$ & Semi-structured \\
\hline Local company [3] & CEO & Male & $05 / 03 / 12$ & $\begin{array}{l}\text { São Paulo - SP } \\
\text { (Brazil) }\end{array}$ & Exploratory \\
\hline MNE [1] & $\begin{array}{l}\text { Former } \\
\text { Director of } \\
\text { Institution- } \\
\text { al Affairs } \\
\text { Former }\end{array}$ & Male & $12 / 03 / 12$ & $\begin{array}{l}\text { São Paulo - SP } \\
\text { (Brazil) }\end{array}$ & Exploratory \\
\hline MNE [2] & $\begin{array}{l}\text { Director of } \\
\text { Institution- } \\
\text { al Affairs }\end{array}$ & Male & $17 / 02 / 12$ & $\begin{array}{l}\text { São Paulo - SP } \\
\text { (Brazil) }\end{array}$ & Exploratory \\
\hline $\mathrm{MoH}[1]$ & $\begin{array}{l}\text { Vice- } \\
\text { minister }\end{array}$ & Male & $14 / 03 / 12$ & $\begin{array}{l}\text { Brasilia - DF } \\
\text { (Brazil) }\end{array}$ & Exploratory \\
\hline $\mathrm{MoH}[2]$ & $\begin{array}{l}\text { Industrial } \\
\text { Policy } \\
\text { especialist }\end{array}$ & Female & $14 / 03 / 12$ & $\begin{array}{l}\text { Brasília - DF } \\
\text { (Brazil) }\end{array}$ & Exploratory \\
\hline
\end{tabular}




\begin{tabular}{|c|c|c|c|c|c|}
\hline $\mathrm{MoH}[3]$ & $\begin{array}{l}\text { Director for } \\
\text { Industrial } \\
\text { Policy }\end{array}$ & Male & $14 / 03 / 12$ & $\begin{array}{l}\text { Brasilia - DF } \\
\text { (Brazil) }\end{array}$ & Exploratory \\
\hline $\mathrm{MoH}[4]$ & $\begin{array}{l}\text { Former } \\
\text { Vice- } \\
\text { minister }\end{array}$ & Male & $07 / 03 / 12$ & $\begin{array}{l}\text { Rio de Janeiro - } \\
\text { RJ (Brazil) }\end{array}$ & Semi-structured \\
\hline $\mathrm{MoH}[5]$ & Director & Female & $13 / 04 / 12$ & $\begin{array}{l}\text { Brasilia - DF } \\
\text { (Brazil) }\end{array}$ & Exploratory \\
\hline NGO [1] & $\begin{array}{l}\text { IPR espe- } \\
\text { cialist }\end{array}$ & Male & $24 / 02 / 12$ & $\begin{array}{l}\text { São Paulo - SP } \\
\text { (Brazil) }\end{array}$ & Exploratory \\
\hline$N G O[2]$ & $\begin{array}{l}\text { IPR espe- } \\
\text { cialist }\end{array}$ & Male & $07 / 03 / 12$ & $\begin{array}{l}\text { Rio de Janeiro - } \\
R J \text { (Brazil) }\end{array}$ & Semi-structured \\
\hline$N G O[3]$ & $\begin{array}{l}\text { IPR espe- } \\
\text { cialist }\end{array}$ & Female & $07 / 03 / 12$ & $\begin{array}{l}\text { Rio de Janeiro - } \\
R J \text { (Brazil) }\end{array}$ & Semi-structured \\
\hline $\begin{array}{l}\text { Public agencies } \\
\text { and autarkies [1] }\end{array}$ & Director & Male & 08/03/12 & $\begin{array}{l}\text { Rio de Janeiro - } \\
R J \text { (Brazil) }\end{array}$ & Exploratory \\
\hline $\begin{array}{l}\text { Public agencies } \\
\text { and autarkies [2] }\end{array}$ & $\begin{array}{l}\text { Civil serv- } \\
\text { ant }\end{array}$ & Male & $16 / 02 / 12$ & $\begin{array}{l}\text { Rio de Janeiro - } \\
R J \text { (Brazil) }\end{array}$ & Exploratory \\
\hline $\begin{array}{l}\text { Public agencies } \\
\text { and autarkies [3] }\end{array}$ & $\begin{array}{l}\text { Civil serv- } \\
\text { ant }\end{array}$ & Female & $13 / 03 / 12$ & $\begin{array}{l}\text { Brasilia - DF } \\
\text { (Brazil) }\end{array}$ & Semi-structured \\
\hline $\begin{array}{l}\text { STD/AIDS De- } \\
\text { partment [1] }\end{array}$ & $\begin{array}{l}\text { Former } \\
\text { Director }\end{array}$ & Male & $10 / 02 / 12$ & $\begin{array}{l}\text { São Paulo - SP } \\
\text { (Brazil) }\end{array}$ & Semi-structured \\
\hline $\begin{array}{l}\text { STD/AIDS De- } \\
\text { partment [2] }\end{array}$ & $\begin{array}{l}\text { Former } \\
\text { Director }\end{array}$ & Male & $14 / 03 / 12$ & $\begin{array}{l}\text { Brasilia - DF } \\
\text { (Brazil) }\end{array}$ & Exploratory \\
\hline $\begin{array}{l}\text { STD/AIDS De- } \\
\text { partment [3] }\end{array}$ & $\begin{array}{l}\text { Former } \\
\text { Director }\end{array}$ & Female & $15 / 02 / 12$ & Skype & Semi-structured \\
\hline
\end{tabular}




\section{A.2 Online survey}

Rate according to the degree of importance for a developing country to be successful in price negotiations of patented drugs protected by patents in the domestic market $(0=$ not important; 1 = somewhat important, 2 = important, 3 = very important). Please use the area reserved for comments to add further comments.

\section{Table A 2 Summary of survey responses}

\begin{tabular}{|c|c|c|c|}
\hline Responded & $\begin{array}{l}\text { Local manufacturing } \\
\text { capacity }\end{array}$ & $\begin{array}{c}\text { International generic } \\
\text { suppliers }\end{array}$ & Reprisals \\
\hline Respondent 1 & 1 & 1 & 2 \\
\hline Respondent 2 & 3 & 2 & 1 \\
\hline Respondent 3 & 3 & 3 & 2 \\
\hline Respondent 4 & 3 & 3 & 3 \\
\hline Respondent 5 & 3 & 1 & 1 \\
\hline Respondent 6 & 2 & 2 & 2 \\
\hline Respondent 7 & 3 & 1 & 2 \\
\hline Respondent 8 & 3 & 3 & 2 \\
\hline Respondent 9 & 2 & 1 & 1 \\
\hline Respondent 10 & 1 & 2 & 1 \\
\hline Respondent 11 & 3 & 3 & 3 \\
\hline Respondent 12 & 2 & 3 & 0 \\
\hline Respondent 13 & 1 & 1 & 1 \\
\hline Respondent 14 & 3 & 3 & 1 \\
\hline Respondent 15 & 2 & 3 & 1 \\
\hline Respondent 16 & 3 & 2 & 3 \\
\hline Respondent 17 & 3 & 2 & 2 \\
\hline Respondent 18 & 3 & 3 & 2 \\
\hline Respondent 19 & 2 & 2 & 3 \\
\hline Respondent 20 & 3 & 3 & 2 \\
\hline Respondent 21 & 3 & 2 & 1 \\
\hline Average & 2,5 & 2,2 & 1,7 \\
\hline
\end{tabular}





\section{Samenvatting}

In deze scryptie wordt geanalyseerd hoe de toegang tot geneesmiddelen verbeterd kan worden door de prijzen ervan te veranderen. De analyse richt zich meer bepaald op het vermogen van een land om meer betaalbare gepatenteerde geneesmiddelen te verkrijgen door middel van bedreiging met dwangvergunning(en) tijdens de prijsonderhandelingen met de verkoper. Daarom is de centrale onderzoeksvraag van deze scriptie: wat zijn de voorwaarden waaronder een land bedreigingen met dwanglicenties kan gebruiken bij prijsonderhandelingen? Dit leidt tot bijkomende vragen: wanneer zullen dergelijke bedreigingen succesvol zijn voor het verkrijgen van meer betaalbare levensreddende geneesmiddelen? Wat drijft de resultaten van deze onderhandelingen tussen farmaceutische multinationals en overheden in ontwikkelingslanden? Hoe kunnen deze aandrijvers, afzonderlijk en gezamenlijk, de uitkomsten bepalen?

Om deze vragen te beantwoorden volgen we een inductieve onderzoeksaanpak. We ontwikkelen eerst een vollediger begrip van de onderliggende context om de aandrijvers van de onderhandelingsresultaten te identificeren. Om dit te doen voeren we in eerste instantie verkennende beoordelingen uit van de bijdrage van de farmaceutische industrie tot de gezondheidssituatie in de ontwikkelingslanden en de uitdagingen om toegang te krijgen tot geneesmiddelen ten gevolge van het huidige systeem van intellectuele eigendomsrechten. Daarna voeren we een systematische beoordeling uit van de literatuur over het gebruik van dwanglicenties van gepatenteerde geneesmiddelen. Vervolgens vullen we de verkennende onderzoeken en de systematische beoordeling aan met informatie die verzameld is uit zowel primaire als secundaire bronnen.

De primaire gegevens bestaan uit zesentwintig semigestructureerde en verkennende interviews met academici, politici, advocaten, activisten en zakenmensen die vertrouwd zijn met de Braziliaanse ervaring op het vlak van prijsonderhandeling. De analyse van deze interviews met experten bouwt niet voort op geformaliseerde coderingsprotocollen, maar controleert verklaringen met betrekking tot informatieve beperkingen, aandrijvers van de onderhandelingspositie, obstakels en alternatieven voor de toekomst. Secundaire bronnen van gegevens omvatten officiële documenten, wetenschappelijke artikelen, nationale en internationale rapporten, websites van het ministerie van Volksgezondheid van Brazilië en krantenartikelen.

Bovendien wordt Brazilië genomen als het te onderzoeken land, omdat het algemeen wordt erkend als een leidende gebruiker van het dreigen met dwangvergunningen bij de onderhandelingen met farmaceutische bedrijven om de prijs van HIV-/AIDSbehandelingen te verminderen. Ondanks het Braziliaanse succes is er echter tot nog toe geen gedetailleerde studie van de aandrijvers van prijsonderhandelingen vanuit de Bra- 
ziliaanse ervaring. Brazilië vormt dus een interessante casestudy om inzicht te verkrijgen hoe de bedreiging met de afgifte van een dwanglicentie gebruikt kan worden om te onderhandelen over prijsverlagingen met innovatieve farmaceutische bedrijven.

Zodra de aandrijvers van de resultaten van de onderhandelingen geïdentificeerd zijn, ontwikkelen we vervolgens een beschrijvende casestudy op basis van veertien gevallen van prijsonderhandelingen voor antiretrovirale (ARV) medicijnen tussen het Ministerie van Volkgezondheid van Brazilië en op onderzoek gebaseerde farmaceutische bedrijven. In deze casestudy wordt een gedetailleerde historische reconstructie van deze onderhandelingen verstrekt om de individuele en onderling afhankelijke invloeden van deze aandrijvers te onderzoeken. Daarna formuleren en ontwikkelen we op basis van de uit de eerste stap afgeleide context en van deze historische reconstructie van de Braziliaanse ervaring een speltheoretisch model van prijsonderhandelingen tussen een farmaceutisch bedrijf en een openbare instantie in een ontwikkelingsland. Dit vormt op zijn beurt de basis voor een integratief analytisch kader dat opgebouwd is uit een reeks veronderstellingen om de omstandigheden te verklaren waaronder een land dwanglicenties kan gebruiken bij prijsonderhandelingen en de voorwaarden waaronder zulke bedreigingen zullen resulteren in meer betaalbare geneesmiddelen.

Ten slotte wordt dit integratief kader getoetst op de veertien gevallen van prijsonderhandelingen voor HIV-/AIDS-therapieën in Brazilië. Wij hanteren een 'patroonherkennende' data-analysetechniek om deze validatieoefening uit te voeren. Met deze methode vergelijken we of de resultaten die verwacht worden van het speltheoretisch model overeenkomen met de waargenomen uitkomst van elke prijsonderhandeling. Daarnaast controleren we of de verklarende variabelen die in het model gebruikt worden daadwerkelijk verantwoordelijk zijn voor de waargenomen resultaten. Het uit de casestudy verzameld bewijs suggereert dat het ministerie van Volksgezondheid van Brazilië bereid was om hogere prijzen te accepteren voor gepatenteerde geneesmiddelen dan wat het met dwanglicenties zou kunnen verkrijgen. Dit was om het negatieve effect te voorkomen dat een dwanglicentie kan veroorzaken in de economie. Bovendien is het voor de octrooihouder een betere keuze om een prijsverlaging toe te staan dan de gehele markt te verliezen - vooral wanneer de markt een aanzienlijke grootte heeft, zoals in het geval van Brazilië. Daarom werd de acceptatie van een prijsverlaging gezien als een beter resultaat voor beide partijen. Toch was er een geval waarin een dwanglicentie verleend werd in Brazilië.

Onze onderzoeksbenadering onthult dat de aanwezigheid van informatieve beperkingen daadwerkelijk cruciaal is om te begrijpen waarom Brazilië zijn enige dwanglicentie heeft afgegeven in één geval van prijsonderhandeling. We stellen ook vast dat Brazilië lagere prijzen had kunnen betalen voor het geneesmiddel waarvoor het technologische capaciteit op laboratorium- of experimentele schaal had gebouwd in de vroege jaren 
2000 (namelijk voor Efavirenz, Nelfinavir en Lopinavir). Voor nieuwere na 2004 geïntroduceerde geneesmiddelen betaalde het Ministerie van Volksgezondheid aanzienlijk meer dan de prijs van de generische versies (indien beschikbaar). Dit was vanwege de obstakels voor de lokale productie - te wijten aan de afwezigheid van lokale capaciteit, zelfs op kleine schaal - en voor de invoer.

Op basis van deze resultaten luiden de centrale aanbevelingen van dit onderzoek voor de verbetering van de toegang tot geneesmiddelen om het massale gebruik van dwanglicenties niet te bevorderen, maar om de ontwikkelingslanden te helpen bij het nastreven van capaciteitsopbouwende strategieën om hun onderhandelingspositie ten opzichte van de farmaceutische bedrijven bij de prijsonderhandelingen te versterken. De beleidsaanbevelingen die hier direct uit voortvloeien zijn dat ontwikkelingslanden eraan moeten werken om hun onderhandelingspositie te versterken. Een actiepunt is de bouw van centra van uitmuntendheid voor de deformulering van geneesmiddelen om lokale productiecapaciteit te creëren - al is het maar op laboratoriumschaal.

In onze analyse wordt aangetoond dat het huidige systeem van intellectuele eigendomsrechten slechts één hindernis is onder andere politieke, economische en institutionele beperkingen die het streven van de ontwikkelingslanden naar meer betaalbare medicijnen tot een ware uitdaging maken. 



\section{Biography}

Eduardo Urias was born in Brazil, in 1984. He started his PhD at UNU-MERIT in September 2010. He also held a bachelor degree in Economics by São Paulo State University and a master degree in Scientific and Technological Policy by Campinas State University. Before joining the UNU-MERIT PhD programme, Eduardo worked in the private sector as associated consultant in the field of science, technology and innovation consultancy. He developed expertise in in conducting conceptual studies on sectorial innovation systems, competitive strategy analysis, internal organization of $\mathrm{R} \& \mathrm{D}$, technological forecasting, among other services to the public ad private sectors. His main areas of interest are economic development, health related industries, bioeconomy, intelectual property rights, access to medicines, innovation management, strategic alliances and industrial dynamics. 

UNITED NATIONS UNIVERSITY

\section{5}

\section{UNU-MERIT}

\section{Fracesca Guadagno}

Why have so few countries industrialised?

\section{Daniel Opolot}

The evolution of beliefs and strategic behavior

\section{Alejandro Lavopa}

Structural Transformation and Economic Development: Can Development Traps be Avoided?

\section{Jinjin Zhao}

Urban water management reform: The case of China

2014

\section{Dirk Crass}

The Impact of Brands on Innovation and Firm Performance: Empirical Evidence from Germany

\section{Samyukta Bhupatiraju}

The Geographic Dimensions of Growth and Development

\section{François Lafond}

The evolution of knowledge systems

\section{Annalisa Primi}

Promoting Innovation in Latin America: What Countries Have Learned (and
What They Have Not) in Designing and Implementing Innovation and Intellectual Property Policies

\section{Fatoumata Lamarana Diallo}

Evaluation of Meal and Deworming

Programs for Primary Schools in Rural

Senegal

2013

\section{Anant Kamath}

Information Sharing through Informal Interaction in Low-Tech Clusters

\section{Flavia Pereira de Carvalho}

What we talk about when we talk about Brazilian Mulitantionals: an investigation on Brazilian FDI, economic structure, innovation and the relationship between them

\section{Jun Hou}

Complementarity in Innovation and Development: A Cross-country Comparison

\section{Rufin Baghana}

Impacts of Government Incentives to R\&D, Innovation and Productivity: A Microeconometric Analysis of the Québec Case

\section{Lilia I. Stubrin}

High-Tech Activities in Emerging Countries: A Network perspective on the Argentinean biotech activity 
2012

\section{Abdul Waheed}

Innovation Determinants and Innovation as a Determinant: Evidence from Developing Countries

\section{Bilal Mirza}

Energy Poverty and Rural Energy Markets in Pakistan

\section{Benjamin Engelstätter}

Enterprise Software and Video Games:

An Empirical Analysis

\section{Fulvia Farinelli}

Natural Resources, Innovation and Export Growth: The Wine Industry in Chili and Argentina

\section{Rodolfo Lauterbach}

Innovation in Manufacturing: From

Product Variety and Labor Productivity Growth to Economic Development in Chile

\section{Kirsten Wiebe}

Quantitative Assessment of Sustainable Development and Growth in SubSaharan Africa.

\section{Julio Miguel Rosa}

Organizational Strategies, Firms' Performance and Spatial Spillovers. The Canadian Case in Research and Development
Johannes Wilhelmus Marie Boels

Joseph Schumpeter, honderd jaar economische ontwikkeling. Een historischtheoretische beschouwing.

2011

\section{Daniel Vertesy}

Interrupted Innovation: Emerging economies in the structure of the global aerospace industry.

\section{Tina Saebi}

Successfully managing alliance portfolios: an alliance capability view.

\section{Nora Engel}

Tuberculosis in India - A case of innovation and control.

\section{Evans Mupela}

Connectivity and growth in Sub-Saharan Africa: The role of communication satellites

\section{Nantawan Kwanjai}

Cross cultural intelligence amid intricate cultural webs: A tale of the UnDutchables in the land of 1002 smiles

\section{Lina Sonne} Innovation in Finance to Finance Innovation: Supporting pro-poor entrepreneur-based innovation 


\section{Fernando Santiago}

Human Resources Management Practices and Learning for Innovation in Developing Countries: Pharmaceutical Firms in Mexico

\section{Zakaria Babutsidze}

Essays on Economies with Heterogenous Interacting Consumers

\section{Bertha Vallejo}

Learning and Innovation Under Changing Market Conditions: The Auto Parts Industry in Mexico

\section{Donatus Ayitey}

Technical Change, Competitiveness and Poverty Reduction: A Study of the Ghanaian Apparel Industry

\section{Sergey Fillipov}

Multinational Subsidiary Evolution:

Corporate Change in New EU Member States

\section{Asel Doranova}

Technology Transfer and Learning under the Kyoto regime; Exploring the Technological Impact of CDM projects in developing countries

\section{Alexis Habiyaremye}

From Primary Commodity Dependence to Diversification and Growth". "Absorptive Capacity and Technological Catch Up in Botswana and Mauritius".

\section{Yoseph Getachew}

The Role of Public Capital in Economic Development

\section{Sandra Leitner}

Embodied Technological Change and Patterns of Investment in Austrian Manufacturing

\section{Semih Akçomak}

The Impact of Social Capital on Economic and Social Outcomes

\section{Abraham Garcia}

The Role of Demand in Technical Change

\section{Saurabh Arora}

Coherence in socio-technical systems: a network perspective on the innovation process

2008

\section{Rutger Daems}

Medicines for the developing world 
53. Johannes Hanel

Assessing Induced Technology: Sombart's

Understanding of Technical Change in the History of Economics

\section{Rifka Weehuizen}

Mental Capital: the economic significance of mental health

\section{Danielle Cloodt}

The relationship between $R \& D$ partnership formation, social embeddedness and innovative performance

\section{Sabine Fuss}

Sustainable Energy Development under

Uncertainty

2007

\section{Tobias Kronenberg}

Reconciling Environmental Conservation with Economic Prosperity: The Feasibility of Double Dividends in the Short and Long Run

\section{Viktoria Kravtsova}

Assessing the Impact of Foreign Direct Investment in Transition Economies

\section{Suhail Sultan}

The Competitive Advantage of Small and Medium Sized Enterprises: The Case of Jordan's Natural Stone Industry
2006

\section{Bulat Sanditov}

Essays on Social Learning and Imitation

\section{Mamata Parhi}

Dynamics of New Technology Diffusion: A Study of the Indian Automotive Industry

\section{Andreas Reinstaller}

Social structures and the innovation process: Their role in the demand of firms and consumers

\section{Rose Kiggundu}

Innovation systems and development: the journey of a Beleaguered Nile Perch Fishery in Uganda

\section{Thomas Pogue}

The Evolution of Research Collaboration in South African Gold Mining: 18861933

\section{Geoffrey Gachino}

Foreign Direct Investment, Spillovers and Innovation: The Case of Kenyan Manufacturing Industry

\section{0. Önder Nomaler}

Technological Change, International Trade and Growth: An Evolutionary, Multi-Agents-Based Modeling Approach 
39. Samia Satti Osman Mohamed-

Nour

Change and Skill Development in the Arab Gulf Countries

\section{Elad Harison}

Intellectual Property Rights: Economics and Policy Analysis

\section{Daniel Dalohoun}

The relationship between $R \& D$ partnership formation, social embeddedness and innovative performance: a multi-level approach of social embeddedness

\section{Müge Ozman}

Networks, Organizations and Knowledge

\section{Bas Straathof}

Product variety and economic growth:

The counteracting effects of scale and idiosyncrasy

\section{Wilfred Schoenmakers}

Knowledge Flows between Multinational Companies: A Patent Data Analysis

\section{Myriam Cloodt}

Mergers and Acquisitions (M\&As) in High-Tech Industries: Measuring the Post-M\&A Innovative Performance of Companies

\section{Paola Criscuolo}

$\mathrm{R} \& \mathrm{D}$ Internationalisation and

Knowledge Transfer. Impact on MNEs and their Home Countries

\section{Maarten Verkerk}

Trust and Power on the Shop Floor

\section{Gottfried Leibbrandt}

Adoption, harmonization and succession of network technologies across countries

\section{Mark Sanders}

Skill Biased Technical change - Its Origins, the Interaction with the Labour Market and Policy Implications

2003

\section{Nadine Roijakkers}

Inter-firm cooperation in high-tech industries: a study of $R \& D$ partnerships in pharmaceutical biotechnology

\section{Viki Sonntag}

Speed, Scale and Sustainability

\section{Masaru Yarime}

From End-of-Pipe Technology to Clean Technology

\section{Stéphane Malo}

The combinatorial Chemistry Revolution

- Sustaining a Superior Performance

Position through Technological Learning 


\section{Annelies Hogenbirk}

Determinants of Inward Foreign Direct Investment: the Case of the Netherlands

2001

\section{John Adeoti}

Technology Investment in Pollution

Control in Sub-Saharan Africa: The Case of the Nigerian Manufacturing Industry

\section{Edward Huizenga}

Innovation Management: How Frontrunners Stay Ahead. An Empirical Study on Key Success Factors in the ICT sector

2000

\section{Machiel van Dijk}

Technological Change and the Dynamics of Industries. Theoretical Issues and Empirical evidence from Dutch Manufacturing

1999

\section{Jan Cobbenhagen}

Managing Innovation at the Company Level: A Study on Non-Sector-Specific Success Factors

\section{Marjolein Caniëls}

Regional Growth Differentials: The Impact of Locally Bounded Knowledge Spillovers

\section{Aldo Geuna}

Resource allocation and knowledge production: Studies in the economics of university research

\section{6}

\section{Reinoud Joosten}

Dynamics, Equilibria, and Values

\section{Hugo Kruiniger}

Investment, $\mathrm{R} \& \mathrm{D}$, and the Financing

Decisions of the Firm

1995

\section{Hans van Meijl}

Endogenous Technological Change: The Case of Information Technology. Theoretical Considerations and Empirical Results

\section{René Kemp}

Environmental Policy and Technical Change. A Comparison of the Technological Impact of Policy Instruments

\section{Rohini Acharya}

The Impact of New Technologies on Economic Growth and Trade. A Case Study of Biotechnology 


\section{Geert Duysters}

The Evolution of Complex Industrial

Systems. The Dynamics of Major IT

Sectors

\section{Marjan Groen}

Technology, Work and Organisation, A

Study of the Nursing Process in Intensive

Care Units

1994

\section{Huub Meijers}

On the Diffusion of Technologies in a

Vintage Framework; Theoretical Considerations and Empirical Results

\section{Theon van Dijk}

The Limits of Patent Protection. Essays on the Economics of Intellectual Property Rights

\section{Hans Voordijk}

Naar Integrale Logistiek in Bedrijfsketens, Ontwikkelingen in de Bouw

1993

\section{Paul Diederen}

Technological Progress in Enterprises and Diffusion of Innovations. Theoretical Reflections and Empirical Evidence.

\section{Ben Dankbaar}

Economic Crisis and Institutional

Change. The crisis of Fordism from the perspective of the automobile industry

\section{Hanno Roberts}

Accountability and Responsibility: The Influence of Organisation Design on Management Accounting

1992

\section{Bart Verspagen}

Uneven Growth Between Interdependent Economies. An Evolutionary View on Technology Gaps, Trade and Growth

\section{Sjoerd Romme}

A Self-organization Perspective on Strategy Formation 1989

\section{John Spangenberg}

Economies of Scale, and Atmosphere in Research Organisations

\section{8}

\section{John Hagedoorn}

Evolutionary and heterodox innovation analysis: a study of industrial and technological development in process control and information technology 

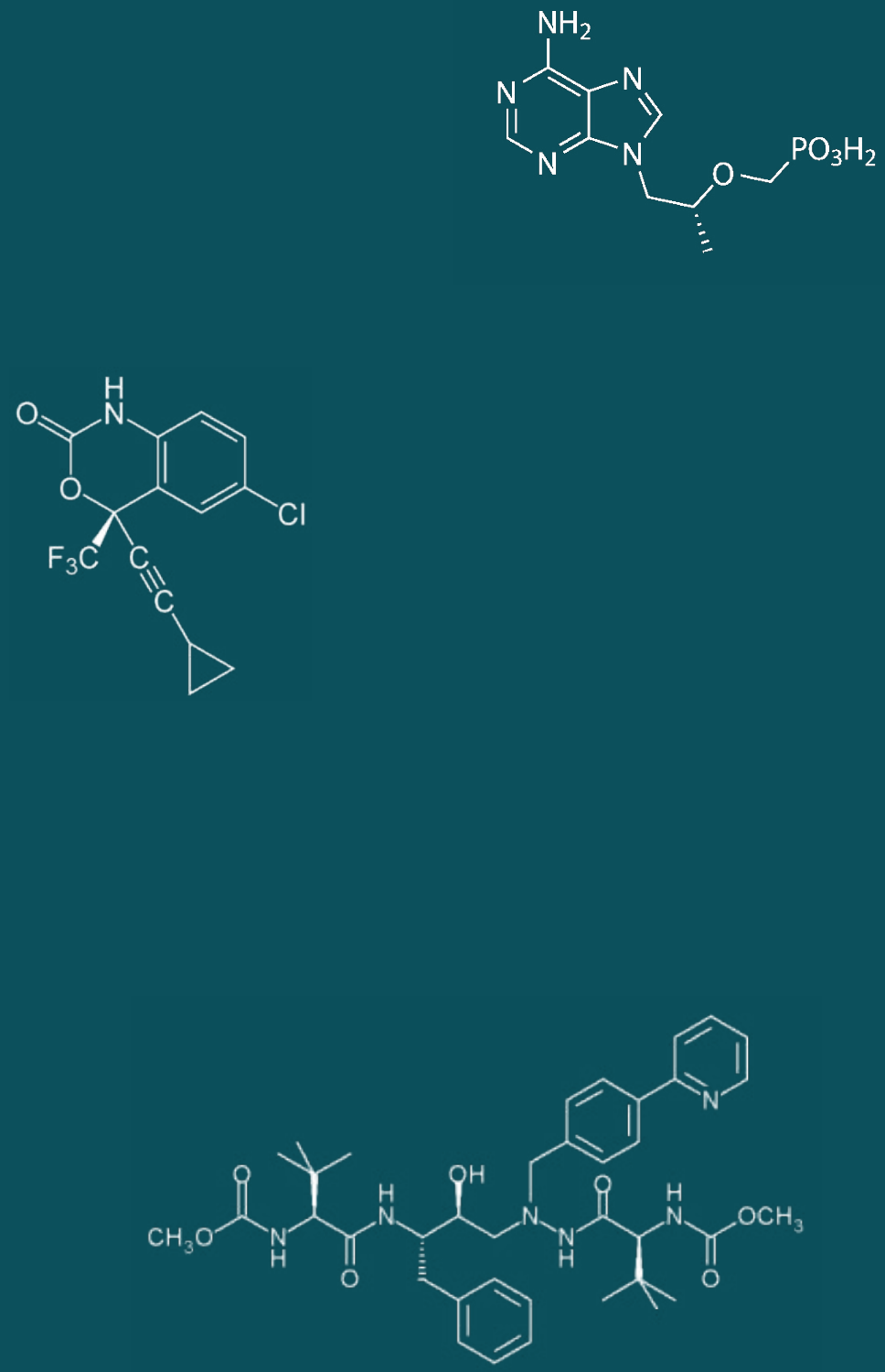